\title{
Bending and bond behavior and design of concrete beams reinforced with fiber-reinforced plastic rebars
}

\author{
Salem Samir Faza \\ West Virginia University
}

Follow this and additional works at: https://researchrepository.wvu.edu/etd

\section{Recommended Citation}

Faza, Salem Samir, "Bending and bond behavior and design of concrete beams reinforced with fiberreinforced plastic rebars" (1991). Graduate Theses, Dissertations, and Problem Reports. 3669.

https://researchrepository.wvu.edu/etd/3669

This Dissertation is protected by copyright and/or related rights. It has been brought to you by the The Research Repository @ WVU with permission from the rights-holder(s). You are free to use this Dissertation in any way that is permitted by the copyright and related rights legislation that applies to your use. For other uses you must obtain permission from the rights-holder(s) directly, unless additional rights are indicated by a Creative Commons license in the record and/ or on the work itself. This Dissertation has been accepted for inclusion in WVU Graduate Theses, Dissertations, and Problem Reports collection by an authorized administrator of The Research Repository @ WVU.

For more information, please contact researchrepository@mail.wvu.edu. 
BENDING AND BOND BEHAVIOR AND DESIGN OF CONCRETE BEAMS REINFORCED WITH FIBER REINFORCED PLASTIC REBARS

\section{DISSERTATION}

Submitted to the College of Engineering

of

West Virginia University

In Partial Fulfillment of the Requirements for

The Degree of Doctor of Philosophy

by

Salem Samir Faza, MSCE

Morgantown

West Virginia

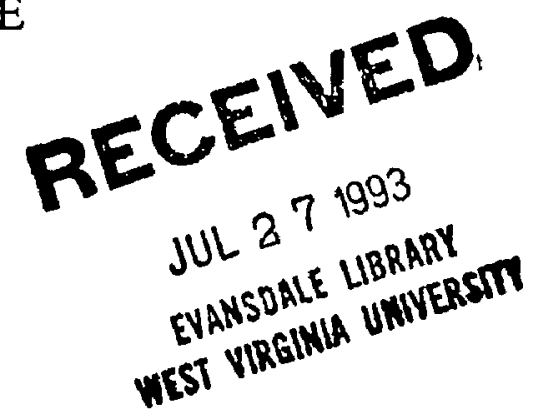

1991 


\section{ACKNOWLEDGMENTS}

The author wishes to express his sincere thanks and appreciation to Dr. Hota V.S. GangaRao, the advisor and committee chairman, who made significant contributions toward the completion of this dissertation and for the financial support.

This work has been sponsored by the Federal Highway Administration, the West Virginia Department of Highways and fiber reinforced plastic rebar industry through the Constructed Facilities Center at WVU.

Thanks are due to Dr. Jacky C. Prucz, Dr. Julio Davalos and Dr. Sam Kiger for technical and helpful discussions during the course of this research. The author would like to acknowledge the invaluable contribution of Mr. Richard Roll for technical and helpful discussions during the course of this study. Thanks are also due to Sharon Santos for reviewing the manuscript and to Paul Frum for his invaluable help in the laboratory. Thanks are also extended for Mr. Jack Justice, Federal Highway Administration, for his continual support.

The author wishes to express his sincere thanks to all the persons who helped him during the experimental phase of the project including the many students, friends and relatives.

The author wishes to express his deepest thanks to his parents and brother for their support and encouragement throughout his academic career. Finally, the author expresses his gratitude to his wife Randa and daughter Dina, whose patience, understanding and self-sacrifice were the incentives for completing this dissertation. 


\begin{abstract}
The use of non-corrosive fiber reinforced plastic (FRP) rebars in lieu of mild steel rods is investigated. The present work cover experimental testing of twenty seven concrete beams reinforced with FRP rebars subjected to bending, twenty four cantilever specimens subjected to bond forces, and twelve straight pull-out specimens. The following response of concrete beams reinforced with FRP rebars were investigated: pre- and post-cracking behavior, load-deflection and stress variations, elastic and ultimate load carrying capacities, crack widths and patterns, bond stress and embedment length, and modes of failure. In order to take advantage of the high tensile strength of FRP rebars (80 to $130 \mathrm{ksi})$, high strength $(6-10 \mathrm{ksi})$ concrete in lieu of regular strength concrete ( $4 \mathrm{ksi})$ is used. The use of sand coated FRP rebars in addition to high strength concretes improved the overall behavior of the beams. It is shown that a $90 \%$ increase in ultimate moment capacity is achieved over beams reinforced with steel rebars for the same area and strength of concrete. Theoretical correlations with experimental results are conducted in terms of elastic and ultimate bending moment, crack width, post cracking deflection, and bond and development length. Simple design equations for structural design applications are developed with similarities and parallels to current $\mathrm{ACI}$ 318-89 code equations. A step by step design example is presented based on the above design equations.
\end{abstract}




\section{Table of Contents}

Acknowledgement

Abstract iii

Table of Contents iv

Nomenclature viii

List of Tables $\quad x$

List of Figures $\quad$ xi

CHAPTER 1

INTRODUCTION 1

1.1 Objective 3

$\begin{array}{ll}1.2 \text { Scope } & 3\end{array}$

$\begin{array}{lll}\text { CHAPTER } 2 & 7\end{array}$

LITERATURE REVIEW

2.1 Introduction 7

2.2 Early Research on FRP $\quad 8$

$\begin{array}{ll}\text { 2.2.1 Mechanical Properties } & 9\end{array}$

2.2.2 FRP Performance as a Reinforcing

$\begin{array}{ll}\text { Element for Concrete } & 10\end{array}$

2.2.3 Externally Induced Stress Levels $\quad 12$

2.2.4 Gripping Mechanisms $\quad 13$

2.3 ASCE Specialty Conference $\quad 14$

$\begin{array}{ll}\text { CHAPTER } 3 & 19\end{array}$

$\begin{array}{ll}\text { MATERIAL PROPERTIES } & 19\end{array}$

3.1 FRP Rebar Characteristics 19

3.1.1 Gripping Mechanisms 20

3.1.2 Tension Properties 25 
3.1.4 Torsion Properties 31

3.1.5 Bending Properties 31

3.2 Concrete Properties 33

$\begin{array}{ll}\text { CHAPTER } 4 & 39\end{array}$

EXPERIMENTAL RESULTS $\quad 39$

4.1 Specimen Fabrication and Curing 39

4.2 Test Apparatus and Instrumentation $\quad 42$

4.2.1 Bending Tests 42

4.2.2 Bond Tests $\quad 42$

4.3 Experimental Program 48

4.3.1 Bending Tests . $\quad 48$

4.3.2 Bond Tests $\quad 50$

4.4 Experimental Results $\quad 54$

4.4.1 Bending Behavior $\quad 54$

4.4.1.1 Pre-and post-cracking behavior $\quad 54$

4.4.1.2 Ultimate load carrying capacity 55

4.4.1.3 Crack patterns 55

4.4.1.4 Modes of failure $\quad 56$

4.2.2 Bond Behavior 65

4.2.2.1 Cantilever Specimens $\quad 68$

4.2.2.2 Cylinder Specimens $\quad 75$

$\begin{array}{ll}\text { CHAPTER } 5 & 77\end{array}$

THEORETICAL CORRELATION WITH EXPERIMENTAL RESULTS 77

5.1 Ultimate Moment Capacity 77

5.1.1 Compressive Stress Distribution $\quad 77$

5.1.1.1 Rectangular Stress Distribution $\quad 81$ 
5.1.1.2 Parabolic Stress Distribution

5.1.2 Ultimate Moment 84

5.2 Flexural Cracking 91

5.2.1 Flexural Cracking in FRP Reinforced Beams 93

5.2.2 Crack Width Analysis $\quad 105$

5.3 Deflection 111

5.3.1 Precracking Stage $\quad 111$

5.3.2 Postcracking Stage $\quad 113$

5.3.2.1 Modified Moment of Inertia $\quad 116$

5.4 Balanced Reinforcement Ratio 127

5.5 Bond Strength and Development Length 128

5.7.1 Anchorage and Adhesion Bond 130

5.7.2 Basic Development Length 131

5.7.2.1 ACl Approach $\quad 132$

5.7.2.2 Basic Development Length for FRP $\quad 132$

CHAPTER 6

SIMPLIFIED ENGINEERING DESIGN EQUATIONS 135

6.1 Design Charts and Tables 137

6.2 Design Procedures 139

6.2.1 Design for Flexure

(Ultimate strength design method) $\quad 140$

6.2.2 Design for Flexure

(Working stress design method) 141

6.2.3 Crack width analysis 142

6.2.4 Deflection and modified moment of inertia 143

6.2.5 Development length 143

6.3 Design Example 143 
$\begin{array}{ll}\text { CHAPTER } 7 & 148\end{array}$

CONCLUSIONS AND RECOMMENDATIONS 148

7.1 Summary 148

$\begin{array}{ll}7.2 \text { Conclusions } & 150\end{array}$

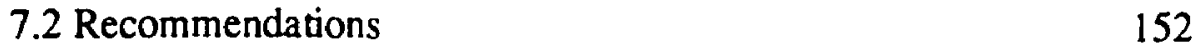

REFERENCES 154

APPENDLX (Design Charts and Tables) 159

$\begin{array}{ll}\text { VITA } & 199\end{array}$

APPROVAL OF EXAMINING COMMITTEE 200 


\section{Nomenclature}

A Area (in ${ }^{2}$ )

$A_{b}$ Cross sectional area of reinforcing bar (in ${ }^{2}$ )

A Area of concrete in tension divided by number of rebars

A Cross sectional area of steel reinforcement (in ${ }^{2}$ )

b width of concrete section (in)

C Compression Force (lb)

c Depth of neutral axis (in)

d Depth of tension reinforcement (in)

$d_{c} \quad$ Thickness of cover to the center of first layer of reinforcement (in)

$\mathrm{E}_{\mathrm{c}} \quad$ Concrete modulus of elasticity (psi)

$\mathrm{E}_{\mathrm{f}} \quad$ FRP rebar modulus of elasticity (psi)

$\mathrm{f}_{\mathrm{c}} \quad$ Concrete stress (psi)

$\mathrm{f}_{\mathrm{c}}{ }^{\prime} \quad$ Concrete compressive strength (psi)

$f_{f} \quad$ Tensile stress in FRP rebar (psi)

$f_{r}^{\prime} \quad$ Modulus of rupture (psi)

$f_{s} \quad$ Tensile stress in steel rod (psi)

$\mathrm{f}_{\text {sp }}{ }^{\prime} \quad$ Tensile Spliting strength (psi)

$\mathrm{f}_{\mathrm{u}} \quad$ Ultimate tensile strength (psi)

$f_{y} \quad$ Yield strength of steel rod (psi)

$f_{y f}$ Effective yield strength of FRP rebar (psi)

h Total depth of section (in)

$\mathrm{I}_{\mathrm{cr}} \quad$ Cracked moment of inertia (in ${ }^{4}$ )

$\mathrm{I}_{\mathrm{e}} \quad$ Effective momnet of inertia (in ${ }^{4}$ )

Ig Gross moment of inertia (in ${ }^{4}$ ) 
$I_{m} \quad$ Modified moment of inertia (in ${ }^{4}$ )

$\mathrm{k}_{1}$ Constant

k2 Constant

k3 Constant

L Length (in)

$l_{d} \quad$ Development length (in)

$\mathrm{I}_{\mathrm{db}} \quad$ Basic development length (in)

$\mathbf{M}_{\mathbf{n}} \quad$ Nominal moment strength of section (in.lb)

n Modular ratio

P Load applied (lb)

$\mathrm{T}$ Tension force (lb)

$\mathrm{W}_{\max }$ Maximum crack width (in)

$\beta_{1} \quad$ Stress block depth factor

$\mu \quad$ Bond stress (psi)

Pbal Balanced reinforcement ratio

$\rho_{\min }$ Minimum reinforcement ratio 
List of Tables

3.1 Properties of High Strength Concrete 34

4.1 Reinforcement Detail and Concrete Strength of Bending

$\begin{array}{ll}\text { Specimens Tested } & 49\end{array}$

4.2 Reinforcement Details and Concrete Strenghs of Cantilever

Specimens Subjected to Bond $\quad 52$

4.3 Pull-out Cylinders Details 53

4.4 Bending Test Results of Group A Through E 59

4.5 Cantilever Bond Test Results 66

$\begin{array}{lll}4.6 & \text { Cylinder Pull-out Results } & 77\end{array}$

$\begin{array}{lll}5.1 & \text { Flexural Parameters } & 83\end{array}$

5.2 Theoretical vs experimental moment evaluation 87

5.3 Theoretical versus experimental crack widths 110

5.4 Modulus of Elasticity Variations 112

5.5 Average experimental bond strength 133

6.1 Effective yield strength of FRP rebars 136 


\section{List of Figures}

1.1 FRP Rebar Samples 5

3.1 Sand Coated FRP Rebar Samples $\quad 20$

3.2 Proposed Grip \#1 21

3.3 Proposed Grip \#2 22

3.4 Proposed Grip \#3 22

3.5 Proposed Grip \#4 23

3.6 Sand Coated Grip for FRP Rebar Testing 24

3.7 Detail of The Sand Coted Grips Used in Pre-tensionning The $\begin{array}{ll}\text { FRP Rebars } & 24\end{array}$

3.8 Tensile Stress Strain Curve of \#3 FRP Rebar

3.9 Experimental Setup for Tension Test of FRP rebars 27

3.10 Tensile Modulus of FRP Rebars $\quad 28$

3.11 Tensile Strength Results of FRP Rebars 29

3.12 Compressive Strength Results of FRP Rebars 30

3.13 Bending Strength Results of FRP rebars 32

3.14 Stress Versus Strain for Concrete Cylinder, $f c^{\prime}=6500 \mathrm{psi}$

3.15 Stress Versus Strain for Concrete Cylinder, fc' $=7500$ psi 36

3.16 Stress Versus Strain for Concrete Cylinder, $f c^{\prime}=8800$ psi 37

3.17 Stress Versus Strain for Concrete Cylinder, $\mathrm{fc}^{\prime}=10000 \mathrm{psi}$

4.1 Formwork and Reinforcement Detail of Bending Specimens 40

4.2 Formwork and Reinforcement Detail of Bond Specimens 40

4.3 Cast Specimens Under Curing Conditions 41

4.4 Bending Test Setup 43

4.5 Bond Specimen Reinforcement Detail 44

4.6 Cylinder Pullout Specimens 44 
$\begin{array}{lll}4.7 & \text { Pullout Test Setup } & 46\end{array}$

4.8 Detail of Load Distribution Plates 47

4.9 Detail of the Sand Coated Grips 47

4.10 Load vsDeflection (Group D) 62

4.11 Cracking Pattern of Beam \#D Reinforced with 3\#4

Sand Coated Rebars $\quad 62$

4.12 Load vs Deflection (Group E) 63

4.13 Load vs reinforcement strain (FRP vs Steel reinforced beams) 63

4.14 Load vs concrete strain (FRP vs steel reinforced beams) 64

4.15 Load vs deflection (FRP vs steel reinforced beams) 64

4.16 Cracking Pattern of Bond Specimen BO.1.1 69

4.17 Cracking Pattem of Bond Specimen BO.1.3 69

4.18 Rebar Failure Outside Specimen with No Slip 70

4.19 Cracking Pattern Around the Rebar in BO.H5 71

4.20 Strain Distribution Along Embedment Length

\#4 Sand Coated Rebar with EL = 8 in. 72

4.21 Setup and Failure of Cantilever Specimen 73

4.22 Close up of Failed Specimen B.O.H9 73

4.23 Bond stress vs Elongation $\quad 74$

$\begin{array}{lll}4.24 & \text { Bond Stress vs slip } & 75\end{array}$

4.25 Splitting Concrete Failure Around the 2 in

Embedment Length Specimen $\quad 76$

4.26 Straight Pull-out Failure of Cylinder with 6 in Embedment Length (\#4 Sand Coated) 76

5.1 Equivalent Rectangular Stress Distribution (Whitney's) 78

5.2 Parabolic Stress Distribution (Kaar, Hanson, Capell) 79

$\begin{array}{lll}5.3 & \text { Jensen's Trapezoidal Distribution } & 80\end{array}$ 
5.4 Load vs FRP strain under varying concrete strengths 85

5.5 Effect of varying concrete strength on ultimate moment 86

5.6 Crack width measurements vs measured stress 95

5.7 Cracking pattem Group C 96

5.8 Cracking Pattern Group E 97

$\begin{array}{lll}5.9 & \text { Cracking Pattern Group B } & 98\end{array}$

5.10 Cracking Pattem Group D 99

5.11 Cracking Pattem Group D (Higher Strength Concrete) 100

5.12 Cracking Pattern with Arch Arrangements 101

5.13 Cracking Pattern with Increase of perimeter 102

5.14 Effect of using Sand Coated Rebars on Cracking Pattern 103

5.15 Crack Pattem Group A 104

5.16 Load, moment, cracking section of loaded beam 115

5.17 Concentrated point load case 118

5.18 Uniform load case 118

5.19 Theoretical vs experimental deflection 120

5.20 Theoretical vs experimental deflection 121

5.21 Theoretical vs experimental deflection 122

5.22 Theoretical vs experimental deflection 123

5.23 Theoretical vs experimental deflection 124

5.24 Theoretical vs experimental deflection 125

5.25 Theoretical vs experimental deflection 126

$\begin{array}{lll}5.26 & \text { Balanced strain conditions } & 127\end{array}$

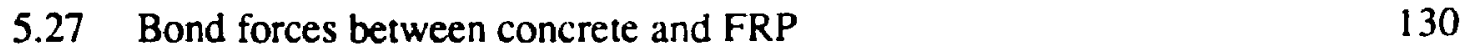




\section{CHAPTER 1}

\section{INTRODUCTION}

Concrete reinforced with mild steel rebars is commonly used in the construction of bridge decks, parking garages, and numerous other constructed facilities. The extensive use of deicing chemicals is reducing the service life of these facilities. In addition, concrete structures exposed to highly corrosive environments, such as coastal and marine structures, chemical plants, water and wastewater treatment facilities, experience drastically reduced service life and cause user inconveniences.

The gradual intrusion of chloride ions into concrete eventually leads to corrosion of steel reinforced concrete structures. Steel rebar corrosion may be aggravated by the inadequacy of protective concrete cover over the embedded steel rebars or cracking of concrete. Cracking of concrete, in addition, may be due to shrinkage, creep, thermal variations, or some unexpected design inadequacies due to external loads (Nawy, 1990). Steel rebar corrosion phenomenon is not fully resolved eventhough research on the corrosion retardation of steel has been going on for a long time. The cost of replacing a disintegrated structure commonly runs TWICE the original cost of construction (America's Highway, 1984). A corrosion protection system that would extend the performance of our constructed facilities would have a payoff in billions of dollars.

Several recommendations have been adopted in the design of concrete structures to prevent the corrosion of steel reinforcement. For example, most bridge deck design standards incorporate waterproofing admixtures in concrete, placement of an 
impermeable membrane, epoxy-coated steel rebars, and a 2" minimum clear cover with dense or latex-modified concrete.

Since neither a practical nor an economic solution has yet been developed to prevent corrosion related degradation of concrete structures, the use of noncorrosive fiber reinforced plastic (FRP) rebars in place of mild steel rebars appears to be a good alternative to improve the longevity of these structures. In addition, FRP rebars are being used in applications where a nonmagnetic environment is essential, such as in microchip manufacturing and testing plants, and in those areas of hospitals where magnetic resonance imaging systems are located.

The performance of the FRP rebars embedded in concrete is not fully understood, even though FRP rebars have been used in structural applications. The curret mathematical models and design equations of concrete beams reinforced with mild steel cannot be applied directly to beams reinforced with FRP rebars for the following reasons:

1) Low modulus of elasticity of FRP rebars

2) Inadequate understanding of bond behavior

3) Long term degradation of FRP rebars

4) Crack width development and post-cracking behavior of the concrete beams reinforced with FRP rebars

In order to understand the behavior of FRP rebars in concrete, a comprehensive understanding is essential for concrete specimens reinforced with FRP rebars which are subjected to bending, bond and other forces such as axial, shear, and dowel effects. 


\subsection{Objective}

The primary focus of this investigation is to study the feasibility of reinforcing concrete beams and bridge decks with FRP rebars. The main objectives of the this work include three aspects of the behavior of FRP rebars used as reinforcement in concrete: (1) Investigation of the pre- and post-cracking behavior under bending and bond forces of concrete beams reinforced with FRP rebars; (2) Investigation of the influence of various parameters on bending and bond resistance, crack propagation, ductility, and deflection limits of concrete beams reinforced with FRP rebars; (3) Development of design equations for FRP reinforced concrete, which are practical and simple to use for structural design applications.

In order to achieve the above objectives, it is necessary to investigate the mechanical characteristics of FRP rebars. A comprehensive study was performed by Wu (1990) on the thermomechanical properties of fiber reinforced plastic rebars, which included the mechanical properties of FRP rebars under tension, bending, compression, and torsion. The strength and stiffness results of FRP rebar properties are included in Chapter 3.

\subsection{Scope}

Understanding the performance of different types of FRP rebars embedded in concrete is the first objective of this research. This objective is achieved by embedding FRP rebars with different surface conditions (smooth, ribbed, sand coated) and different diameters in concrete specimens. The concrete compressive strength of the specimens ranged from 4000 psi to 10,000 psi. The specimens were tested for bending and bond behavior of FRP rebars. The following issues have been evaluated:

a) Stress-Strain Relationship 


\section{b) Load-Deflection Variations}

c) Load Carrying Capacities (ultimate moment)

d) Crack Patterns (spacing, width, propagations)

e) Modes of Failure.

Based on the experimental results, the second objective of this work is to develop a theoretical correlation for the structural performance of concrete beams reinforced with FRP rebars. The study is carried out in order to investigate the effects of reinforcement configuration in terms of the type, size and area of the FRP reinforcement, and concrete compressive strengths on bending and bond resistance, crack width and propagation, and deflection behavior.

The third objective of this work is to develop practical yet simple engineering design equations for concrete sections reinforced with FRP rebars. Design curves and equations are generated for different rebar sizes, including the effect of changing concrete compressive strength. Equations for design loads and bending resistance, bond and development lengths, crack widths and post-cracking behavior are developed in a simplified form for practical design applications. Similarities and parallels of these design equations with current $\mathrm{ACI}$ 318-89 equations are maintained when possible.

The FRP rebars used in these experiments were donated by Morrison Molded Fiber Glass (MMFG), Vega Technologies, Inc., Creative Pultrusion, Inc. and International Grating, Inc. (KODIAK). These FRP rebars are made from E-glass fibers embedded in either vinylester or isophthalic resin. The FRP rebars provided by Vega Technologies and International Grating companies have a rough surface finish caused by wrapping the rebar with an additional strand of resin-soaked fibers in a 45 degree helical 
pattern. The FRP rebars (refer to Fig. 1.1) supplied by MMFG and Creative Pultrusion have smooth surface.
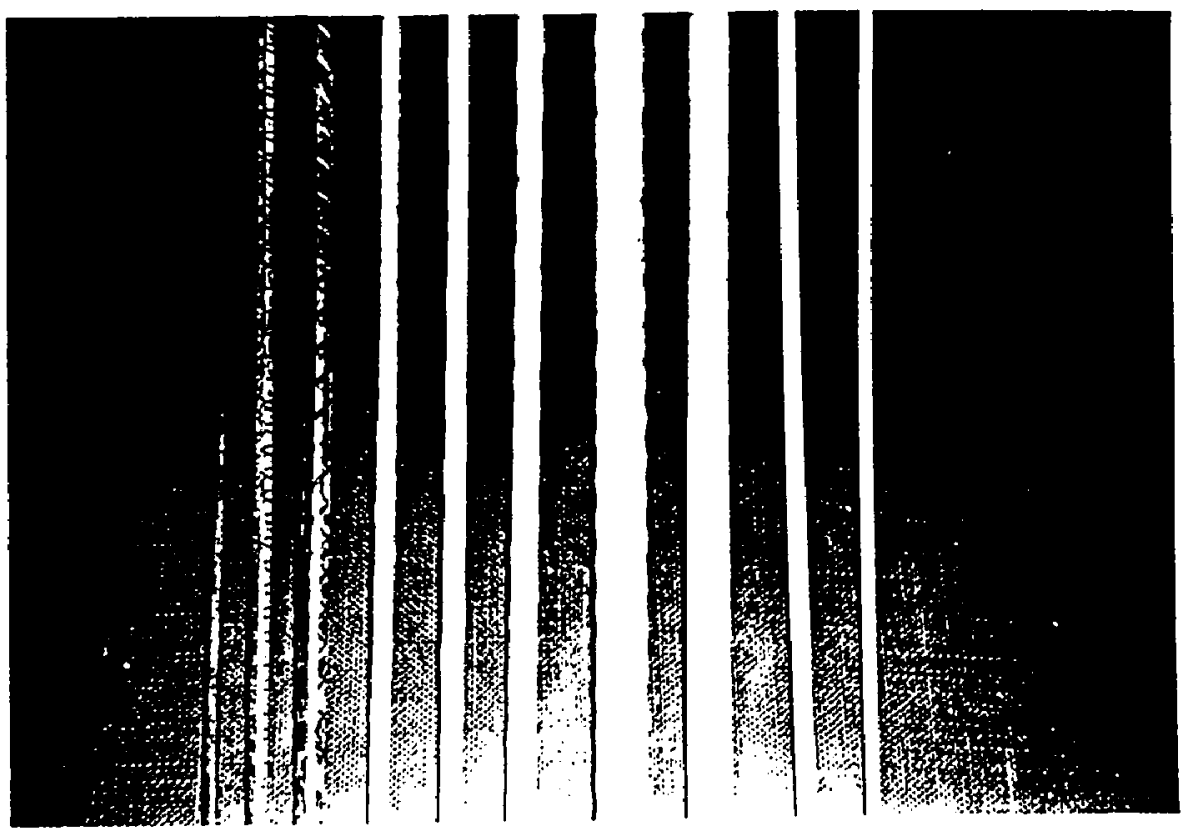

\section{Figure 1.1 FRP Rebars}

Twenty seven rectangular beams, $6 \times 12$ inches by $10 \mathrm{ft}$, are tested under pure bending (as simply supported under four point bending), using different configuration of FRP reinforcements and concrete strengths, such as:
a) Rebar size (\#3, \#4, \#7, \#8)
b) Type of rebar (smooth, ribbed, sand coated)
c) Type of stirrups (steel, smooth FRP, ribbed FRP) 


\section{d) Reinforcement distribution (3\#4 versus 5\#3)}

e) Concrete compressive strength $(4.2,5.0,6.5,7.5$, and $10 \mathrm{ksi})$

The static loading test results include the ultimate moment capacity, deflection, crack width, load vs strain variation in FRP and concrete, and modes of failure. The specimens are analyzed using an elastic design method as well as an ultimate strength design theory. Guidelines for the design of concrete beams reinforced with FRP rebars are also provided, including crack width and deflection limits.

Twenty four bond specimens similar to the WVU modified cantilever type are tested (Kemp and Wilhelm, 1979). The front of the concrete end block was cut out in these specimens for modeling the portion of a beam adjacent to a diagonal crack. The compression zone of the bond specimen is designed to prevent premature crushing failure. The specimens are designed so that no shear or moment failure is expected to occur during the tests. In addition twelve pull-out tests were conducted for comparison purposes. Variables in both the cantilever and cylinder pull-out included:

a) Size of the rebar (\#3, \#4, and \#8)

b) Type of rebar (ribbed and sand coated)

c) Embedment length $(24,18,12,8,6,4$, and 2 in)

e) Concrete compressive strength (5.0, ó.5, 7.5, and $10 \mathrm{ksi})$.

The theoretical correlation utilizes, as a first step, the current mathematical models and design equations for concrete reinforced with mild steel rods. These equations are checked with the experimental values and changed as necessary to accommodate FRP reinforcement. Based on the theoretical correlation, the applicable design equations are used to develop design charts. 


\section{CHAPTER 2}

\section{LITERATURE REVIEW}

\subsection{Introduction}

What is Fiber Reinforced Plastic (FRP) ? Since the 1930's, glass has been considered as a possible substitute to steel for reinforcing or prestressing a concrete section. Surface protection of glass from attacks by the environment was accomplished with plastics. The resultant system consisted of fibers of glass embedded in a matrix of plastic, generally referred to as glass fiber reinforced plastic (GFRP) system. Various forms of glass fibers are produced. These include fiber glass yarns and cords composed of twisted strands with several surface treatments, as well as glass fiber rods and tapes, some of them made up of unidirectional fibers bonded together with plastics or resins. In order to develop a good bond between concrete and glass fiber rods, different surface conditions have been developed, such as coating the rods with epoxy, rolling them in a bed of sand, or sanding the rod with emery cloth to create a roughened surface.

International Grating, Inc., and Vega Technologies, Inc., recently introduced to the market a fiberglass reinforced rod that has a deformed surface. The deformation is made by wrapping the rod with an additional strand of resin soaked fiberglass in a 45 degree helical pattern. The shape of the resulting rod resembles the shape of steel rebars used in the concrete construction industry.

Why use FRP ? The FRP rebar exhibits excellent properties. These properties include high tensile strength ( $\equiv 130 \mathrm{ksi}$ ), low density $\left(0.074 \mathrm{lb} / \mathrm{in}^{3}\right.$ ), high energy absorption, high impact resistance, good chemical resistance to acids (noncorrosive) and 
bases, especially to alkaline and carbonated concrete. The rebar is also nonmagnetic and nonconductive. Although the FRP's thermoset resin matrix is brittle when unreinforced, the presence of reinforcement imparts good toughness characteristics and ability to absorb energy. Energy absorption is accomplished by high elastic deformation prior to failure due to the low modulus of elasticity $\left(E=7.2 \times 10^{6} \mathrm{psi}\right.$ for $55 \%$ glass volume fraction). FRP rebar also improves the ductility of concrete specimens due to its low modulus which leads to tolerance of large deformations.

\subsection{Early research on FRP}

Studies in the early 1950s suggested that the only field of considerable engineering promise appeared to be that concerned with the use of fiberglass reinforced plastic rebars as prestressing elements (Wines and Hoff 1961). Significant developmenit since the $1950 \mathrm{~s}$ in the use of fiber reinforced plastics suggested the need for a review of recent research and development work on the use of this material for reinforced concrete.

Recent reports and publications by Wu (1990), Pleiman (1987), Saadatmanesh and Ehsani (1989), Larralde, Renbaum and Morsi (1989), and Bunea (1989) were reviewed, and additional information was supplied by Reynolds-Schlattner-Chetter-Roll, Inc., on early and recent designs using FRP rebars. In addition, published reports on the prestressing work in West Germany on the UlenBergstrasse Bridge (1987) have been reviewed. The current reports and publications present only a few experiments conducted on the bending and bond behavior of concrete beams reinforced with FRP rebars. The experimental results that are reported in the literature are not conclusive and no design recommendations were established.

The objective of this section is to review both the early and more recent work on FRP rebars in terms of mechanical properties, performance as a reinforcing element in concrete, relaxation behavior, and gripping mechanisms. 


\subsubsection{Mechanical Properties}

The first consideration of glass fibers appears to have been by Rubinski in the early 1950s. Rubinski (1951) reported that the ultimate tensile strength of glass fibers can be anticipated to be over 1,000,000 psi, but noted that the tensile strength of glass fibers decreases with increasing diameter due to the effect of irregularities and cracks. Rubinski explained the variation in strength with diameter by stating that a smaller number of irregularities may be found in smailer diameter fibers, leading to higher average ultimate stress. Another problem cited in his report was that of obtaining equal distribution of stress among fibers of a strand or rebar. Rubinski explained: "It is very important to develop a type of strand or rebar that would have a high effective strength." Therefore, the strength is dependent upon the diameter and length of the fiber. Rubinski reports that various theories were put forward to explain this relationship. The most feasible theory reported is that the variation in strength is due to the existence of defects or minute cracks in the glass, causing an uneven load distribution and leading to early failure.

Tension tests by Pleiman (1987) on FRP rebars furnished by Vega Technologies, Inc., confirm that this material has good properties for reinforcement of concrete. The ultimate tensile strength tests were performed on \#2 and \#3 rebars. The ultimate tensile strength values showed some discrepancy between the specimens tested of the same rebar diameter, and the values also depended on the specimen size. The report concluded that it was safe to assume a value of $160,000 \mathrm{psi}$ for the ultimate tensile strength and a value of $7.5 \times 10^{6} \mathrm{psi}$ for the modulus of elasticity for the FRP rebars. The above mentioned values are somewhat different from those reported by Wu (1990) on FRP rebars supplied by the same company. The causes of variation in strength among the specimens with changes in diameter were neither discussed nor explained by Pleiman. 
The mechanical properties of the commercially available FRP rebars under tension, compression, bending, and torsion have been obtained by Wu (1990). Results generated from these experiments include stiffness, ultimate strength, and associated modes of failure. These issues are further discussed in Chapter 3 of this report.

\subsubsection{FRP Rebar Performance as a Reinforcing Element in Concrete}

A review of the available information on the utilization of FRP rebars as reinforcing elements in concrete members subjected to bending is presented in this section.

Wines and Hoff (1967) used a smooth-surface FRP rebar, 1/4 in. in diameter, composed of unidirectional glass fibers bonded with epoxy resin to study the use of glaşs fibers as reinforcing elements in concrete. Their study included tensile tests on FRP rebars to determine the yield point and ultimate strength, modulus of elasticity, and longduration load effects. In addition, Wines and Hoff conducted bond tests using various types of surface treatments to find the best and easiest method to achieve good bond in concrete and also conducted three point flexural loading on comparative steel reinforced and FRP reinforced concrete beams. From the experimental results, Wines and Hoff concluded the following:

- The full strength of FRP rebars is never utilized

- Everything being equal, the ultimate carrying capacity of FRP reinforced concrete is $50 \%$ of that of steel reinforced concrete

- The low modulus of elasticity of FRP rebars approaches that of concrete and cause the neutral axis in FRP reinforced beams to occur closer to the highest compression surface of concrete 
- A bond stress of 1125 psi was achieved when \#2 smooth rebar was sandblasted, coated with epoxy and rolled in sand, compared to 550 psi for a smooth rebar

- Lack of adequate bond between the FRP rebar and concrete resulted in larger deflections than anticipated

- All beam failures were of diagonal tension type

- At ultimate load, FRP reinforced beams deflected more than twice as much and carried only $1 / 3$ to $1 / 2$ of the load the steel reinforced beam did.

Nawy and Neuwerth (1977) studied the behavior of concrete elements reinforced with FRP rebars in terms of the flexural cracking characteristics of the elements, their deflection, and their load capacities up to failure. Their study included the testing of both concrete slabs and beams. They concluded that the ultimate strength of the FRP rebars could not be developed due to the low modulus of elasticity of the fiberglass material. At working load levels of approximately $20 \%$ of ultimate test loads, the FRP reinforced slabs were observed to be within existing code limitations for deflection and cracking. A large factor of safety in the design of slabs will exist at low working-stress levels due to the large amount of reserve strength in the FRP rebars. Nawy and Neuwerth determined that fiberglass was found to be a potential reinforcing material for concrete slabs, but further work is needed on the possibility of raising the modulus of elasticity of the fiberglass reinforcement as well as long-term and impact loading effects on reinforced elements.

Larralde, Renbaum, and Morsi (1988) conducted only a few tests on concrete beams reinforced with FRP rebars, and combination of steel and FRP rebars. Their results were presented with theoretical load-deflection curves calculated with the aid of elasticity principles before cracking. Their results also include the ultimate loads computed using standard theories of flexural failure of concrete. In another research 
paper, Larralde (1990) presented an investigation of bond stress-slip behavior based on straight pull-out tests on FRP rebars. From the tests, it was found that the ultimate bond strength was lower than the nominal bond strength calculated from the equation used for steel reinforcement. These pull-out tests do not reflect the actual conditions of the rebars in concrete elements with flexural reinforcement. In his test, the concrete surrounding the rebars is under compression, reducing the possibility of cracking and increasing the bond strength. In contrast, concrete surrounding the rebar is under tension in concrete beams subjected to flexure. Larralde concluded that the embedment length as specified in the ACI building code is questionable for FRP rebars.

Bunea (1988) conducted a small number of bending and bond tests on I, T and rectangular concrete cross sections reinforced with FRP rebars. Bunea's experimental bond strength results from beam bending tests are similar in magnitude to his cantilever specimen test results. His bond strength computations are based on conventional $\mathrm{ACI}$ building code approach.

Saadatmanesh and Ehsani (1989) experimentally investigated the behavior of concrete beams reinforced with FRP rebars to determine the feasibility of using FRP rebars as a substitute for steel bars in reinforced concrete construction. They concluded that great potential exists for using FRP rebars as reinforcing element in concrete sections, but specified that the deflection of the concrete beams should be used as the limiting design criterion. In addition, their research reports good bond exists between concrete and the FRP rebars but does not specify any values for bond strength.

\subsubsection{Externally Induced Stress Eeygls}

Earlier studies by Rubinski (1954) on long duration flexure tests on fiber glass rods revealed that no creep was present in the rods, but loads between 60 and 80 percent of the ultimate strength caused failure to occur at time intervals ranging from 30 minutes 
at 80 percent to 39 days at 60 percent. Rubinski suggested that high humidity and surface moisture of the rods reduced the load carrying capacity of the rods. $\mathrm{He}$ concluded that one of the most important phenomena encountered in connection with the FRP tests was that of static fatigue, loss of strength over time under loading conditions which varies with the percentage of ultimate tensile or flexural stress to which the sample is subjected to.

In another study by Keane (1961), test results showed that creep is present, by suggesting that the load-carrying capacity of a rod is a result of both binding resin and glass fiber, and that the nature of the resin is such that it creeps when placed under sustained load. Keane developed a theory of stress transfer from the resin to glass fiber, which in turn causes the overloading of glass fibers, and hence failure of the rod. Other studies reported by Wines and Hoff (1966) suggested that the increase in the strain is not large enough to cause the rod to fail.

\subsubsection{Gripping Mechanism}

The design of suitable grips, either temporary for pretensioned concrete and for testing the rebars in tension, or permanent for post-tensioned concrete presents a major challenge since the brittle rebar is liable to fail in the grip itself because of the combined effects of shearing and crushing stresses. An ideal grip must be such that the tension is transmitted gradually from the grips to the FRP rebar. A completely reliable technique for testing FRP rebars in tension needs to be developed, since difficulties are encountered in holding the rods in the testing machine jaws when employing known standard methods for metals and plastic laminates.

Very few grip designs have been tried. Practical results have not been achieved by Keane, who used a grip consisting of a $1 / 4$ in. diameter pipe which is 12 in. long, with the fiber glass rod bonded to it by a cold-setting resin. The adhesive must be selected 
with care, however, to minimize creep. Other researchers in the United States and Europe claim to have developed some kind of gripping mechanism. Their results are yet to be seen and tested.

\subsection{ASCE Specialty Conference on Advanced Materials}

The Specialty Conference on Advanced Composites in Civil Engineering Structures (1991) covered a wide variety of subjects related to new research on advanced composites. A review of research relevant to the use of fiber reinforced plastic rebars as tension elements for reinforcement, post-tensioning or prestressing of concrete is outlined, herein.

From the experience gained in designing actual structures using FRP rebars, Roll (1990) emphasized that successful performance of FRP reinforced concrete has been achieved using the following guidelines:

- Avoid the use of shallow beam depth/span ratio

- Not to consider full development of FRP rebar strength

- Calculate bending moment capacities conservatively using modified working stress equations

- Do not allow concrete compressive strength to exceed $0.45 \mathrm{f}_{\mathrm{c}}{ }^{1}$ due to the low modulus of elasticity of the FRP rebar.

In the study of Porter and Barnes (1991), correlation of theoretical ultimate tensile strengths of the FRP rebars through flexural tests of concrete beams reinforced with FRP rebars and actual testing of the rebars was incomplete. The effects of dowel shear and flexural deformations on the FRP rebars' ultimate tensile strength capacity was mentioned with no explanations. In their attempt to come up with a suitable gripping 
mechanism for the tensile testing of the FRP rebar, Porter and Barnes concluded that by embedding the specimen in a copper pipe filled with epoxy, the FRP rebars can be tested in traditional wedge action grips. In order for this method to be successful in testing the FRP rebars without inducing any slip or failure in the grip region, some preparations of the rebar ends is necessary, namely, cleaning and light sandblasting.

With a limited number of tests on fiberglass (S2 glass), and graphite prestressing cables, Iyer and Anigol (1991) evaluated their possible use in pretensioned concrete. An anchorage system (patent pending) was used and conclusions were made on its successful use to hold static, sustained, and cyclic load on advanced composite cables. From their bond tests, they reported that bond strength of the advanced cables is comparable to steel cables. In addition, very little creep was noticed in either short or long term sustained load tests.

Pleiman's research on the tensile strength and modulus of elasticity tests was extended to include Kevlar fiber reinforced rebars. The ultimate tensile strength of the Kevlar rebar was reported in the range of $215 \mathrm{ksi}$ versus $160 \mathrm{ksi}$ for the E-glass rebars. In terms of the modulus of elasticity, a value of $8.8 \times 10^{3} \mathrm{ksi}$ was reported for the Kevlar rebar compared to $7.5 \times 10^{3} \mathrm{ksi}$ for the E-glass rebar. Pleiman (1991) reports that the bond strength of the fiberglass rebar improves with size and that the embedment length of the E-glass rebar can be safely assumed to be given by

$$
l_{d}=\frac{f_{u} A_{b}}{18 \sqrt{f_{c}^{\prime}}}
$$

where,

$f_{\mathcal{u}}=$ Ultimate strength of FRP rebar.

$$
A_{b}=\text { Area of FRP rebar. }
$$


$f_{C}{ }^{\prime}=28$ day compressive concrete strength.

$l_{d}=$ Embedment length .

While for the Kevlar 49 rebar, the embedment length can be safely assumed to be given by

$$
l_{d}=\frac{f_{u} A_{b}}{20 \sqrt{f_{c}^{\prime}}}
$$

The above expressions were based on straight pull out tests which does not simulate the actual conditions that FRP rebars and concrete are subjected to. In addition, some specifications on the rebar surface conditions have to be specified when FRP rebars are used.

In the international arena, advanced composite rebars, tendons, and cables are produced, tested and implemented in actual structures as prestressing or reinforcing elements. A variety of products is currently available in the international market, and a significant amount of research is underway in Germany, The Netherlands, and Japan. In addition to glass fibers, carbon and aramid fibers are being implemented by the construction industry.

A new Aramid rod for the reinforcement of concrete structures is being developed and tested by Teijin Ltd. in Osaka, Japan. A tensile strength of $1.9 \mathrm{GPa}(275 \mathrm{ksi})$ and a modulus of elasticity of $54 \mathrm{GPa}\left(7.83 \times 10^{3} \mathrm{ksi}\right)$ was reported for the new AFRP rod. The new rod has a fiber volume fraction of $65 \%$. The development of the AFRP rod has almost reached a stage of practical use.

Carbon Fiber Composite Cable (CFCC) have been developed in Japan by Tokyo Rope MFG. Co. LTD. A bundle of 12,000 pieces of carbon fibers impregnated with 
resin forms the strands, which are then further twisted into a cable. Cables are heated to harden the resin and molded into the final product.

ARAPREE, a commercial name of aramid / epoxy tendon jointly developed by AKZO of Germany and HBG of The Netherlands is currently used in different applications. The first application of ARAPREE in practice has been realized in a noise barrier along a busy motorway. Other applications include, a hollow-core floor slab for private homes and prestressing of masonry cavity walls.

Walton and Yeung (1977) investigated the fatigue performance of structural strands of pultruded composite rods made of E-glass, Kevlar 49, and Carbon fibers. The results indicate that the glass-resin-reinforced strand is inferior in tension fatigue to the steel strand, in that the permissible stress range is much lower for the glass strand. However, it still can prove to be a good alternative because of its relative lightness. The present glass strand results fall significantly short of the tension fatigue performance of unidirectional glass composites loaded in the fiber direction as reported by Agarwal and Browtman (1980).

Kim and Meier (1990) conducted some tests on carbon fiber reinforced plastic (CFRP) cables. They concluded that high strength and Young's Modulus, excellent fatigue and corrosion characteristics, and a low thermal expansion coefficient make CFRPs an ideal material for slender tension elements for large structures subject to high amplitude tests. The brittle behavior and the high costs seem to be the major drawbacks in implementing them in engineering designs at the current time.

Rostasy and Budelmann (1991) of Germany investigated the application of FRP elements for the post-tensioning of concrete structure. Their research focused on developing a suitable tendon-anchorage assembly for the transfer of prestress to the structure. The report shows the possible avenues for the design of anchorages and for the 
experimental verification of their suitability, especially for the anchorage of GFRP elements by polymeric bond.

The most successful application of advanced composite tendons was accomplished by STRABAG BAU-AG of West Germany. In 1980, glass fiber tensioning bars were used for an antenna system and a trial bridge was erected using four different anchorage systems in Dusseldorf, FRG. The first prestressed concrete bridge, Ulenbergstrasse Bridge, designed for heavy traffic loads was constructed in 1986 in Dusseldorf, FRG. A prestressed prefabricated two span beam structure was erected over a brine pit in Dormagen, West Germany, in 1987. The successful use of fiber glass tendons in situations where corrosion retardant material is required can considerably increase the service life of a structure. In 1988, the Marienfelde Bridge was built in Berlin, West Germany. This two-span pedestrian bridge consists of spans of 22.90 meters and 27.58 meters. The bridge superstructure is being constructed for the first time in Germany with partial prestressing without bond. Glass fiber tendons were successfully used in bracing the arch walls of the Mairie d'Ivry Metro Station in Paris, France, in 1989. Thirty six prestressing tendons with a length of 16.00 meters were installed. The electromagnetic neutrality of the bar materials proved very advantageous in this successful rehabilitation project. Currently, a three-span solid concrete slab bridge is being constructed in Leverkusen, West Germany. The Schiessbergstrasse Bridge is designed with partial prestressing and post-bonding. Construction is underway on the first bridge in Austria using glass fiber composite prestressing tendons. The Notsch Bridge in Karnten is designed with partial prestressing and post-bonding. Monitoring the integrity of the above-mentioned bridges was achieved by the use of optical fiber sensors. The optical fiber sensors are used to monitor both the glass fiber tendons and concrete. 


\section{CHAPTER 3}

\section{MATERIAL PROPERTIES}

\subsection{FRP Rebar Characteristics}

Since the 1930s, glass has been considered a good substitute to steel for reinforcing or prestressing concrete structures. Surface protection of certain types of continuous glass fibers, particularly E-glass fibers, from attacks by the environment or alkaline reaction has been accomplished by coatings, including resins. For example, a typical continuous E-glass fiber reinforced plastic rebar has 55 percent glass volume fraction embedded in a matrix of vinylester or isophthalic resin. These thermoset resin systems have excellent resistance to corrosion and impact, are good electrical and thermal insulators, are easy to manufacture, and are cost effective. Manufacturers of composites have long recognized that a continuous manufacturing process is essential in order to maintain a reliable and high quality fiber reinforced plastic rebar. It is obvious as well that continuous manufacturing processes lead to higher production rates (5-7 meters per minute) and lower unit costs. One such manufacturing process is known as the pultrusion process, a process which is analogous to metallic extrusion. Originally, simple solid uniform composite sections reinforced with unidirectional fibers were developed. However, since the pultrusion process has matured significantly, it now can produce a variety of cross sectional shapes, including hollow sections with cross-plied strips.

In order to develop good bond strength between FRP rebars and concrete, different surface conditions for rebars are developed. Among them, 45 degree angular wrapping or helical ribs produce a deformed surface on the rebar (Fig. 3.1). Coating 
FRP rebars with epoxy and rolling them in a bed of sand creates a roughened surface and is one of the alternatives that would improve bond strength.

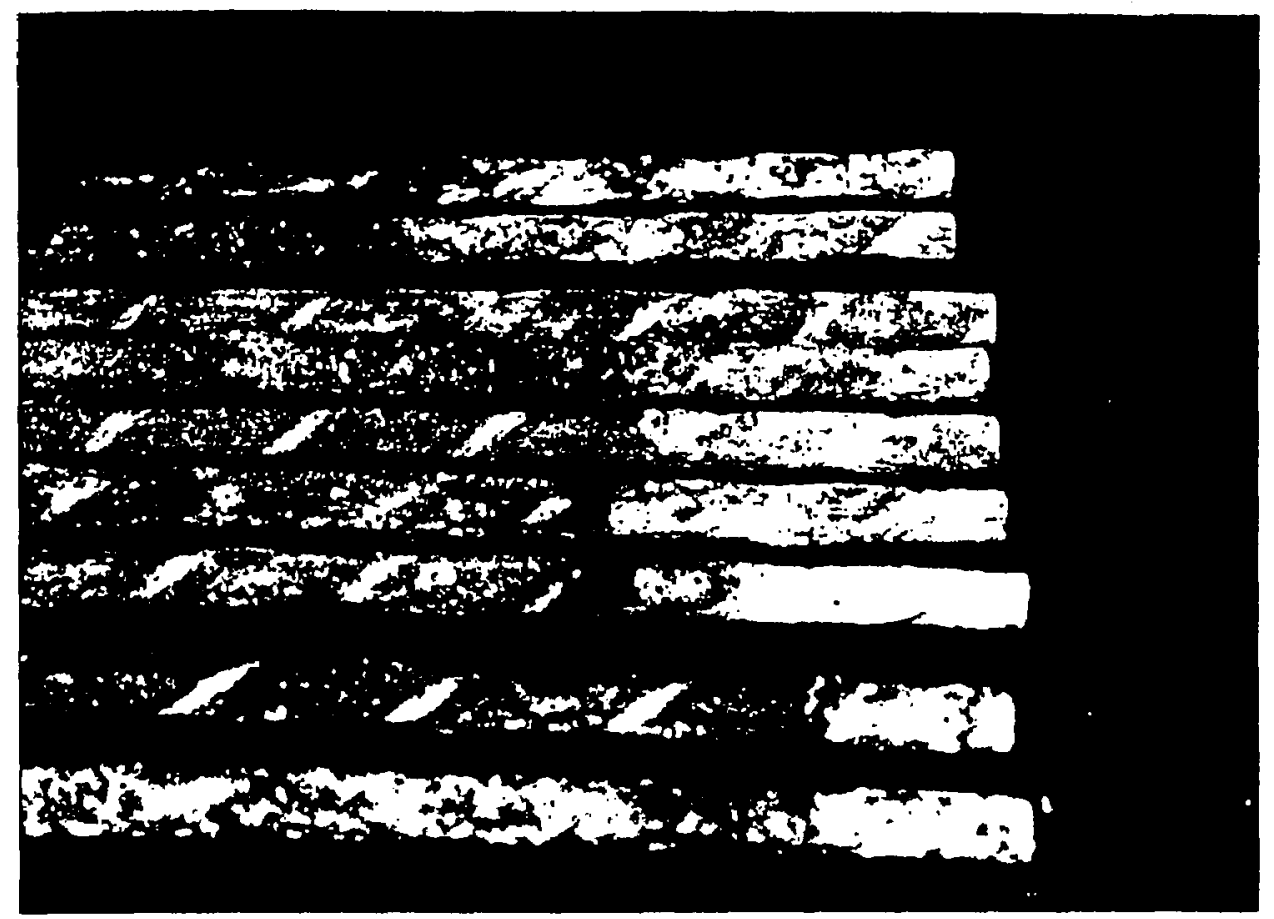

Figure 3.1 Sand coated FRP rebar samples

\subsubsection{Gripping Mechanism}

The design and development of suitable grips for FRP rebars in tension tests, pretensioned and post-tensioned concrete have presented major difficulties in earlier studies as described in Chapter 2. Typically, the FRP rebar is found to fail in the grip itself due to the combined effects of shear and crushing coupled with the tensile stresses. An ideal grip must be easy to use and handle in the field. The grip must grasp the rebar in a manner as to avoid failure of the rebar at the grips; on the contrary, the failure must take place in the rebar away from the grip region.

Outlined in Chapter 2 on the early history of gripping mechanisms, literature review does not reveal any availability of a simple reusable grip that is suitable to test the 
rebars in the laboratory. Several methods for anchoring the FRP rebars have been investigated, as part of this study. The main objective of the proposed grips shown in Figures 3.1 through 3.5 is to test FRP rebars in tension without breaking the rebars at the edge or in the grip section. The proposed grips involve extensive preparation of the rebar ends, and ample time should be given before testing takes place. In addition, the proposed grips are not reusable in most cases. Prior to conducting the tests on the proposed grips, a sand coated grip used in testing of wire cables at WVDOH's Materials and Testing Laboratories were examined. Three FRP rebars of different diameters were tested using the sand coated grips. The tests were successful in avoiding slippage and leading to rebar failure in-between the grips.

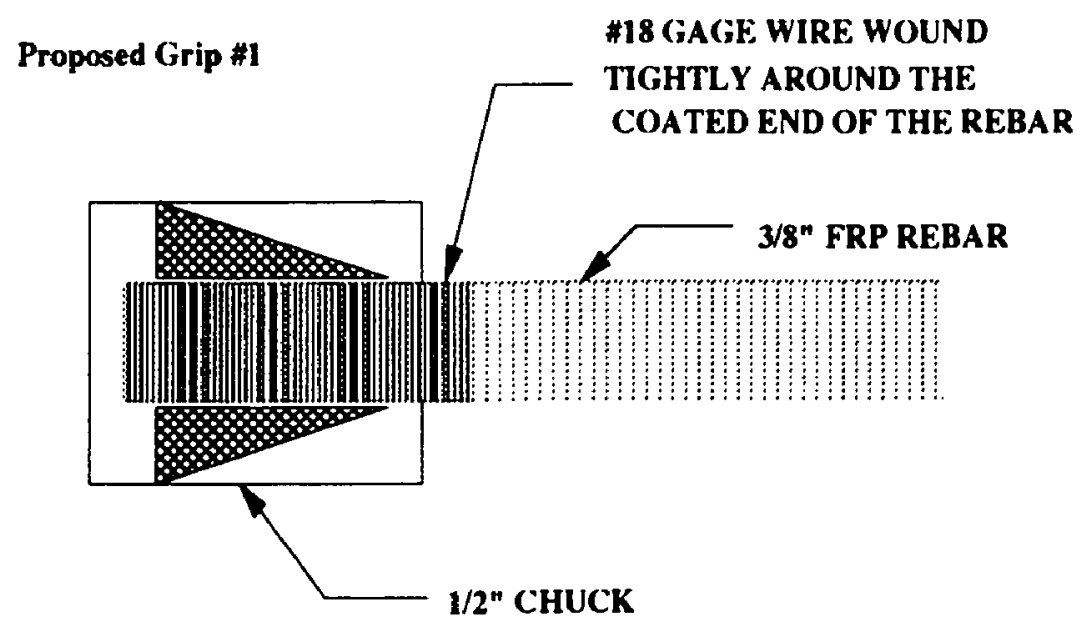

\footnotetext{
Apply epoxy coating at the rebar ends

Wrap very tightly and closely \#18 gage wire over the coated end

Use a standard chuck to grip the bar
}

Figure 3.2 Proposed grip \#1 
Proposed Grip \#2
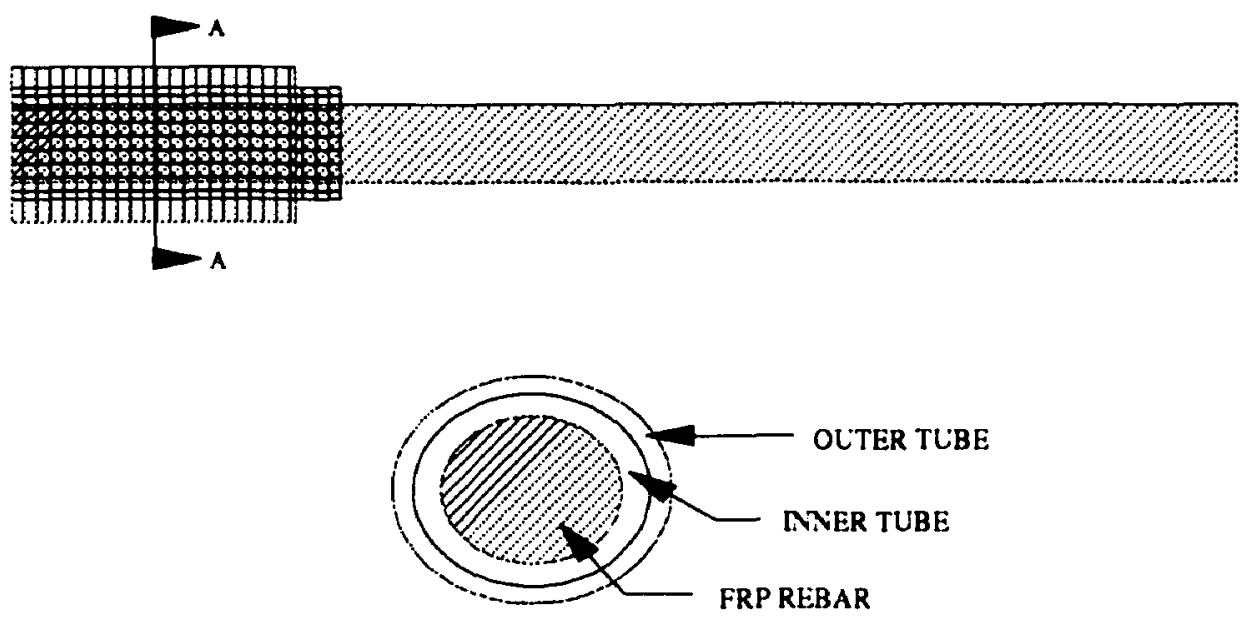

SECTION A - A

The use of 2 thin top quality tubes with epoxy

in order to increase the tiameter size

Figure 3.3 Proposed grip \#2

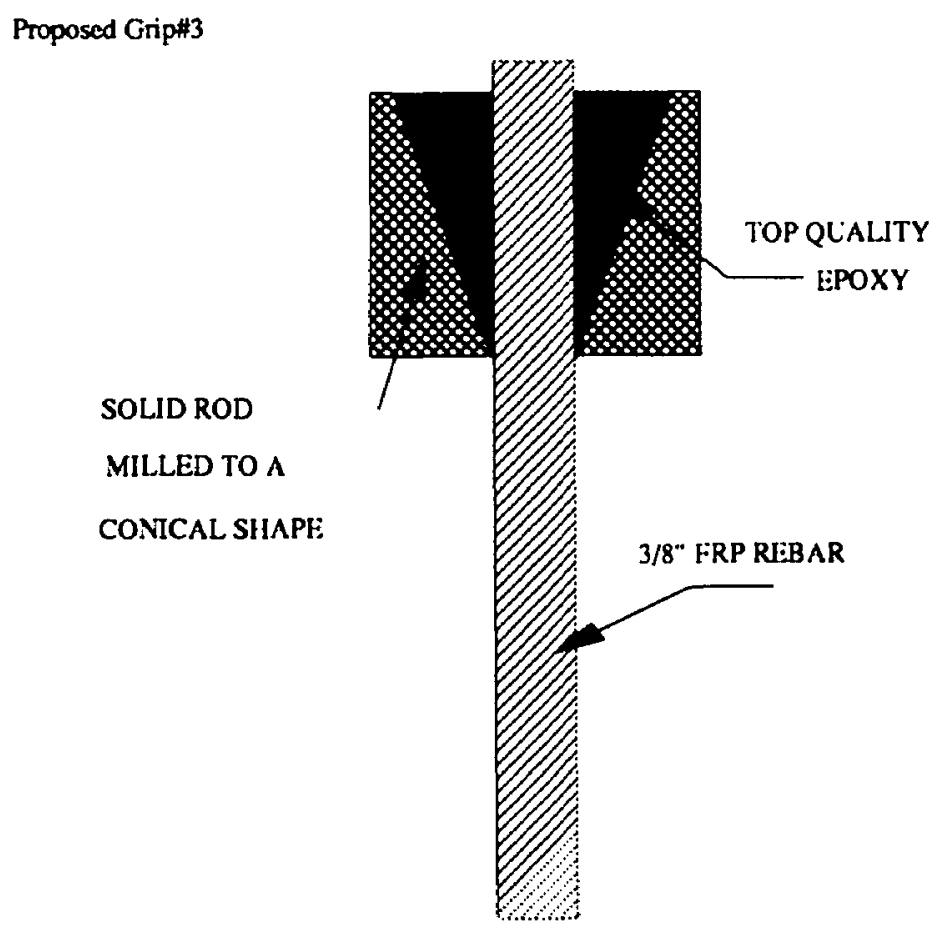

Figure 3.4 Proposed grip \#3 


\section{Proposed Grip \#4}

SOLID ROD

MILLED TO A

CONICAL SHAPE

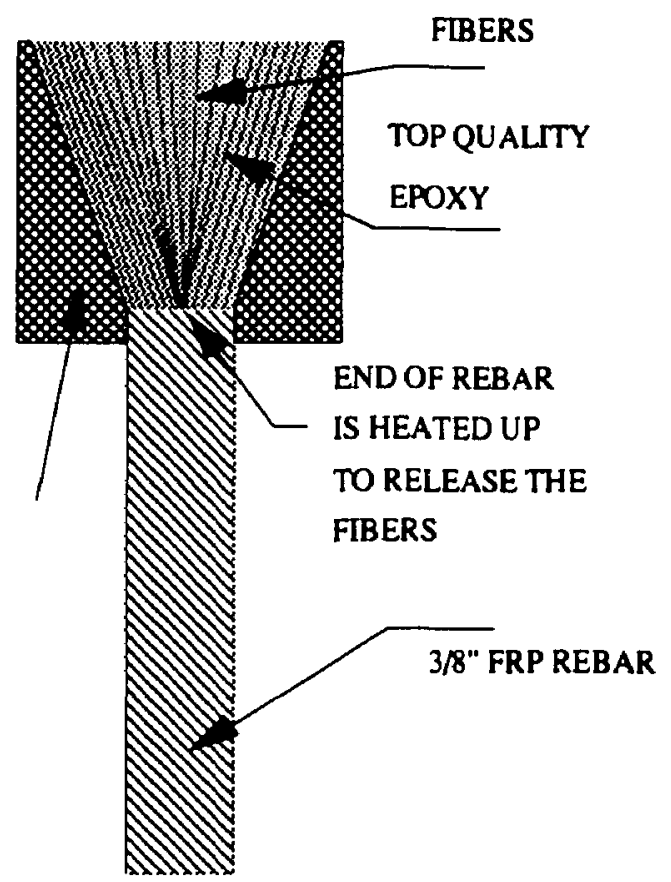

Figure 3.5 Proposed grip \#4

The WVU GRIP

The sand grips, $7 \times 3$ in. and 0.75 in. in thickness, as illustrated in Figure 3.6, are developed by CFC and made out of cold form steel. A semi-circular groove is cut out of each plate. The groove diameter is increased by $1 / 8$ in. over the size of the rebar size to be tested to allow for variations in the size of the rebar. Fine wet sand is used to fill the groove. A top piece is attached to the plates in order to seat them properly inside the jaws of the Baldwin Testing Machine. With slight modification to the original set of grips used in the testing machine, a set of grips have been successfully used outside the testing machines as in the case of pre-tensioning of the FRP rebars. Six high strength bolts are used to tie the two plates together, as shown in Figure 3.7. 


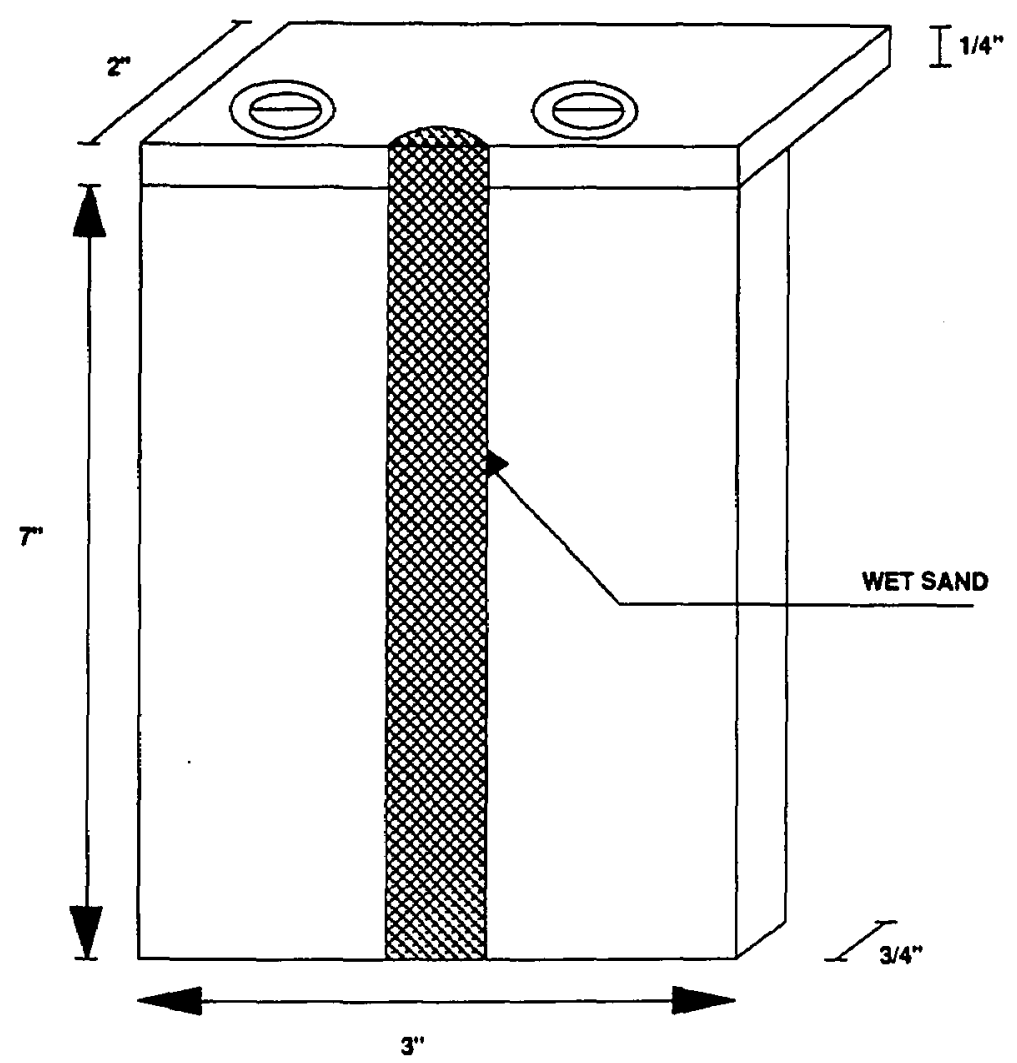

Figure 3.6 Sand coated grip for FRP rebar testing

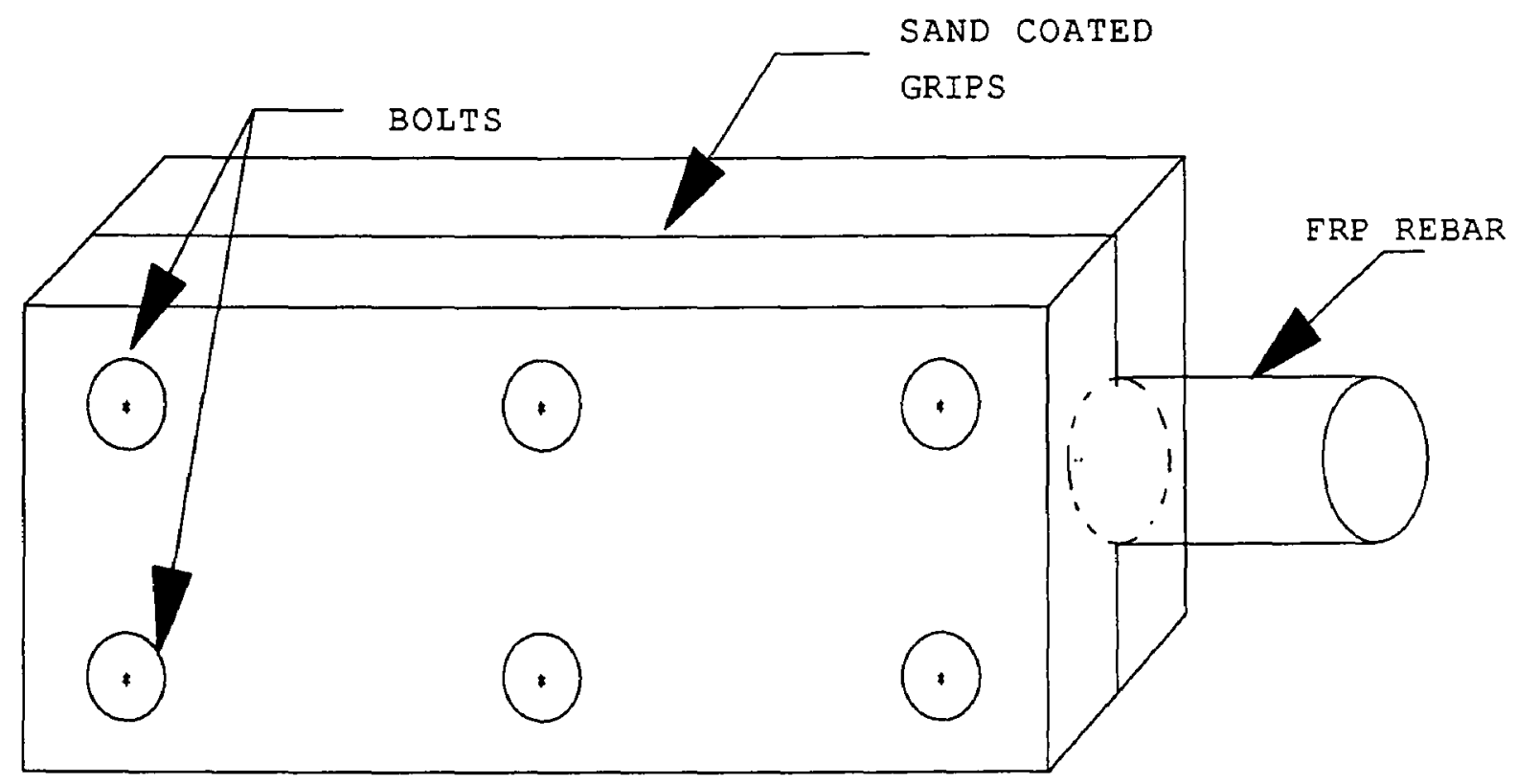

FIGURE 3.7 Detail of the sand coated grips used in pre-tensioning FRP rebars 


\subsubsection{Tension Properties}

Static tensile strength and stiffness are measured by subjecting FRP rebars to uniaxial tension. All tension test results give a linear stress-strain relation up to $95-98 \%$ of its ultimate strength as shown in Figure 3.8. For smooth FRP rebar, failure is governed by the tensile strength of fibers, whereas matrix cracking is noted for wrapped or ribbed rebars as an initial failure before fiber breakage. Various researchers have experienced difficulties in gripping methods. Sand grips, shown in Fig. 3.6, are used in our tension tests (Wu, 1990) to achieve a gradual and uniform load transfer over the whole gripping surface through friction and to make certain that failure does not take place in the grips. The sand layer is used to prevent slippage and to protect a specimen surface from damage that could be caused by direct contact with steel jaws of the testing machine.

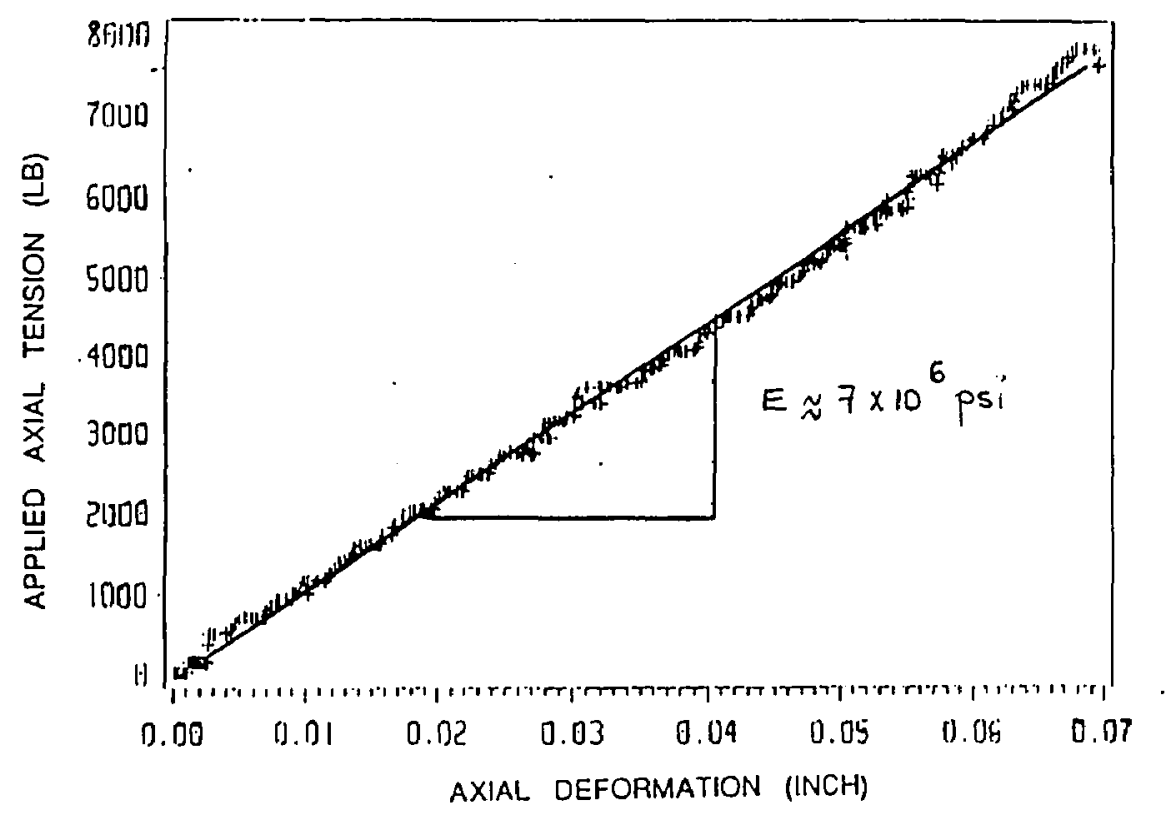

Figure 3.8 Stress versus strain curve of FRP rebar tested in tension 
A typical experimental set-up under tension with sand grips is shown in Fig. 3.9. The tensile stress-strain curve obtained is linear up to $95-98 \%$ of its ultimate failure load. The average tensile stiffness depends on the fiber type and volume fraction, and virtually independent of manufacturing company, bar size, bar type (with or without ribs), test procedure, and type of resin. The tests of glass fiber reinforced rebars with approximately 55 percent fiber volume fraction indicated a mean tensile stiffness of $7.2 \times 10^{6}$ psi. A summary of the tensile modulus results obtained by Wu (1990) is shown in Fig. 3.10. The ultimate tensile strength shows a strong sensitivity to various factors including bar size or diameter, quality control in manufacturing, matrix system, and fiber type. The ultimate tensile value is also very sensitive to the gripping mechanism used. In ribbed rebars, outer fibers break first, then peel off. As the diameter of the E-glass continuous fiber rebar increases from 0.375 in. (\#3) to 0.875 in. (\#7), matrix cracking becomęs more pronounced and clearly noticed at about eighty percent of the rebar's ultimate tensile strength. Once the critical load is reached, a brittle catastrophic failure is observed in the gage section. Since the ultimate tensile strength depends on several factors, average experimental tensile strengths of FRP rebars with 55\% fiber volume, obtained from different manufacturers is given in Fig. 3.11, which is representative of the state-ofthe-art FRP rebar quality. Results in Fig. 3.11 reveal that with the increase of bar diameter the ultimate tensile strength of continuous glass fiber reinforced rebars with vinylester resins decreases rapidly. The strength reduction is attributed to the resin dependent shear lag phenomenon. 
FIGURE 3.10 TENSILE MODULUS OF FRP REBARS AS OBTAINED BY WU (1990)

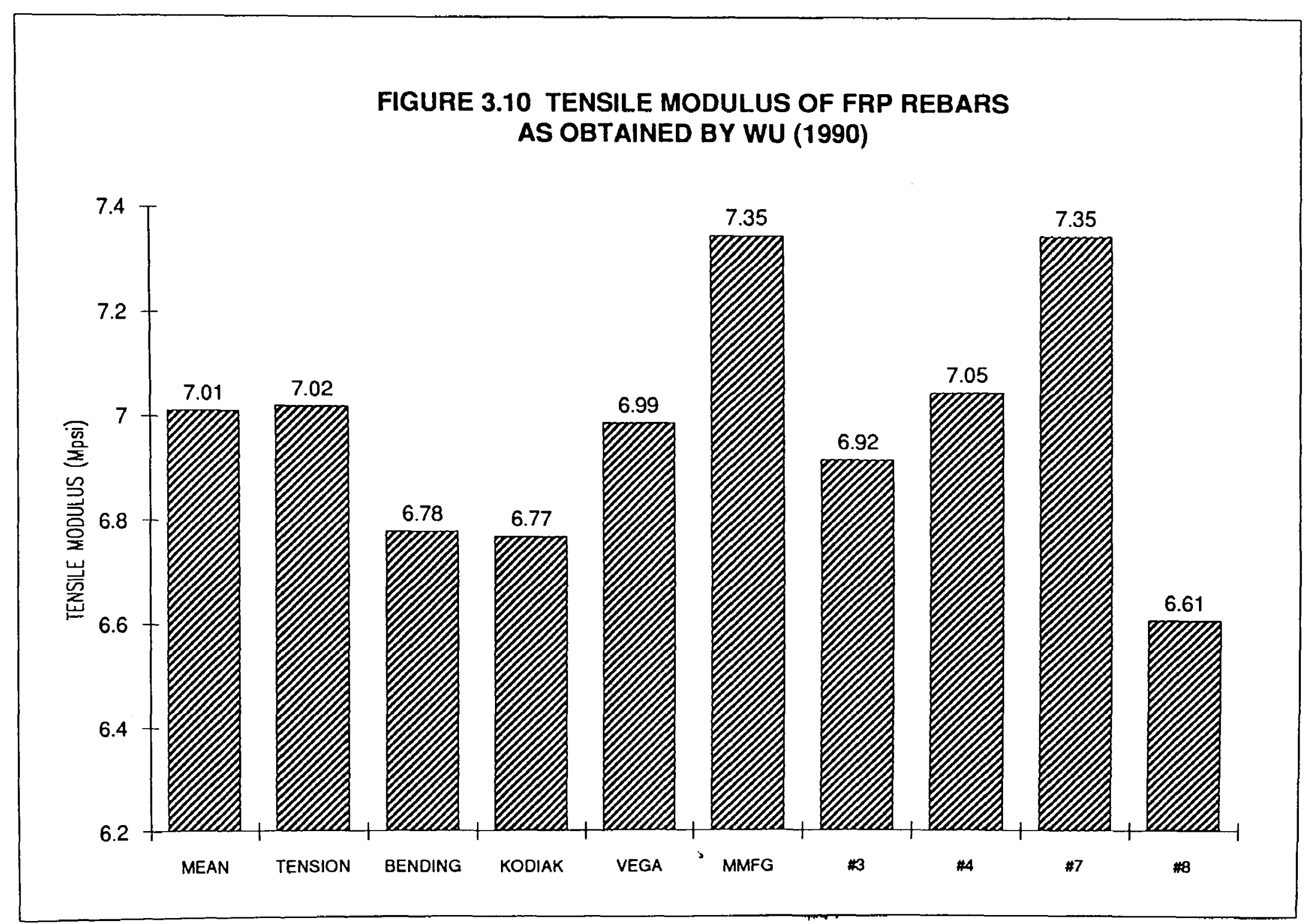




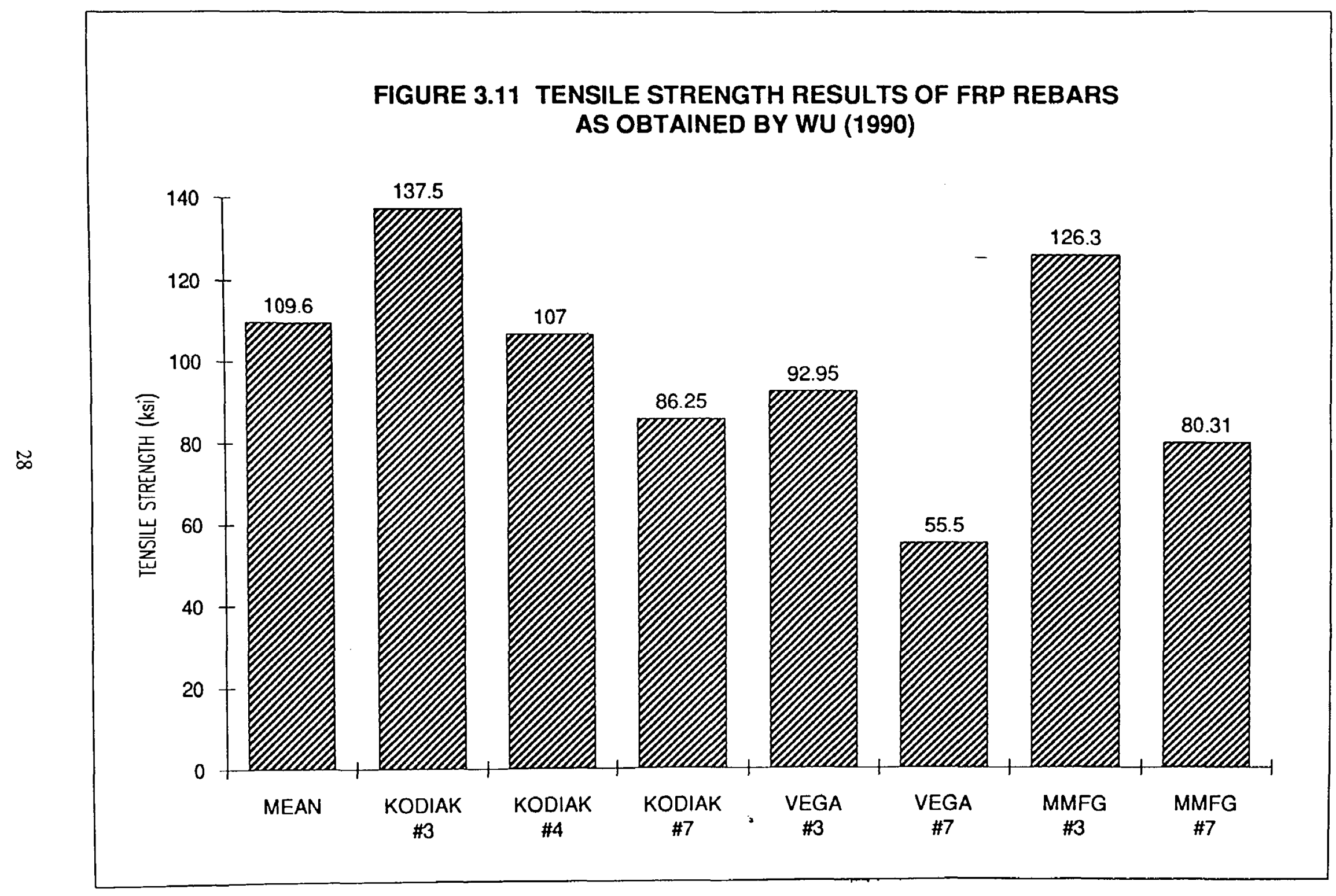




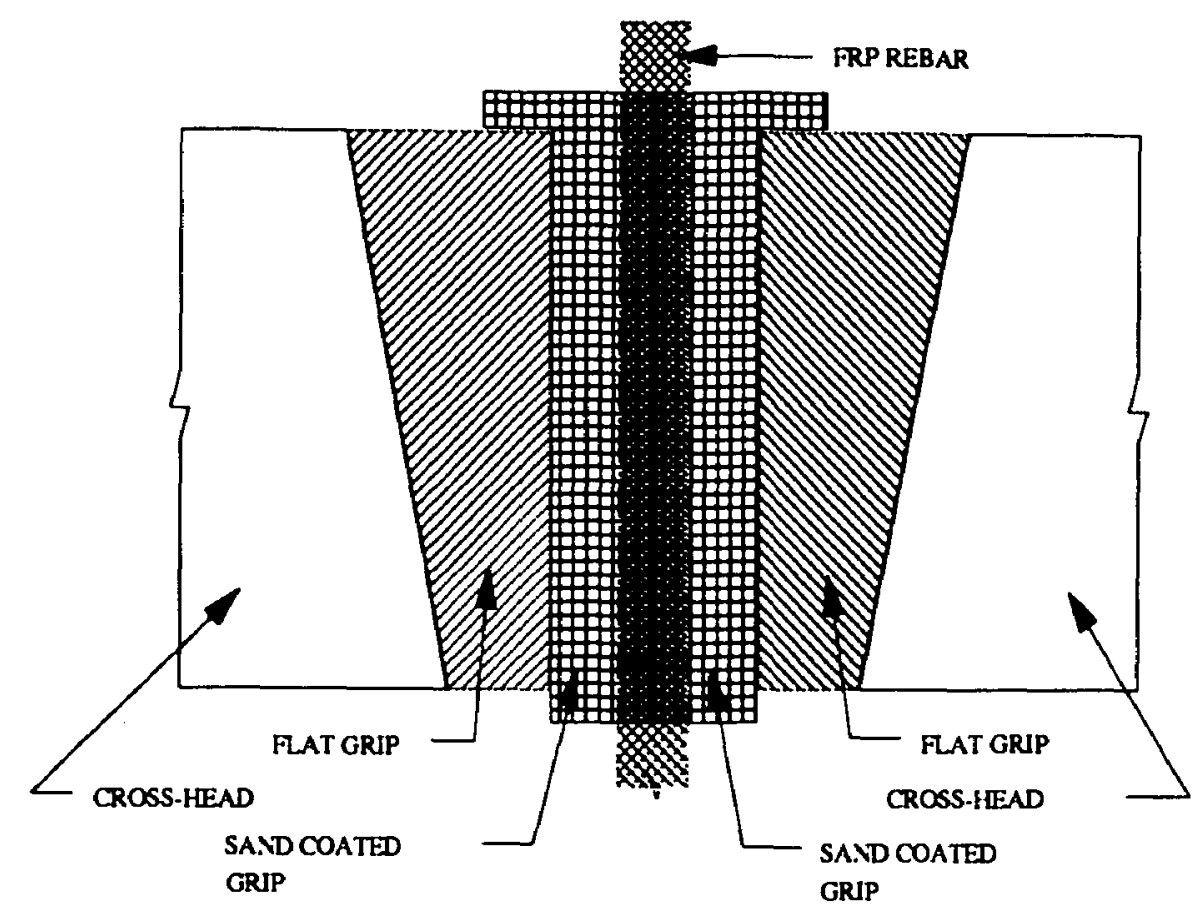

Figure 3.9 Experimental set-up for tension test of FRP rebars

\subsubsection{Compression Properties}

Static compression stiffness and strength properties were measured by $\mathrm{Wu}$ (1990). The rebar specimens are prepared following the ASTM D 695 standard with the length twice the diameter of the specimen and the ends machined flat. These tests show a linear stress-strain relation for smooth rebars while slight deviation from linearity is observed for ribbed rebars. The combination of matrix cracking and fiber kinking failure modes are observed for ribbed rebars. Fiber-matrix splitting failure is observed for smooth rebars. Unlike the tensile stiffness, the compressive stiffness varies with rebar size, type, quality control in manufacturing, and length to diameter ratio of the test specimen. A summary of ultimate compressive stiffness and strength values of 55 percent volume fraction of continuous E-glass fiber and vinylester or isophthalic resin obtained by Wu (1990) is given in Figure 3.12. 


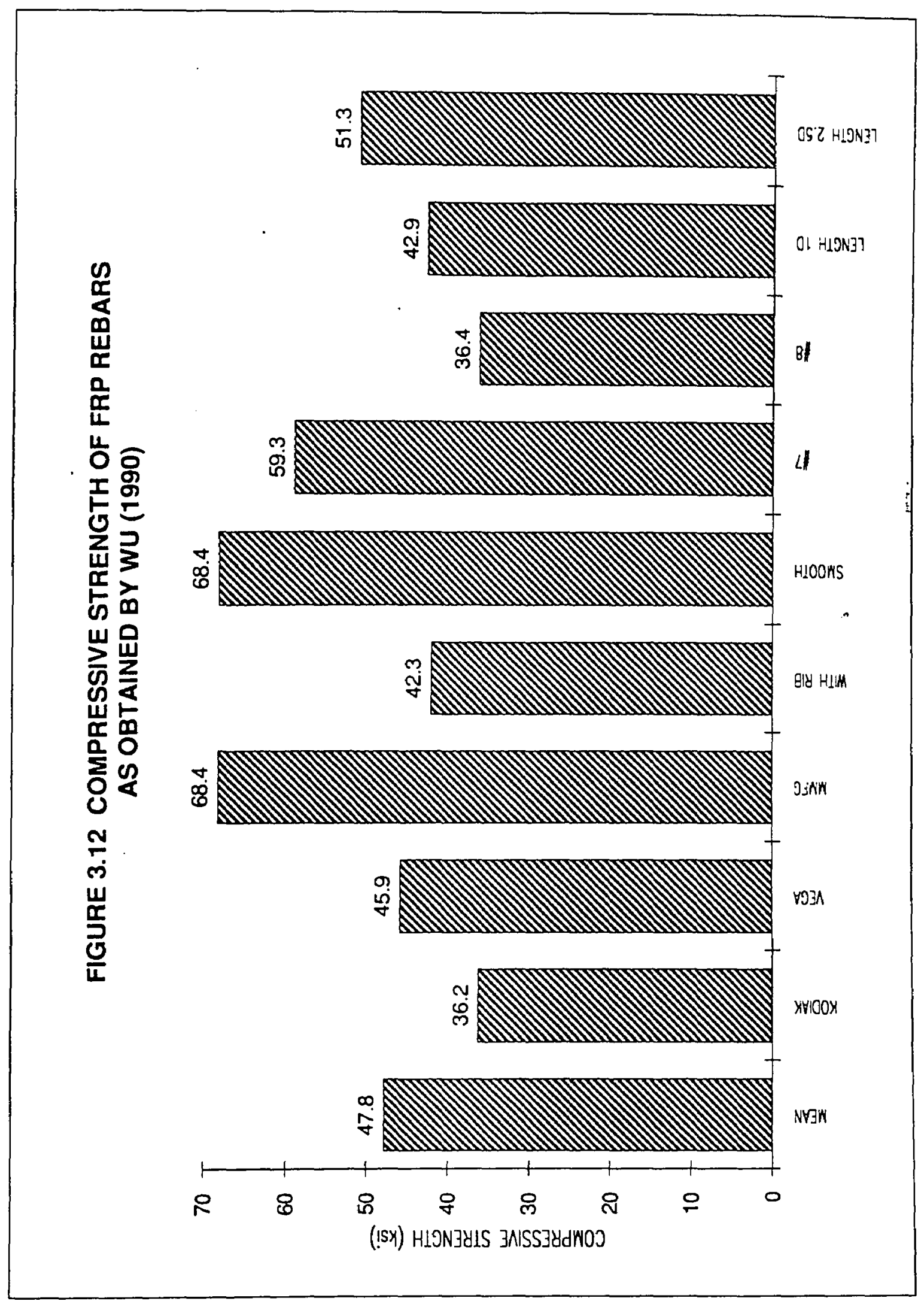




\subsubsection{Torsion Properties}

Static properties such as longitudinal shear stiffness and torsional strength of FRP rebars were determined from tests performed by Wu (1990) on a Reihle Machine. All rebars showed a linear torque versus twist relationship. The failure mode of ribbed rebars is a combination of rib breakage and matrix fracture. Matrix cracking is the failure mode of smooth rebars. Shear stiffness does not significantly vary with the manufacturing quality or rebar type. A shear stiffness of $0.66 \times 10^{6} \mathrm{psi}$ was obtained as the mean value of eighteen tests. However, torsional strength decreased with increasing diameter, from $10.6 \mathrm{ksi}$ for $0.5 \mathrm{in}$. diameter bar to $8.85 \mathrm{ksi}$ for $0.875 \mathrm{in}$. diameter bar. Torsional strength also depends on manufacturing quality. Once again, the torsional properties are based on 55 percent volume fraction of continuous E-glass fibers and vinylester resin.

\subsubsection{Bending Properties}

Static flexural stiffness and strength results were obtained by Wu (1990) from three point bending tests. Strain gages were used on top and bottom surfaces to measure compressive and tensile strains respectively. Ultimate bending strength varies with diameter as in the case of ultimate tensile strength of the FRP rebars. The dominant failure mode for both smooth and ribbed rebars is matrix cracking with no buckling of fibers in compressive zone is noted. The mean value of flexural stiffness in tension is $6.8 \times 10^{6} \mathrm{psi}$ whereas the mean value of flexural strength in compression is $6.00 \times 10^{6}$ psi. This is typical of composite materials having different stiffness in tension and compression. Bending stiffness values are virtually independent of rebar type or manufacturing quality. However, ultimate bending strength values varied greatly depending upon the specimen diameter, as it can be seen in Fig. 3.13. 


\section{FIGURE 3.13 BENDING STRENGTH RESULTS OF FRP REBARS}

AS OBTAINED BY WU (1990)

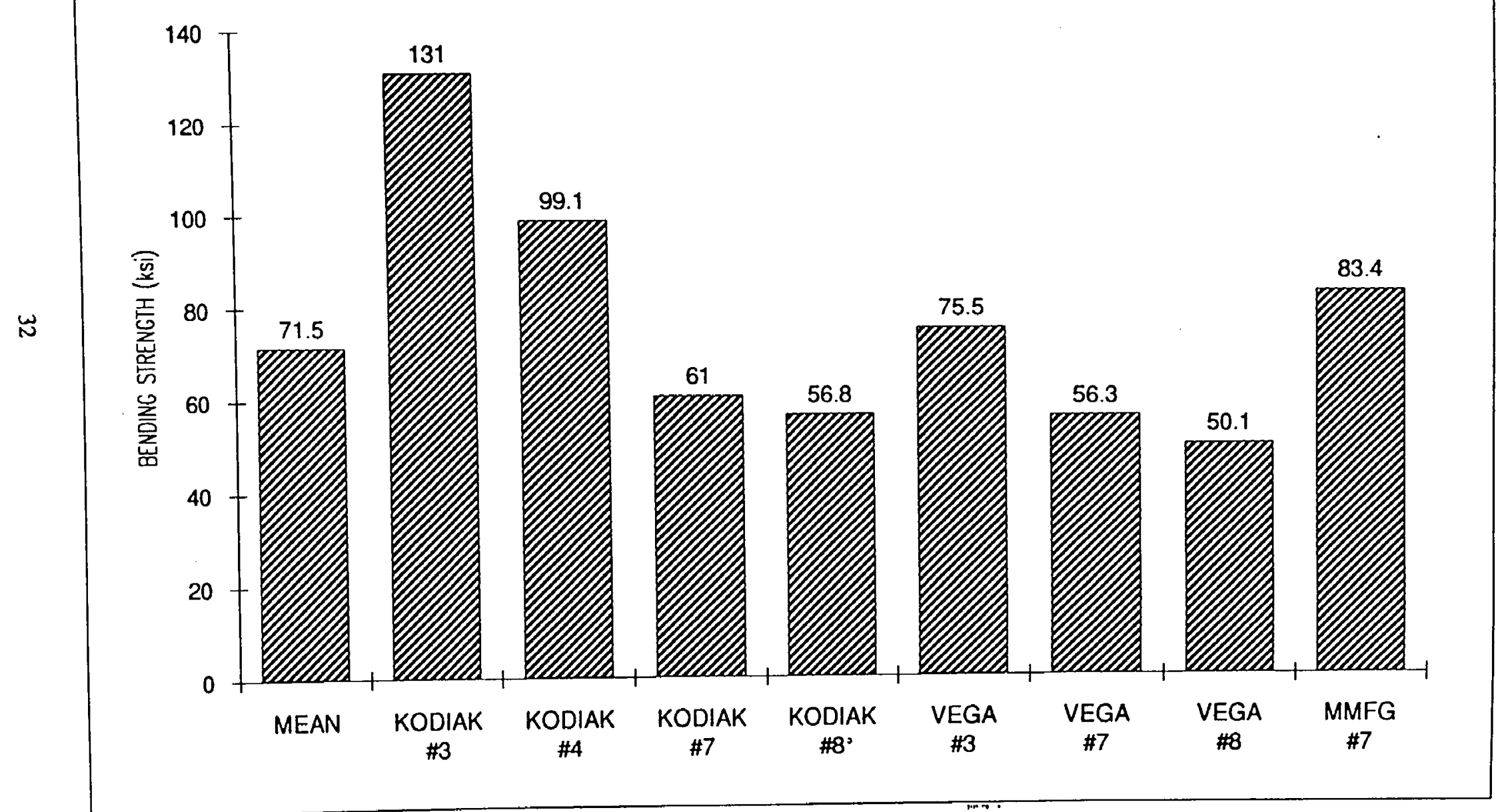




\subsection{Concrete Properties}

In order to take advantage of the high tensile strength of the FRP rebars, high strength concrete was used in our testing program. The development of high strength concretes has been gradual over many years. In the 1950s, 5000 psi concrete was considered high strength concrete. More recently, compressive strength over $16,000 \mathrm{psi}$ has been considered for applications in cast-in-place buildings and prestressed concrete members. In general, concretes with a compressive strengths over $6000 \mathrm{psi}$ are considered to be high strength concrete. Throughout this work, concretes with compressive strengths of 6000-10000 psi will be classified as high strength concretes.

High strength concretes have some characteristics and engineering properties that may be different from those of lower strength concretes $(<5000 \mathrm{psi})$. It is recognizeèd that high strength concrete may be closely characterized as linearly elastic up to stress levels approaching the maximum stress. Thereafter, the stress-strain curve of high strength concrete decreases after initial cracking at much greater rate than lower strength concretes.

Extensive experimentation at several research centers has provided a fundamental understanding of the behavior of high strength concrete. The current state-of-the-art on high strength concrete reinforced with steel rebars will be adopted in the following chapters with the use of FRP rebars as the reinforcing element rather than steel. The properties of high strength concrete are presented in Table 3.1, according to the ACI 363 committee on high strength concrete along with the $\mathrm{ACl} 318$ committee recommendations for regular strength concrete. 
Table 3.1 Properties of high strength concrete

\begin{tabular}{|c|c|c|}
\hline Property/Code & ACI 363 & ACI 318 \\
\hline $\begin{array}{c}\text { Modulus of Elasticity } \\
\mathrm{E}_{\mathrm{c}} \text { (psi) }\end{array}$ & $\begin{array}{c}40,000 \sqrt{\mathrm{f}_{\mathrm{c}}{ }^{\prime}+1 \times 10^{6}} \\
3000<\mathrm{f}_{\mathrm{c}}{ }^{\prime}<12,000\end{array}$ & $57,000 \sqrt{\mathrm{f}_{\mathrm{c}}{ }^{\prime}}$ \\
\hline $\begin{array}{c}\text { Modulus of Rupture } \\
\mathrm{f}_{\mathrm{r}}{ }^{\prime}(\mathrm{psi})\end{array}$ & $11.7 \sqrt{\mathrm{f}_{\mathrm{c}}{ }^{\prime}}$ & $7.5 \sqrt{\mathrm{f}_{\mathrm{c}}{ }^{\prime}}$ \\
\hline $\begin{array}{c}\text { Tensile Splitting Strength, } \\
\mathrm{f}_{\mathrm{sp}}{ }^{\prime}(\mathrm{psi})\end{array}$ & $3000<\mathrm{f}_{\mathrm{c}}{ }^{2}<12,000$ & \\
\hline
\end{tabular}

Concrete was purchased from a local mixing plant for all the specimens. For each batch of concrete delivered, eight $4 \times 8$ in. cylinders were cast and cured with the specimens, an average of two cylinders per specimen cast. The ASTM C-39 test procedure was followed in order to determine the concrete compressive strength for each cylinder. Cylinder tests were performed on the same day the specimens were to be tested, generally after 28 days. In addition to the compressive strength of the cylinders, strain gages were bonded to two cylinders per batch of concrete in order to develop the stress-strain curve and obtain the actual modulus of elasticity of that batch. A plot of stress versus strain of all the concrete used is shown in Figures $3.14-3.17$. 


\section{FIGURE 3.14 STRESS VS STRAIN \\ CONCRETE CYLINDER, $\mathrm{fc}^{\prime}=6500 \mathrm{psi}$}

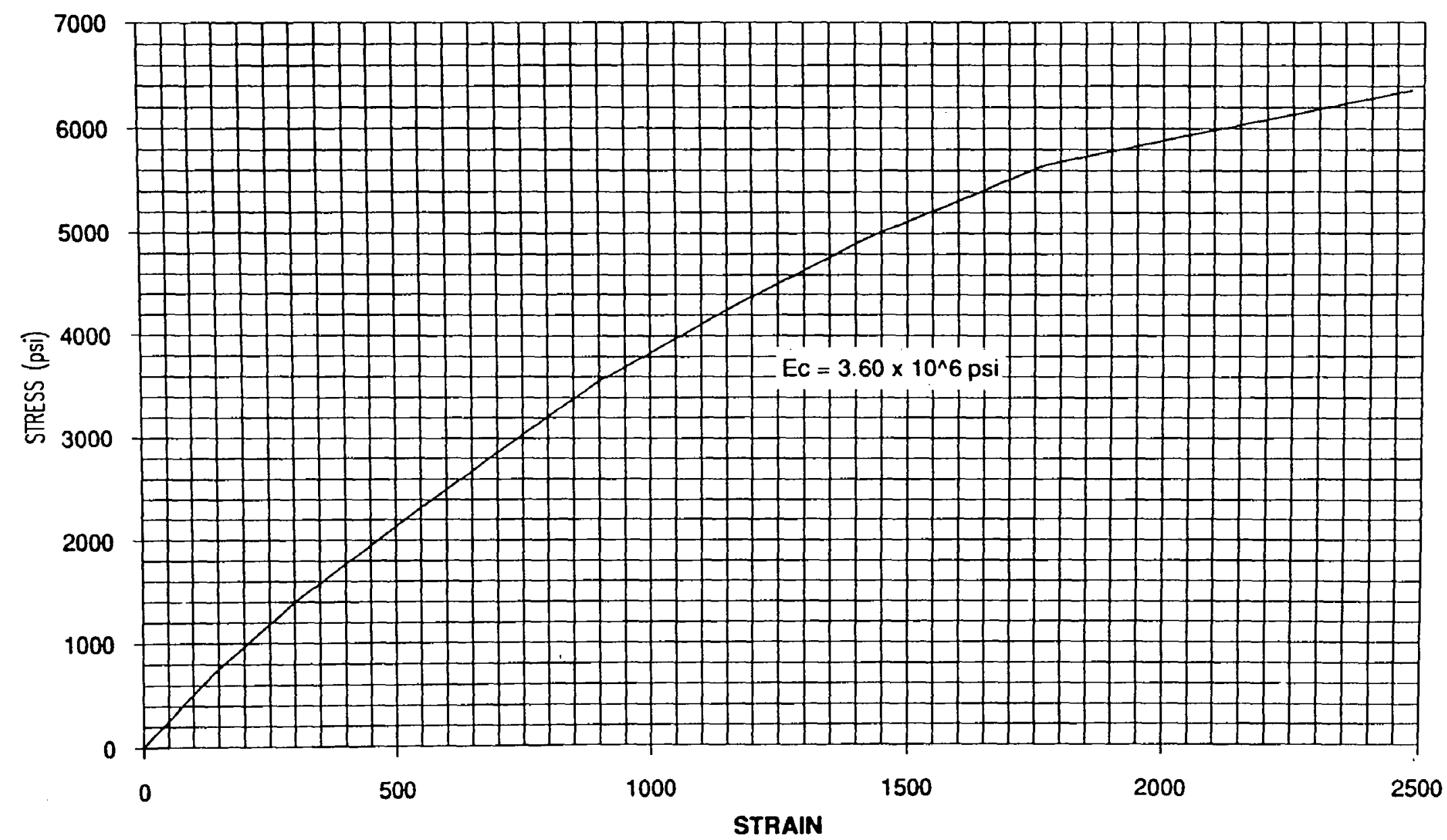




\section{FIGURE 3.15 STRESS VS STRAIN CONCRETE CYLINDER, $\mathrm{fc}^{\prime}=7500 \mathrm{psi}$}

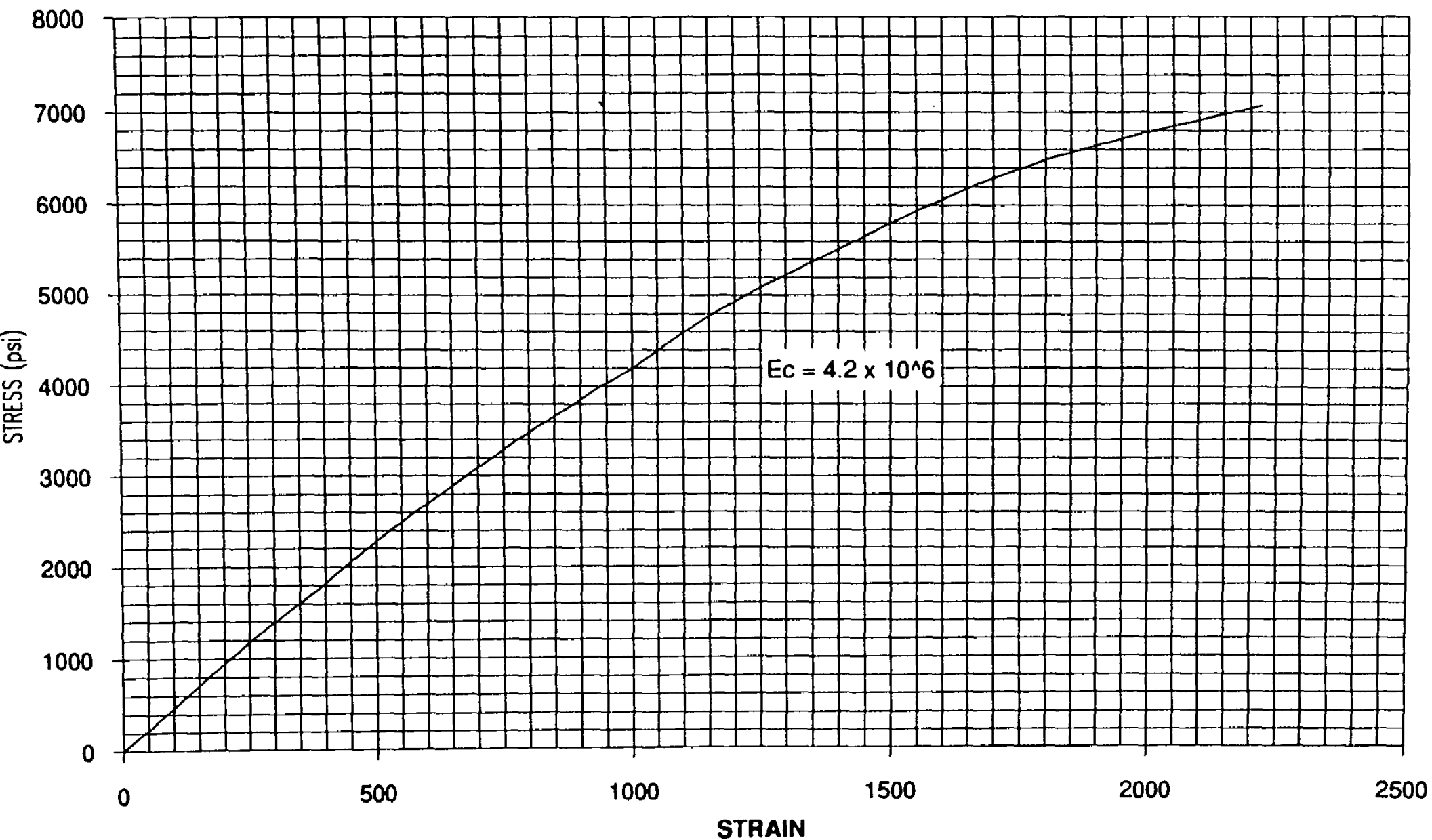




\section{FIGURE 3.16 STRESS vS STRAIN CONCRETE CYLINDER $\mathrm{fc} \mathrm{c}^{\prime}=\mathbf{8 8 0 0} \mathrm{psi}$}

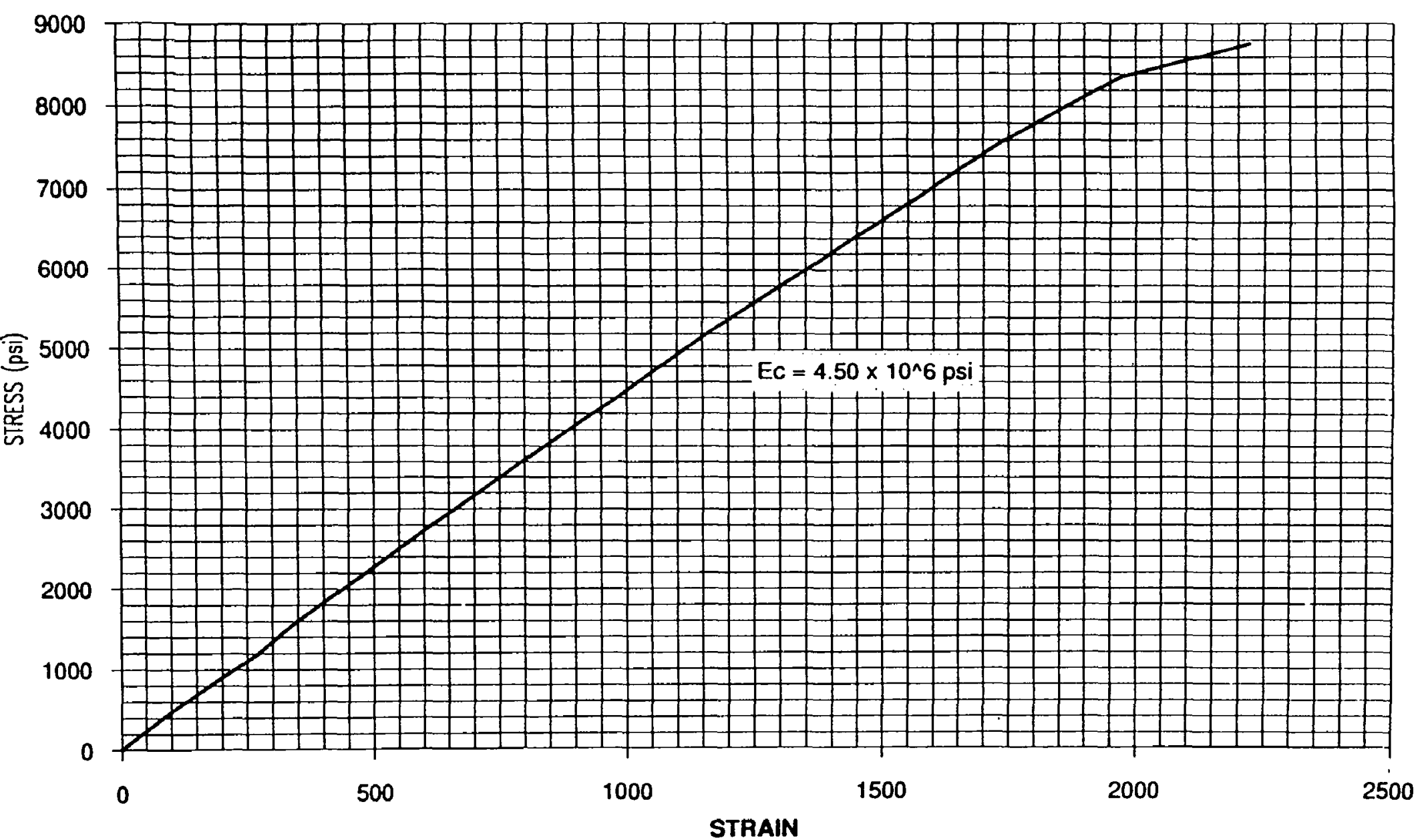


FIGURE 3.17 STRESS VS STRAIN

CONCRETE CYLINDER $\mathrm{c}^{\circ}=10,000$ psi

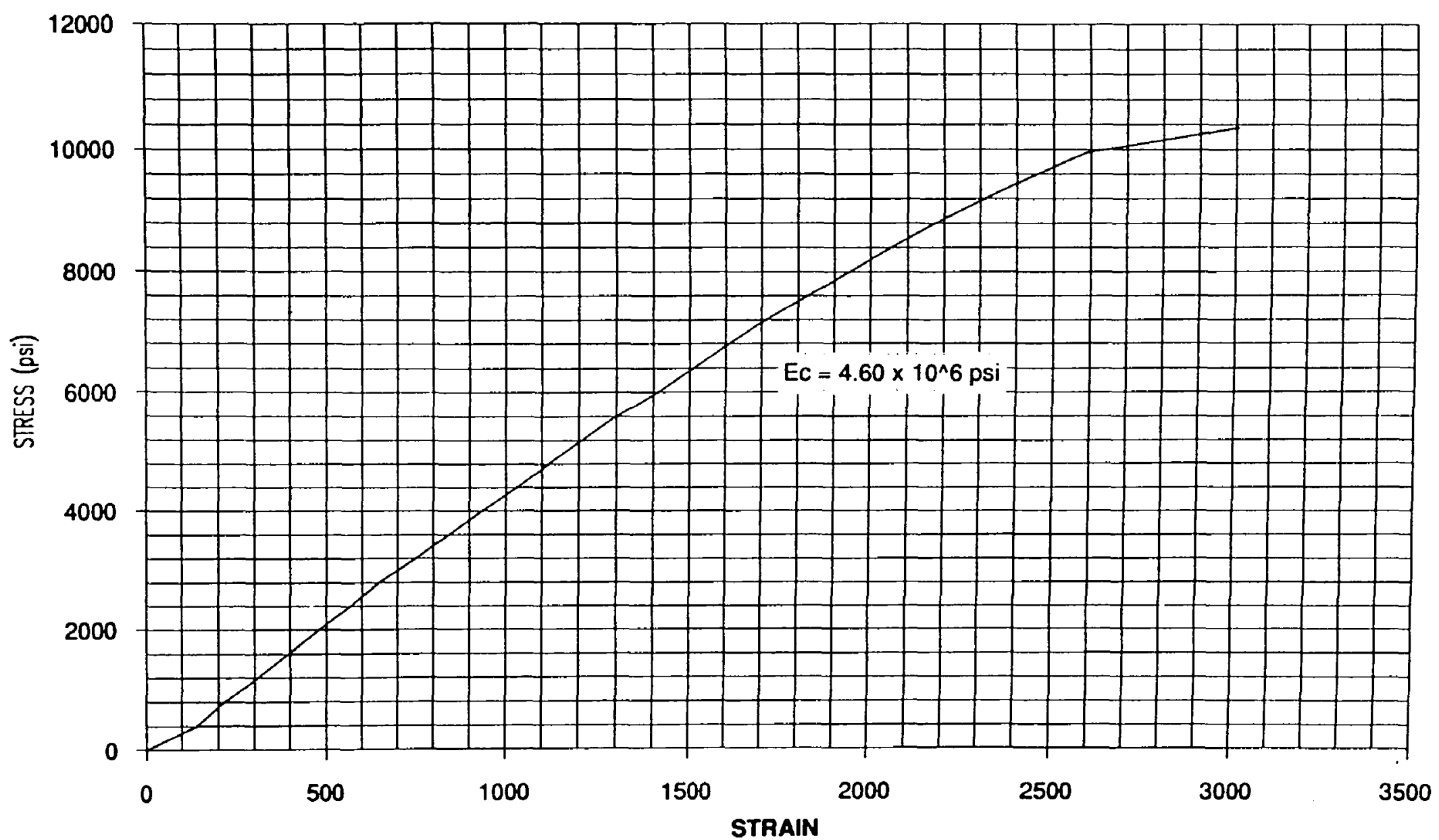




\section{CHAPTER 4}

\section{EXPERIMENTAL RESULTS OF CONCRETE BEAMS UNDER BENDING AND BOND}

Experimental results of concrete beams reinforced with fiber reinforced plastic (FRP) rebars and subjected to bending and bond forces are presented in this chapter. Results are summarized and discussed in subsections according to the reinforcement areas, diameter, coatings and concrete strengths. Bending test results were generated from experiments which included ultimate moment capacity, load vs concrete-strain and reinforcement-strain variations, load-deflection behavior, crack pattern and associated modes of failure. Bond test results include ultimate bond strength and load vs slip behavior for varying concrete strengths and FRP rebar sizes.

\subsection{Specimen Fabrication and Curing}

Bending specimens were cast in wooden forms whereas the bond specimens were cast in steel forms. In the case of the bond specimens, a thin wall conduit was inserted over and along the unloaded end of the test rebar to eliminate bond, thus giving the desired embedment length, EL.

After assembling the forms, the surfaces were oiled for easy removal. Before readimix concrete was placed in the forms in layers of about one third of the depth of the specimen, the reinforcement was positioned carefully as shown in Figure 4.1 and 4.2, and the overall dimensions were checked . 


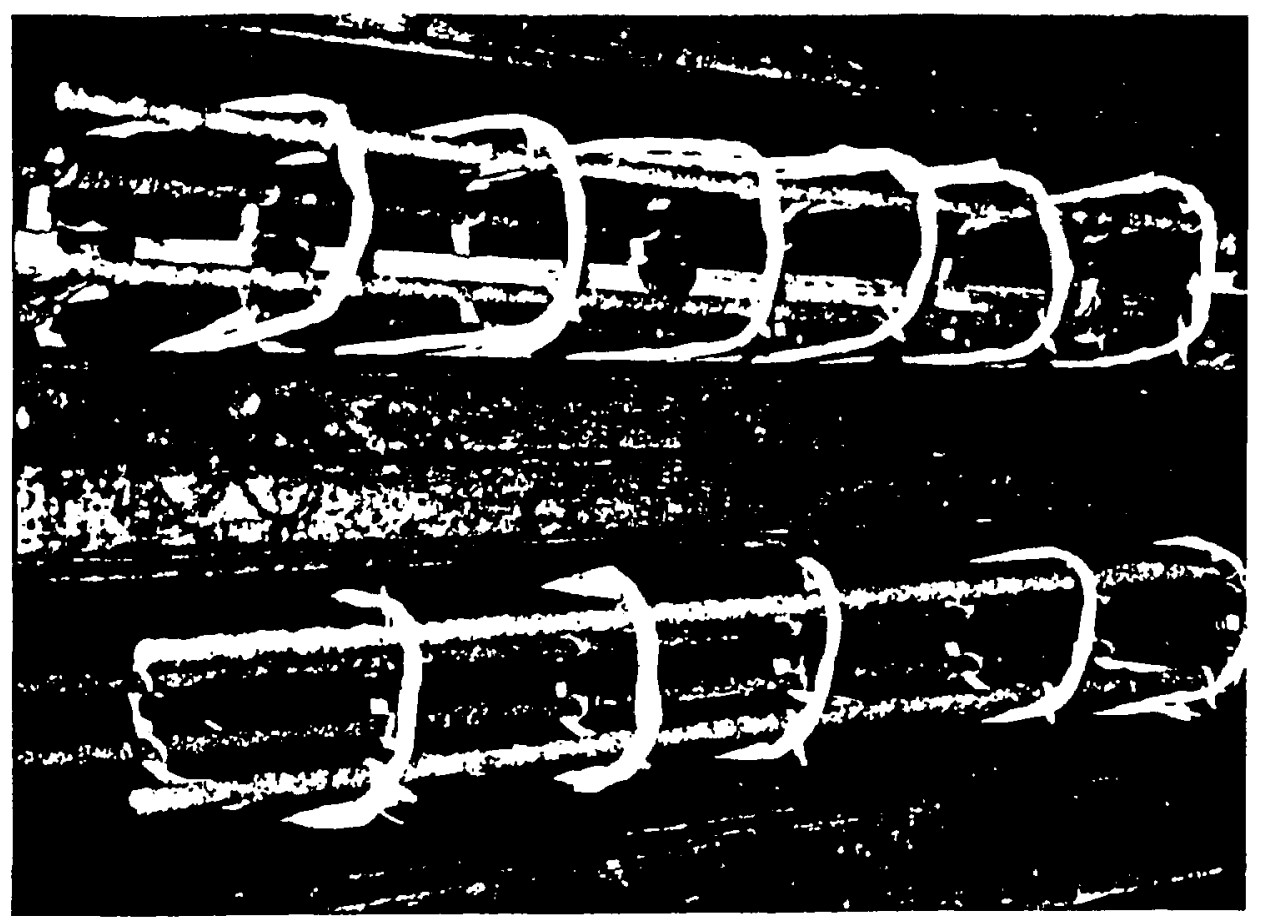

Figure 4.1 Formwork and reinforcement detail of bending specimen

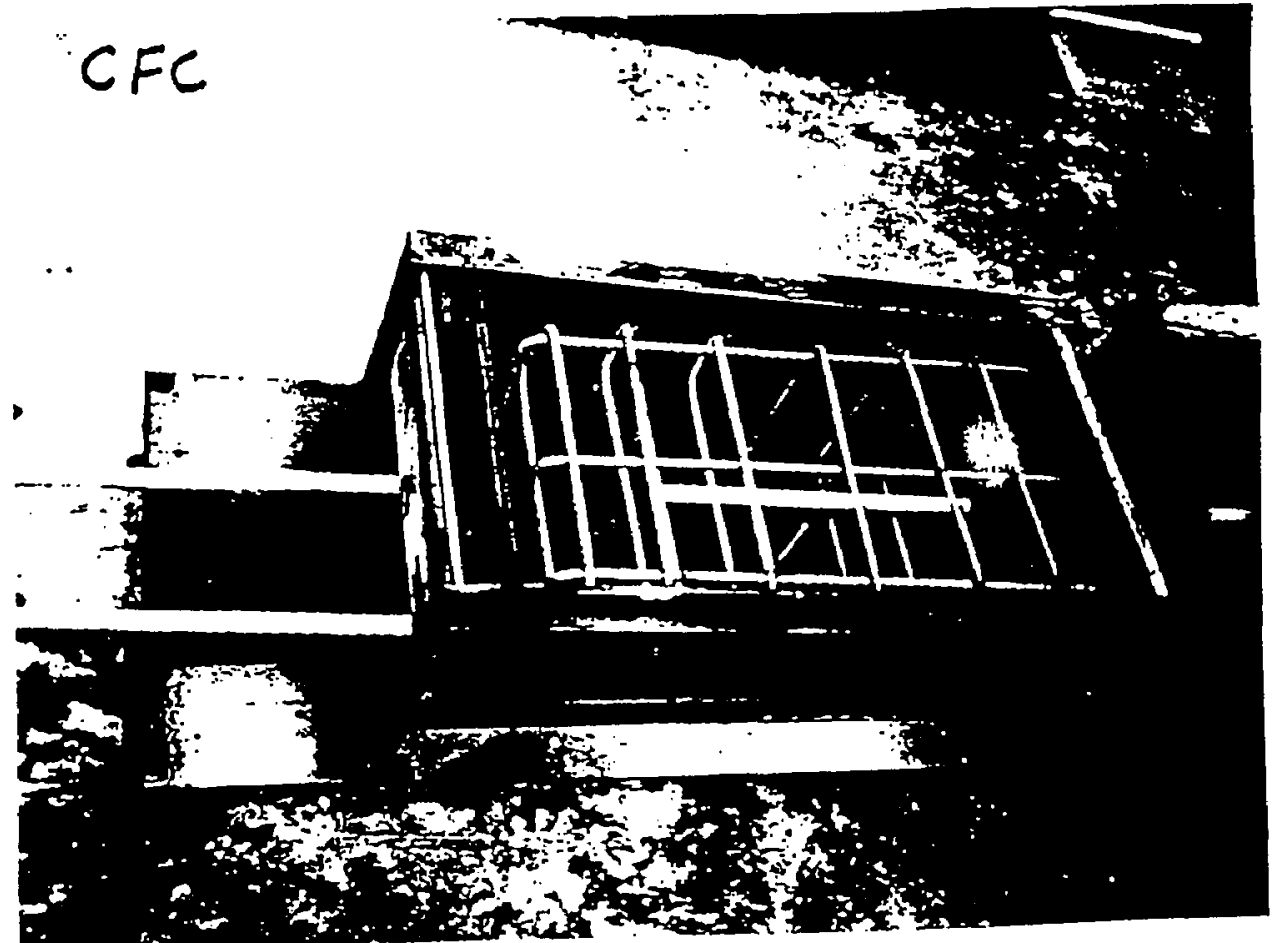

Figure 4.2 Formwork and reinforcement detail of bond specimens 
All the rebars used in our test program are made of a thermoset resins, vinylester or isophthalic, and continuous E-glass fibers. These rebars were supplied by International Grating, Inc., Vega Technologies, Inc., and MMFG. The properties of the FRP rebars are outlined in Chapter 3. A portable electric vibrator was used to vibrate each concrete layer. The surfaces of the specimens were leveled to a smooth surface as illustrated in Figure 4.3. Test cylinders were cast at the same time as the specimens. For each mix of concrete the slump was measured.

The specimens and cylinders were covered with wet burlap and plastic sheathing, then allowed to cure in the forms for at least seven days. After removing the specimens from the forms, they were allowed to cure at ambient conditions for three weeks. For each bending specimen, two cylinders were tested. ASTM C-39 test procedure was followed to determine the concrete compressive strength $\mathrm{f}_{\mathrm{c}}{ }^{\prime}$.

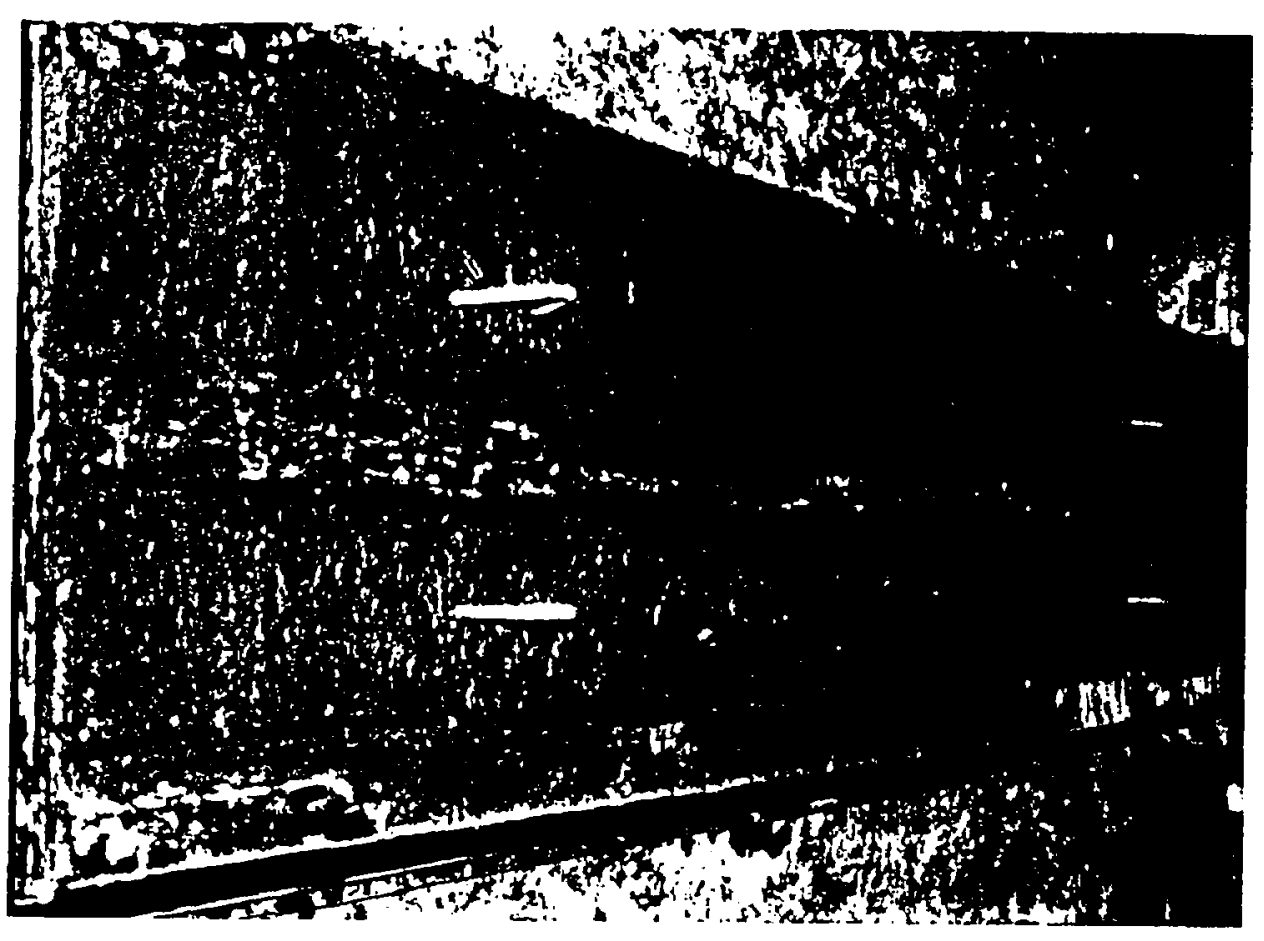

Figure 4.3 Cast specimens under curing conditions 


\subsection{Test Apparatus and Instrumentation}

\subsubsection{Bending Tests}

Twenty seven $10 \mathrm{ft}$ rectangular beams, as the one shown in Figure 4.4, were tested under pure bending, (as simply supported under four point bending), using different configurations of FRP reinforcements, such as rebar size, type of rebar (smooth, ribbed, sand coated), and type of stirrups (steel, FRP smooth, FRP ribbed). The applied force was measured by a load cell connected to a strain indicator, Strain gages were carefully selected and placed on the reinforcement as well as on the concrete top surface. At every load stage, the strains were recorded with the use of a strain indicator. A dial gage positioned at the center of the beam was used to measure deflections at each load stage. In addition, cracks were monitored, sketched, and measured.

\subsubsection{Bond tests}

Twenty specimens were cast using different configurations of FRP reinforcements, such as rebar size, type of rebar (ribbed, sand coated) and embedment length. The specimens were similar to the WVU modified cantilever type shown in Figure 4.5. A portion of concrete block in the front of test specimens (Figure 4.5) was cut out in these specimens to emulate the portion of a beam adjacent to a diagonal crack. The compression zone of the beam was designed to prevent premature crushing failure. The specimens were designed so that no shear or moment failure was expected to occur during the tests. In addition to the cantilever specimens, twelve pullout cylinder specimens were cast for comparison purposes as shown in Figure 4.6. 


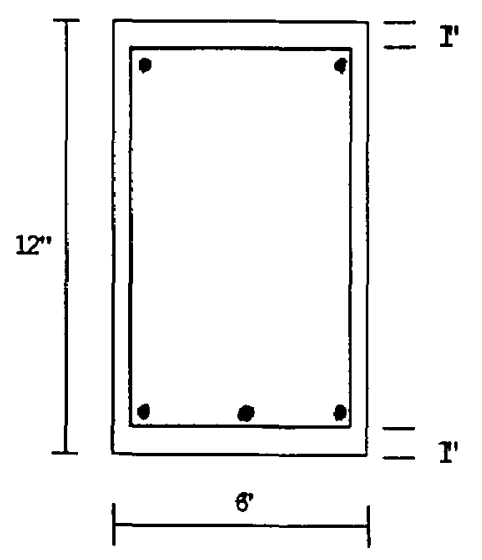

$$
\text { (- } 30 \text { TON JACK }
$$

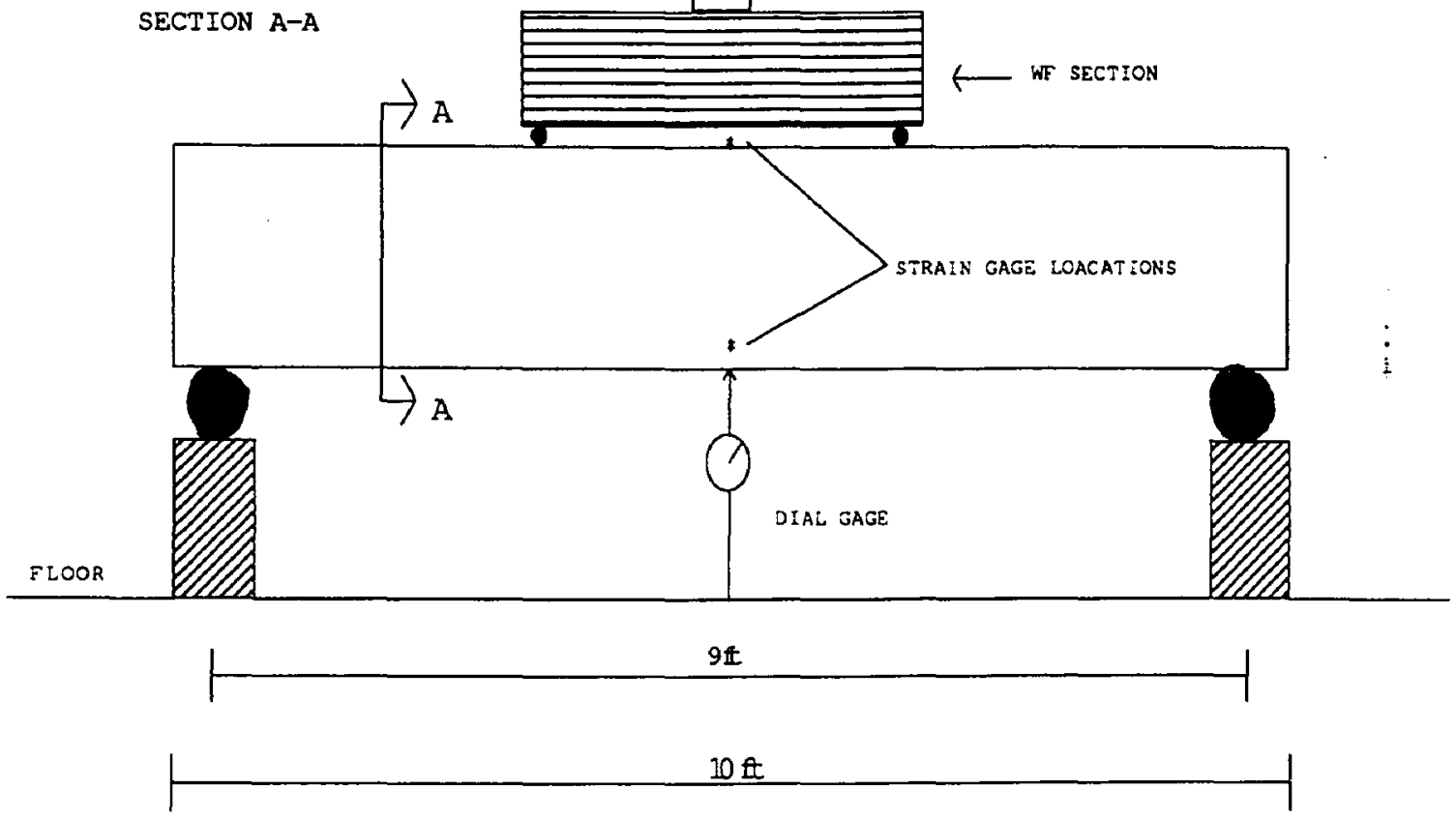

Figure 4.4 Bending test set-up 


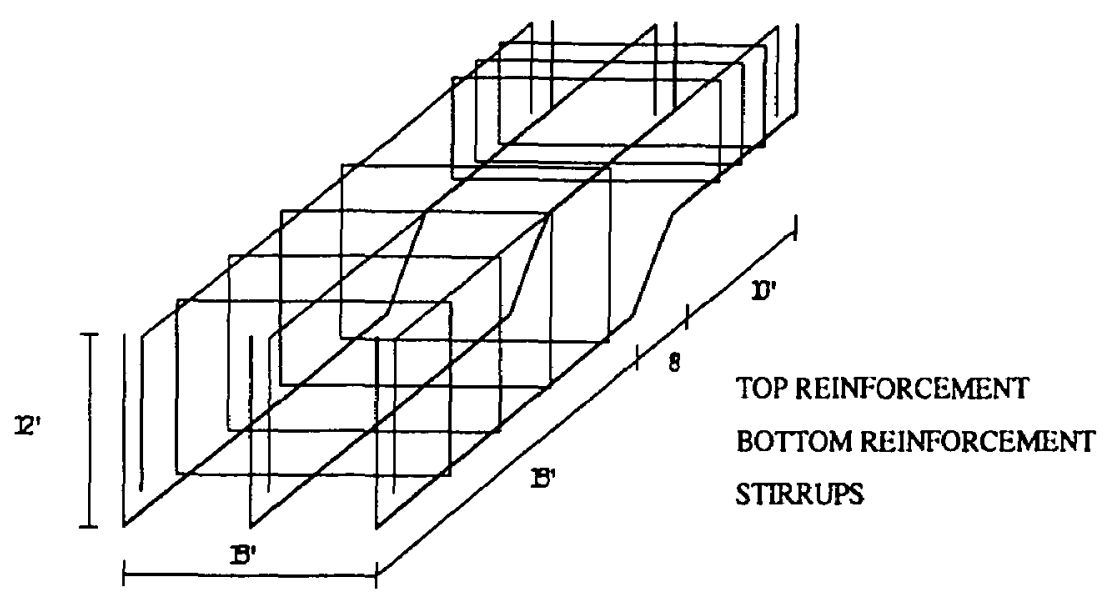

3\#4 GRADE 60

3\#5 GRADE 60

\#3 GRADE 60
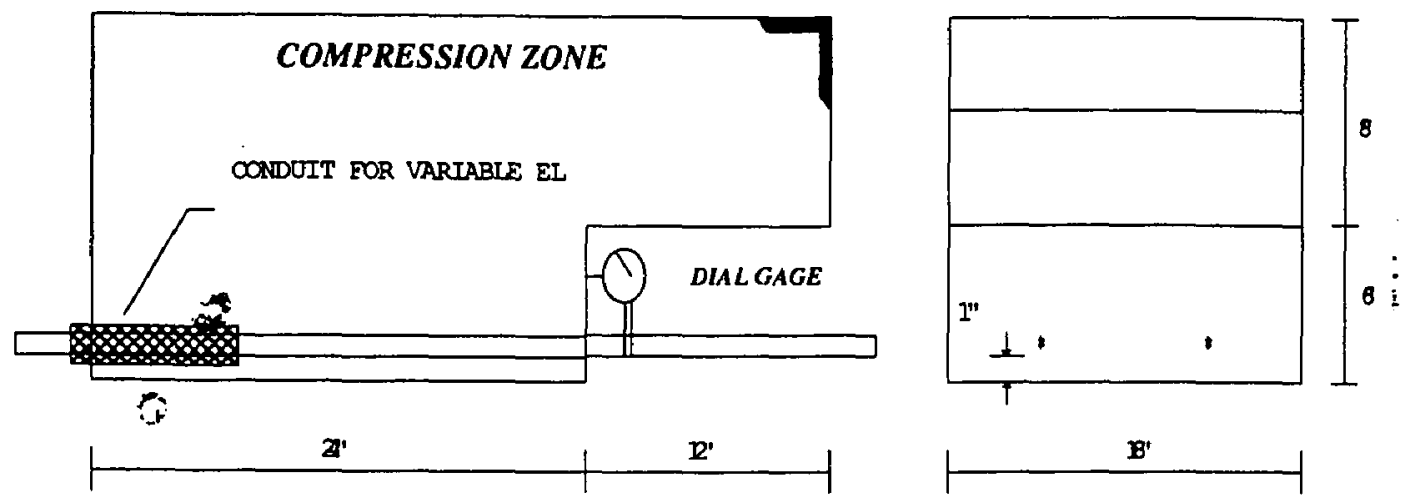

Figure 4.5 Bond specimen reinforcement detail

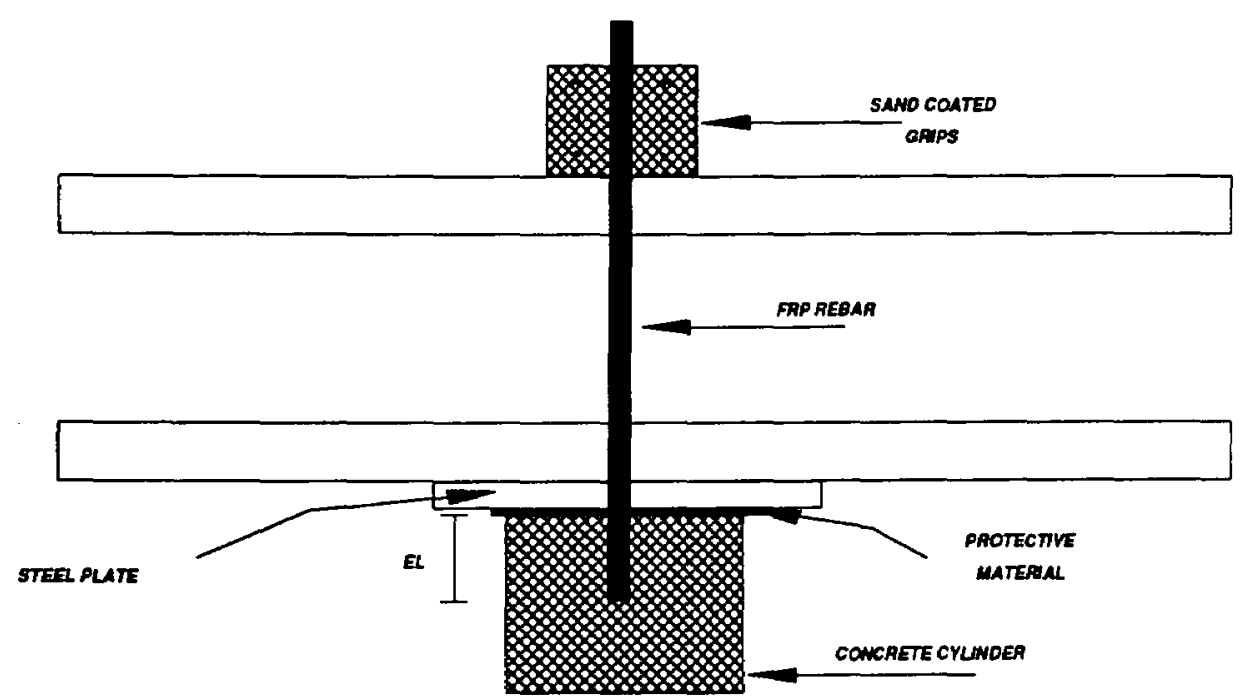

Figure 4.6 Cylinder pullout specimens 
The specially designed and fabricated testing rig utilized for this study was originally developed by the Civil Engineering Department at WVU in the early 1970s. It consisted of a frame and two load reaction systems as shown in Figure 4.7. One of the load reaction systems was a buildup steel bearing beam, used as the horizontal support at the front end of the specimen. The other load reaction system, used for the vertical support at the rear end of the specimen, was composed of a 100-ton jack, a 60-ton load transducer and a steel bearing plate. The bearing plate was used to reduce the local bearing stresses which might affect the failure mode and crack pattern. At the front end of the specimen was an adjustable WF beam carrying the vertical reaction down by four vertical rods to the horizontal girder. Two $1 \times 12 \times 26$ inch steel plates were bolted together to act as load distribution plates with an adjustable gap as shown in Figure 4.8. :

The load distribution plates rested on four bolts. During testing, the bolts were released to avoid any undesirable restraints. For additional details refer to Figure 4.8. The applied horizontal bar force was produced by a pair of 60 -ton jacks and was transmitted to the FRP rebars through the distribution plates and sand coated grips, as shown in Figure 4.8. The applied forces were measured by load cells connected to a strain indicator and were increased in increments of 1 kip.

In earlier stages, the design and development of suitable grips to pull FRP rebars embedded in concrete have presented some difficulties. Typically, the FRP rebar is found to fail in the grip itself due to combined effects of local horizontal shear and crushing. An ideal grip must grasp the rebar in a manner as to avoid failure of the rebar at the grip. 


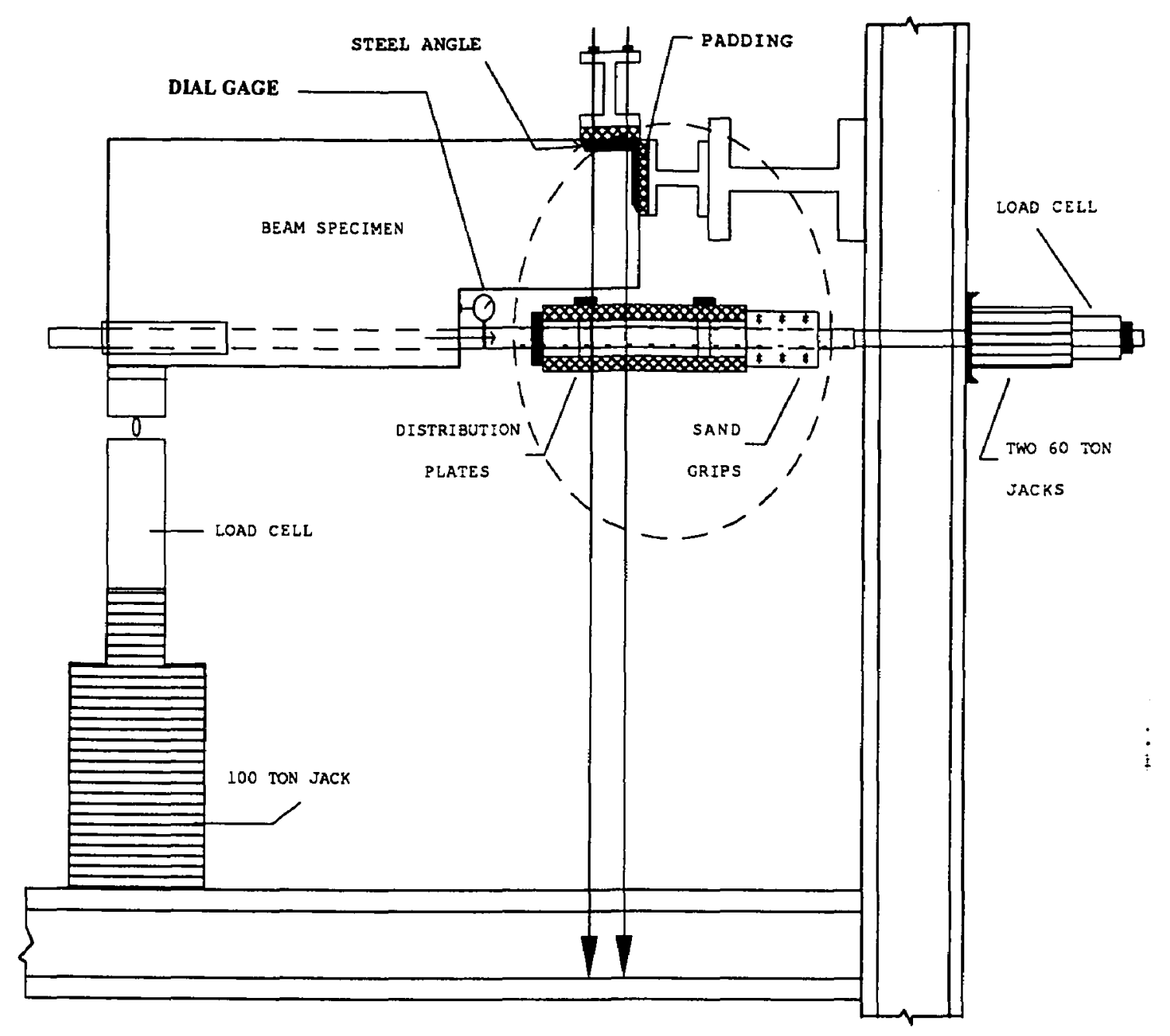

Figure 4.7 Pullout test setup

Several methods for anchoring FRP rebars have been investigated as a part of this study. However, the sand-coated grips filled with sand are found to be most suitable to transfer axial bar forces, Figure 4.9 .

After placing the FRP rebars between the two sand coated grips, the set of grips are tightened together by six bolts. 


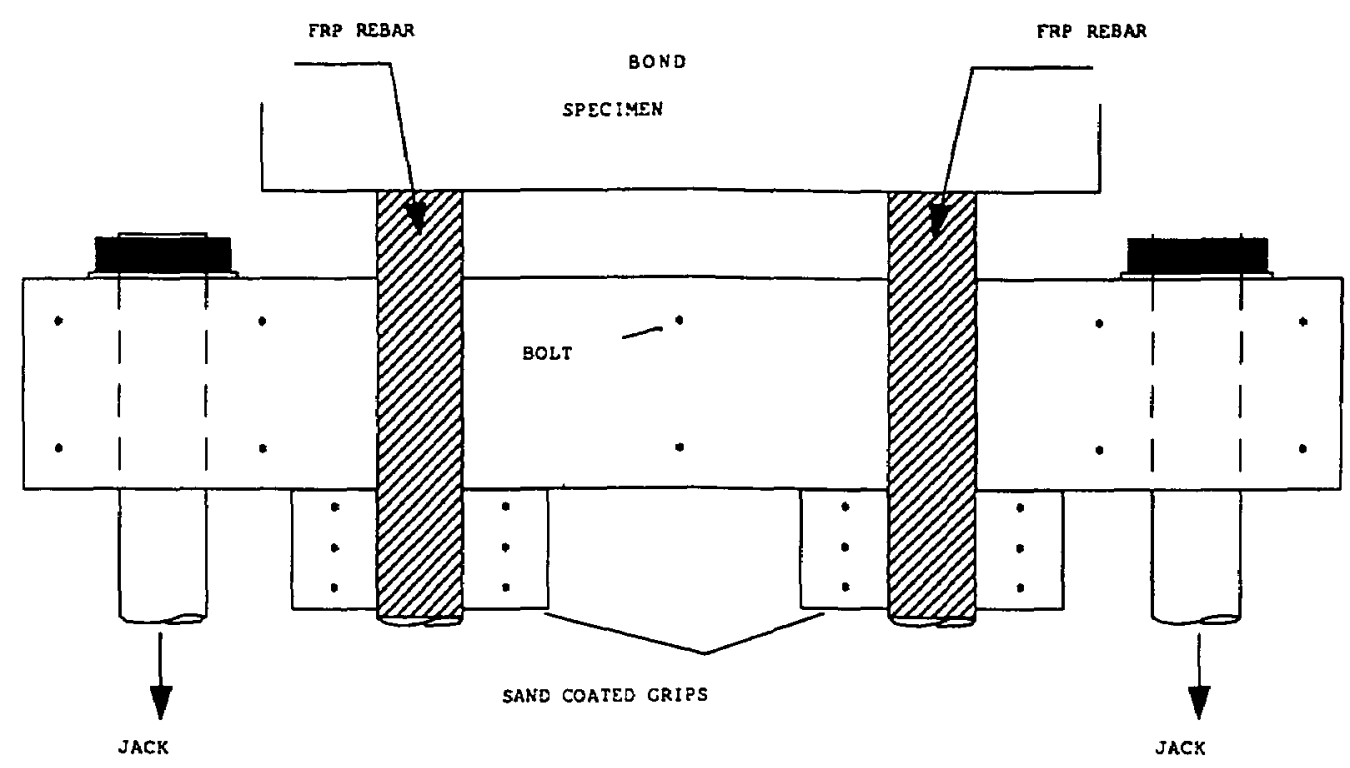

Figure 4.8 Detail of load distribution plates
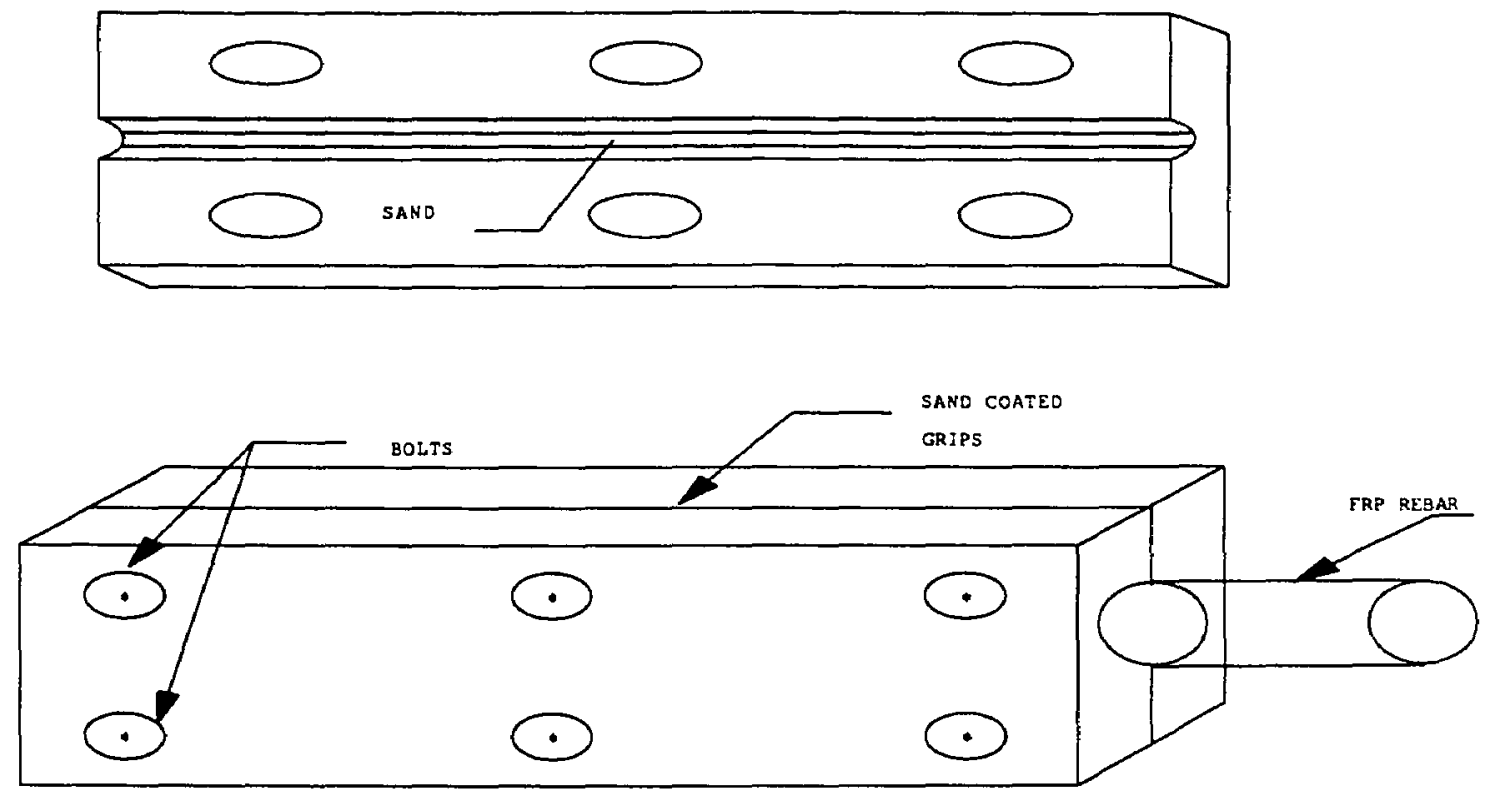

Figure 4.9 Detail of the sand coated grips

The specimen was seated in its proper position as shown in Figure 4.7 on the test frame. After applying the initial load of $5 \mathrm{kip}$, the bolts which support the distribution 
plates were released. The test was continued by loading the specimen in an increment of 1 kip per load stage. At each load stage, dial gages were recorded and the crack pattern was sketched on the specimen. The test was stopped when the rebars could not hold any extra load, i.e. slippage was evident.

\subsection{Experimental Program}

\subsubsection{Bending tests}

A series of laboratory tests on twenty five concrete beams reinforced with FRP rebars were conducted. In addition, two concrete beams were cast using mild steel reinforcement for comparison purposes. The major emphasis of these tests was to investigate whether or not concrete beams reinforced with FRP rebars behave in a manner similar to those reinforced with mild steel rebars in terms of:

- Stress-Strain Behavior

- Load-Deflection Variations

- Load Carrying Capacities (ultimate moment)

- Crack Patterns (spacing, width, propagations)

- Modes of Failure.

In order to compare the beam bending results and to evaluate the effect of changing some parameters, the beams are grouped into five categories, Group A through E. Table 4.1 summarizes the beam reinforcement and the concrete strength. 
Table 4.1 Reinforcement detail and concrete strength of bending specimens tested

\begin{tabular}{|c|c|c|c|c|}
\hline Group & Beam & $\begin{array}{c}\text { Tension } \\
\text { Reinforcement }\end{array}$ & $\begin{array}{c}\text { Stirrup } \\
\text { Type } \\
\& \\
\text { Size } \\
\end{array}$ & $\begin{array}{l}\text { Concrete } \\
\text { Strength } \\
\text { (psi) }\end{array}$ \\
\hline $\mathrm{A}$ & 2 & FRP 3\#3 & \#2 STEEL & 4200 \\
\hline $\mathrm{A}$ & 3 & FRP 3\#3 & \#2 STEEL & 4200 \\
\hline A & VH4 & $\begin{array}{c}\text { FRP 6\#2 } \\
\text { SAND COATED } \\
\end{array}$ & \#3 FRP & 10000 \\
\hline A & VH5 & $\begin{array}{c}\text { FRP } 3 \# 3 \\
\text { SAND COATED } \\
\end{array}$ & \#3 FRP & 10000 \\
\hline $\mathrm{B}$ & 5 & FRP 2\#4 & \#3 FRP & 4200 \\
\hline B & 6 & FRP 2\#3 & $\# 3$ FRP & 4200 \\
\hline $\mathrm{B}$ & 7 & FRP 2\#4 & \#3 FRP smooth & 5000 \\
\hline C & 1 & $\begin{array}{l}\text { FRP 2\#7 } \\
\text { SMOOTH } \\
\end{array}$ & \#2 STEEL & 4200 \\
\hline $\mathrm{C}$ & 4 & FRP 2\#8 & \#2 STEEL & 4200 \\
\hline $\mathrm{C}$ & 8 & FRP 2\#7 & \#2 STEEL & 5000 \\
\hline $\mathrm{C}$ & $\mathrm{H} 5$ & FRP 2\#8 & \#3 FRP & 6500 \\
\hline C & C & FRP 2\#8 & \#3 FRP & 6500 \\
\hline D & 9 & FRP 2\#3 & \#2 FRP smooth & 5000 \\
\hline $\mathrm{D}$ & 10 & FRP 2\#3 & \#2 STEEL & 5000 \\
\hline $\mathrm{D}$ & 11 & STEEL 2\#3 & \#2 STEEL & 5000 \\
\hline
\end{tabular}


Table 4.1 Reinforcement detail (continued)

\begin{tabular}{|c|c|c|c|c|}
\hline $\mathrm{D}$ & $\mathrm{H} 1$ & FRP 2\#3 & \#3 FRP & 6500 \\
\hline $\mathrm{D}$ & $\mathrm{H} 6$ & FRP 2\#3 & \#3 FRP & 6500 \\
\hline $\mathrm{D}$ & $\mathrm{A}$ & FRP 2\#3 & \#3 FRP & 7500 \\
\hline $\mathrm{D}$ & $\mathrm{B}$ & FRP 2\#3 & \#3 FRP & 7500 \\
\hline $\mathrm{E}$ & $\mathrm{H} 2$ & FRP 3\#4 & \#3 FRP & 6500 \\
\hline $\mathrm{E}$ & $\mathrm{H} 4$ & FRP 5\#3 & \#3 FRP & 6500 \\
\hline $\mathrm{E}$ & $\mathrm{D}$ & FRP 3\#4 & \#3 FRP & 7500 \\
\hline \hline $\mathrm{E}$ & $\mathrm{E}$ & FRP 5\#3 & \#3 FRP & 7500 \\
\hline $\mathrm{E}$ & F & FRP 3\#4 & \#3 FRP & 7500 \\
\hline $\mathrm{E}$ & VH1 & $\begin{array}{c}\text { FRP 3\#4 } \\
\text { SAND COATED }\end{array}$ & \#3 FRP & 10000 \\
\hline \hline $\mathrm{E}$ & $\mathrm{VH}$ & $\begin{array}{c}\text { FRP 3\#4 } \\
\text { SAND COATED }\end{array}$ & \#3 FRP & 10000 \\
\hline \hline
\end{tabular}

\subsubsection{Bond tests}

Bond strength development is a complicated phenomenon which is influenced by concrete strength, embedment length, concrete cover, rebar size and spacing, and associated shear and flexure. The bond stresses are induced either from FRP rebar anchorage to concrete or changes in bending moment along the specimen length.

In order to study the bond performance (bond force and failure pattern) of the FRP rebars, a set of twenty experiments were conducted using the cantilever specimen 
developed by the Civil Engineering Department at West Virginia University, illustrated in Figures 4.5 and 4.7. In addition twelve cylinders were embedded with FRP rebars for the standard pull-out tests of Figure 4.6.

The cantilever specimen tests are more realistic in simulating bond behavior and preferred over the conventional pull-out specimen tests. The cantilever specimens provide more realistic strain gradient through the depth of the specimen similar to the gradient expected in a flexural member while subjecting both the concrete and the rebar to tension forces. The cylinder pull-out test does not represent the actual behavior in a beam subjecting concrete to compression forces and the rebar to tension forces.

As shown in Figure 4.5 the compression zone of the beam is designed to prevent premature crushing failure and is designed to prevent shear or moment failures during experiments. A concrete block is cut out of the specimen for modeling the portion of a beam adjacent to a diagonal crack.

The major emphasis of these tests was to investigate whether or not concrete beams reinforced with FRP rebars behave in a manner similar to those reinforced with mild steel rebars in terms of bond strength and development length. Table 4.2 summarizes the beams reinforcement and concrete strength used in the cantilever beam specimens. Table 4.3 summarizes the details of the pull-out cylinder tests specimens. 
Table 4.2 Reinforcement details and concrete strengths of cantilever specimens subjected to bond

\begin{tabular}{|c|c|c|c|c|}
\hline BEAM \# & $\begin{array}{c}\text { REBAR } \\
\text { SIZE } \\
\end{array}$ & $\begin{array}{l}\text { EMBEDMENT } \\
\text { LENGTH (in) }\end{array}$ & $\begin{array}{c}\text { CONCRETE } \\
\text { STRENGTH (psi) }\end{array}$ & $\begin{array}{l}\text { BOTTOM } \\
\text { COVER (in) } \\
\end{array}$ \\
\hline BO.1.1 & $\# 8$ & 16 & 4000 & 1 \\
\hline BO.1.2 & $\# 8$ & 16 & 4000 & 1 \\
\hline BO.1.3 & $\# 8$ & 24 & 4000 & 1 \\
\hline BO.1.4 & $\# 8$ & 24 & 4000 & 1 \\
\hline BO.2.1 & $\# 3$ & 16 & 4000 & 1 \\
\hline BO.2.2 & $\# 3$ & 16 & 4000 & 1 \\
\hline BO.2.3 & $\# 3$ & 24 & 4000 & 1 \\
\hline BO.2.4 & $\# 3$ & 24 & 4000 & 1 \\
\hline BO.H1 & $\# 3$ & 12 & 7500 & 1 \\
\hline BO.H2 & $\# 3$ & 12 & 7500 & 1 \\
\hline BO.H3 & $\# 3$ & 8 & 7500 & 1 \\
\hline BO.H4 & $\# 3$ & 8 & 7500 & 1 \\
\hline BO.H5 & $\# 2$ & 4 & 7500 & 3 \\
\hline BO.H6 & $\# 2$ & 4 & 7500 & 3 \\
\hline BO.H7 & $\# 4$ & 6 & 7500 & 3 \\
\hline BO.H8 & \#4 SAND & 6 & 7500 & 3 \\
\hline BO.H9 & \#4 SAND & 8 & 9500 & 3 \\
\hline B.PHH 10 & $\# 4 S A N^{D}$ & ${ }^{8} 8$ & Y & $2^{3}$ \\
\hline BO.H11 & $\# 3$ & 4 & 9500 & 3 \\
\hline BO.H12 & $\# 3$ & 4 & 9500 & 3 \\
\hline
\end{tabular}


Table 4.2 Reinforcement details and concrete strengths of

cantilever specimens subjected to bond

\begin{tabular}{|c|c|c|c|c|}
\hline BEAM \# & $\begin{array}{c}\text { REBAR } \\
\text { SIZE } \\
\end{array}$ & $\begin{array}{l}\text { EMBEDMENT } \\
\text { LENGTH (in) }\end{array}$ & $\begin{array}{c}\text { CONCRETE } \\
\text { STRENGTH (psi) }\end{array}$ & $\begin{array}{l}\text { BOTTOM } \\
\text { COVER (in) }\end{array}$ \\
\hline BO.1.1 & $\# 8$ & 16 & 4000 & 1 \\
\hline BO.1.2 & $\# 8$ & 16 & 4000 & 1 \\
\hline BO.1.3 & $\# 8$ & 24 & 4000 & 1 \\
\hline BO.1.4 & $\# 8$ & 24 & 4000 & 1 \\
\hline BO.2.1 & $\# 3$ & 16 & 4000 & 1 \\
\hline BO.2.2 & $\# 3$ & 16 & 4000 & 1 \\
\hline BO. 2.3 & $\# 3$ & 24 & 4000 & 1 \\
\hline BO. 2.4 & $\# 3$ & 24 & 4000 & 1 \\
\hline BO.H1 & $\# 3$ & 12 & 7500 & 1 \\
\hline BO.H2 & $\# 3$ & 12 & 7500 & 1 \\
\hline BO.H3 & $\# 3$ & 8 & 7500 & 1 \\
\hline BO.H4 & $\# 3$ & 8 & 7500 & 1 \\
\hline BO.H5 & $\# 2$ & 4 & 7500 & 3 \\
\hline BO.H6 & $\# 2$ & 4 & 7500 & 3 \\
\hline BO.H7 & $\# 4$ & 6 & 7500 & 3 \\
\hline BO. $\mathrm{H8}$ & \#4 SAND & 6 & 7500 & 3 \\
\hline BO.H9 & \#4 SAND & 8 & 9500 & 3 \\
\hline BO.H10 & \#4 SAND & 8 & 9500 & 3 \\
\hline BO.H11 & $\# 3$ & 4 & 9500 & 3 \\
\hline BO.H12 & \#3 & 4 & 9500 & 3 \\
\hline
\end{tabular}


Table 4.5 Pullout cylinders details

(concrete compressive strength $f_{c}{ }^{\prime}=9500$ psi)

\begin{tabular}{|c|c|c|}
\hline $\begin{array}{c}\text { SPECIMEN } \\
\# \\
\end{array}$ & $\begin{array}{c}\text { REBAR } \\
\text { SIZE } \\
\end{array}$ & $\begin{array}{l}\text { EMBEDMENT } \\
\text { LENGTH (in) }\end{array}$ \\
\hline 1 & \#4 FINE SAND & 6 \\
\hline 2 & \#4 FINE SAND & 6 \\
\hline 3 & \#4 COARSE SAND & 6 \\
\hline 4 & \#4 COARSE SAND & 6 \\
\hline 5 & \#4 COARSE SAND & 4 \\
\hline 6 & \#4 COARSE SAND & 4 \\
\hline 7 & \#4 FINE SAND & 4 \\
\hline 8 & \#4 FINE SAND & 4 \\
\hline 9 & $\# 3$ & 4 \\
\hline 10 & $\# 3$ & 4 \\
\hline 11 & \#4 FINE SAND & 2 \\
\hline 12 & \#4 FINE SAND & 2 \\
\hline
\end{tabular}




\subsection{Experimental Results}

\subsubsection{Bending Tests}

A series of laboratory tests on concrete beams reinforced with FRP rebars were conducted. The major emphasis of these tests was to investigate whether or not concrete beams reinforced with FRP rebars behave in a manner similar to those reinforced with mild steel rebars in terms of:

- Pre- and Post-Cracking Behavior

- Load-Deflection and Stress-Strain Variations

- Elastic and Ultimate Load Carrying Capacities

- Crack Patterns (spacing, width, propagations)

- Modes of Failure.

The simply supported rectangular beams of $10 \mathrm{ft}$ lengths with $9 \mathrm{ft}$ effective spans, Figure 4.3, were tested under four point load condition (pure bending), using different configurations of FRP reinforcements. In order to take advantage of the high tensile strengths of the FRP rebars, beams with higher strength concrete $(6500,7500$, and 10000 psi) were tested for the purpose of maximizing the bending resistance of the beams.

\subsubsection{Pre- and post-cracking behavior}

The precracking segments of load-deflection curves in all specimens are essentially straight lines indicating the full elastic behavior. The maximum tensile stress in concrete beams in this region is less than the tensile strength of concrete. The flexural stiffness $\boldsymbol{E} \boldsymbol{I}$ of the beams can be estimated using Young's modulus $\boldsymbol{E}_{\boldsymbol{c}}$ of concrete and the 
moment of inertia of the uncracked reinforced concrete cross section. The loaddeflection behavior before cracking is dependent on the stress-strain relationship of concrete.

When flexural cracking develops, contribution of concrete in the tension zone is considered negligible. Thus the flexural rigidity of the beam is reduced and the slope of a load-deflection (or stiffness) curve is less steep than in the precracking stage. The stiffness continues to decrease with increasing load, reaching a lower limit that corresponds to the moment of inertia of the cracked section, $\boldsymbol{I}_{\boldsymbol{c r}}$.

\subsubsection{Ultimate load carrying capacity}

Every variable being identical, $90 \%$ increase in ultimate moment capacity was obtained when FRP rebars of $130 \mathrm{ksi}$ ultimate tensile strength were used in lieu of mild steel rods when high strength concrete $(6-10 \mathrm{ksi})$ is used. In addition, the cracking moment of the high strength concrete beams increased and a substantial decrease in the crack width was noted.

\subsubsection{Crack patterns}

In the first five concrete beams, which were reinforced with deformed FRP rebars using regular strength concrete ( $4000 \mathrm{psi})$, crack formation was sudden and propagated toward the compression zone soon after the concrete stress reached the tensile strength. The crack spacing was very close to the stirrup spacing ( 6 in. c.c.), and crack formation was nearly at the stirrup location. This sudden propagation of cracks and wider crack width have decreased by about $50 \%$ when higher strength concretes $(7500 \mathrm{psi})$ together with sand coated FRP rebars were used in our test specimens. This may be attributed to improvement in bond strength between sand coated FRP rebar and concrete, leading to reduced primary crack spacing and in turn reduced crack widths. Another important 
observation in specimens tested with sand coated rebar and higher strength concrete is formation of finer cracks with smaller crack spacing. The crack patterns of beams reinforced with sand coated rebars resembled the crack patterns expected in beams reinforced with steel rebars, with shorter spacings at ultimate levels.

\subsubsection{Modes of failure}

The modes of failure of the concrete beams ranged from pure compression failure and shear / compression failure when the concrete beams were over-reinforced, to pure tension failure when the concrete beams were under-reinforced. Bond failure of concrete beams reinforced with smooth FRP rebars resulted from the poor bond between the FRP rebars (stirrups) and concrete.

In order to compare the beam bending test results and to evaluate the influence of certain parameters, the results are grouped into five categories, Group A through E. Tables 4.4 summarize the beams test results.

\section{Group A}

This group consists of three beams reinforced with 3\#3 FRP rebars with either \#2 steel and \#3 FRP stirrups, while the forth beam is reinforced with $6 \# 2$ sand coated rebars. Parameters of beams A-2 and A-3 were kept the same except for rebars, which were supplied from two different companies. A maximum difference of $10 \%$ was found in the moment capacities of the two beams in this group of which beam A-2 reached an ultimate moment capacity of $27.75 \mathrm{kip}-\mathrm{ft}$. While the above-mentioned beams were cast with regular strength concrete and regularly deformed rebars, beams A-VH4 and A-VH5 were cast using 10,000 psi concrete with sand coated rebars. The effect of increasing the perimeter of the rebars in beam A-VH4 is clearly shown when compared with beam AVH5. The ultimate moment applied on beam A-VH4 is increased by $50 \%$ over the beam 
A-VH5. A shear failure in beam A-VH5 prevented it from reaching a higher moment capacity.

Group B

The behavior of three beams reinforced with 2\#4 FRP rebars were investigated in terms of the type of stirrups. The use of smooth FRP stirrups resulted in a bond failure between the smooth stirrup and concrete, thus reducing the moment capacity of the beam by $35 \%$. However, other stirrups performed well and the failure mode was a typical bending failure followed by shear or diagonal tension failure. An ultimate moment capacity of $27.75 \mathrm{k}-\mathrm{ft}$ was reached by beam B-5 and $24.67 \mathrm{k}-\mathrm{ft}$ reached by beam B-6. The difference can be attributed to the use of hand made FRP stirrups in beam B-6 made out of straight pieces cut and tied with plastic ties.

\section{Group C}

This group of beams was reinforced with either $2 \# 7$ or $2 \# 8$ FRP rebars. The use of smooth FRP rebars in Beam C-1 reduced the moment capacity of the beam by $60 \%$ compared to Beam $\mathrm{C}-8$, which was reinforced with ribbed rebars. Only six cracks developed in beam $\mathrm{C}-1$ with one crack opening by as much as one inch due to bond failure. By using high strength concrete $(7.5 \mathrm{ksi})$ versus regular strength concrete $(4.2$ ksi) the moment capacity of Beam C-C was increased by $50 \%$ compared to beam C-4, due to better utilization of the rebar's higher tensile and bending strength. All failed in compression or compression / shear, except for C-1.

\section{Group D}

In order to take advantage of the high tensile strength of FRP rebars (130 ksi), high strength concrete (7.5 ksi) was used in beams D-A and D-B, as well as beams D-H1 and D-H6 (6.5 ksi). The ultimate tensile strength of the FRP rebars was attained in 
beams D-H1, D-H6, D-A, and D-B, by using concrete strengths of 6500 psi and $7500 \mathrm{psi}$, thus increasing the moment capacity of the beams by a factor of TWO. The moment capacities of beams D-H1 and D-H6 did not reach the ultimate moment exhibited by beam D-A, due to a tension failure in the rebars with lower ultimate tensile strength, (100 vs $130 \mathrm{ksi}$ ), which were supplied by another company. The tensile strengths were also verified by conducting tension test on both rebars.

The use of an additional FRP reinforcement in an arch form in beam D-B has increased the moment capacity of the beam by $60 \%$ over beam D-A as shown in Table 4.4. This increase in resisting bending is attributed not only to the increase in FRP area but also to the shape of FRP. In addition, the crack width was reduced by $50 \%$ when using the arch form. The effects of changing concrete strength in addition to the use of the arch arrangement are best illustrated by the load versus deflection plot in Figure 4.10.

The post-cracking experimental deflections of FRP reinforced beams (Beams $9 \&$ 10) were about four times larger than the beam reinforced with steel (beam \#11) as shown in Figure 4.10. These larger deflections were expected due to the low modulus of elasticity of FRP rebars, which is about $7 \times 10^{6}$ psi.

\section{Group E}

In this group, the effect of increasing the perimeter of the reinforcement in addition to the use of sand coated rebars was investigated. The use of $5 \# 3$ rebars $(0.55$ in $\left.^{2}\right)$ versus $3 \# 4$ rebars $\left(0.59\right.$ in $\left.^{2}\right)$ increased the ultimate moment capacity by $20 \%$. The crack pattern in terms of the crack width, propagation and distribution has vastly improved by the use of the sand coated rebars as shown in Figure 4.11. This behavior is related to a better bond between the sand coated rebar and concrete. The crack pattern is very similar to a pattern expected of a beam reinforced with steel rods. The load versus deflection plot in Figure 4.12 illustrates an increase of $40 \%$ in the initial cracking 
moment when sand coated rebars are used. A comparison of the load versus reinforcement strains, concrete strains, and deflection variations of concrete beams reinforced with FRP rebars and steel reinforced concrete beam is illustrated in Figures 4.13 through 4.15 . The figures illustrate the high ductility exhibited by the beams reinforced with FRP rebars.

Table 4.4 Bending test results of Groups A through E

\begin{tabular}{|c|c|c|c|c|c|c|}
\hline $\begin{array}{c}\text { Group } \\
\#\end{array}$ & $\begin{array}{c}\text { Beam } \\
\#\end{array}$ & $\begin{array}{c}\text { FRP } \\
\text { Reinf. }\end{array}$ & $\begin{array}{c}\text { Stirrup } \\
\text { Size } \\
\text { \& Type }\end{array}$ & $\begin{array}{c}\text { Concrete } \\
\text { Strength } \\
(\mathrm{ksi})\end{array}$ & $\begin{array}{c}\text { Ultimate } \\
\text { Moment } \\
\text { kip-ft }\end{array}$ & $\begin{array}{c}\text { Mode of } \\
\text { Failure }\end{array}$ \\
\hline A & 2 & $3 \# 3$ & $\# 2 \mathrm{~S}$ & 4.2 & 27.75 & $\begin{array}{c}\text { BENDING } \\
\text { COMP. REBAR }\end{array}$ \\
\hline A & 3 & $3 \# 3$ & $\# 2 \mathrm{~S}$ & 4.2 & 24.67 & $\begin{array}{c}\text { BENDING } \\
\text { COMP.SHEAR }\end{array}$ \\
\hline A & VH4 & $6 \# 2$ & $\# 3 \mathrm{~F}$ & 10 & 31.5 & $\begin{array}{c}\text { BENDING } \\
\text { COMPRESSION }\end{array}$ \\
\hline A & VH5 & $3 \# 3$ & $\# 3 \mathrm{~F}$ & 10 & 21 & $\begin{array}{c}\text { BENDING } \\
\text { SHEAR }\end{array}$ \\
\hline B & 5 & $2 \# 4$ & $\# 2 \mathrm{~S}$ & 4.2 & 27.75 & $\begin{array}{c}\text { BENDING } \\
\text { SHEAR }\end{array}$ \\
\hline B & 6 & $2 \# 4$ & $\# 3 \mathrm{~F}$ & 4.2 & 24.67 & $\begin{array}{c}\text { BENDING } \\
\text { SHEAR }\end{array}$ \\
\hline 7 & $2 \# 4$ & $\# 2 \mathrm{~F}$ & 5.0 & 16.96 & $\begin{array}{c}\text { BOND IN } \\
\text { STIRRUP }\end{array}$ \\
\hline
\end{tabular}


CHAPTER 4

Table 4.4 Bending test results (continued)

\begin{tabular}{|c|c|c|c|c|c|c|}
\hline $\mathrm{C}$ & 1 & $2 \# 7$ & $\# 2 \mathrm{~S}$ & 4.2 & 16.50 & BOND \\
\hline $\mathrm{C}$ & 4 & $2 \# 8$ & $\# 2 \mathrm{~S}$ & 4.2 & 40.00 & $\begin{array}{c}\text { COMP. } \\
\text { SHEAR }\end{array}$ \\
\hline $\mathrm{C}$ & 8 & $2 \# 7$ & $\# 2 \mathrm{~S}$ & 5.0 & 41.63 & COMPRESSION \\
\hline $\mathrm{C}$ & $\mathrm{H} 5$ & $2 \# 8$ & $\# 3 \mathrm{~F}$ & 6.5 & 54.75 & $\begin{array}{c}\text { COMP. } \\
\text { SHEAR }\end{array}$ \\
\hline $\mathrm{C}$ & $\mathrm{C}$ & $2 \# 8$ & $\# 3 \mathrm{~F}$ & 7.5 & 60.00 & $\begin{array}{c}\text { COMP. } \\
\text { SHEAR }\end{array}$ \\
\hline $\mathrm{D}$ & 9 & $2 \# 3$ & $\# 2 \mathrm{~F}$ & 5.0 & 12.95 & $\begin{array}{c}\text { BENDING } \\
\text { BOND/STIR }\end{array}$ \\
\hline $\mathrm{D}$ & 10 & $2 \# 3$ & $\# 2 \mathrm{~S}$ & 5.0 & 10.64 & TENS./EX. \\
CRACK
\end{tabular}


Table 4.4 Bending test results (continued)

\begin{tabular}{|c|c|c|c|c|c|c|}
\hline $\mathrm{E}$ & $\mathrm{H} 2$ & $3 \# 4$ & $\# 3 \mathrm{~F}$ & 6.5 & 31.13 & COMPRESSION \\
\hline $\mathrm{E}$ & $\mathrm{H} 4$ & $5 \# 3$ & $\# 3 \mathrm{~F}$ & 6.5 & 37.50 & $\begin{array}{c}\text { COMP. } \\
\text { TENSION }\end{array}$ \\
\hline$E$ & $\mathrm{D}$ & $\begin{array}{r}3 \# 4 \\
\text { SAND } \\
\end{array}$ & $\# 3 \mathrm{~F}$ & 7.5 & 40.50 & $\begin{array}{c}\text { SHEAR } \\
\text { TENSION }\end{array}$ \\
\hline $\mathrm{E}$ & $\mathrm{E}$ & $5 \# 3$ & \#3 F & 7.5 & 40.50 & $\begin{array}{c}\text { SHEAR } \\
\text { TENSION }\end{array}$ \\
\hline$E$ & F & $3 \# 4$ & $\# 3 \mathrm{~F}$ & 7.5 & 34.5 & $\begin{array}{c}\text { SHEAR } \\
\text { TENSION }\end{array}$ \\
\hline E & VHI & $\begin{array}{r}3 \# 4 \\
\text { SAND } \\
\end{array}$ & $\# 3 \mathrm{~F}$ & 10 & 40.95 & COMPRESSION \\
\hline $\mathrm{E}$ & $\mathrm{VH} 2$ & $\begin{array}{r}3 \# 4 \\
\text { SAND } \\
\end{array}$ & \#3 F & 10 & 43.5 & COMPRESSION \\
\hline $\mathrm{E}$ & VH3 & $\begin{array}{c}3 \# 4 \\
\text { STEEL }\end{array}$ & \#3 F & 10 & 24.38 & TENSION \\
\hline
\end{tabular}




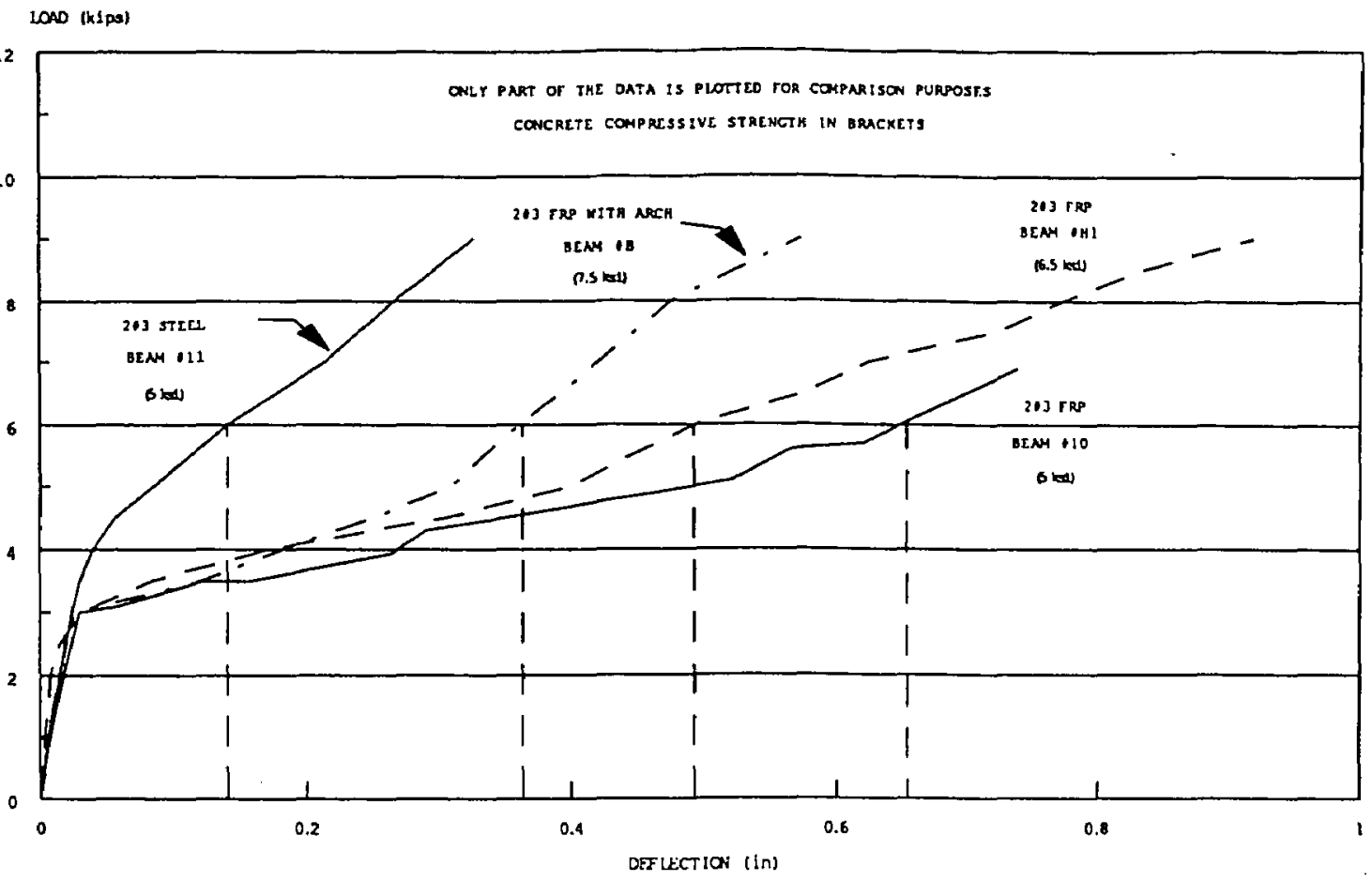

Figure 4.10 Load vs deflection (Group D)

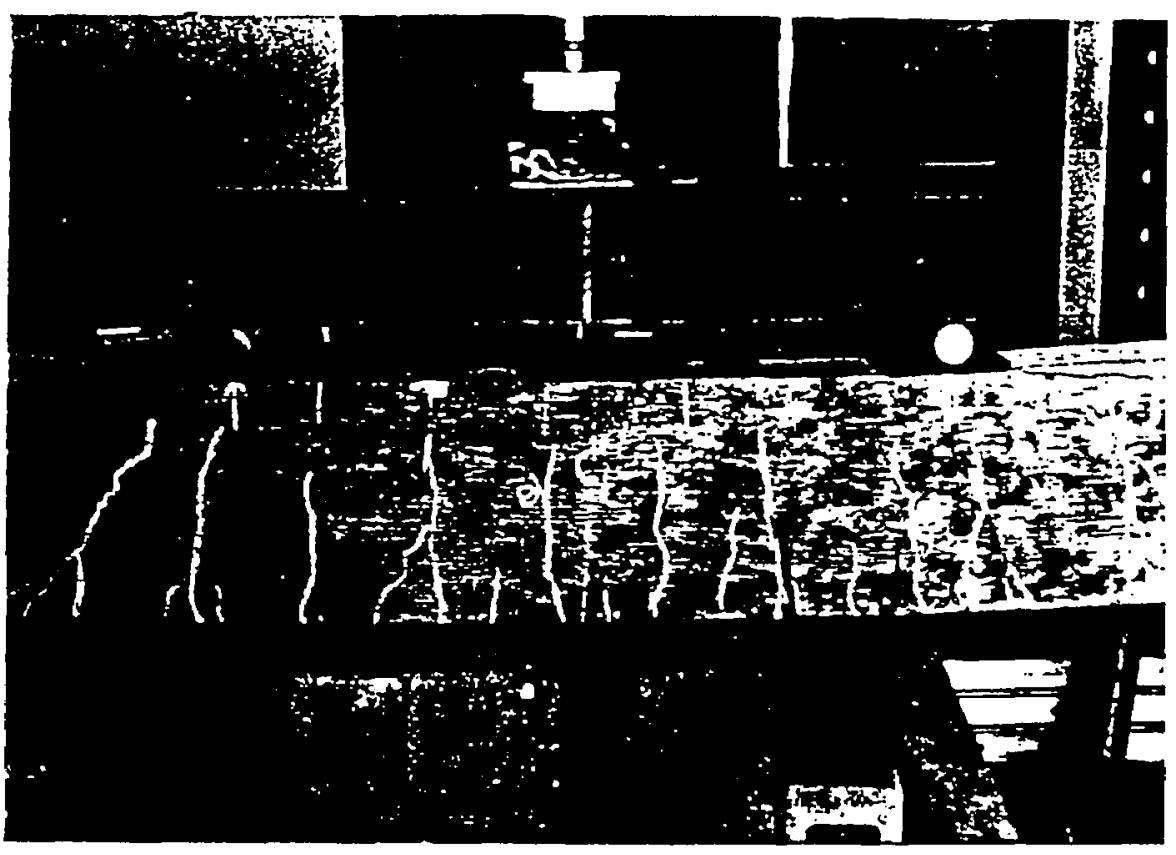

Figure 4.11 Cracking pattern of beam E-D reinforced with $3 \# 4$ sand coated rebars 


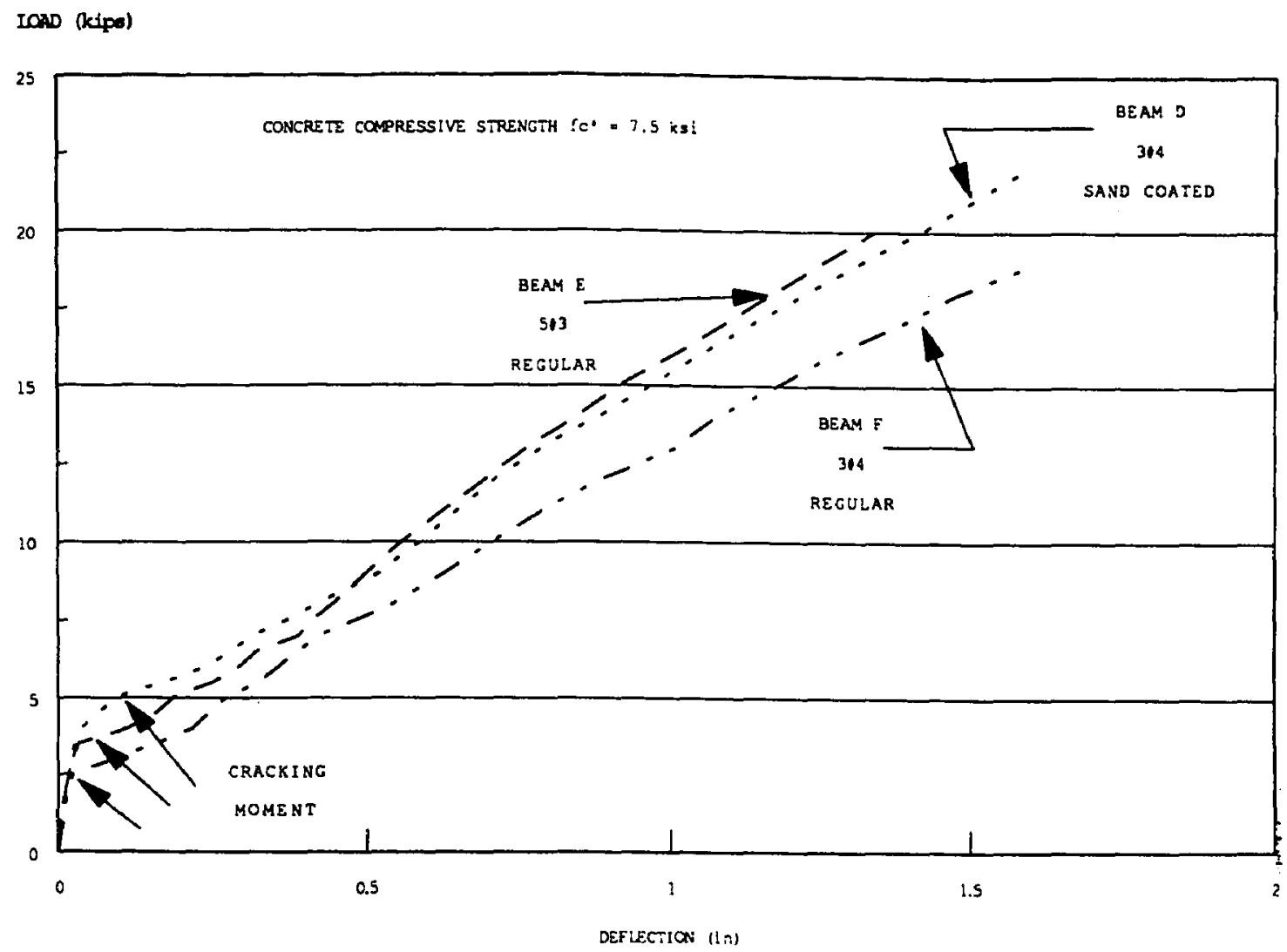

Figure 4.12 Load vs deflection (Group E)

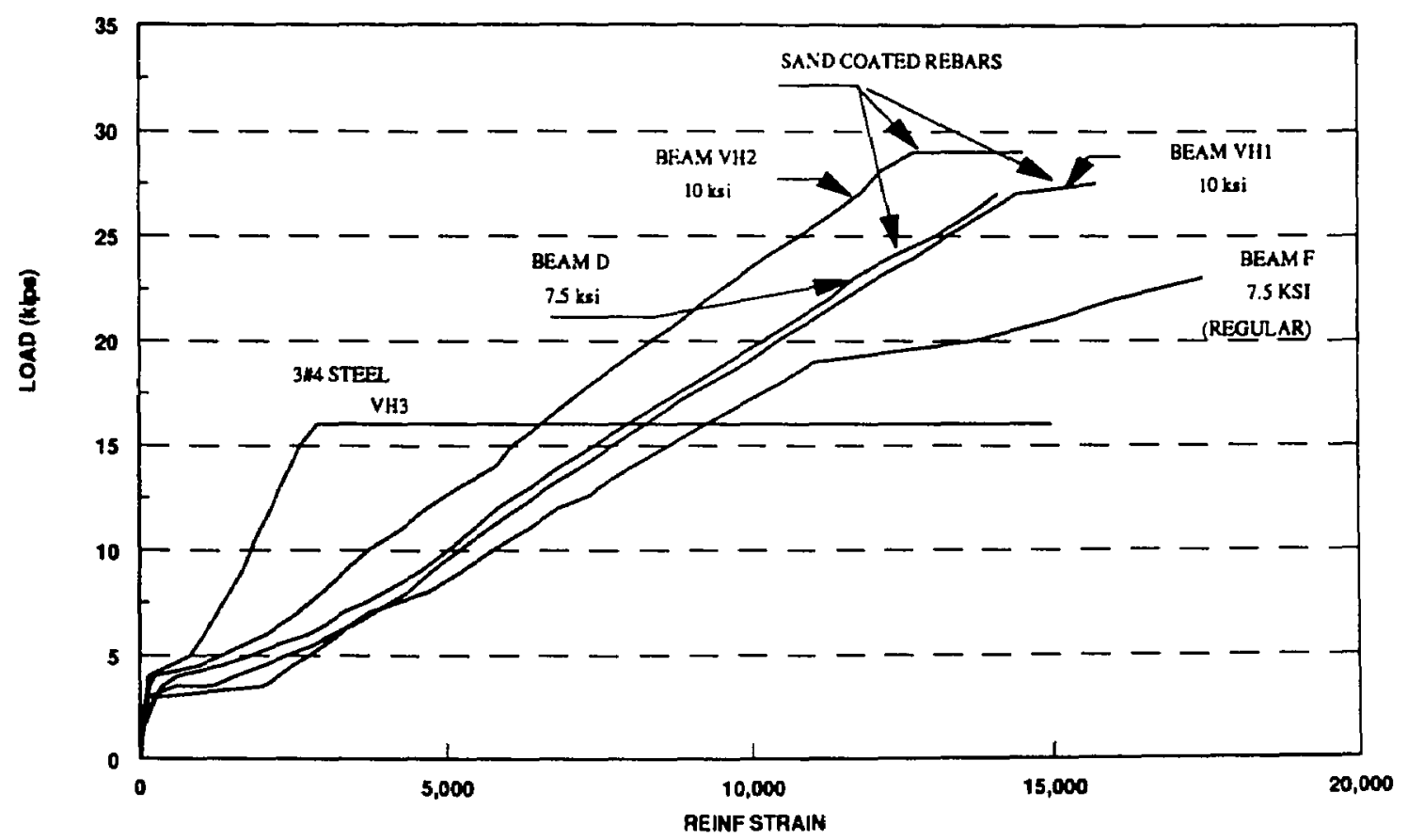

Figure 4.13 load vs reinforcement strain (FRP vs steel reinforced beams) 


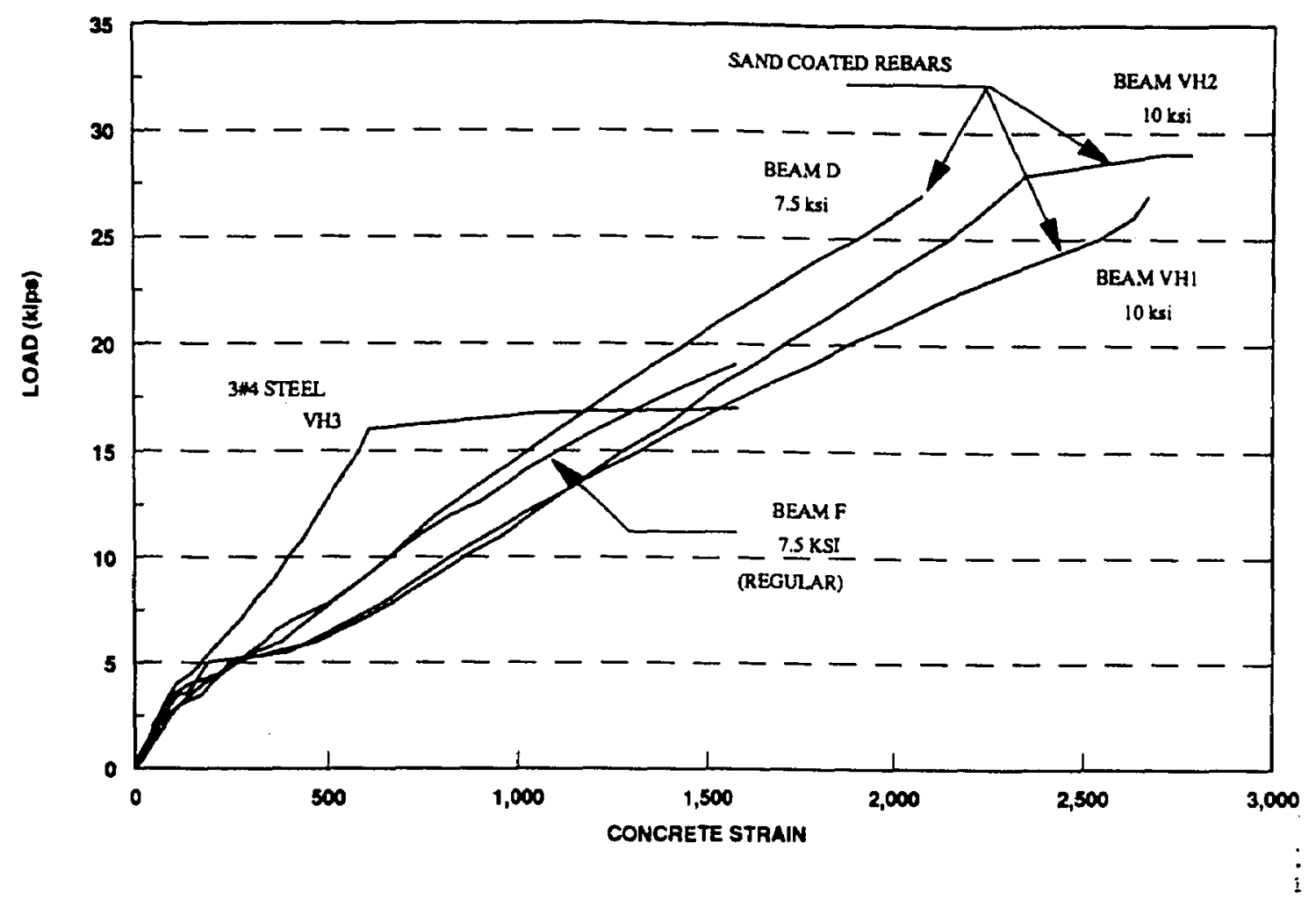

Figure 4.14 Load vs concrete strain (FRP vs steel reinforced beams)

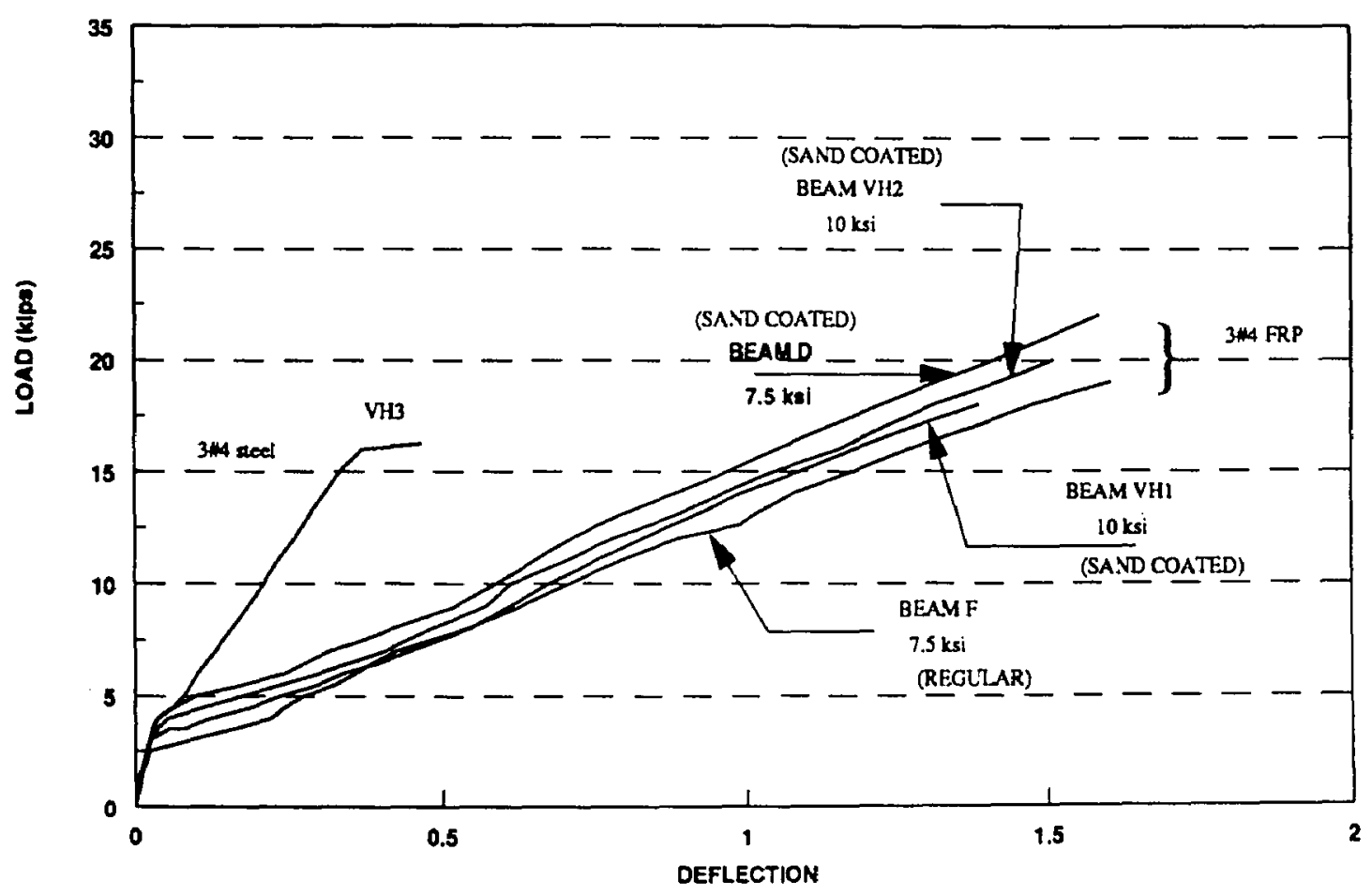

Figure 4.15 Load vs deflection (FRP vs steel reinforced beams) 


\subsubsection{Bond Behavior}

A series of laboratory tests on cantilever bond specimens and straight pull-out specimens using FRP rebars were conducted. The major emphasis of these tests was to investigate the bond behavior between concrete and FRP rebars for different parameters. Different rebar types (regularly deformed and sand coated) sizes $(3 / 8,4 / 8$, and 1 in dia.), and embedment lengths were used with concrete strengths ranging from $4000 \mathrm{psi}$ to 10,000 psi. The use of higher strength concrete was necessary to establish bond behavior when higher strength concretes are used in the design and in the bending testing of beams reinforced with FRP rebars.

For each experiment in the test program, the loading, crack pattern, mode of failure, and slip of the rebar were recorded and plotted. A summary of the cantilever bond specimens sizes and their results are given in Table 4.5; whereas, those for cylinder pullout tests are given in Table 4.6.

For analyzing the test results, the critical ultimate bond stress, $\mu$, was calculated from the maximum recorded pullout load assuming a uniform distribution of bond stresses. For tests where the FRP rebar failed outside the concrete, the maximum load was taken as that corresponding to the ultimate failure load of the rebar. 
Table 4.5 Cantilever bond test results

\begin{tabular}{|c|c|c|c|c|c|c|}
\hline $\begin{array}{l}\mathbf{G} \\
\mathrm{R} \\
\mathrm{O} \\
\mathrm{U} \\
\mathrm{P}\end{array}$ & $\begin{array}{c}\text { Beam } \\
\#\end{array}$ & $\begin{array}{l}\text { Rebar } \\
\text { Size }\end{array}$ & $\begin{array}{c}\text { Embedment } \\
\text { Length } \\
\text { (in) } \\
\end{array}$ & $\begin{array}{c}\text { Ultimate } \\
\text { Load @ } \\
\text { Failure (kip) }\end{array}$ & $\begin{array}{l}\text { Exp. Bond } \\
\text { Stress (psi) }\end{array}$ & Remarks \\
\hline A & BO1.1 & $\# 8$ & 16 & 22.46 & 450 & SPLITTING \\
\hline A & BO.1.2 & $\# 8$ & 16 & 24.00 & 480 & SPLITTING \\
\hline $\mathrm{A}$ & BO.1.3 & $\# 8$ & 24 & 29.00 & 387 & SPLITTING \\
\hline $\mathrm{A}$ & BO.1.4 & $\# 8$ & 24 & 30.00 & 400 & SPLITTING \\
\hline B & BO.2.1 & $\# 3$ & 16 & $*$ & $*$ & Failure in Grip \\
\hline B & BO.2.2 & $\# 3$ & 16 & $*$ & $*$ & Failure in Grip \\
\hline B & BO. 2.3 & $\# 3$ & 24 & 11.00 & $>389$ & REBAR FAILURE \\
\hline B & BO. 2.4 & $\# 3$ & 24 & 10.90 & $>389$ & REBAR FAILURE \\
\hline $\mathrm{B}$ & BO.H.1 & $\# 3$ & 12 & 8.20 & $>580$ & REBAR FAILURE \\
\hline B & BO.H.2 & $\# 3$ & 12 & 8.10 & $>573$ & REBAR FAILURE \\
\hline $\mathrm{B}$ & BO.H.3 & $\# 3$ & 8 & 9.04 & $>997$ & REBAR FAILURE \\
\hline B & BO.H.4 & $\# 3$ & 8 & 8.00 & $>849$ & REBAR FAILURE \\
\hline $\mathrm{C}$ & BO.H. 5 & $\# 4 \mathrm{~s}$ & 6 & 12.33 & 1308 & BOND/SLIP \\
\hline $\mathrm{C}$ & BO.H.6 & $\# 4$ & 6 & 14.00 & 1486 & BOND/SLIP \\
\hline $\mathrm{C}$ & BO.H.7 & $\# 2$ & 4 & 5.5 & 1750 & REBAR FAILURE \\
\hline C & BO.H. 8 & $\# 2$ & 4 & 5.7 & 1814 & REBAR FAILURE \\
\hline $\mathrm{D}$ & BO.H.9 & $\# 4 \mathrm{~s}$ & 8 & 16.79 & 1336 & Splitting/Bending \\
\hline $\mathrm{D}$ & BO.H.10 & $\# 4 \mathrm{~s}$ & 8 & 14.33 & 1140 & Splitting/Bending \\
\hline $\mathrm{D}$ & BO.H.11 & \#3 & 4 & 9.63 & 2043 & PULLOUT \\
\hline $\mathrm{D}$ & BO.H.12 & $\# 3$ & 4 & 6.74 & 1430 & PULLOUT \\
\hline
\end{tabular}


Table 4.6 Cylinder pullout results

\begin{tabular}{|c|c|c|c|c|}
\hline $\begin{array}{c}\text { Cyl. } \\
\#\end{array}$ & $\begin{array}{c}\text { Rebar } \\
\text { Size }\end{array}$ & $\begin{array}{l}\text { E.L. } \\
\text { (in) }\end{array}$ & $\begin{array}{c}\text { Ultimate } \\
\text { Load } \\
\text { (kips) } \\
\end{array}$ & $\begin{array}{c}\text { Experimental. } \\
\text { Bond } \\
\text { Stress (psi) }\end{array}$ \\
\hline 1 & $\# 4 \mathrm{FS}$ & 5.5 & 11.00 & 1273 \\
\hline 2 & \#4 FS & 5.5 & 10.70 & 1239 \\
\hline 3 & $\# 4 \mathrm{CS}$ & 5.5 & 10.95 & 1267 \\
\hline 4 & $\# 4 \mathrm{CS}$ & 5.5 & 10.35 & 1198 \\
\hline 5 & $\# 4 \mathrm{CS}$ & 3.5 & 8.05 & 1464 \\
\hline 6 & $\# 4 \mathrm{CS}$ & 3.5 & 7.85 & 1427 \\
\hline 7 & $\# 4 \mathrm{FS}$ & 3.5 & 12.00 & 2182 \\
\hline 8 & \#4 FS & 3.5 & 8.45 & 1537 \\
\hline 9 & $\# 3$ & 3.5 & 6.60 & 1600 \\
\hline 10 & $\# 3$ & 3.5 & 7.75 & 1880 \\
\hline 11 & \#4FS & 1.5 & 6.00 & 2550 \\
\hline 12 & $\# 4 \mathrm{FS}$ & 1.5 & 5.00 & 2120 \\
\hline
\end{tabular}

FS = Fine sand coating

$\mathrm{CS}=$ Coarse sand coating 


\subsubsection{Cantilever specimens}

In order to compare the bond test results shown in Table 4.5 and to evaluate the influence of certain parameters, the beams tested are grouped into four categories, Group A through D.

\section{Group A}

This group consisted of four beams using \#8 FRP rebar and concrete compressive strength of 4000 psi as shown in Table 4.5. Beams BO.1.1 and BO.1.3 included supplementary steel reinforcement below the FRP rebars. No apparent effect was noticed in the bond strength value when the supplementary rebars were included in the design of the beams.

Beams BO.1.1 and BO.1.2 had FRP rebars with 16 inch embedment length and BO.1.3 and BO.1.4 with 24 inch embedment length. A pullout failure following the splitting of concrete under rebars was established at a maximum load of 24 kips in specimen BO.1.2, which corresponds to a bond stress of $478 \mathrm{psi}$, and at $30 \mathrm{kips}$ in specimen BO.1.4, which corresponds to 400 psi in bond stress.

The decrease in the bond strength calculation with increasing embedment length is attributed to the increase in the perimeter area of the rebars. The calculated bond strength value is based on the assumption that the load is distributed uniformily along the length of the embedment. The cracking pattern leading to pull out failure of the rebar is shown in Figures 4.16 and 4.17. Cracking is initiated under the rebars and propagated on thè bóttom of the cantilever beam as the load was increased. Additional cracks formed between the two rebars in all the beams of this group. 


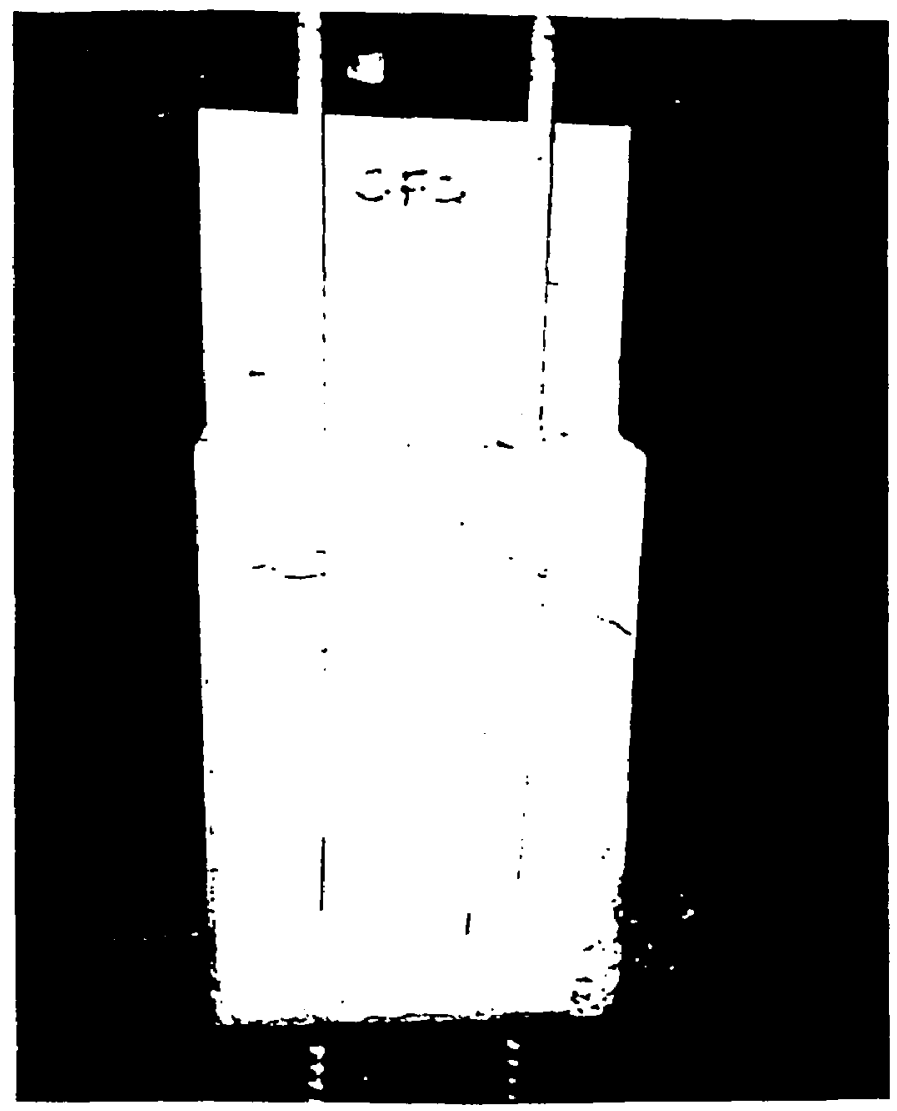

Figure 4.16 Cracking pattern of bond specimen BO.1.1

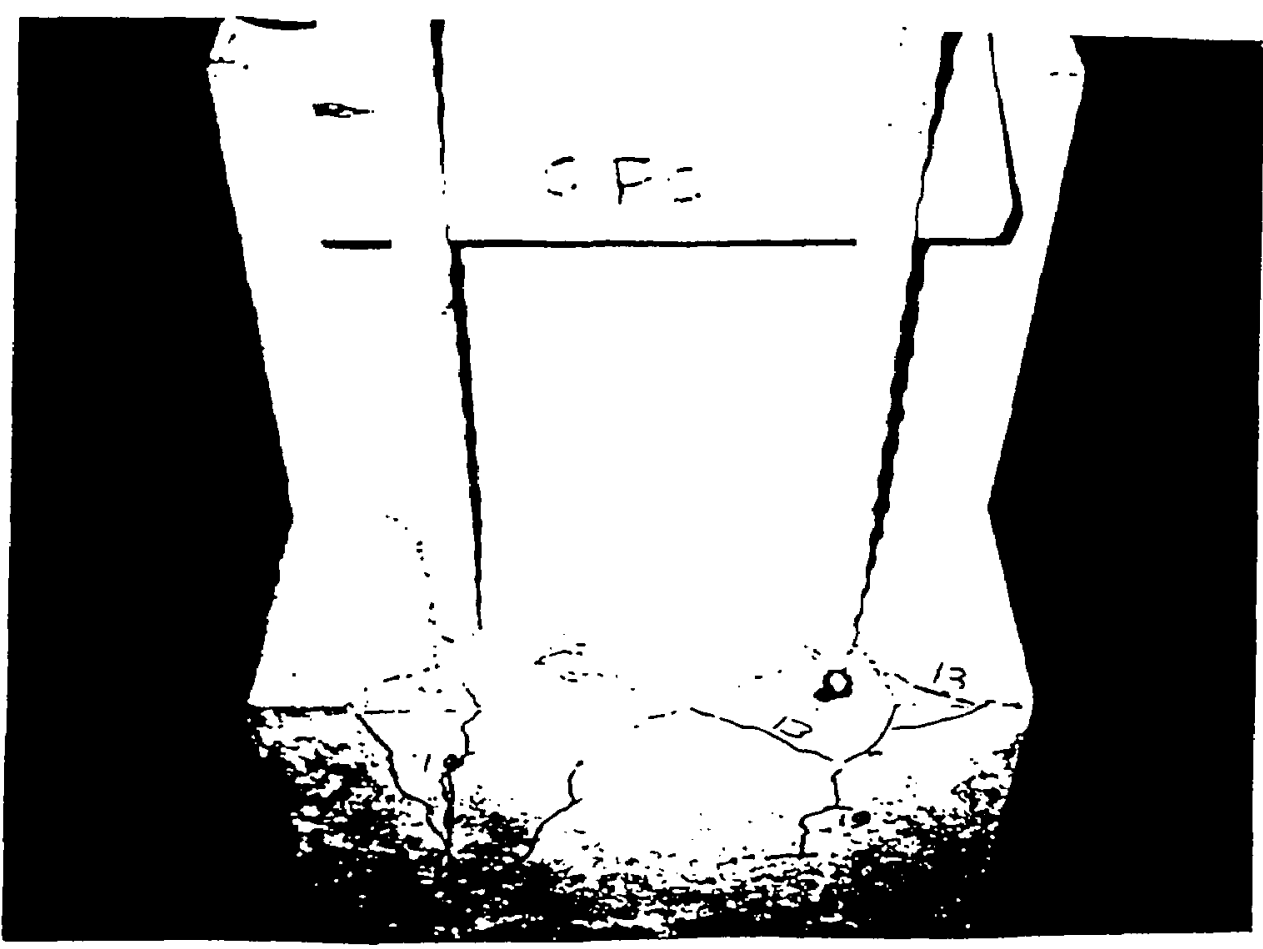

Figure 4.17 Cracking pattern of bond specimen BO.1.3 


\section{Group B}

Eight cantilever specimens were cast using 4000 and 7500 psi concrete. Two \#3 FRP rebars were used in all eight beams with embedment length of 8, 12, 16 and 24 inches. In all the specimens, the \#3 FRP rebars failed outside the concrete block in tension as shown in Figure 4.18. The ultimate tensile strength varied between $72 \mathrm{ksi}$ and $100 \mathrm{ksi}$ with no slip between the FRP rebar and concrete. The ultimate tensile strength reached was about $25 \%$ lower than the expected ultimate tensile strength of the rebar (130 ksi) due to some bending and misalignment in the rebars. The concrete specimen was free of any visible cracks.

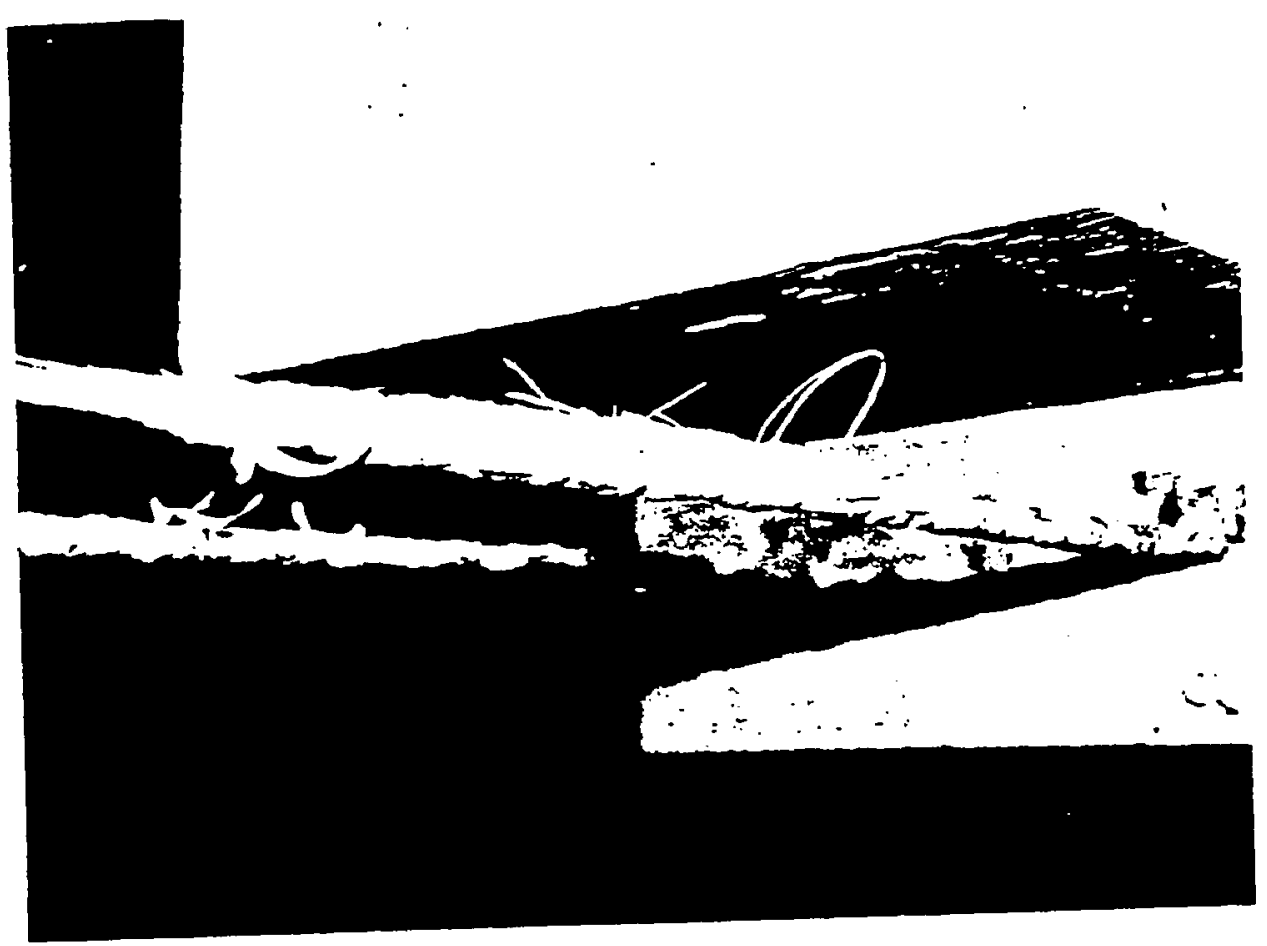

Figure 4.18 Rebar Failure outside specimen with no slip 


\section{Group C}

Specimens BO.H5 and BO.H6 were embedded with \#2 sand coated FRP rebars with an embedment length of four inches. Failure of the rebar outside the concrete, without any slip, occurred when the tensile strength of the rebar reached $116 \mathrm{ksi}$. The lower than expected value for the ultimate tensile strength of the \#2 rebar is attributed to some misalignment of the rebar. Specimens BO.H7 and BO.H8 were cast with \#4 FRP rebars, regularly deformed and sand coated. An actual pullout failure was reached in both specimens that corresponds to 1308 and 1486 psi bond strength. Figure 4.19 shows the type of cracks around the rebar that lead to pull out failure of the rebar.

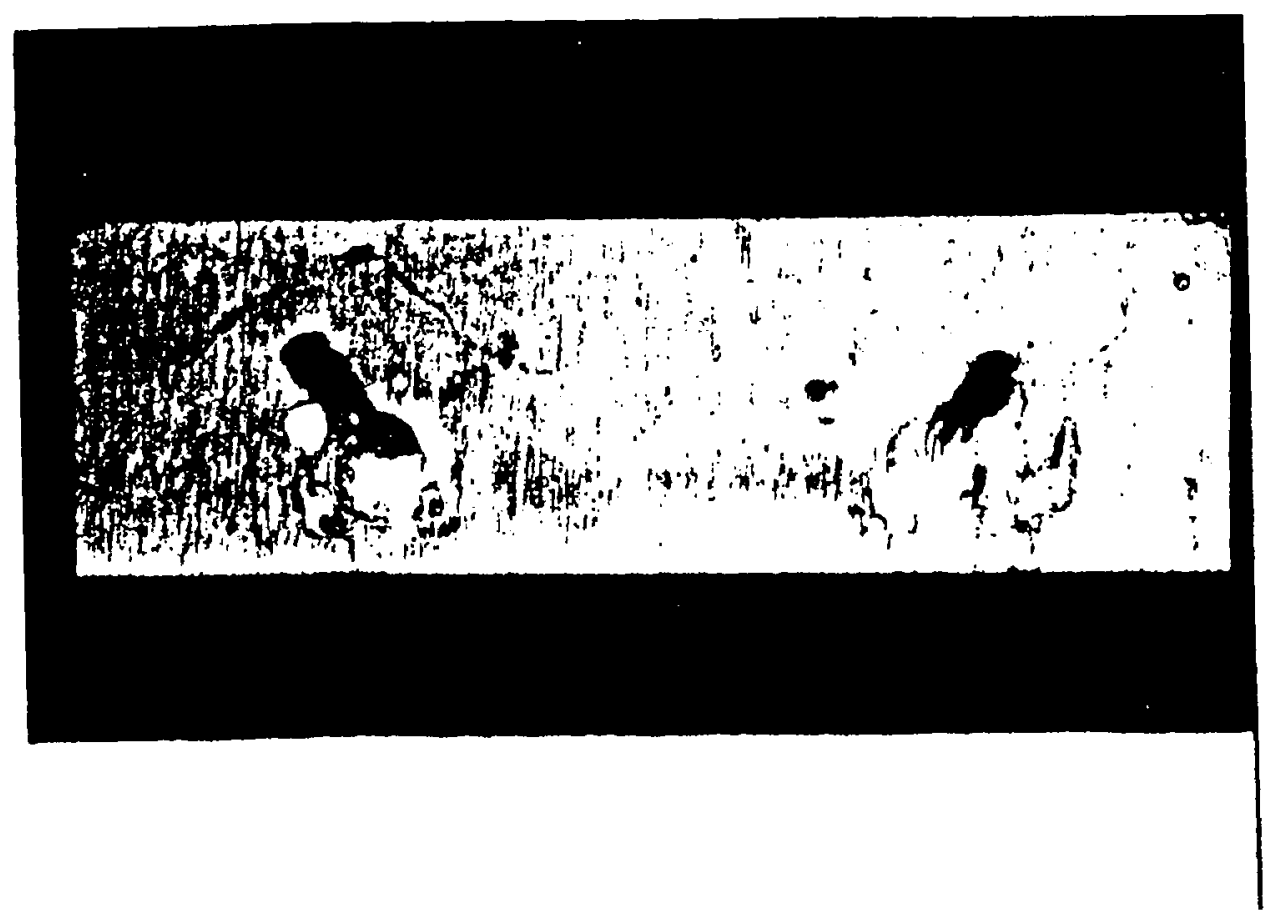

Figure 4.19 Cracking of concrete around the rebar in B.O.H5 


\section{Group D}

In order to develop the actual stress distribution along the embedment length, four specimens were cast using 9500 psi concrete with \#3 and \#4 FRP rebars. Strain gages were attached on the \#3 rebars of one specimen at 1 and 3 in. from its edge before casting the concrete. On another specimen with \#4 rebar, strain gages were bonded at 1, 4, and 7 in. from the edge. The other two specimens were cast without strain gages to monitor if any reduction in bond strength results from the application of the strain gages and the protective material. The actual distribution of the stresses on the \#4 rebar was successfully recorded as shown in Figure 4.20. In the case of the \#3 rebar specimen, the strain gages were damaged because of slip failure, which occurred due to the reduction of the embedment length as a result of the application of the strain gages which resulted in a smooth surface from the protective material on the gages. Figures 4.21 and 4.22 show splitting / bending failure in concrete leading to the pull-out failure of the rebars.

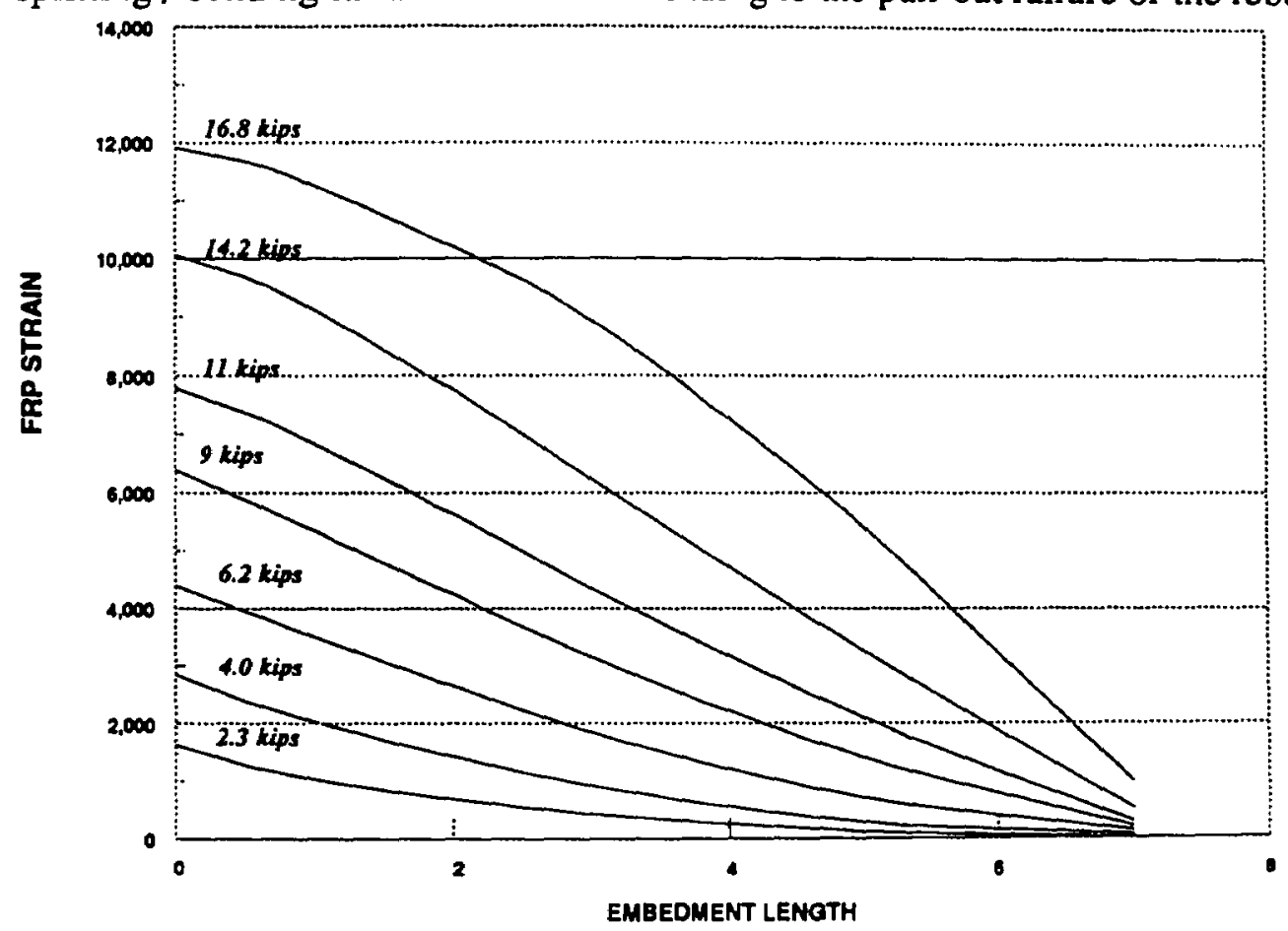

Figure 4.20 Strain distribution along embedment length

\#4 sand coated rebar with embedment length $=8$ in. 


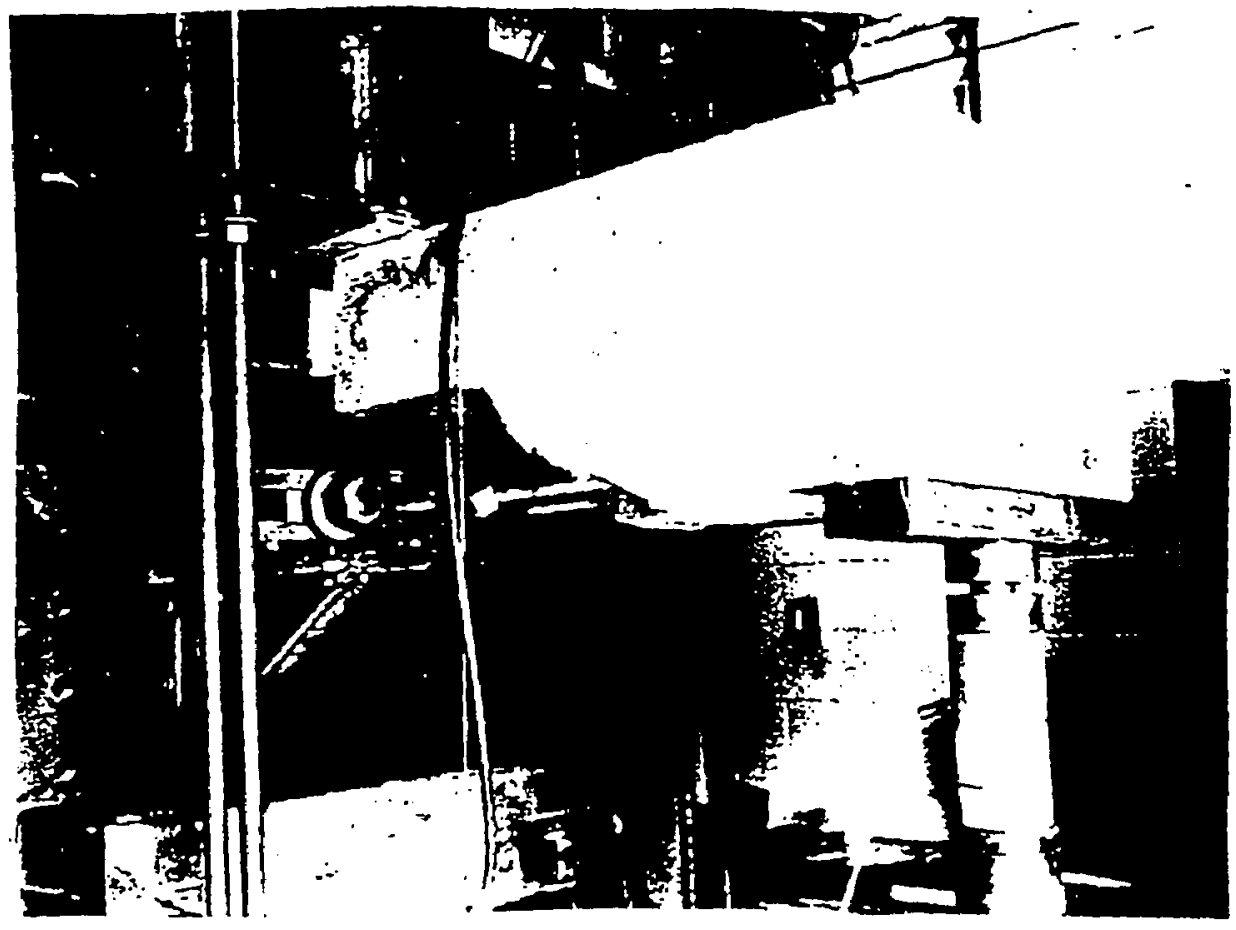

Figure 4.21 Setup and failure of cantilever specimen

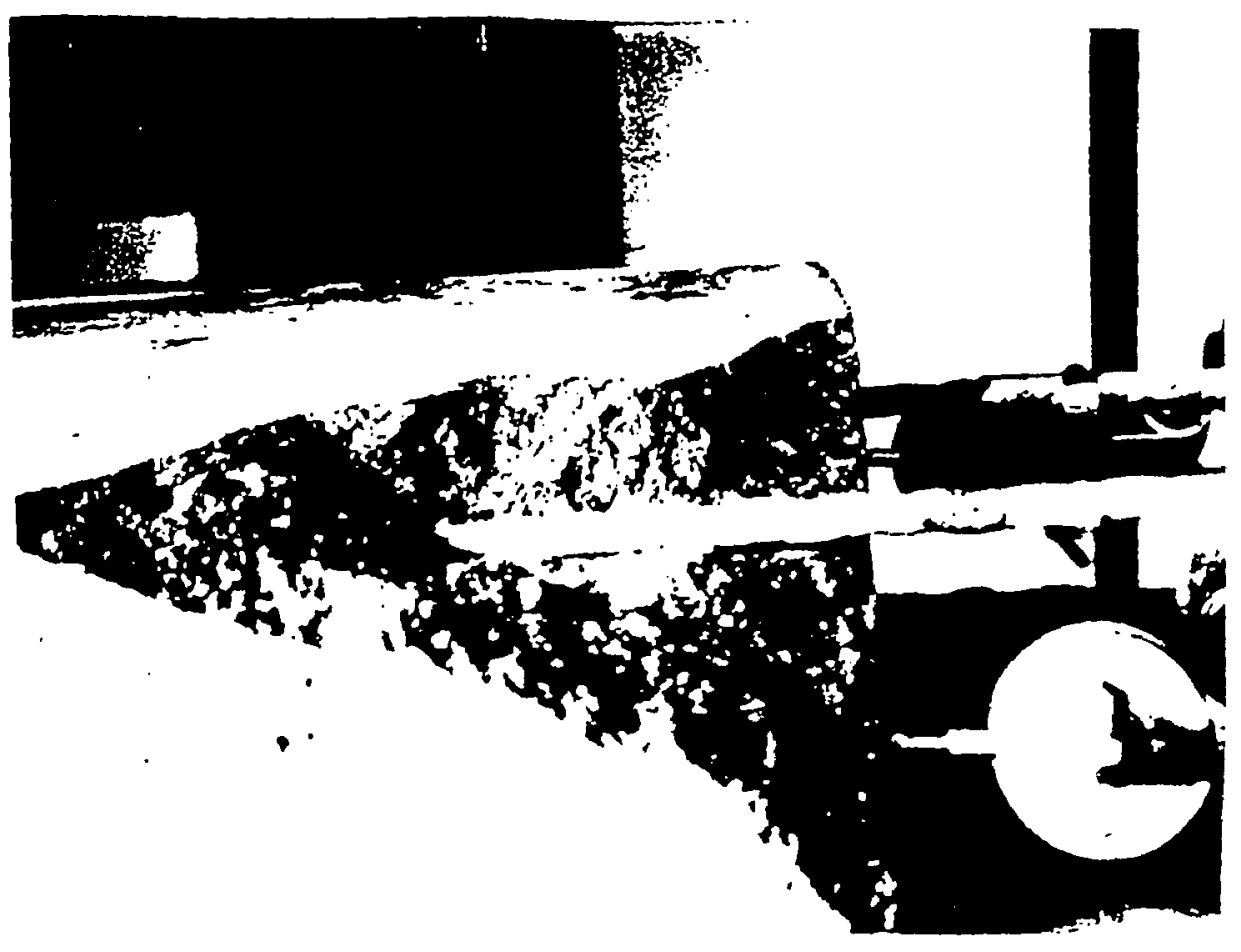

Figure 4.22 Close up of failed specimen B.O.H9 
A typical average bond stress versus elongation leading to rebar failure with no slip of two specimens with 8 and 12 in embedment lengths is clearly illustrated in Figure 4.23. The $3 / 8$ in. diameter rebar failed in tension between the concrete surface and the sand coated grips. Figure 4.24 illustrates the case when \#8 rebar with embedment length of 24 in. elongate outside the concrete leading to slip out of the concrete.

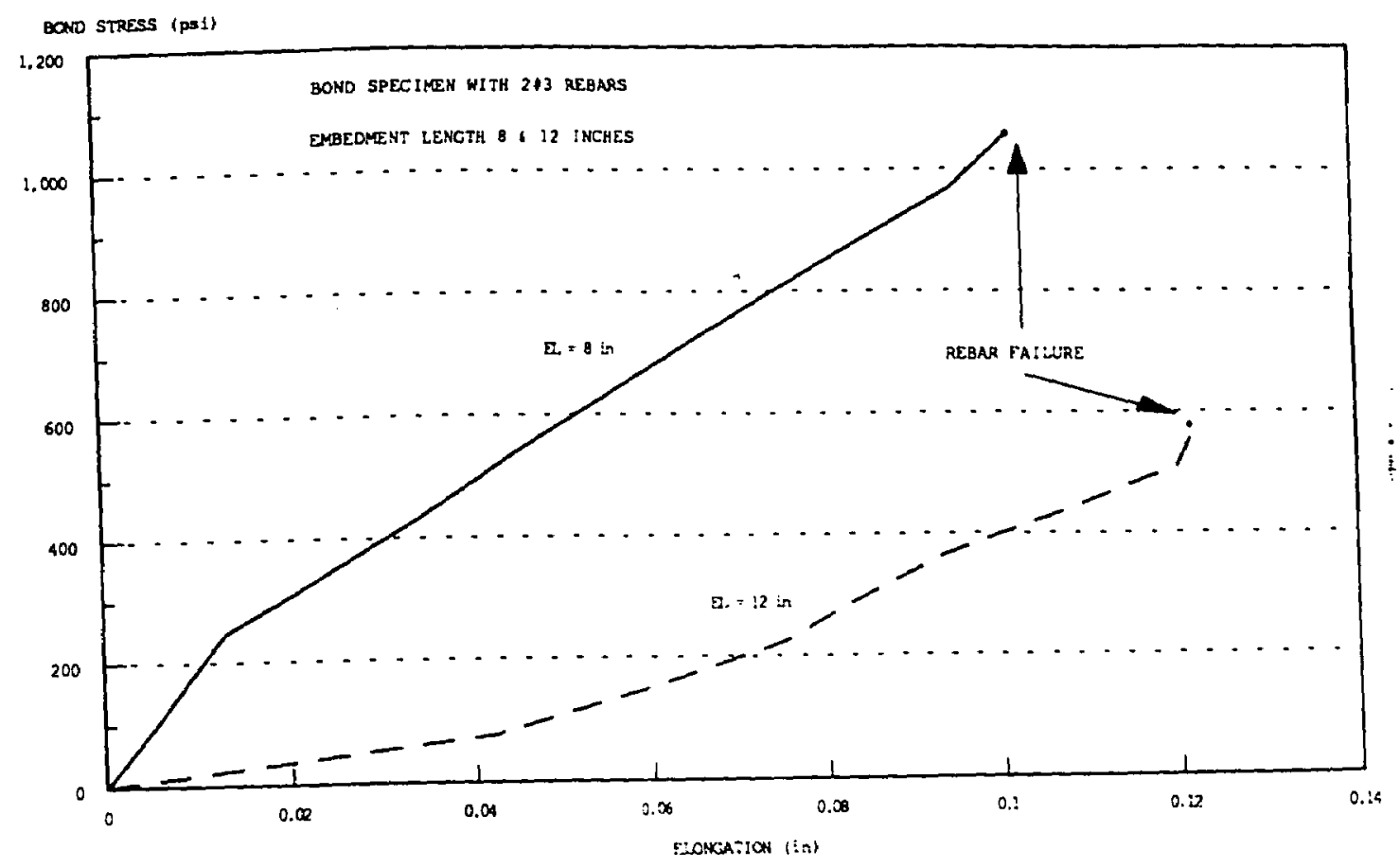

Figure 4.23 Bond stress versus elongation 


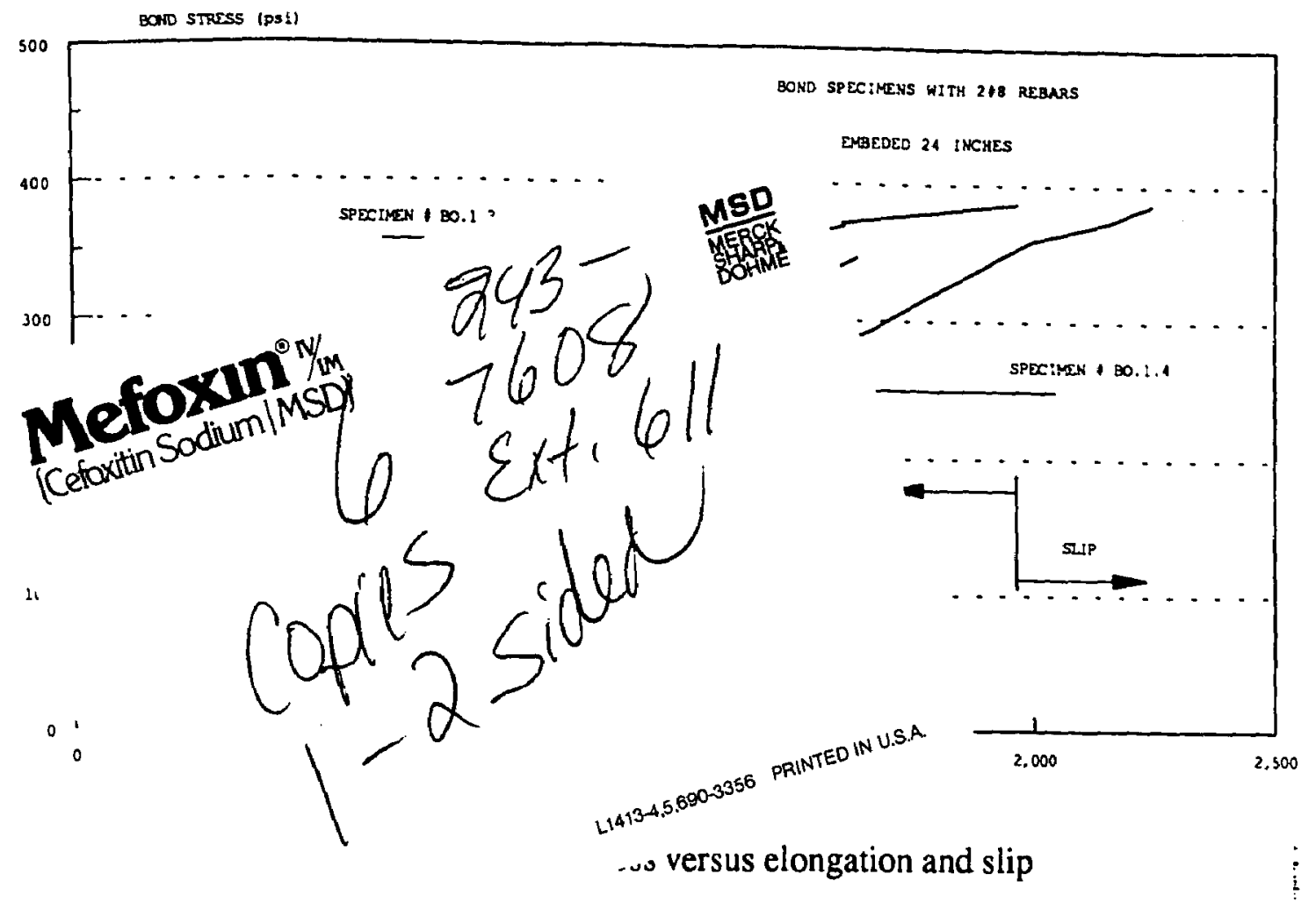

\subsubsection{Straight pull-out cylinders}

Twelve cylinders were use embedded with FRP rebars at variable embedment lengths $(2,4$, and 6 in.), with concrete strength kept constant at 9500 psi. Three types of rebars are used, \#3 regularly deformed, \#4 fine sand coated, and \#4 coarse sand coated FRP rebars. All twelve specimens failed under straight pullout by splitting concrete leading to release of the rebar from concrete. No slip failure prior to the splitting of the concrete was noted. A typical failure of a cylinder is shown in Figures 4.25 and 4.26. Test results are shown in Table 4.6. Bond stress values are found to be higher than the ones in a cantilever test setup. This may be attributed to the type of tests which do not simulate actual conditions that are expected in a beam reinforced with FRP rebars, i.e. instead of rebar and concrete being in a state of tensile stress, concrete in a straight pullout test is in a state of compression. 


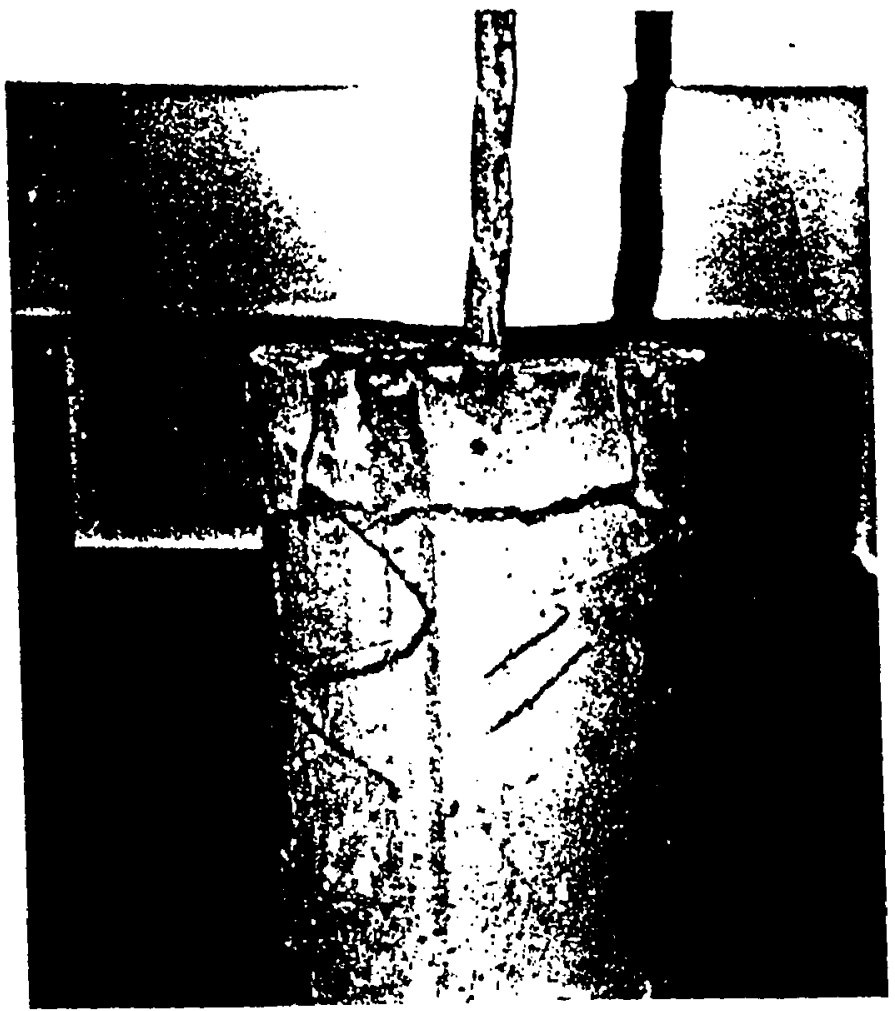

Figure 4.25 Splitting concrete failure around the 2 in. embedment length specimen

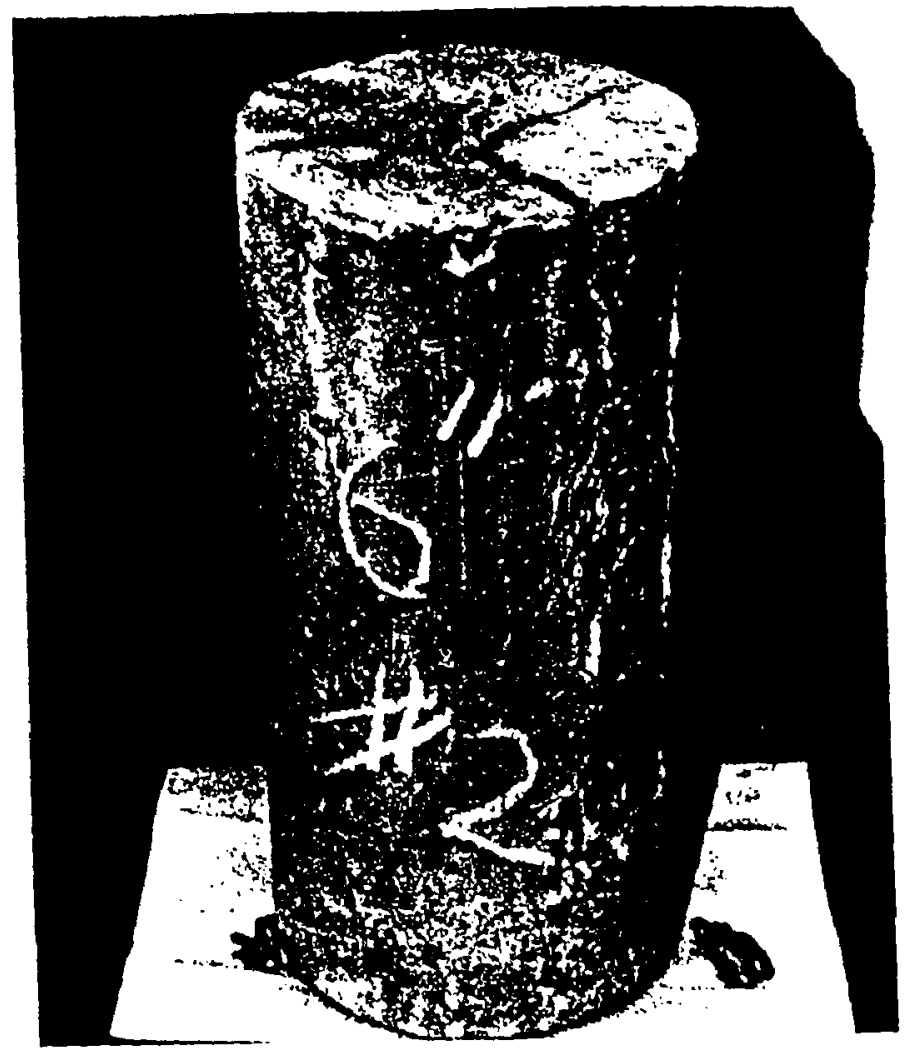

Figure 4.26 Straight pull-out failure of cylinder with 6 in. embedment length (\#4 sand coated) 


\section{CHAPTER 5}

\section{THEORETICAL CORRELATION OF EXPERIMENTAL RESULTS}

The material properties of higher strength concrete described in Chapter Three may affect the behavior of higher strength concrete beams reinforced with FRP rebars. In many cases, higher strength concrete beams may behave according to the rules that are similar to the ones that describe the behavior of beams made of lower strength concrete. However, some questions remain to be answered on the deflection behavior, ultimate load capacity, crack pattern, bond strength, and the modes of failure associated with the FRP reinforced high strength $(6-10 \mathrm{ksi})$ concrete beams.

In this chapter, emphasis is placed on the beam bending analysis and design using high strength ( $6-10 \mathrm{ksi})$ concretes reinforced with FRP rebars by modifying the state-of-the-art design as per ACI 318-89 code provisions that is applicable for steel reinforced beams. However, modifications (from current ACI code) for FRP reinforced beams in terms of ultimate moment capacity, deflection behavior, crack pattern and development length are made without deviating very much from the current design equation formats given by the $\mathrm{ACI} 318-89$ code..

\subsection{Ultimate Moment Capacity}

\subsubsection{Stress Distribution in compression zone}

The compressive stress distribution in concrete beams subjected to bending is directly related to the shape of the stress-strain curve of cylinders in uniaxial compression test. Due to the differences displayed in the shape of the stress-strain curve of higher strength concrete, and also due to the lower modulus of elasticity of FRP rebar which 
causes the neutral axis to shift closer towards the top compression fiber, differences in the flexural compressive stress distribution are expected to be different from concrete beam reinforced with steel rods.

The nominal resisting moment of a concrete beam may be calculated if the internal tensile and compressive forces, and their lever arm are known. For design purposes, it is convenient to work with an equivalent rectangular compressive stress distribution, shown in Figure 5.1. This uniform distribution is specifically referenced and permitted in the ACI 318-89 code for concrete reinforced with steel rods. With the uniform value of concrete compressive stress assumed equal to $0.85 f_{C}^{\prime}$, a single parameter $\beta_{1}$ is sufficient to define both the magnitude and line of action.

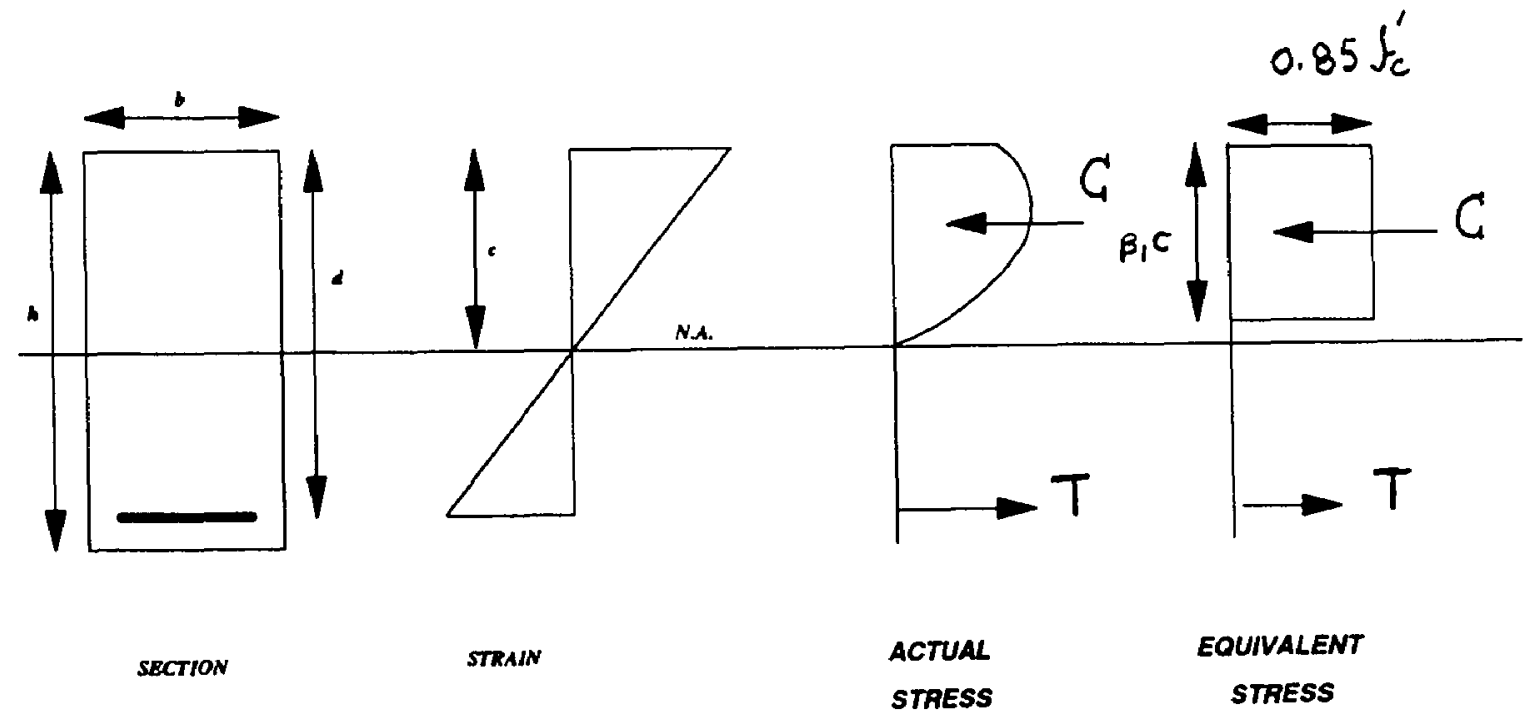

Figure 5.1 Equivalent rectangular stress distribution

(Whitney's Method)

However, for high strength concrete $(6-10 \mathrm{ksi})$, the stress-strain curve is more linear than parabolic, which leads us to believe that the stress distribution may be 
significantly different from those of lower strength concretes. Alternatives to the rectangular stress block have been proposed, such as those in Figures 5.2 and 5.3. The ACI 318-89 code specifies that the relationship between the concrete compressive stress distribution and the concrete strain may be assumed as a rectangular, trapezoidal, parabolic, or any other shape that results in an accurate strength prediction.

In the following subsections, the methodology of different stress distributions is investigated and the analysis of the beams tested using the parabolic distribution methodology is outlined.

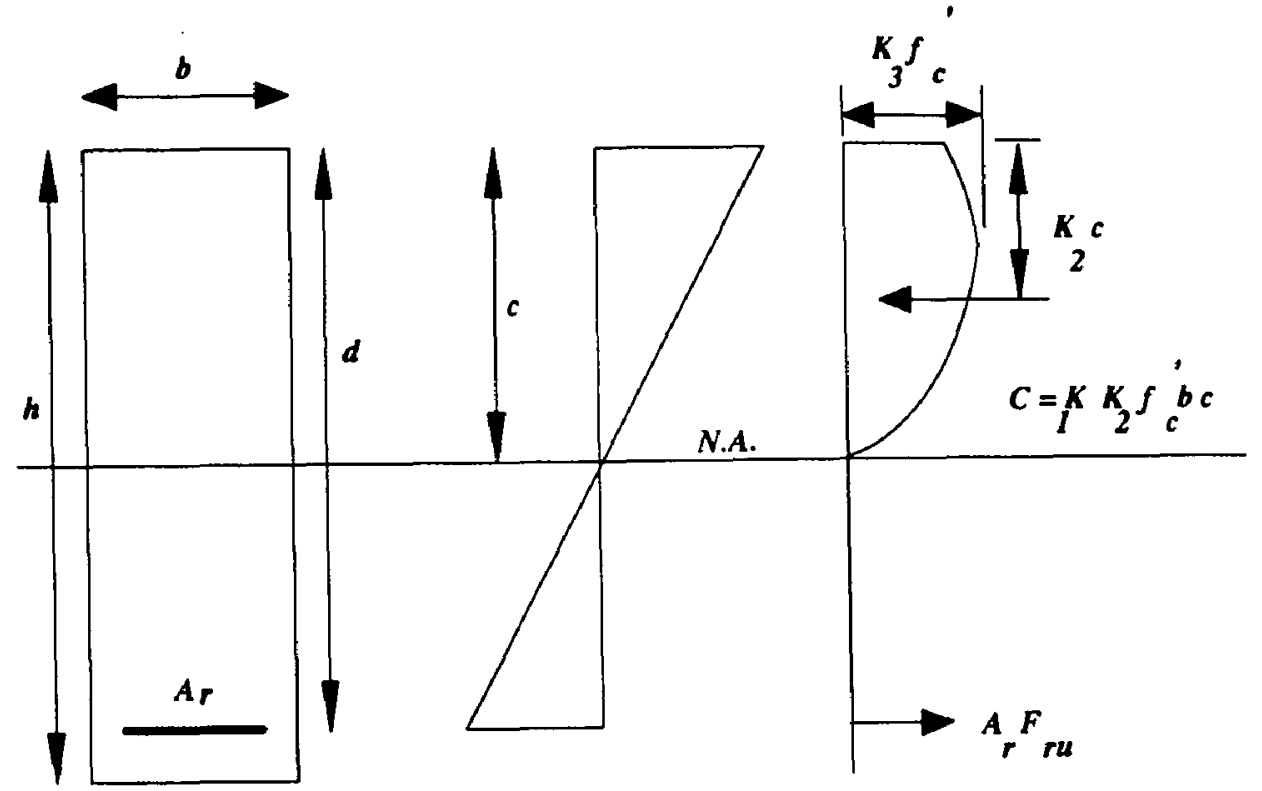

SECTION

STRAIN

STRESS

$k_{1}, k_{2}, k_{3}=$ constants, $F_{r u}=$ Ultimate reinforcement stress, $A_{r}=$ Area of reinforcement

Figure 5.2 Parabolic Stress Distribution (Kaar, Hanson, and Capell, 1975) 


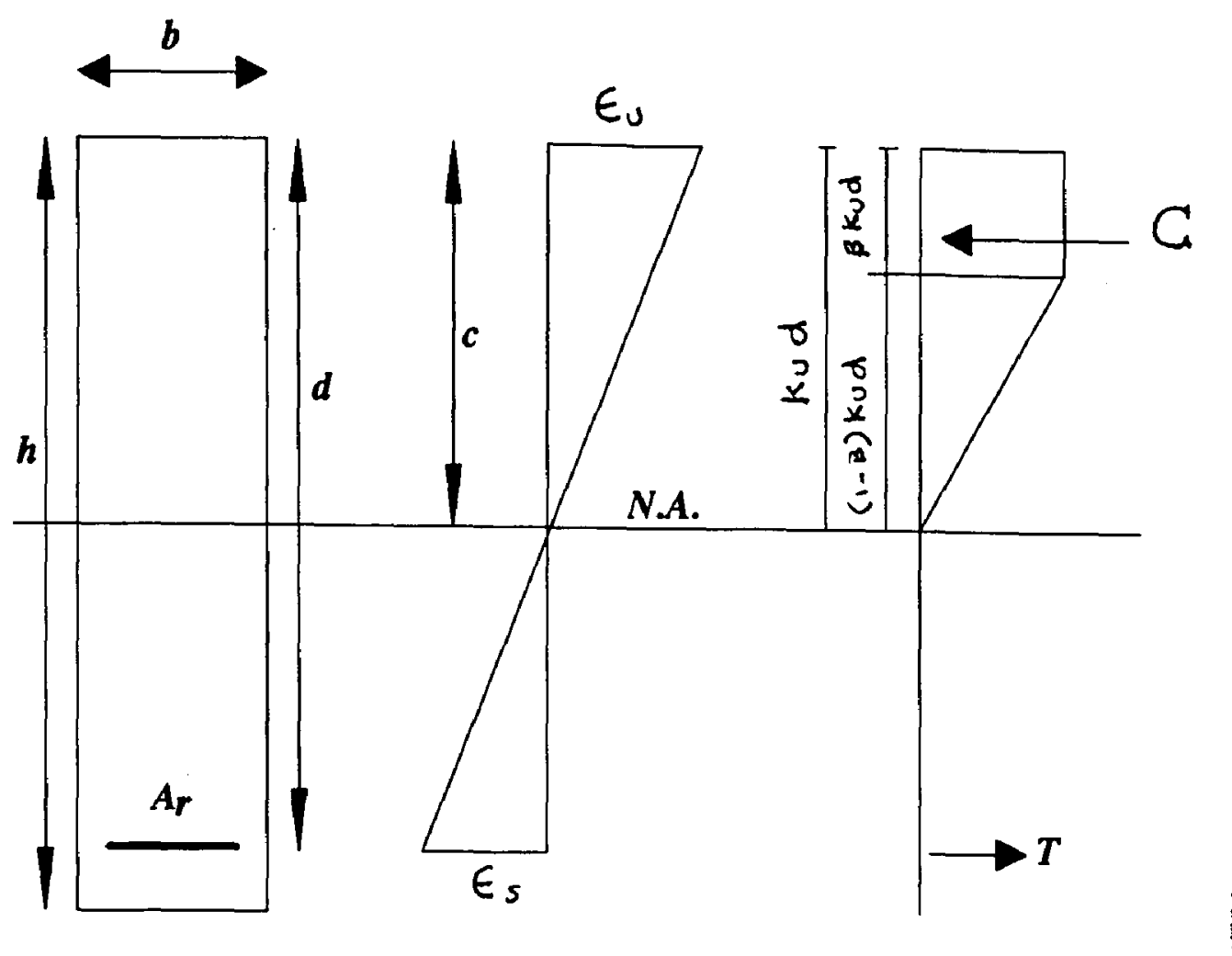

SECTION

$$
\begin{gathered}
k_{2}, k_{\mathrm{u}}=\text { constants } \\
\varepsilon_{\mathrm{u}}=\text { Ultimate strain in concrete } \\
\varepsilon_{\mathrm{S}}=\text { Strain in reinforcement }
\end{gathered}
$$

Figure 5.3 Jensen's trapezoidal distribution 


\subsubsection{Rectangular Stress Distribution}

The ACI 318-89 rectangular stress distribution as shown in Figure 5.2 is defined as follows:

" Concrete stress of $0.85 f_{C}^{\prime}$ shall be assumed uniformly distributed over an equivalent compressive zone bounded by edges of the cross section and a straight line located parallel to the neutral axis at a distance $a=\beta_{1}$ from the fiber of maximum compressive strain. Distance $c$ from fiber of maximum strain to the neutral axis shall be measured in a direction perpendicular to that axis. Factor $\beta_{1}$ shall be taken as 0.85 for concrete strengths $f_{C}^{\prime}$ up to and including 4000 psi. For strengths above $4000 \mathrm{psi}, \beta_{1}$ shall be reduced continuously at a rate of 0.05 for each 1000 psi of strength in excess of 4000 psi, but $\beta_{l}$ shall not be taken less than 0.65."

ACI 318-89 suggests (based on an equivalent rectangular stress block) that the nominal flexural strength of singly reinforced beams that are under-reinforced can be calculated by;

$$
M_{n}=A_{s} f_{y} d\left(1-0.585 \rho \frac{f_{y}}{f_{c}^{\prime}}\right) \ldots \ldots \ldots \ldots .(5.1)
$$

where,

$$
\begin{aligned}
& M_{n}=\text { nominal moment strength of a section, in.lb } \\
& A_{s}=\text { area of tension reinforcement, in }{ }^{2} \\
& f_{y}=\text { specific yield strength of reinforcement, psi }
\end{aligned}
$$


$d$ = distance from extreme compression fiber to centroid of tension reinforcement, in

$\rho=$ ratio of tension reinforcement $=A_{\mathcal{S}} / b d$

$f_{C}{ }^{\prime}=$ specified compressive strength of concrete, psi

$b=$ width of concrete section.

For under-reinforced beams, the present ACI 318 method can be used without change for concrete strengths up to 12,000 psi.

\subsubsection{Parabolic Stress Distribution}

The rectangular stress distribution is an excellent approximation of the actual stress distribution for regular strength concretes. However, due to the differences displayed in the shape of the stress-strain curve of high strength $(6-10 \mathrm{ksi})$ concretes, and due to the low modulus of elasticity exhibited by the FRP rebar, it is appropriate to investigate the actual compressive stress distribution using the flexural constants outlined by Kaar, Hanson, and Capell (1975), in their study of the stress-strain characteristics of high strength concrete.

The three stress-block properties defined by Kaar, Hanson, and Capell (1975), $k_{1} k_{3}, \frac{k_{2}}{k_{1} k_{3}}$, and $\varepsilon_{u}$, needed for strength design are given as a function of concrete strength. Using the parabolic distribution, the nominal strength of singly reinforced beams that are under-reinforced can be calculated by:

$$
M_{n}=A_{s} f_{y} d\left(1-\frac{k_{2}}{k_{1} k_{3}} \rho \frac{f_{y}}{f_{c}}\right)
$$


in which the value of $\frac{k_{2}}{k_{1} k_{3}}$ is substituted for the value of 0.585 in the rectangular stress distribution. The values of $\frac{k_{2}}{k_{l} k_{3}}$ are summarized in Table 5.1 for different concrete strengths used in this study.

Table 5.1 Flexural parameters

\begin{tabular}{|c|c|}
\hline $\begin{array}{c}\text { CONCRETE } \\
\text { COMPRESSIVE } \\
\text { STRENGTH } \\
\text { (pSi) }\end{array}$ & $\frac{k_{2}}{k_{1} k_{3}}$ \\
\hline 4000 & 0.58 \\
\hline 5000 & 0.59 \\
\hline & \\
\hline 6500 & 0.62 \\
\hline & \\
\hline 7500 & 0.62 \\
\hline & \\
\hline
\end{tabular}

After investigating the calculated ultimate moment capacity based on the rectangular stress distribution (equation 5.1) and the parabolic distribution (equation 5.2), we concluded that there is negligible difference between the two distribution procedures. It is therefore safe to assume that the rectangular stress distribution approximation gives excellent results and will be used throughout this study. 


\subsubsection{Ultimate Moment}

The phenomenon of developing moment resistance in FRP reinforced beams is identical to that of beams reinforced with steel rods, i.e., the ultimate moment capacity of FRP reinforced concrete beams can be obtained by satisfying internal force and moment equilibrium equation (Figure 5.1). The ultimate resisting moment based on the equilibrium equation (equation 5.1) is applied for FRP reinforced concrete beams as shown in equation 5.3, in which the yield stress of steel is substituted with the effective yield stress expression of FRP rebars. The validity of this equation is substantiated through the experimental results outlined in Chapter 4. However, a designer has to check for bond capacity of the FRP reinforced beams as well as the sudden crack formation and growth. It should be noted that modes of failure due to bond, shear and compression must be avoided to attain full bending resistance.

$$
\left.M_{n}=A_{f} f_{y f} d\left(1-0.585 \rho \frac{f_{y f}}{f_{c}^{\prime}}\right) \ldots \ldots \ldots . \ldots \ldots .3\right)
$$

where,

$A_{f}=$ Area of FRP rebars in tension, in 2

$f_{y f}=$ Effective tensile strength of the FRP rebars, psi.

in which $f_{y f}=0.85 f_{f}$ ( rupture failure) in order to account for the current variation in manufacturing and quality control of the FRP rebars.

Previous research on FRP rebars as reinforcement for concrete by Nawy and Newerth (1975) showed that in most cases it was not possible for the FRP rebars to develop their full strength due to high tensile strength associated with these rebars. In order to take advantage of the high tensile strength of the rebars, beams with high 


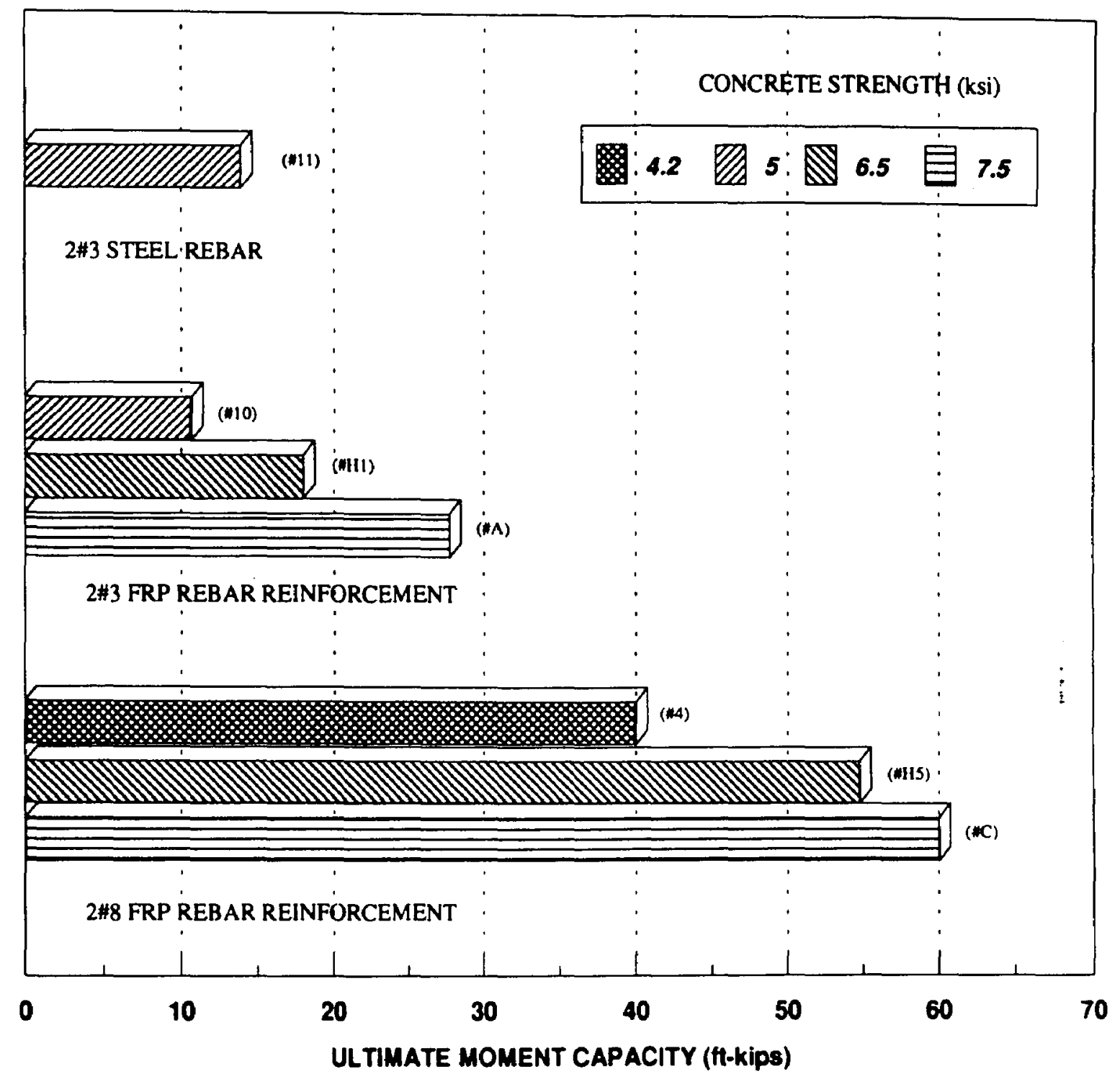

Figure 5.5 Effect of varying concrete strength on ultimate moment capacity

Theoretical ultimate moment capacities of the concrete beams reinforced with FRP rebars are compared with the observed experimental values in Table 5.2. 
strength concretes (6000 - $10000 \mathrm{psi})$ were tested in this research effort to maximize the bending resistance of the beams (outlined in Chapter 4). A $90 \%$ increase in the ultimate moment capacity was obtained when the tensile stress of the FRP rebars reached over $100 \mathrm{ksi}$ at the time of crushing of concrete in the compression zone. In addition, the cracking moment of the high strength concrete beams increased and a substantial decrease in the cracking width was noted. The effects of increasing the concrete strength is clearly shown in the load versus FRP reinforcement strain plot in Figure 5.4, and the bar chart of the moment capacity in Figure 5.5.

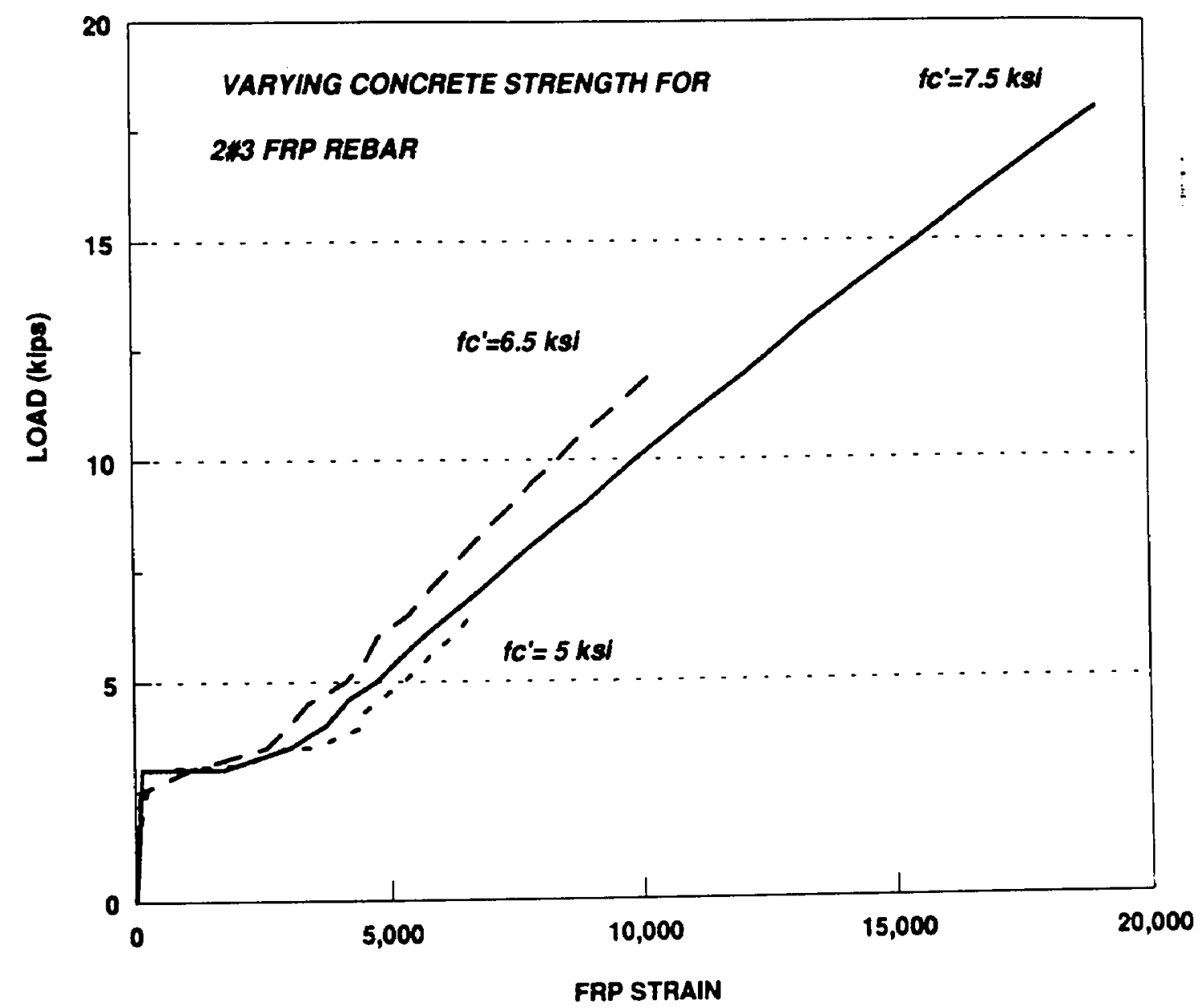

Figure 5.4 Load versus FRP strain with varying concrete strength 
Table 5.2 Theoretical versus experimental moment evaluations

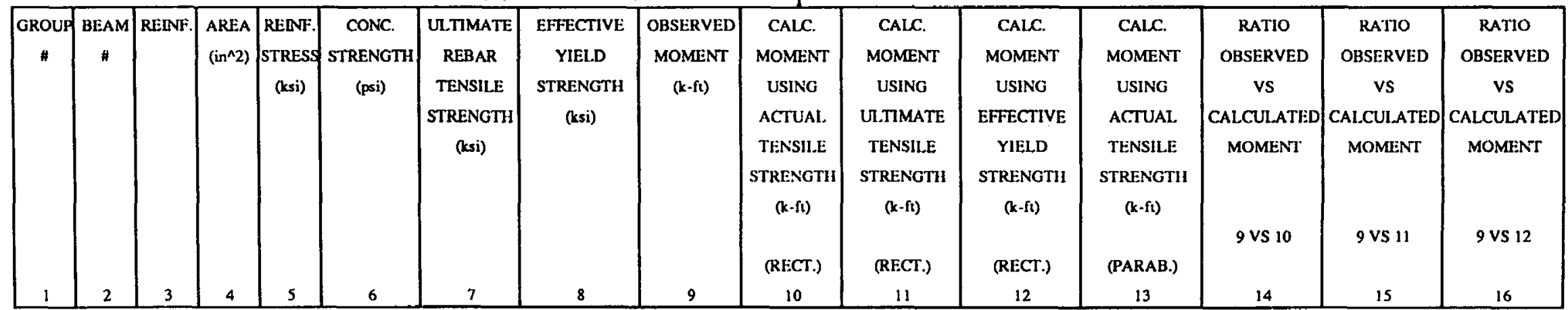

\begin{tabular}{|c|c|c|c|c|c|c|c|c|c|c|c|c|c|c|c|}
\hline A & 2 & $3 \# 3$ & 0.33 & 102 & 4200 & 130.00 & 110.50 & 27.75 & 28.09 & 35.80 & 30.43 & 28.12 & 0.99 & 0.78 & 0.91 \\
\hline $\mathrm{A}$ & 3 & $3 \# 3$ & 0.33 & 76 & 4200 & 90.00 & 76.50 & 24.67 & 21.26 & 25.29 & 21.49 & 21.28 & 1.16 & 0.98 & 1.15 \\
\hline$A$ & $\mathrm{VH} 4$ & $6 \# 2$ & 0.30 & 85 & 10000 & 130.00 & 110.50 & 31.50 & 22.92 & 34.93 & 29.69 & 22.89 & 1.37 & 0.90 & 1.06 \\
\hline $\mathrm{A}$ & VH5 & $3 \# 3$ & 0.33 & 72 & 10000 & 130.00 & 110.50 & 21.00 & 20.79 & 37.78 & 32.12 & 20.77 & 1.01 & 0.56 & 0.65 \\
\hline B & 5 & $2 \# 4$ & 0.39 & 84 & 4200 & 80.00 & 68.00 & 27.75 & 27.28 & 25.96 & 22.07 & 27.31 & 1.02 & 1.07 & 1.26 \\
\hline B & 6 & $2 \# 4$ & 0.39 & 69 & 4200 & 80.00 & 68.00 & 24.67 & 22.54 & 26.33 & 22.38 & 22.56 & 1.09 & 0.94 & 1.10 \\
\hline B & 7 & $2 \# 4$ & 0.39 & 72 & 5000 & 80.00 & 68.00 & 16.96 & 23.80 & 26.52 & 22.54 & 23.80 & 0.71 & 0.64 & 0.75 \\
\hline $\mathrm{C}$ & 1 & $2 \# 7$ & 1.20 & 15 & 4200 & 86.00 & 73.10 & 16.50 & 15.58 & 87.02 & 73.97 & 15.59 & 1.06 & 0.19 & 0.22 \\
\hline $\mathrm{C}$ & 4 & $2 \# 8$ & 1.57 & 45 & 4200 & 80.00 & 68.00 & 40.00 & 52.32 & 92.55 & 78.67 & 52.45 & 0.76 & 0.43 & 0.51 \\
\hline C & 8 & $2 \# 7$ & 1.20 & 0 & 5000 & 80.00 & 68.00 & 41.63 & 0.00 & 84.40 & 71.74 & & & 0.49 & 0.58 \\
\hline C & H5 & $2 \# 8$ & 1.56 & 47 & 6500 & 80.00 & 68.00 & 54.75 & 57.72 & 97.63 & 82.98 & 57.35 & 0.95 & 0.56 & 0.66 \\
\hline C & $\mathrm{C}$ & $2 \# 8$ & 1.56 & 43 & 6500 & 80.00 & 68.00 & 60.00 & 52.91 & 98.71 & 83.90 & 52.60 & 1.13 & 0.61 & 0.72 \\
\hline D & 9 & $2 \# 3$ & 0.22 & 76 & 5000 & 90.00 & 76.50 & 12.95 & 14.56 & 17.28 & 14.69 & 19.80 & 0.89 & 0.75 & 0.88 \\
\hline $\mathrm{D}$ & 10 & $2 \# 3$ & 0.22 & 43 & 5000 & 90.00 & 76.50 & 10.64 & 8.43 & 17.51 & 14.89 & 28.48 & 1.26 & 0.61 & 0.71 \\
\hline $\mathrm{D}$ & 11 & $2 \# 3 S$ & 0.22 & 70 & 5000 & 60.00 & 51.00 & 13.88 & 13.47 & 11.55 & 9.82 & 22.98 & 1.03 & 1.20 & 1.41 \\
\hline $\mathrm{D}$ & $\mathrm{H} 1$ & $2 \# 3$ & 0.22 & 72 & 6500 & 130.00 & 110.50 & 18.00 & 13.93 & 25.17 & 21.40 & 37.69 & 1.29 & 0.72 & 0.84 \\
\hline D & $\mathrm{H6}$ & $2 \# 3$ & 0.22 & 70 & 6500 & 130.00 & 110.50 & 16.50 & 13.49 & 25.19 & 21.41 & 35.71 & 1.22 & 0.66 & 0.77 \\
\hline $\mathrm{D}$ & $\mathrm{A}$ & $2 \# 3$ & 0.22 & 133 & 7500 & 130.00 & 110.50 & 27.75 & 25.45 & 24.83 & 21.10 & 36.21 & 1.09 & 1.12 & 1.31 \\
\hline
\end{tabular}




\begin{tabular}{|c|c|c|c|c|c|c|c|c|c|c|c|c|c|c|c|}
\hline $\begin{array}{c}\text { GROUP } \\
\#\end{array}$ & $\begin{array}{c}\text { BEAM } \\
\#\end{array}$ & REINF. & $\begin{array}{r}\text { AREA } \\
\left(\mathrm{in}^{\wedge} 2\right) \\
\end{array}$ & $\begin{array}{c}\text { REINF. } \\
\text { STRESS } \\
(\mathrm{ksi})\end{array}$ & $\begin{array}{c}\text { CONC. } \\
\text { STRENGTH } \\
\text { (psi) }\end{array}$ & $\begin{array}{c}\text { ULTIMATE } \\
\text { REBAR } \\
\text { TENSILE } \\
\text { STRENGTH } \\
\text { (ksi) }\end{array}$ & $\begin{array}{l}\text { EFFECTIVE } \\
\text { YIELD } \\
\text { STRENGTH } \\
\text { (ksi) }\end{array}$ & $\begin{array}{c}\text { OBSERVED } \\
\text { MOMENT } \\
(\mathbf{k}-\mathrm{ft})\end{array}$ & $\begin{array}{c}\text { CAIC. } \\
\text { MOMENT } \\
\text { USING } \\
\text { ACTUAL. } \\
\text { TENSILE } \\
\text { STRENGTH } \\
\text { (k-fi) } \\
\\
\text { (RECT.) } \\
10 \\
\end{array}$ & $\begin{array}{c}\text { CALC. } \\
\text { MOMINT } \\
\text { USING } \\
\text { ULTIMATE } \\
\text { TENSILE } \\
\text { STRENGTH } \\
\text { (k-ft) } \\
\text { (RECT.) } \\
11\end{array}$ & $\begin{array}{c}\text { CALC. } \\
\text { MOMENT } \\
\text { USING } \\
\text { EFFECTIVE } \\
\text { YIELD } \\
\text { STRENGTH } \\
\text { (k-ft) } \\
\text { (RECT.) } \\
12\end{array}$ & $\begin{array}{c}\text { CALC. } \\
\text { MOMENT } \\
\text { USING } \\
\text { ACTUAL } \\
\text { TENSILE } \\
\text { STRENGTH } \\
\text { (k-ft) } \\
\text { (PARAB.) } \\
13 \\
\end{array}$ & $\begin{array}{c}\text { RATIO } \\
\text { OBSERVED } \\
\text { VS } \\
\text { CALCULATED } \\
\text { MOMENT }\end{array}$ & $\begin{array}{c}\text { RATIO } \\
\text { OBSERVED } \\
\text { VS } \\
\text { CAI.CUL_ATED } \\
\text { MOMENT }\end{array}$ & $\begin{array}{c}\text { RATIO } \\
\text { OBSERVED } \\
\text { VS } \\
\text { CALCULATED } \\
\text { MOMENT }\end{array}$ \\
\hline D & B & $2 \# 3$ & 0.44 & 127 & 7500 & 130.00 & 110.50 & 43.50 & 46.92 & 48.00 & 40.80 & 29.76 & 0.93 & 0.91 & 1.07 \\
\hline$E$ & $\mathrm{H} 2$ & $3 \# 4$ & 0.59 & 41 & 6500 & 107.00 & 90.95 & 31.13 & 20.98 & 54.63 & 46.44 & 42.57 & 1.48 & 0.57 & 0.67 \\
\hline$E$ & $\mathrm{H} 4$ & $5 \# 3$ & 0.55 & 79 & 6500 & 130.00 & 110.50 & 37.50 & 36.65 & 60.45 & 51.39 & 28.68 & 1.02 & 0.62 & 0.73 \\
\hline $\mathrm{E}$ & D & 3\#4 & 0.59 & 99 & 7500 & 107.00 & 90.95 & 40.50 & 48.51 & 52.55 & 44.66 & 48.31 & 0.83 & 0.77 & 0.91 \\
\hline$E$ & $E$ & $5 \# 3$ & 0.55 & 100 & 7500 & 130.00 & 110.50 & 40.50 & 46.22 & 60.06 & 51.05 & 46.04 & 0.88 & 0.67 & 0.79 \\
\hline$E$ & $\mathrm{~F}$ & $3 \# 4$ & 0.59 & 122 & 7500 & 107.00 & 90.95 & 34.50 & 58.94 & 51.59 & 43.86 & 58.64 & 0.59 & 0.67 & 0.79 \\
\hline$E$ & $\mathrm{VHI}$ & $3 \# 4$ & 0.59 & 110 & 10000 & 107.00 & 90.95 & 40.95 & 54.72 & 53.21 & 45.22 & 54.53 & 0.75 & 0.77 & 0.91 \\
\hline $\mathrm{E}$ & $\mathrm{VH} 2$ & $3 \# 4$ & 0.59 & 102 & 10000 & 107.00 & 90.95 & 43.50 & 50.81 & 53.46 & 45.44 & 50.65 & 0.86 & 0.81 & 0.96 \\
\hline$E$ & $\mathrm{VH} 3$ & $3 \# 4 S$ & 0.59 & 60 & 10000 & 60.00 & 51.00 & 24.38 & 30.69 & 30.69 & 26.09 & 30.63 & 0.79 & 0.79 & 0.93 \\
\hline
\end{tabular}


A brief description of columns 1 to 16 of Table 5.2 is given below.

(1) Group Number

(2) Beam Number

(3) Tension reinforcement and type

(4) Area of the FRP reinforcement (in ${ }^{2}$ )

(5) Ultimate tensile strength measured in the FRP rebar (ksi)

(6) Concrete compressive strength of companion cylinders at 28 days (psi)

(7) Experimental tensile strength (rupture) of the FRP rebar as obtained by Wu in the tension tests $(\mathrm{ksi})$

(8) Effective yield tensile strength $\left(f_{y f}=0.85 \times f_{\text {rupture }}\right)$ of the FRP rebar (ksi)

(9) Observed (experimental) ultimate moment capacity of the tested beams, $M_{n}=P \times L / 3,(K-f t)$

(10) Calculated moment capacity using recorded ultimate stress in the rebars, utilizing equation (5.1), (K-ft)

(11) Calculated ultimate moment capacity using ultimate (rupture) stress values of the rebars, utilizing equation (5.1), (K-ft)

(12) Calculated ultimate moment capacity using effective yield stress values of the rebars, utilizing equation (5.1), (K-ft)

(13) Calculated moment capacity using the actual stress distribution developed in equation (5.2), $(\mathrm{k}-\mathrm{ft})$ 
(14) Ratio of observed ultimate moment capacity to calculated moment capacity using the actual stress values of the rebars

(15) Ratio of observed ultimate moment capacity to calculated moment capacity using the ultimate tensile strength of the rebars

(16) Ratio of observed ultimate moment capacity to calculated moment capacity using the effective yield strength of the rebars.

In column \#14, the ratio of the experimental ultimate moment capacity to the theoretical ultimate moment capacity in most beams was close to or over 1.00 , with a mean value of 1.095 . In cases of beams $\# 7, \# 4, \# 9$, and $\# F$ (column 2 ), where the primary failure was either in bond between the rebar and concrete or in shear, their ultimate capacities are much lower than the theoretical predictions. The use of sand coated rebars with higher strength concrete as in beams \#VH1 and \#VH2 resulted in a nearly balanced failure of tension failure of rebars reaching to 100 and $110 \mathrm{ksi}$, which is immediately followed by the compression failure in concrete. 


\subsection{Flexural Cracking}

Various limitations on crack widths of steel reinforced beams have been proposed by different investigators (Halvorsen 1978). Excessive cracking is undesirable because it reduces stiffness, enhances the possibility of deterioration, and causes undesirable appearance. The ACI 318 code prescribes rules for the distribution of flexural reinforcement to control flexural cracking in concrete beams. Good detailing practice is also required to lead to adequate crack control.

Cracking is expected to occur when the induced tensile stress in the beam reaches the ultimate concrete tensile stress. The tensile stress in concrete is transferred to the reinforcing bar through bond forces developed between concrete and reinforcing bar. The tensile stress in concrete at the cracked section is relieved, becoming zero at the time the crack occur; however, the reinforcing bar must carry the tensile forces at that cracked section. The neutral axis position must shift upward at the cracked section in order to maintain equilibrium of forces at that section. Cracking will continue to take place between old cracks until the concrete stresses do not exceed the concrete tensile strength. New cracks will cease to occur because of one of the following reasons:

1) Excessive slip between the rebar and concrete.

2) Reduction in the distance between cracks to transfer sufficient stress to the concrete.

A number of equations have been proposed (Halvorsen 1987) for the prediction of crack widths in flexural members reinforced with steel. The ACI 224 committee report (1986) on control of cracking of steel reinforced concrete beams and the ACI 318-89 code reached to the following conclusions: 
1) The reinforcement stress is the most important variable.

2) The thickness of the concrete cover is an important variable, but not the only geometric consideration.

3) The area of concrete surrounding each reinforcing bar is also an important geometric variable.

4) The bar diameter is not a major variable.

5) The size of the bottom crack width is influenced by the amount of strain gradient from the level of the reinforcement to the tension face of the beam.

The committee concluded that the most probable maximum crack width can be predicted by the Gergely-Lutz expression. The maximum flexural crack width $\boldsymbol{W}_{\text {max }}$ according to Gergley-Lutz, can be expressed as :

$$
W_{\max }=0.076 \beta f_{s} \sqrt[3]{d_{c} A} \times 10^{-3}
$$

in which

$\beta=$ Ratio of distances to the neutral axis from the extreme tension fiber and from the centroid of the main reinforcement. A value of $\beta=1.20$ may be used to estimate the crack widths obtained in flexure.

$d_{c}=$ Thickness of cover measured to the center of the first layer of bars (in.).

$f_{s}=$ Maximum stress $(\mathrm{ksi})$ in the reinforcement at service load level with $0.6 f_{y}$ to be used if no computations are available. 
$\boldsymbol{A}=$ The effective tension area of concrete surrounding the principal reinforcement divided by the number of rebars. It is defined as having the same centroid as the reinforcement $\left(\mathrm{in}^{2}\right)$.

While the above expression can be used to predict the maximum crack width, the ACI 318-89 code prescribes rules for the distribution of flexural reinforcement to control flexural cracking in beams. Good detailing practice is required to lead to adequate crack control. The ACI 318 code specifies:

"When design yield strength $\boldsymbol{f}_{\boldsymbol{y}}$ for tension reinforcement (steel) exceeds 40,000 psi, cross sections of maximum positive and negative moment shall be so proportioned that the quantity $z$ given by

$$
z=f_{s} \sqrt[3]{d_{c} A}
$$

does not exceed 175 kips per inch for interior exposure and 145 kips per inch for exterior exposure."

Equation (5.5) will provide a distribution of the reinforcement bars that will reasonably control flexural cracking. The equation is written in a form emphasizing reinforcement details rather than crack width; yet it is based on the Gergely-Lutz expression (equation 5.4). The numerical limitations of $z$ are 175 and 145 kips per inch correspond to limiting crack widths of 0.016 and 0.013 in.

\subsubsection{Flexural Cracking in FRP Reinforced Beams}

In the first five concrete beams, outlined in Chapter 4, which were reinforced with regularly deformed FRP rebars using regular strength concrete (4000 psi), crack formation was sudden and propagated toward the compression zone soon after the concrete stress reached the tensile strength. The crack spacing was very close to the 
stirrup spacing, and crack formation was nearly on the stirrups which were at intervals of 6 in. This sudden propagation of cracks and wider crack width have decreased vastly when higher strength concretes (7500 psi) together with sand coated FRP rebars were employed in our test specimens. This may be attributed to improvement in bond strength between sand coated FRP rebar and concrete, leading to reduced primary crack spacing and in turn reduced crack widths. Another important observation in specimens tested with sand coated rebar and higher strength concrete is formation of finer cracks with smaller crack spacing. The crack patterns of beams reinforced with sand coated rebars resembled the crack patterns expected in beams reinforced with steel rebars, with shorter spacings at ultimate levels as shown in Figures 5.8 and 5.14.

Figure 5.6 illustrates the crack width measurements versus the measured stress level in the FRP reinforcement. The scatter in the crack width measurements is attributed to variability in major parameters:

1) Rebar bond strength

2) Concrete tensile strength

\section{3) Concrete cover}

4) Distribution of the reinforcement.

The crack pattern in beams reinforced with FRP rebars and the effect of changing the major parameters outlined above is illustrated by Figure 5.7 through Figure 5.15. The beams are grouped according to their reinforcement configurations to illustrate the crack patterns. 
Figure 5.6 FRP stress versus crack width

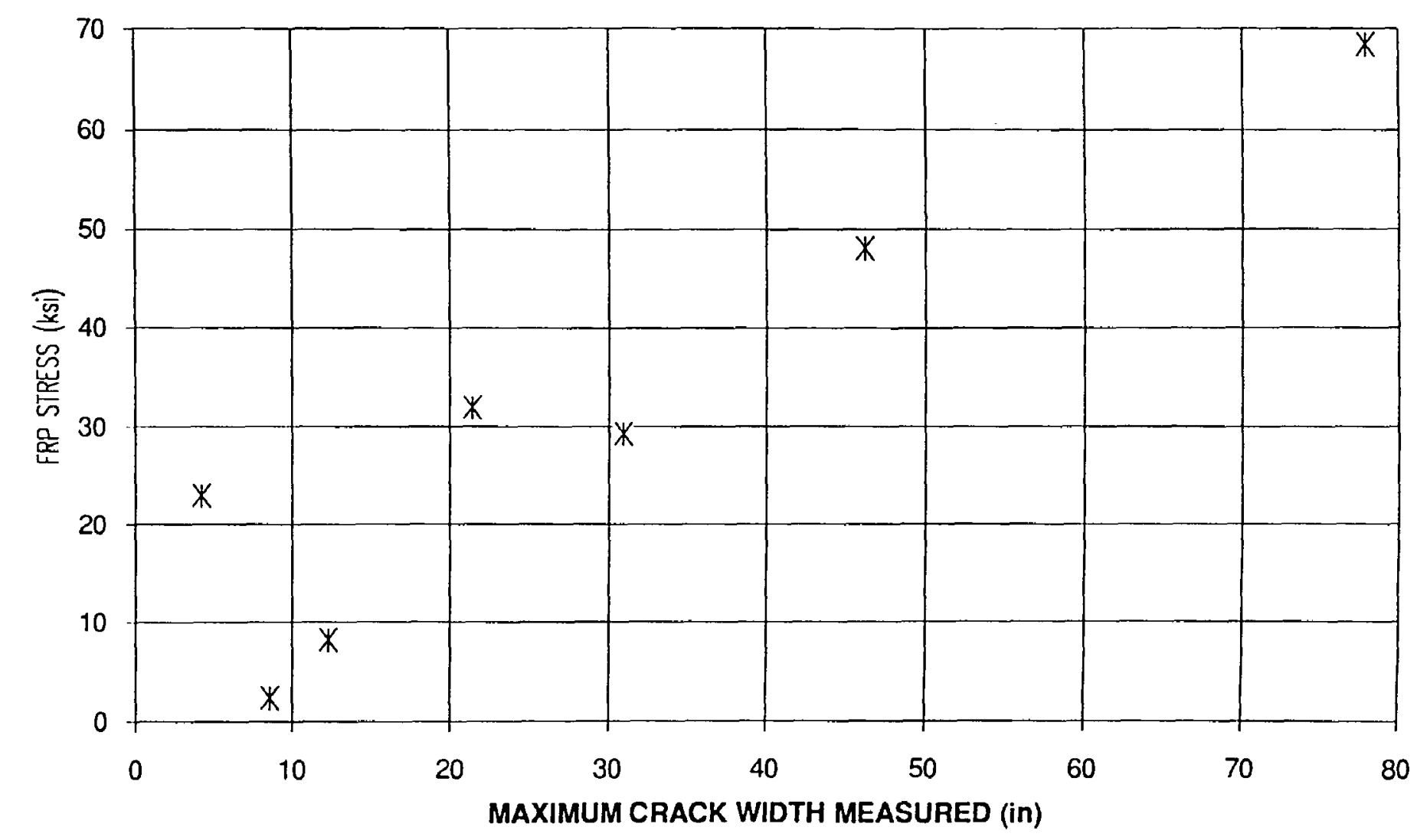



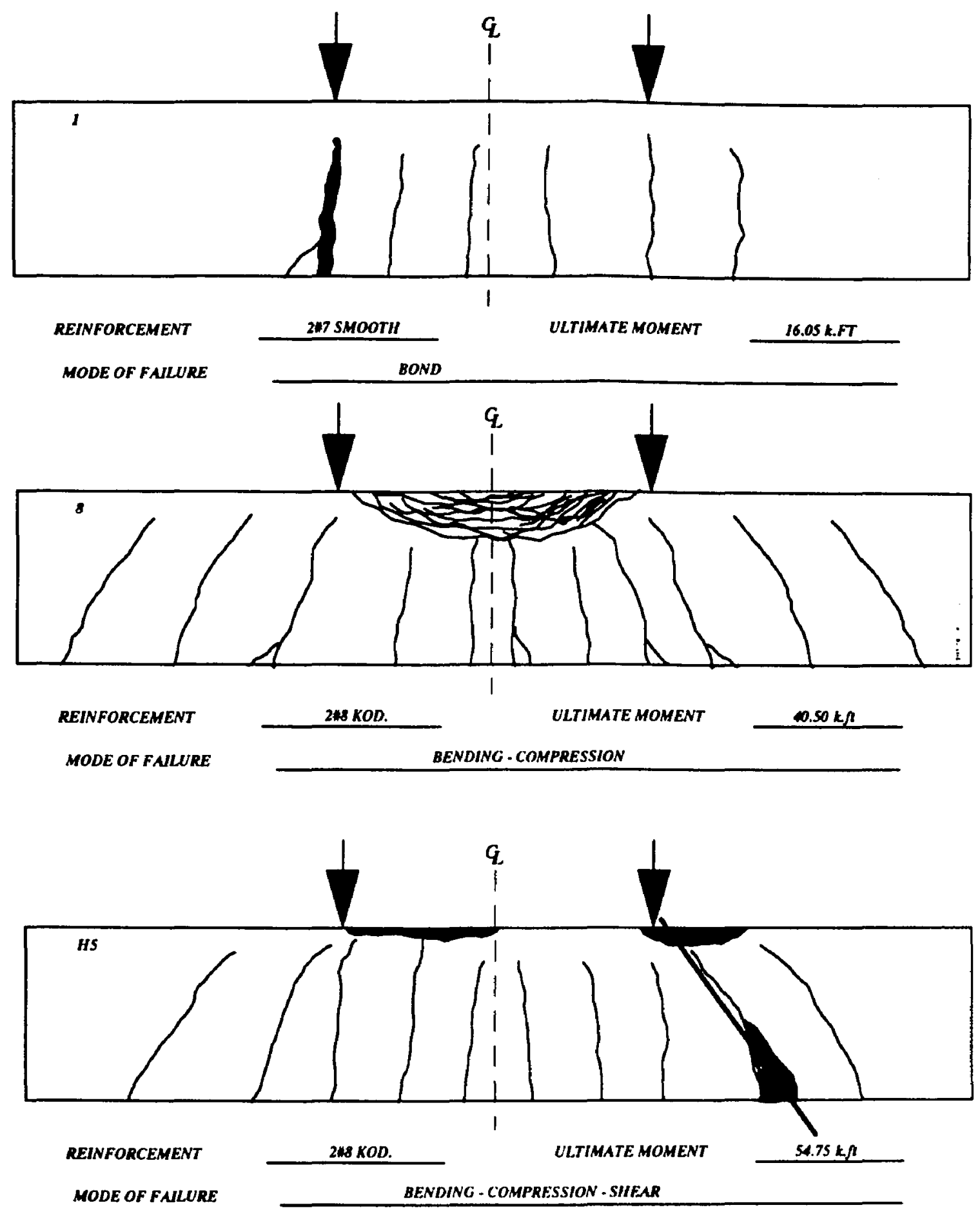

Note: Beams reinforced with smooth FRP versus regularly deformed FRP rebars, effect of increasing concrete strength lead to shear failure in beam \#H5.

Figure 5.7 Cracking Pattern Group C 


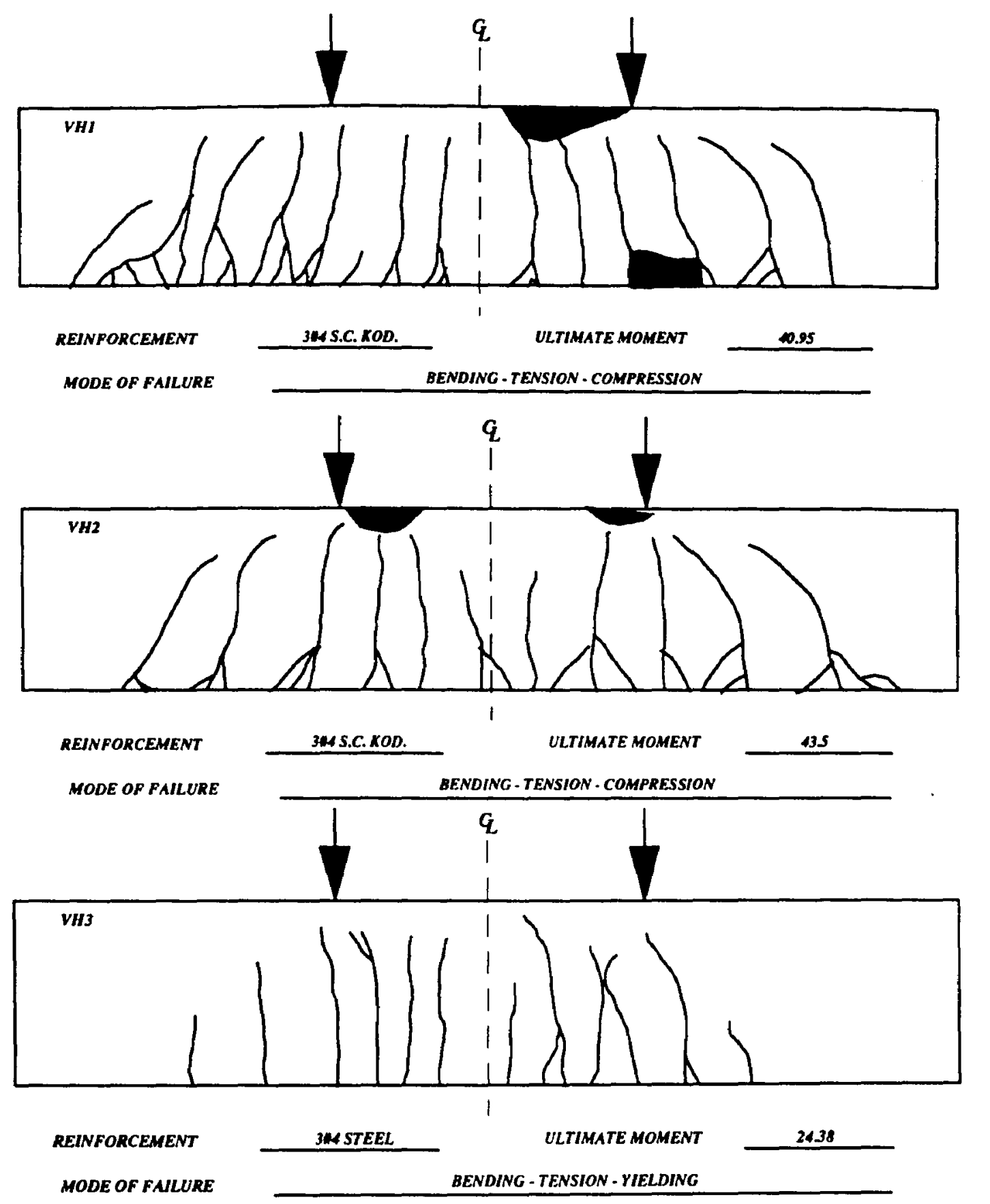

Note: A comparison between the beams reinforced with steel rebars and beams reinforced with FRP rebars using high strength concrete $(10,000 \mathrm{psi})$.

Figure 5.8 Cracking Pattem Group E 


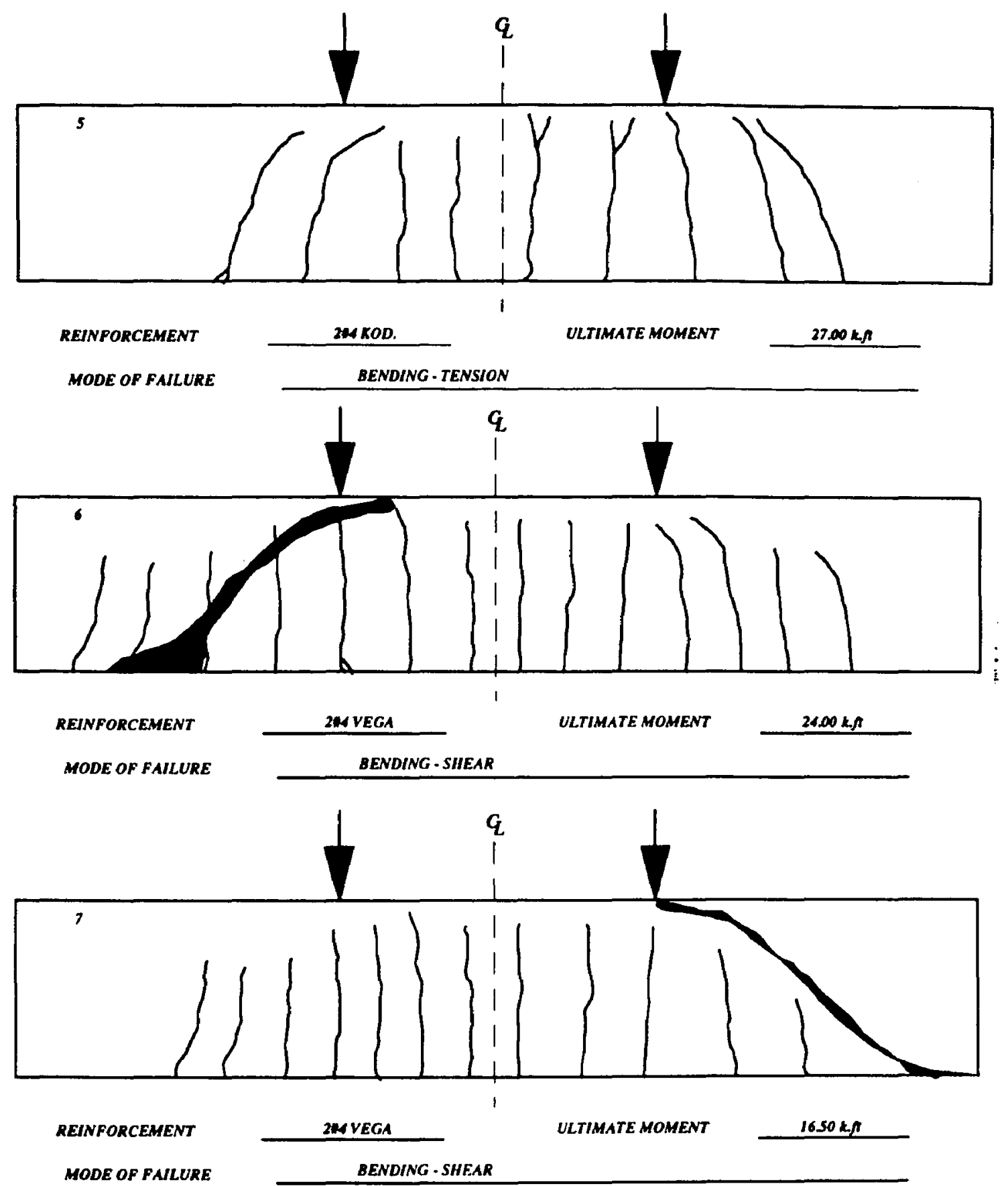

Note: Crack pattern of the beams reinforced with $2 \# 4$ rebars is shown above using regular strength concrete.

Figure 5.9 Cracking Pattern Group B 

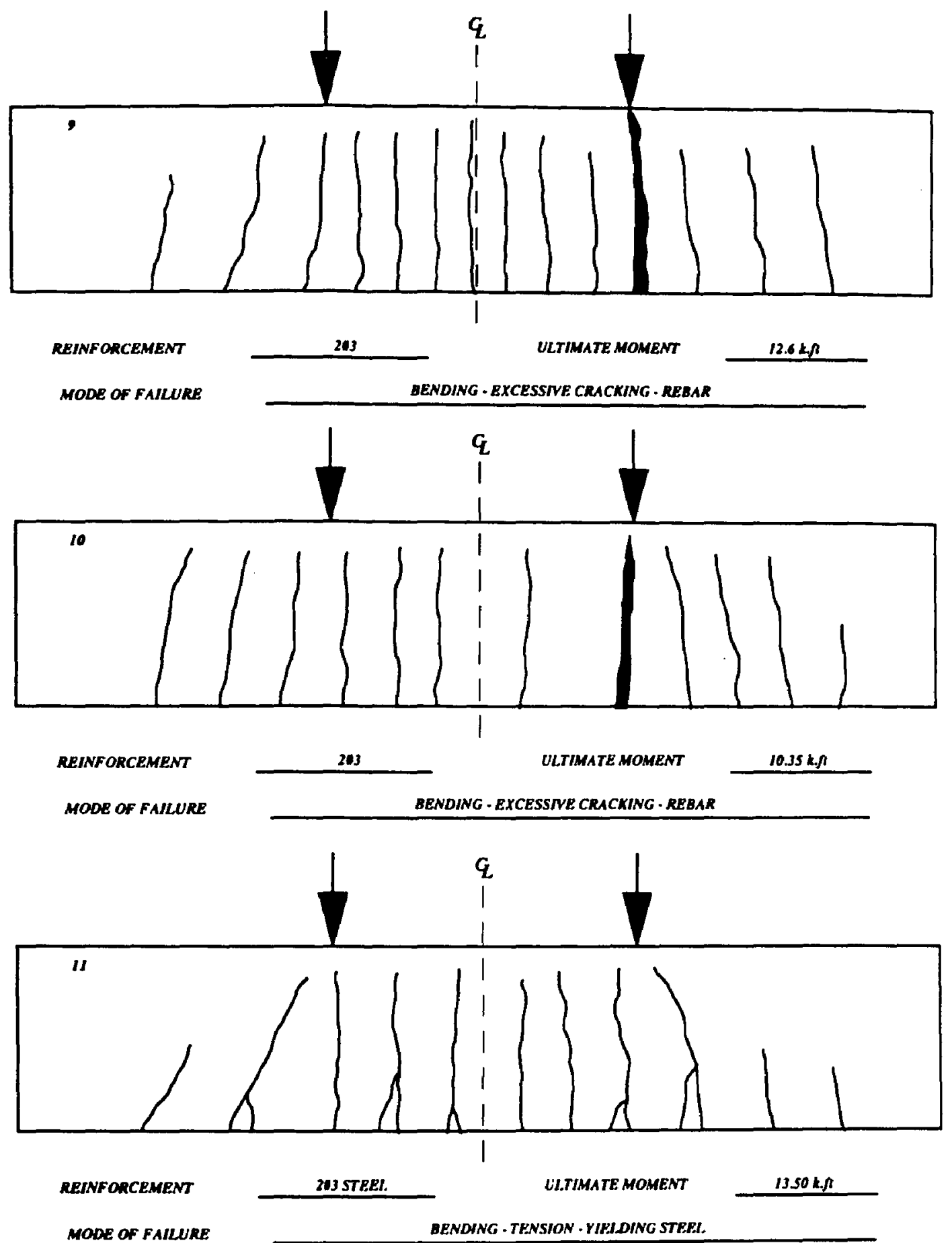

Note: Excessive cracking resulted in a premature failure of the beams reinforced with 2\#3 FRP rebars when compared with a similar beam reinforced with steel rebars using the same regular strength concrete.

Figure 5.10 Cracking Pattern Group D 


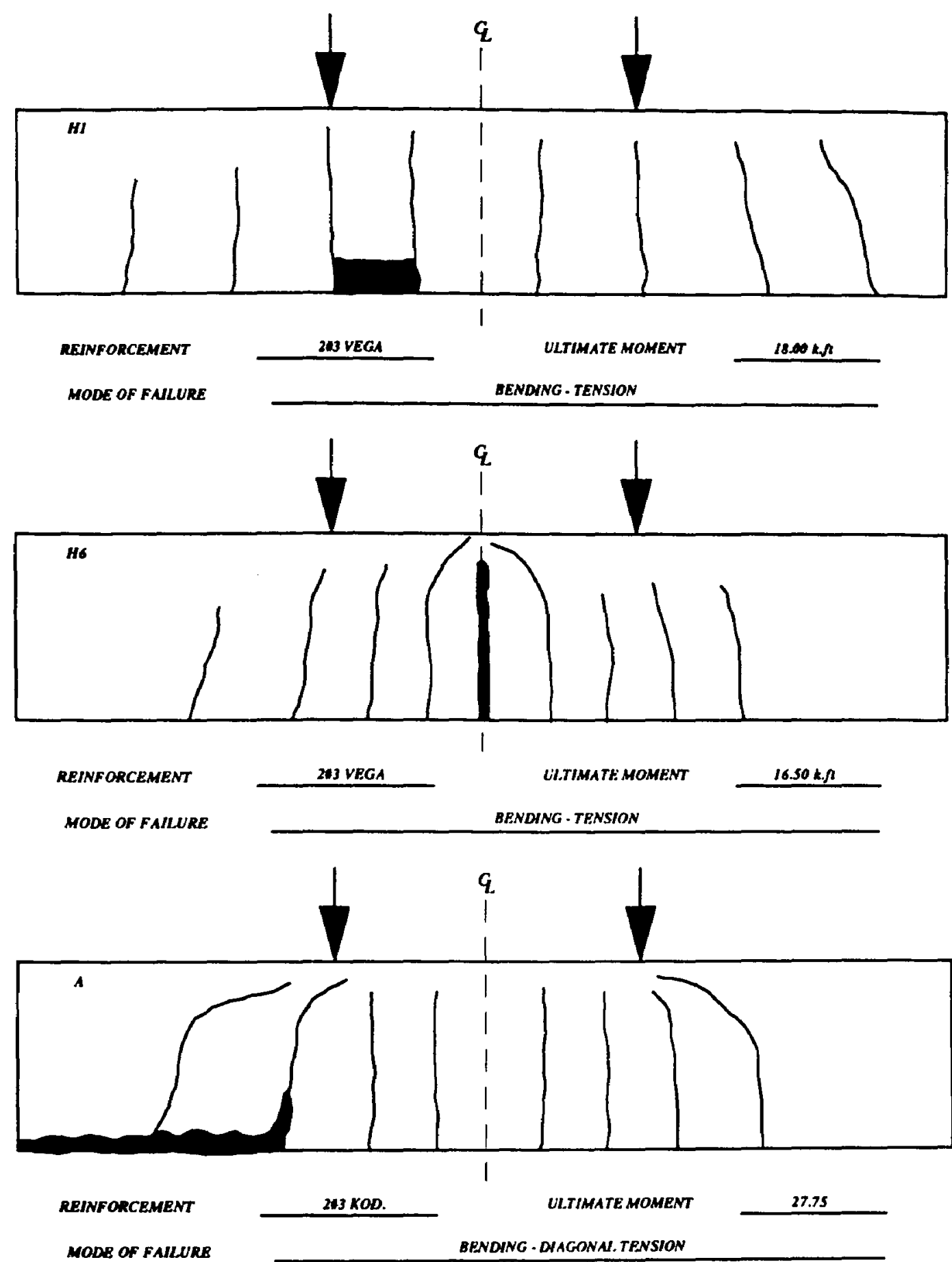

Note: The effect of using high strength concrete compared to the previous figure using regular strength concrete with all other parameters kept constant.

Figure 5.11 Cracking Pattern Group D (High Strength Concrete, 6 - $10 \mathrm{ksi}$ ) 

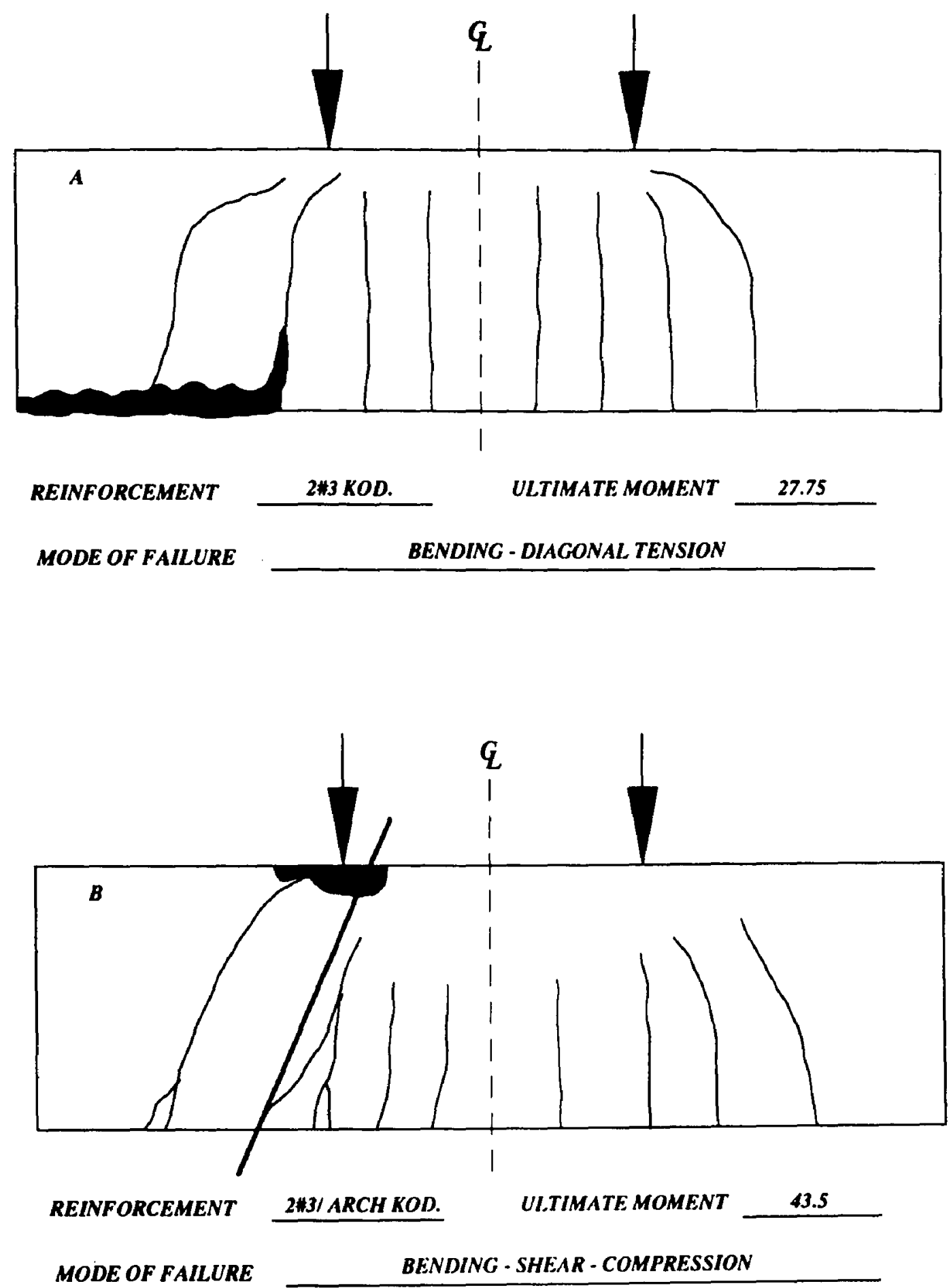

Note: Arch arrangement added to the $2 \# 3$ rebars in beam \#B, reduced and shortened the cracks as shown in the above figure.

Figure 5.12 Cracking Pattern with Arch Arrangement 


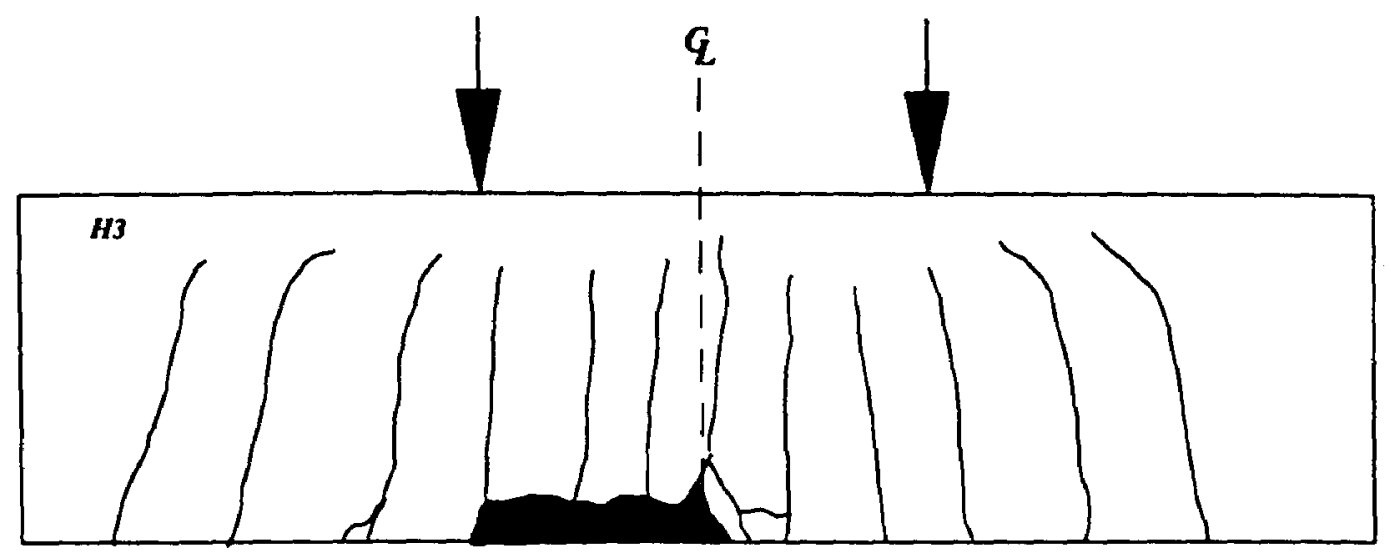

I

REINFORCEMENT

3:4 VEGA

ULTIMATE MOMENT

$31.13 \mathrm{k} \cdot \Omega$

MODE OF FAILURE

BENDING - TENSION

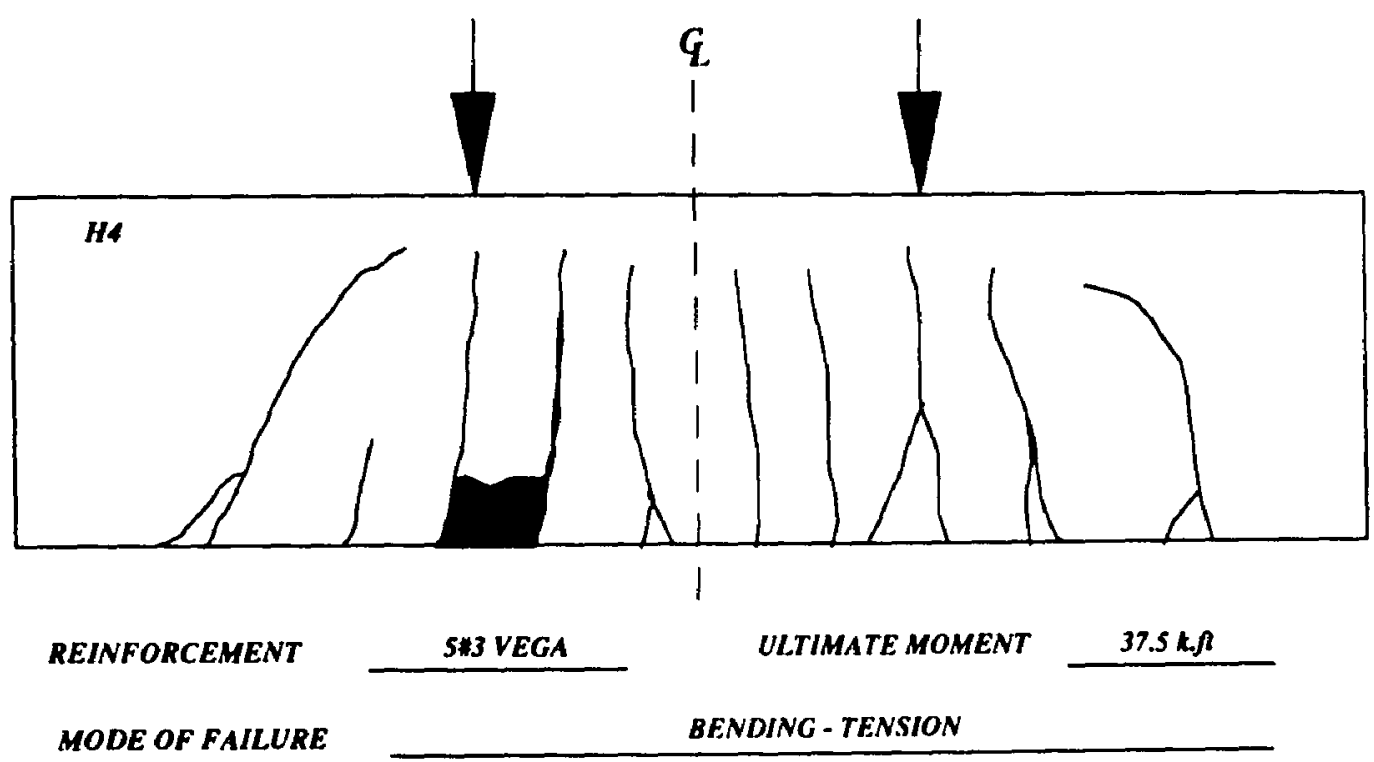

Note: The effect of increasing the perimeter of the reinforcement on the cracking of the beams

Figure 5.13 Cracking Pattern with Increase of Perimeter 


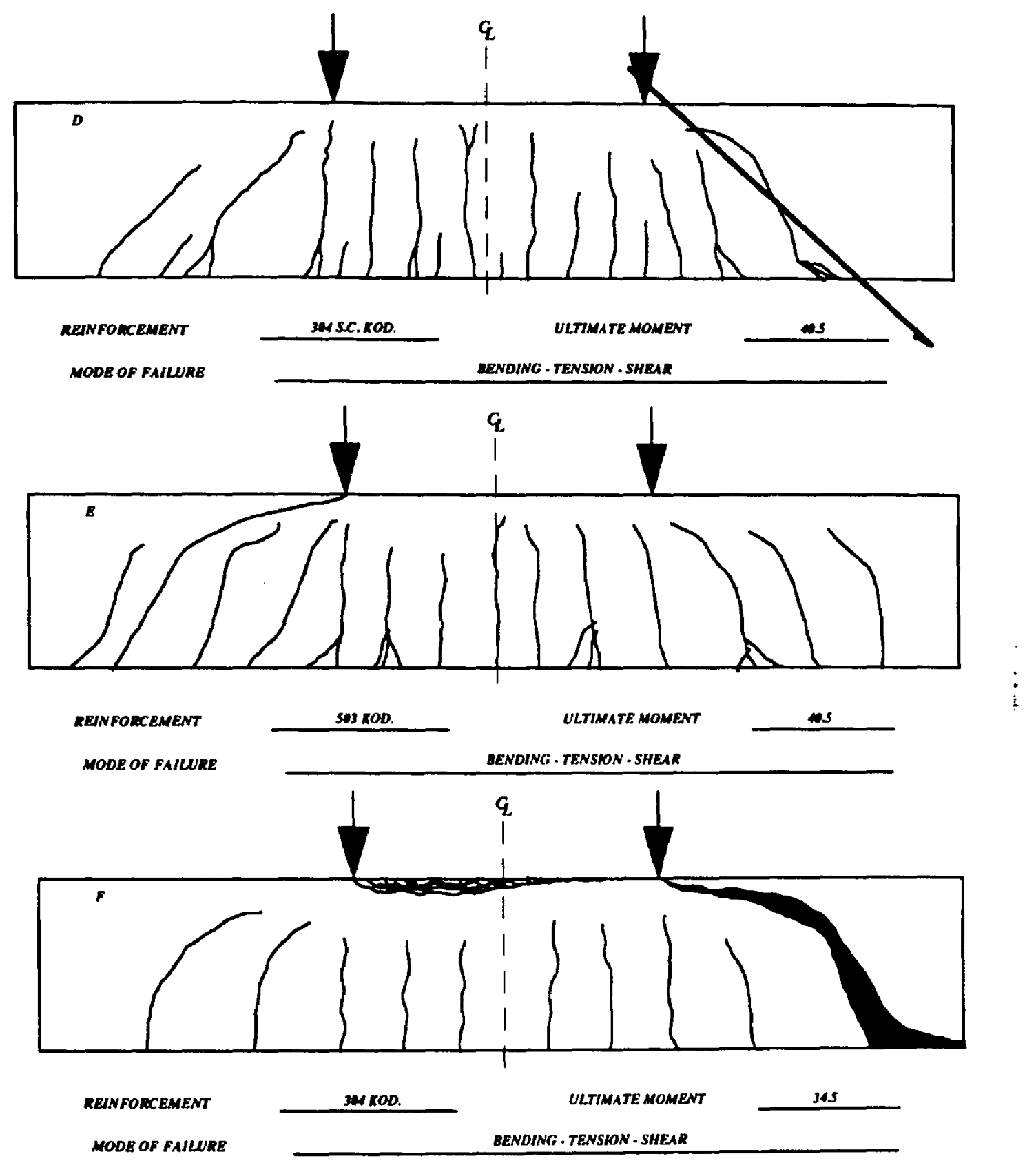

Note: $\mathrm{A}$ better distribution of the cracks is shown in beam \#D reinforced with sand coated rebars compared to beams reinforced with regularly deformed rebars..

Figure 5.14 Effect of Using Sand Coated Rebars on Crack Pattern 

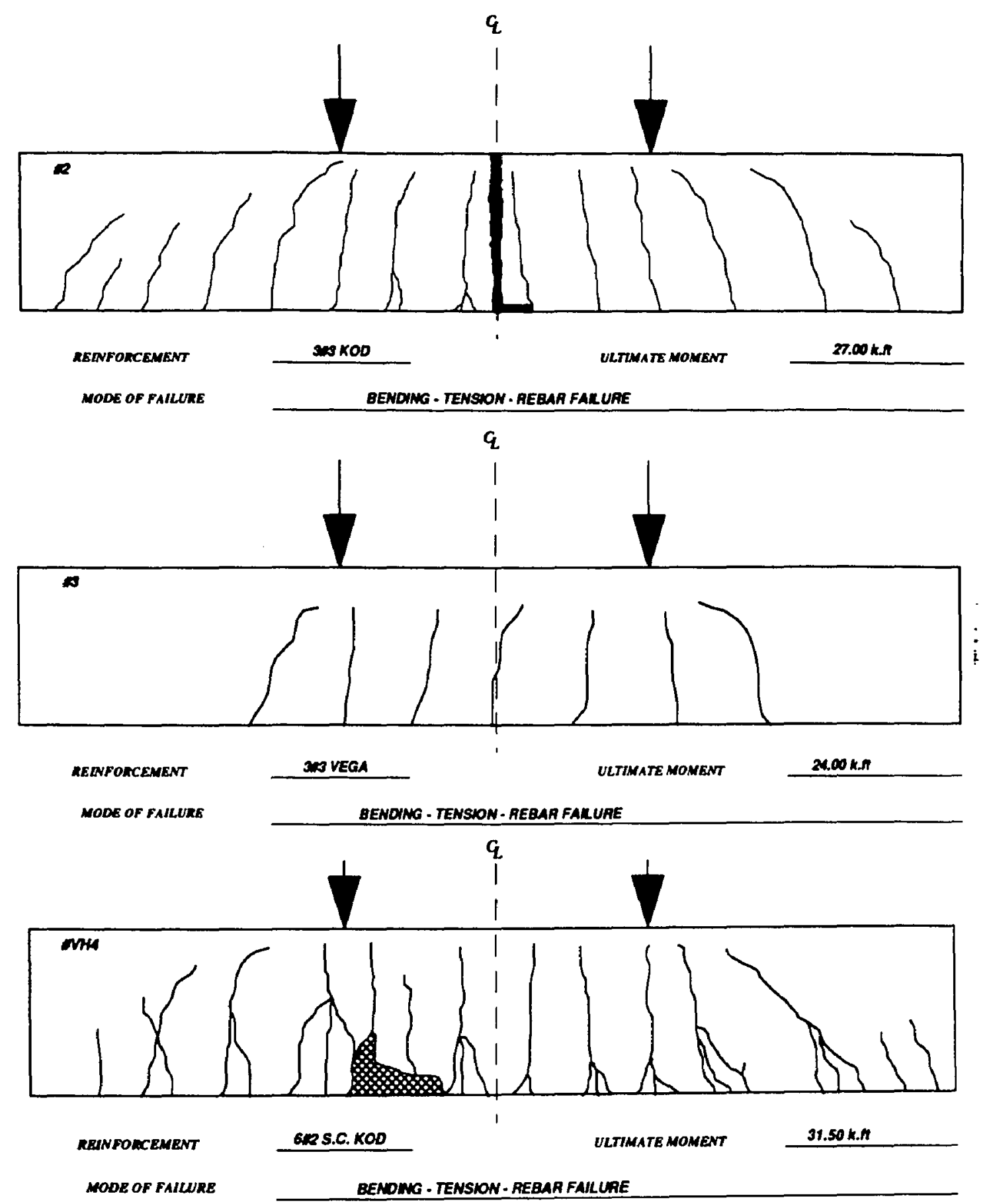

Note: A much better crack distribution is shown when the perimeter of the reinforcement has increased and the sand coated rebars is used.

Figure 5.15 Crack Pattern of Group A Beams 


\subsubsection{Crack Width Analysis of FRP Reinforced Beams}

The ACI 224.2R-86 committee report (1986) on cracking of steel reinforced concrete beams recognizes that the expected value of the maximum crack spacing is about twice that of the average crack spacing. Experimental results on steel reinforced beams outlined by Bresler (1974) have shown that the average crack spacing value is about twice the cover thickness as measured to the center of the reinforcing rebar. Therefore, the maximum crack spacing is equal to about four times the concrete cover thickness. It is recognized by the committee that crack width may be estimated by multiplying the maximum crack spacing (four times the concrete cover) with an average strain in the reinforcement.

The current ACI 224.2R-86 mathematical expressions for predicting crack widths cannot be directly used to predict the crack widths in high strength concrete beams reinforced with FRP rebars because of different material properties associated with higher strength concretes and with FRP rebars. The effects of the tensile strength of higher strength concrete, the bond strength between concrete and FRP rebar, and the low modulus of elasticity of FRP rebars are investigated to establish crack spacing and crack widths.

The low modulus of elasticity of the FRP rebar alone would alter the GergelyLutz expression (equation 5.4) for predicting crack widths for beams reinforced with FRP rebars because the current expressions for maximum flexural crack widths are proportional to the strain in steel reinforcement. The strains in FRP rebars are expected to be four times those of steel because their modulus of elasticity is $7.2 \times 10^{6} \mathrm{psi}$ compared to $29 \times 10^{6}$ psi for steel. By substituting the steel stress with strain, the Gergely-Lutz expression for beams reinforced with steel is rewritten as: 


$$
W_{\max }=0.076 \beta E_{s} \varepsilon_{s} \sqrt[3]{d_{c} A} \times 10^{-3}
$$

Where,

$\varepsilon_{s}=$ strain in the steel rebars.

$$
E_{S}=\text { modulus of elasticity of steel }=29 \times 10^{6} \text { psi. }
$$

In order to incorporate FRP rebar properties in the above expression, where $E_{\mathcal{S}} / E_{f} \equiv 4$, substituting FRP strains, the Gergely-Lutz expression can be modified as follows:

$$
\begin{aligned}
W_{\max } & =0.076 \beta\left(4 E_{f)} \varepsilon_{f} \sqrt[3]{d_{c} A} \times 10^{-3}\right. \\
& =0.30 \beta\left(E_{f}\right) \varepsilon_{f} \sqrt[3]{d_{c} A} \times 10^{-3} \ldots . \\
& =0.30 \beta f_{f} \sqrt[3]{d_{c} A} \times 10^{-3} \ldots \ldots \ldots \ldots
\end{aligned}
$$

Where,

$$
\begin{aligned}
& E_{f}=\text { Modulus of elasticity of FRP rebar }=7.2 \times 10^{3} \mathrm{ksi} \\
& f_{f}=\text { FRP stress }(\mathrm{ksi}) \\
& \varepsilon_{f}=\text { Strain in FRP rebar. }
\end{aligned}
$$

Equation (5.9) would be valid only with the assumption that the same crack spacing is expected to occur when using FRP rebars in lieu of steel rebars. As mentioned earlier, the crack spacing is governed by the tensile strength of concrete and bond strength of the reinforcing rebar. Therefore, an investigation of the legitimacy of equation (5.9) is carried out for cases when higher strength concretes are used with the FRP rebars. 
Watstein and Bresler (1974) have investigated the relationship between the tensile strength of concrete, the bond strength and the crack spacing, leading to the crack width calculation. Their study prescribed the distribution of bond stresses between adjacent cracks to calculate crack spacing and crack widths.

Assuming that bond stress is constant and when concrete reaches its ultimate tensile strength, the crack spacing, $l$, is defined by Watstein and Brester as:

$$
l=\left(2 f_{t}^{\prime} A\right)^{\prime} /\left(\mu_{m} \pi D\right)
$$

where,

$$
\begin{aligned}
& f_{t}^{\prime}=\text { tensile strength of concrete } \\
& \mu_{m}=\text { maximum bond stress } \\
& D=\text { rebar diameter }
\end{aligned}
$$

The crack width may be approximated by an average strain in a FRP rebar multiplied by the crack spacing,$l$.

$$
W_{\max }=\left(f_{f} / E_{f}\right) l
$$

Since crack spacing is governed by the bond stress between the FRP rebar and concrete, it is expected that a higher bond strength will lead to smaller crack spacing and in turn will result in finer cracks. By examining the results of the bond experiments in Tables 4.5 and 4.6, bond strength of sand coated rebars is about two times that of steel rebars. Therefore, it will be expected that the crack spacing in beams reinforced with sand coated FRP rebars, which is defined by the crack spacing multiplied with strain, would be half of that of steel reinforced beams. This can be clearly seen in the crack 
pattern (Figure 5.8) of beams reinforced with sand coated FRP rebars when compared with beams reinforced with steel.

To account for better bond behavior of sand coated FRP rebars, which reduces crack spacing to half the expected spacing in a steel reinforced beam, equation (5.9) which is based on multiplying crack spacing with stress overestimates the crack spacing when high bond strength is developed with sand coated rebars. The quality of the surface condition (deformations) and the quality of the sand coating may vary without a set of standards. In order to accommodate all types of FRP rebar surface conditions and to achieve a more realistic crack width calculation, crack width equation that incorporates the actual bond strength of FRP rebars is needed, which has to be obtained from the experimental data until the rebar manufacturing process is standardized.

Based on the assumption that maximum crack width (equation 5.9) may be approximated by an average strain in FRP rebar multiplied by expected crack spacing, and by substituting expected crack spacing, equation 5.10, the result would give an expression for maximum crack spacing governed by the following parameters:

1) Bond strength of FRP rebar.

2) Splitting tensile strength of concrete.

3) Area of concrete cross section in tension

4) Number of rebars in tension

5) Size of rebar

6) Effective yield strength or working stress of FRP rebar.

The resulting expression for maximum crack width is shown in equation 5.12. 


$$
W_{\max }=\left(f_{f} / E_{f}\right)\left(2 f_{t}^{\prime} A\right) /\left(\mu_{m} \pi D\right)
$$

Substituting for $E_{f}=7.2 \times 10^{3} \mathrm{ksi}$

$$
W_{\max }=0.14 f_{f} \frac{2 f_{t}^{\prime}}{\mu_{m}} \frac{A}{\pi D} \times 10^{-3}
$$

where,

$f_{t}^{\prime}=7.5 \sqrt{f_{c}}$

$f_{f}=$ Maximum stress (ksi) in FRP reinforcement at service load level with $0.5 f_{y f}$ to be used if no computations are available.

$A=$ The effective tension area of concrete surrounding the principal reinforcement divided by the number of rebars. It is defined as having the same centroid as the reinforcement $\left(\right.$ in $\left.^{2}\right)$.

The use of both equations 5.9 and 5.13 are illustrated in the solved example in Chapter 6. To check the validity of these equations, the experimental crack widths for beams reinforced with FRP rebars are compared with the theoretical expressions (5.9 and 5.13) in Table 5.3. The experimental crack widths of Beam E-D do not correlate well with both equations due to the high bond strength between the concrete and sand coated rebar. The experimental crack widths are smaller than the theoretical equations. 
Table 5.3 Theoretical versus experimental crack widths

\begin{tabular}{|c|c|c|c|c|}
\hline Beam \# & $\begin{array}{c}\text { FRP stress } \\
(\mathrm{ksi})\end{array}$ & $\begin{array}{l}\text { Experimental } \\
\text { crack width }\end{array}$ & $\begin{array}{l}\text { Equation } 5.9 \\
\text { crack width }\end{array}$ & $\begin{array}{l}\text { Equation } 5.13 \\
\text { crack width }\end{array}$ \\
\hline E-VHI & 8.5 & 0.011 & 0.010 & 0.011 \\
\hline $\mathrm{E}-\mathrm{VH} 1$ & 11.3 & 0.017 & 0.012 & 0.015 \\
\hline E-VH 1 & 17.2 & 0.02 & .018 & 0.022 \\
\hline E-VHI & 37.5 & 0.041 & .042 & 0.049 \\
\hline$E-F$ & 54.0 & 0.077 & 0.060 & 0.071 \\
\hline$E-F$ & 71.0 & 0.096 & 0.080 & 0.093 \\
\hline E-D & 32.9 & 0.021 & 0.036 & 0.04 \\
\hline E-D & 49.5 & 0.046 & 0.054 & 0.065 \\
\hline
\end{tabular}

Comparisons in Table 5.3 reveal that equation 5.13 leads to a better expression to predict maximum crack widths.

As shown in equation 5.9 the effects of high strains (that develop as a result of low modulus of elasticity of FRP rebars together with higher bond strength when sand coated FRP rebars are used) will produce crack widths that are two times larger than in the steel reinforced beams. Use of sand coated FRP rebars should permit higher tolerable crack widths, since the corrosion problem is not a major concern when using the noncorrosive FRP reinforcement. As a result, the crack widths that might develop in the 
structures should be considered acceptable and a new tolerable width may have to be specified.

\subsection{Deflection}

Various methods have been considered by researchers in an attempt to calculate post cracking deflections of concrete beams reinforced with steel (Nawy 1990). However, precracking deflections can be found routinely by assuming the beam behaves as an elastic and homogeneous structural element. The differences among the various methods consist mainly in the ways in which the modulus of elasticity, $E$, and the moment of inertia, $I$, are computed. Both quantities are difficult to define in a steel reinforced concrete member. Considering that cracking behavior of concrete beams reinforced with FRP bars is different from that of steel reinforced concrete beams, the effective cracked moment of inertia, $I_{e f f}$, would be different from that of conventional steel reinforced beams. Such difference can be attributed mainly to the extent of cracking.

In the following sections, the load-deflection behavior of concrete beams reinforced with FRP rebars is investigated extending the current methods used for steel reinforced beams. In addition, certain recommendations to compute deflections in beams reinforced with FRP rebars are presented.

\subsubsection{Precracking Stage}

The precracking segments of load-deflection curves in all specimens are essentially straight lines indicating the full elastic behavior. The maximum tensile stress in concrete beams in this region is less than the tensile strength of concrete. The flexural stiffness $\boldsymbol{E} I$ of the beams can be estimated using Young's modulus $\boldsymbol{E}_{\boldsymbol{c}}$ of concrete and the moment of inertia of the uncracked reinforced concrete cross section. The load- 
deflection behavior before cracking is dependent on the stress-strain relationship of concrete from which the value of $E_{c}$ can be calculated either using the ACI 318 code expression

$$
E_{c}=57,000 \sqrt{f_{c}^{\prime}}
$$

or the $\mathrm{ACI} 363 \mathrm{R}$ committee recommendation

$$
E_{c}=40,000 \sqrt{f_{c}^{\prime}}+1 \times 10^{6}
$$

The above expressions are compared in Table 5.4 with the experimental values obtained from our cylinder tests. The experimental value of $E_{c}$ was used in the analysis where applicable.

\begin{tabular}{|c|c|c|c|}
\hline $\begin{array}{c}\text { Concrete } \\
\text { Compressive } \\
\text { Strength (psi) }\end{array}$ & $\begin{array}{c}\boldsymbol{E}_{\boldsymbol{c}} \\
\mathrm{ACI} 318 \\
(\mathrm{psi})\end{array}$ & $\begin{array}{c}E_{\boldsymbol{c}} \\
\mathrm{ACl} 363 \mathrm{R} \\
\quad(\mathrm{psi}) \\
\end{array}$ & $\begin{array}{c}\boldsymbol{E}_{\boldsymbol{c}} \\
\text { Experimental } \\
(\mathrm{psi}) \\
\end{array}$ \\
\hline 4200 & $3.69 \times 10^{6}$ & $3.59 \times 10^{6}$ & - \\
\hline 5000 & $4.03 \times 10^{6}$ & $3.83 \times 10^{6}$ & - \\
\hline 6500 & $4.50 \times 10^{6}$ & $4.20 \times 10^{6}$ & $3.60 \times 10^{6}$ \\
\hline 7500 & $4.94 \times 10^{6}$ & $4.46 \times 10^{6}$ & $4.20 \times 10^{6}$ \\
\hline 10000 & $5.70 \times 10^{6}$ & $5.00 \times 10^{6}$ & $4.60 \times 10^{6}$ \\
\hline
\end{tabular}

Table 5.4 Modulus of elasticity variations 
An accurate estimation of the moment of inertia $I$ necessitates the consideration of FRP reinforcement $A_{f}$ in the computations. This can be done by replacing FRP bar area by an equivalent concrete area $\left(E_{f} / E_{c}\right) A_{f}$. Since the modulus of elasticity of the FRP rebar is $7.2 \times 10^{6} \mathrm{psi}$, the transformation is negligible. The use of gross moment of inertia resulted in acceptable results in the precracking stage which is based on the uncracked section and neglecting additional stiffness contribution from the FRP reinforcement.

The precracking stage stops at the initiation of the first flexural crack when concrete reaches its modulus of rupture, $f_{\boldsymbol{r}}$. The modulus of rupture, which is the appropriate measure to predict concrete tensile strength under flexure has been reported by the ACI code to be $7.5 \sqrt{f_{c}^{\prime}}$. The ACI 363R recommends a value of $11.7 \sqrt{f_{c}^{\prime}}$ for normal weight concretes with strength in the range of 3000 to 12,000 psi. It thus appeared that the $\mathrm{ACl} 318$ value of $7.5 \sqrt{f_{c}{ }^{\prime}}$ is low. However, for curing conditions such as seven day moist curing followed by air drying, a value of $7.5 \sqrt{f c^{\prime}}$ is closer to the full strength range.

\subsubsection{Postcracking Stage}

When flexural cracking develops, contribution of concrete in the tension zone is considered negligible. Thus the flexural rigidity of the beam is reduced and the slope of a load-deflection (or stiffness) curve is less steep than in the precracking stage as shown in load-deflection curves in Figures 5.19 to 5.25 . The stiffness continues to decrease with increasing load, reaching a lower limit that corresponds to the moment of inertia of the cracked section, $\boldsymbol{I}_{\boldsymbol{c r}}$. The moment of inertia of a cracked section can be obtained by taking the moment of inertia of the cracked section about the neutral axis which will result in the following relationship after neglecting the concrete section below the neutral axis: 


$$
I_{c r}=\frac{b c^{3}}{3}+n A_{f}(d-c)^{2}
$$

where,

$$
\begin{aligned}
& n=\text { Modular ratio, }\left(E_{f} / E_{c}\right) \\
& c=\text { Distance from top fiber to the neutral axis }
\end{aligned}
$$

In actual cases, only a portion of a beam along its length is cracked. The uncracked segments below the neutral axis possess some degree of stiffness which contributes to the overall beam rigidity. The actual stiffness of the beam lies between $E_{c} l_{g}$ and $E_{c} I_{c r}$. As the load approaches the ultimate value, beam stiffness approaches $E_{c} l_{c r}$. The major factors that influence the beam stiffness are:

1) Extent of cracking.

2) Contribution of concrete below the neutral axis.

The ACI 318 code specifies that deflection shall be computed with an effective moment of inertia, $I_{e}$ as follows, but not greater than $I_{g}$.

$$
I_{e}=\left(\frac{M_{c r}}{M_{a}}\right)^{3} I_{g}+\left(I \cdot\left(\frac{M_{c r}}{M_{a}}\right)^{3}\right) \quad I_{c r}
$$

where,

$$
\begin{aligned}
& M_{c r}=\frac{f_{r} I_{g}}{Y_{t}} \\
& M_{a}=\text { Applied Moment } \\
& \mathrm{Y}_{\mathrm{t}}=\mathrm{h} / 2
\end{aligned}
$$


The effective moment of inertia developed by Branson () and adopted by the ACI 318 is considered sufficiently accurate for use in control of deflection of beams reinforced with steel. $l_{e}$ was developed to provide transitional moments of inertia between $I_{g}$ and $l_{c r}$ and it is a function of $\left(\frac{\boldsymbol{M}_{c r}}{\boldsymbol{M}_{a}}\right)^{3}$.

By investigating the experimental versus theoretical load-deflection curves using $I_{e}$ as prescribed by equation (5.17), a large discrepancy is found in deflection values after the first crack as shown in Figures 5.19 through 5.25

The equation for deflection of a simply supported beam of $\operatorname{span} L$, loaded with two concentrated loads $P$ (Figure 5.16), in kips, at a distance $a$ from each end is written as:

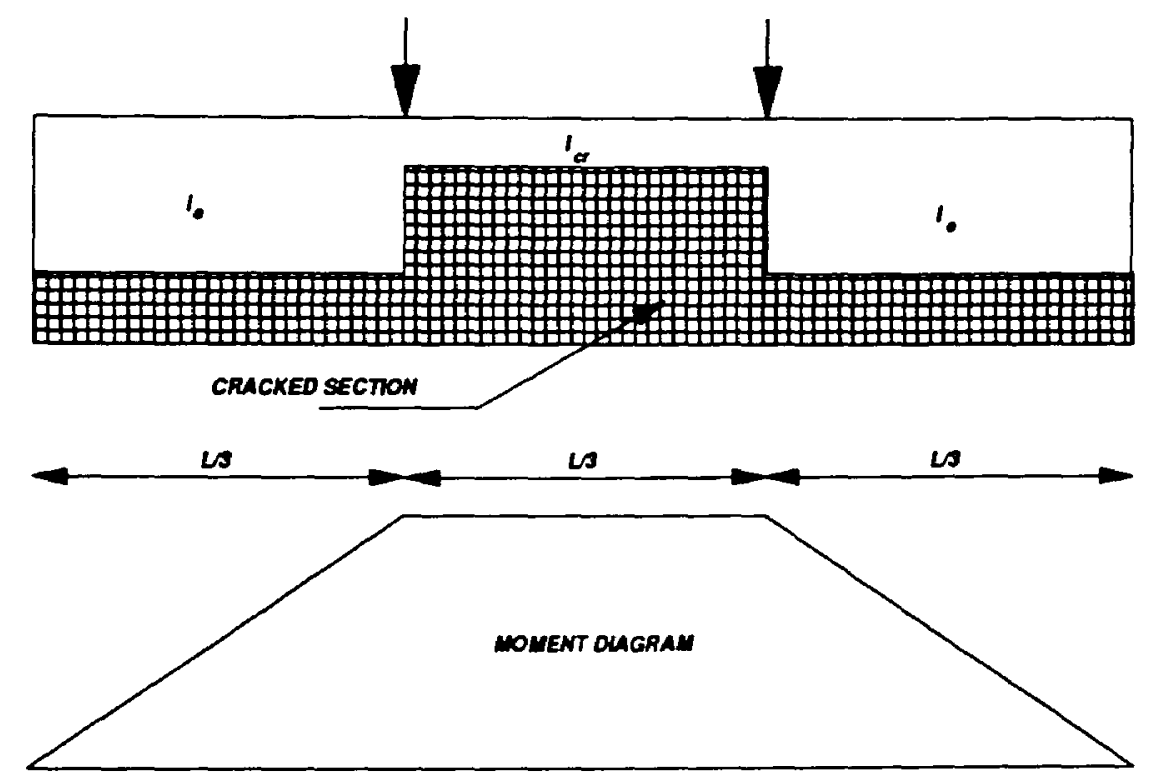

Figure 5.16 Load, moment and cracking section of loaded beam

$$
\begin{aligned}
& \Delta_{\max }=\frac{\mathrm{Pa}_{\mathrm{a}}}{24 \mathrm{Ec} \mathrm{Ie}}\left(3 \mathrm{~L}^{2}-4 \mathrm{a}^{2}\right) \\
& \text { for } \mathrm{a}=\mathrm{L} / 3
\end{aligned}
$$




$$
\Delta_{\max }=\frac{23 \mathrm{PL}^{3}}{648 \mathrm{Ec} \mathrm{Ie}}
$$

in which

$$
\begin{aligned}
& E_{C}=\text { Concrete modulus of elasticity (experimental values) } \\
& I_{e}=\text { Effective moment of inertia }
\end{aligned}
$$

with $L=108$ in. the deflection expression can be rewritten as

$$
\Delta_{\max }=\frac{44712 P}{E_{c} I_{e}}(\text { in })
$$

For evaluating $\mathrm{I}_{\mathrm{e}}$, the experimental cracking moment $\mathrm{M}_{\mathrm{cr}}$, observed from the tests was used.

It is seen from the load-deflection curves, Figures 5.19 to 5.25 , that the deflection Equation (5.18) overestimates the moment of inertia of the beam after the first crack. Thus calculated deflection values from equation 5.20 are lower than the observed values. A better estimate of the moment of inertia is needed. In the following subsection, a new expression for the effective moment of inertia is proposed.

\subsubsection{Modified moment of inertia}

Due to the nature of crack pattern and propagation and the height of the neutral axis which is very small for FRP reinforced concrete beams, a new method in calculating the effective modulus of elasticity is introduced. The new expression is based on the assumption that concrete section between the point loads is assumed to be fully cracked, while the end section are assumed to be partially cracked (Figure 5.16). Therefore, expression for $\mathrm{I}_{\mathrm{cr}}$ is used in the middle third section, and $\mathrm{I}_{\mathrm{e}}$ is used in the end sections. 
Using the moment area approach to calculate the maximum deflection at the center of the beam,as shown in Figure 5.16, would result in an expression for maximum deflection that incorporates both $\mathrm{I}_{\mathrm{e}}$ and $\mathrm{I}_{\mathrm{cr}}$ as shown in equation 5.21

$$
\begin{aligned}
\Delta_{\max }= & \frac{8 P L^{3} E I_{c r}+15 P L^{3} E I_{e}}{648 E I_{c r} E I_{e}} \\
= & \frac{8 P L^{3} I_{c r}+15 P L^{3} l_{e}}{648 E I_{c r} l_{e}}
\end{aligned}
$$

Rewriting the deflection expression in equation 5.22 ,

$$
\Delta_{\max }=\frac{23 P L^{3}}{648 E_{c} I_{m}}(\text { in })
$$

in which,

$$
I_{m}=\frac{23 I_{c r} I_{e}}{8 I_{c r}+15 I_{e}}
$$

The resulting deflection equation (5.23) and the modified moment of inertia (5.24) which is valid for two concentrated point loads that are applied at the third points on the beams are plotted as shown in Figures 5.19 - 5.25.

Two different loading cases, uniform load and a single concentrated point load are investigated based on their respective moment curves as shown in Figures 5.17 and 5.18 respectively. 


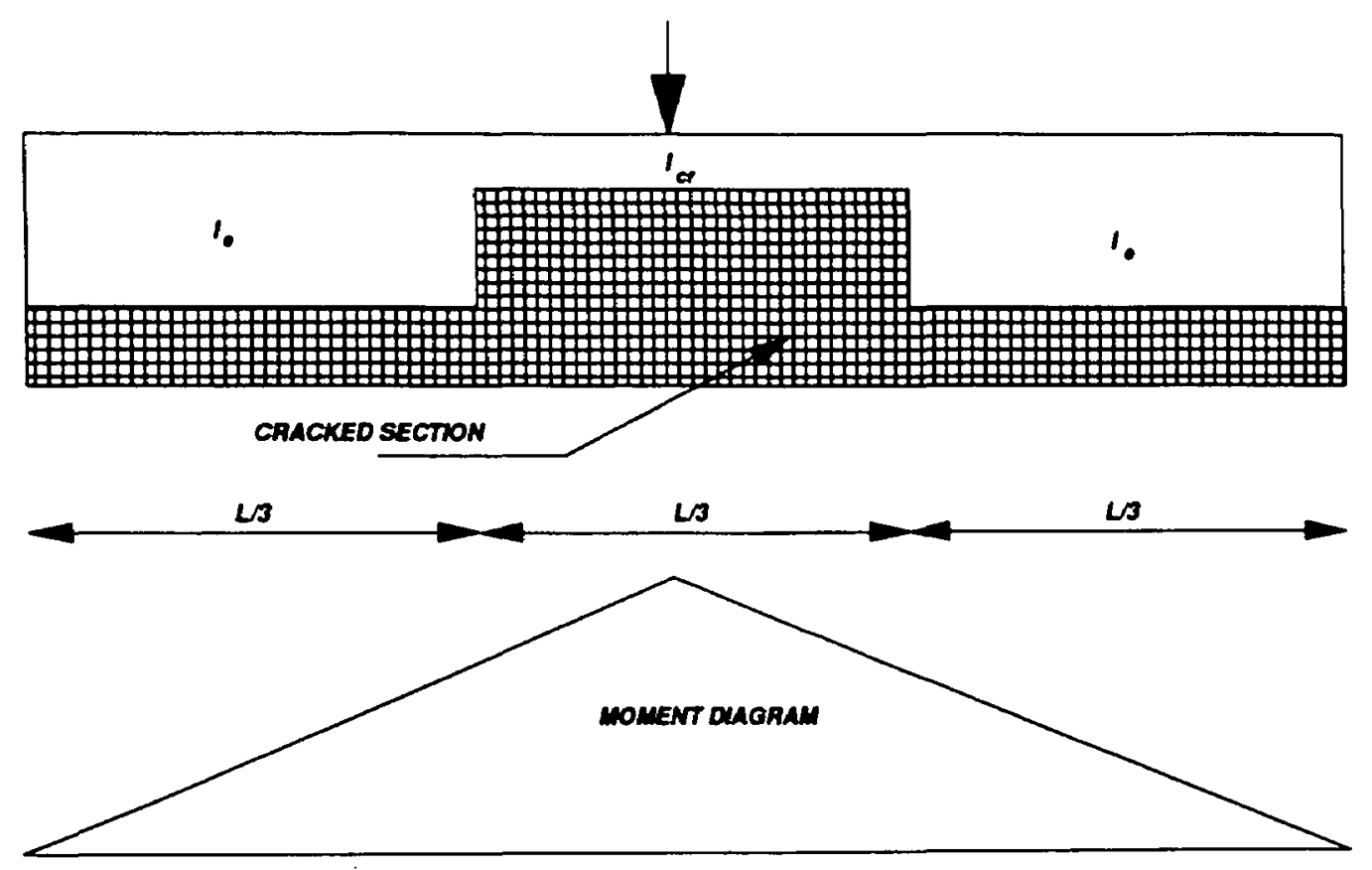

Figure 5.17 Concentrated point load case

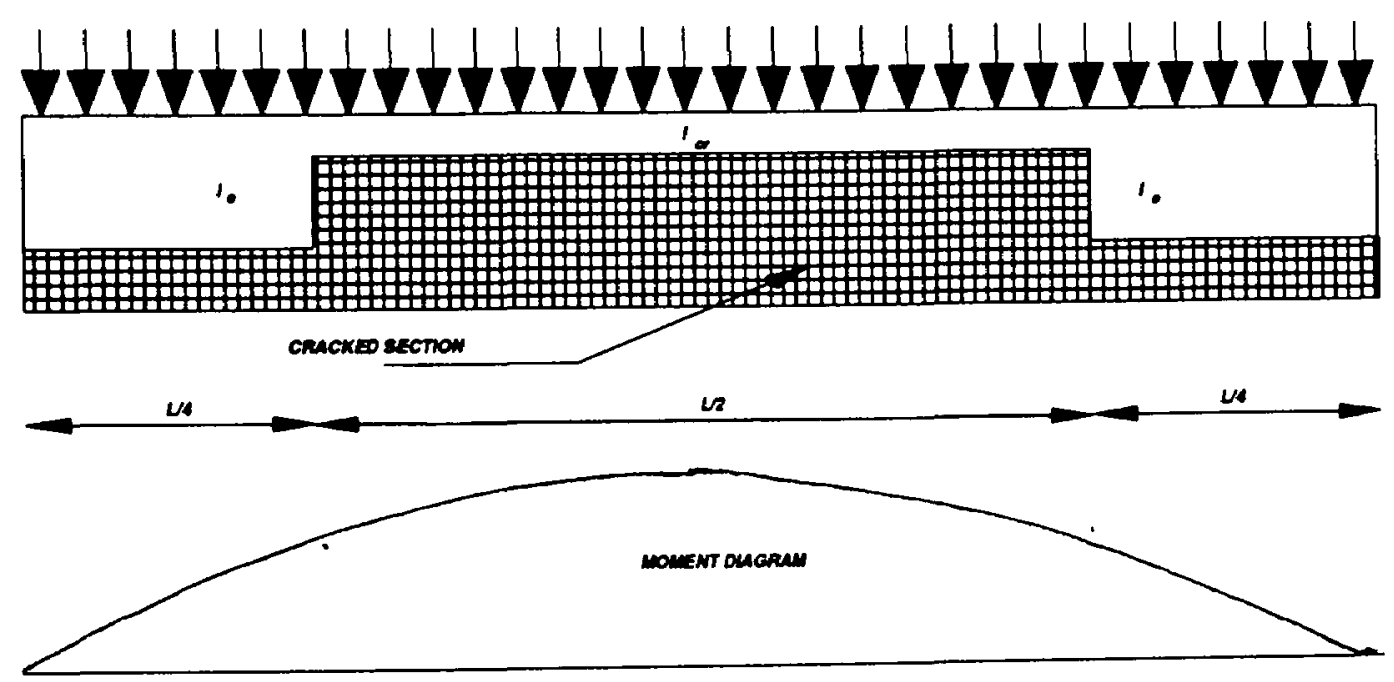

Figure 5.18 Uniform Loading case

Using the same approach as in the case of two concentrated point loads, expressions for maximum deflection and modified moment of inertia are derived for a concentrated point load and for a uniform distributed load. However, no experimental information is available to check their validity (5.25 to 5.28 ). 
For a concentrated point load applied at the center of the beam as shown in Figure 5.17, the maximum deflection expression is

$$
\Delta_{\max }=\frac{P L^{3}}{48 E_{c} I_{m}}(\text { in })
$$

in which,

$$
I_{m}=\frac{54 I_{c r} I_{e}}{23 I_{c r}+45 I_{e}}
$$

For a uniform distributed load applied on the beam as shown in Figure 5.18, the maximum deflection expression is

$$
\Delta_{\max }=\frac{5 W L^{4}}{384 E_{c} I_{m}}(\text { in })
$$

in which,

$$
I_{m}=\frac{240 I_{c r} I_{e}}{45 I_{c r}+202 I_{e}}
$$


Figure 5.19 Load vs Deflection (Theoretical vs Experimental) Beam \#H1 (2\#3)

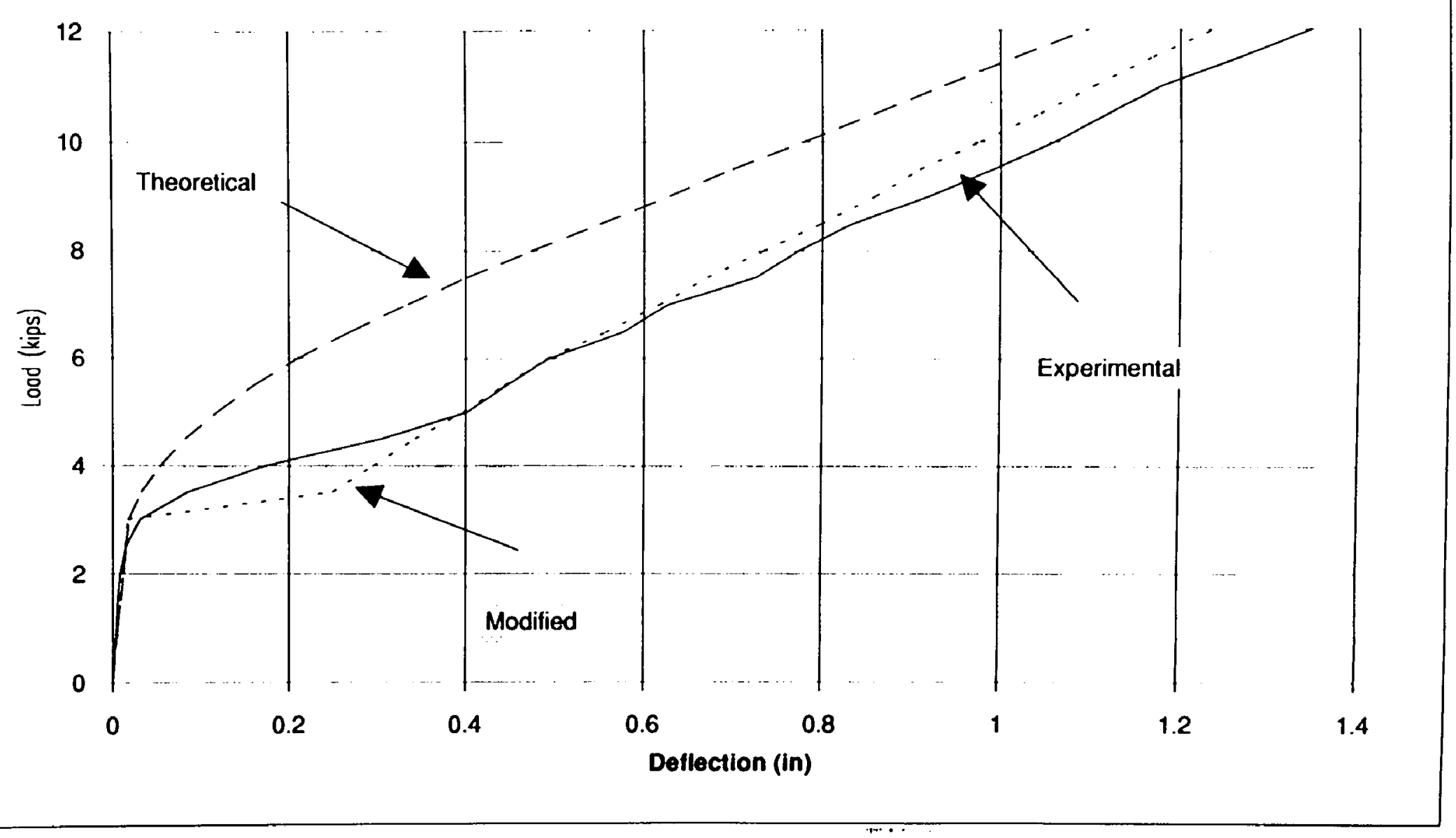




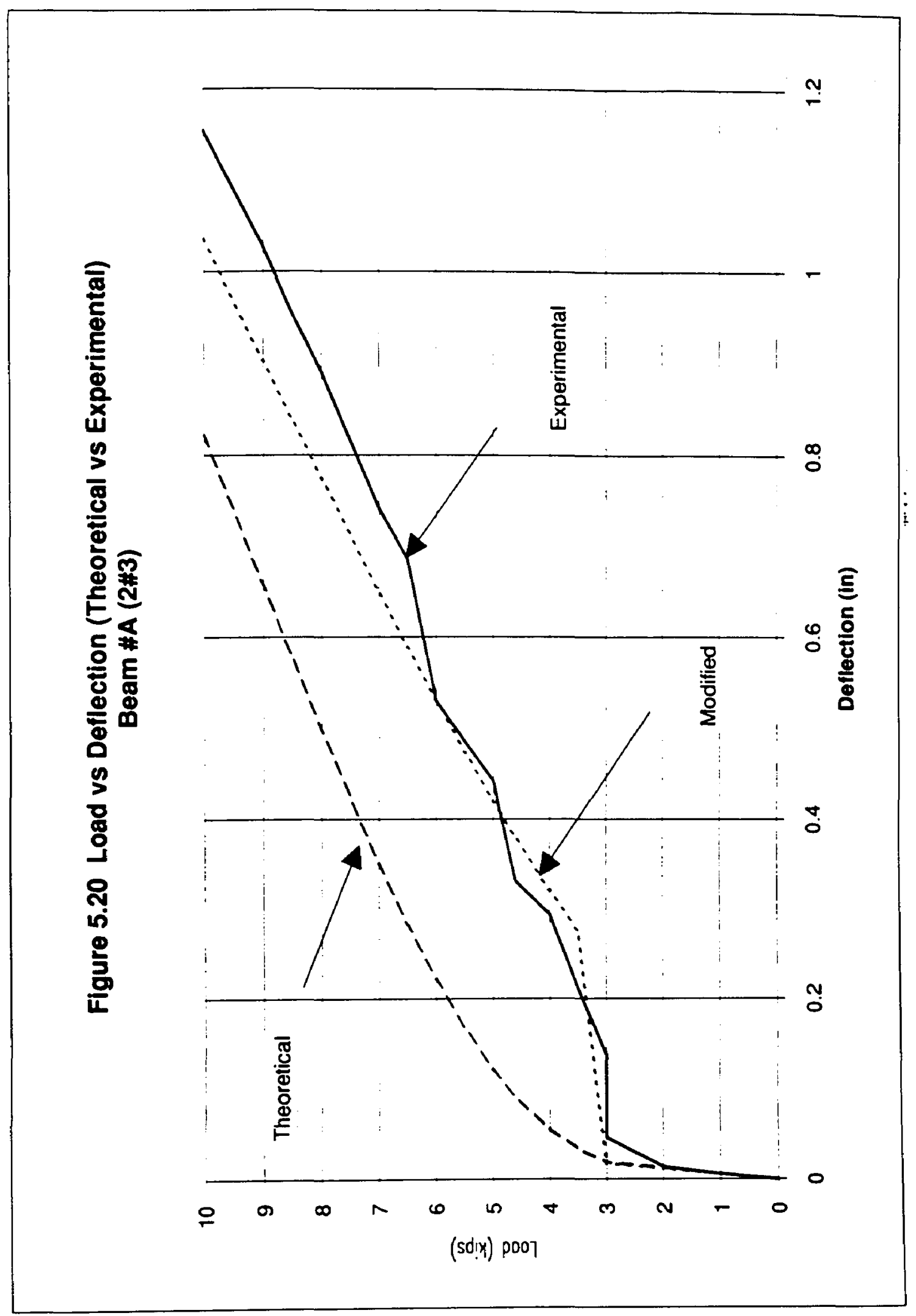


Figure 5.21 LOAD vs DEFLECTION (Theoretical vs Experimental) BEAM VH2, 3\#4, 10,000 psi

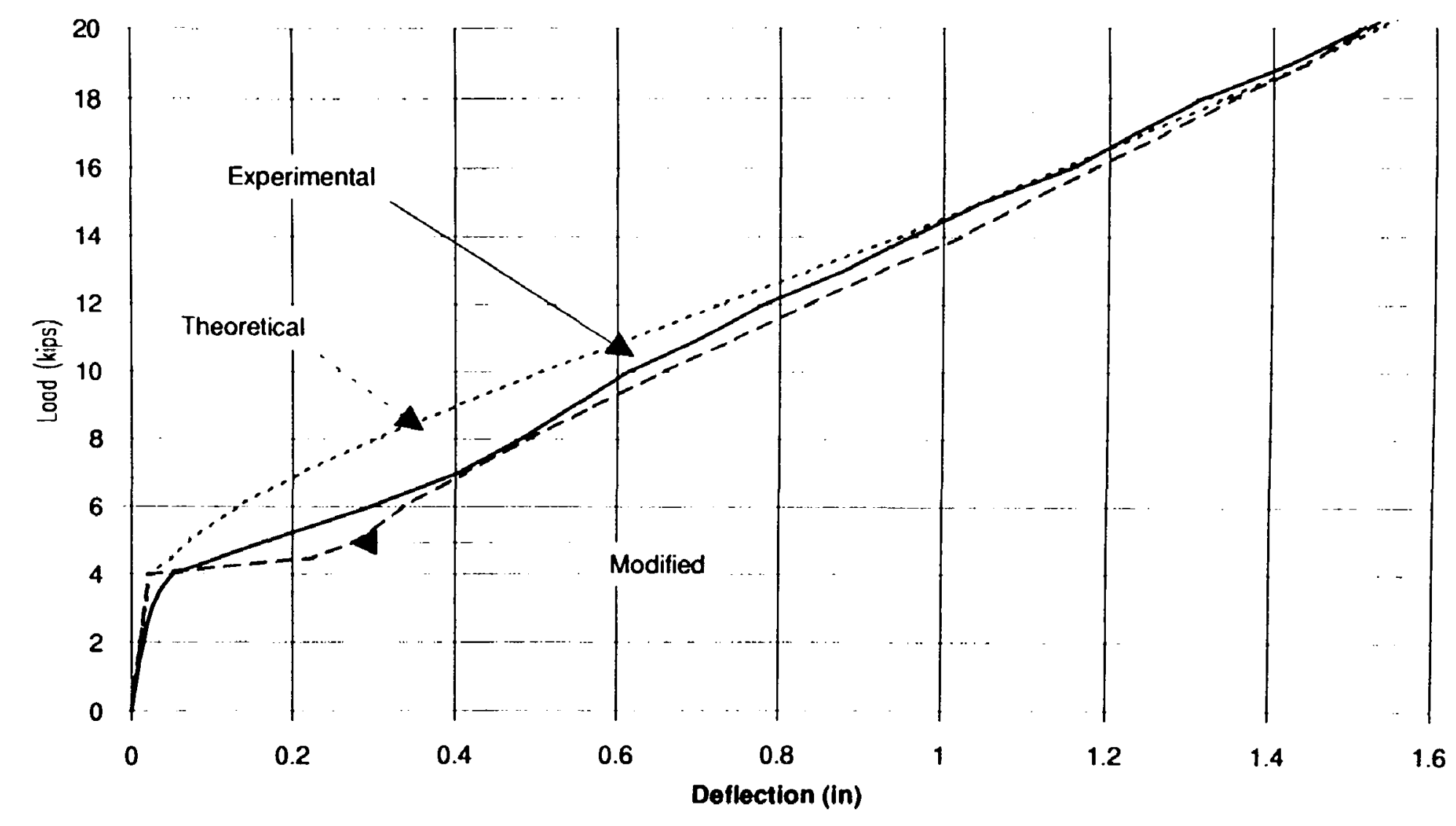




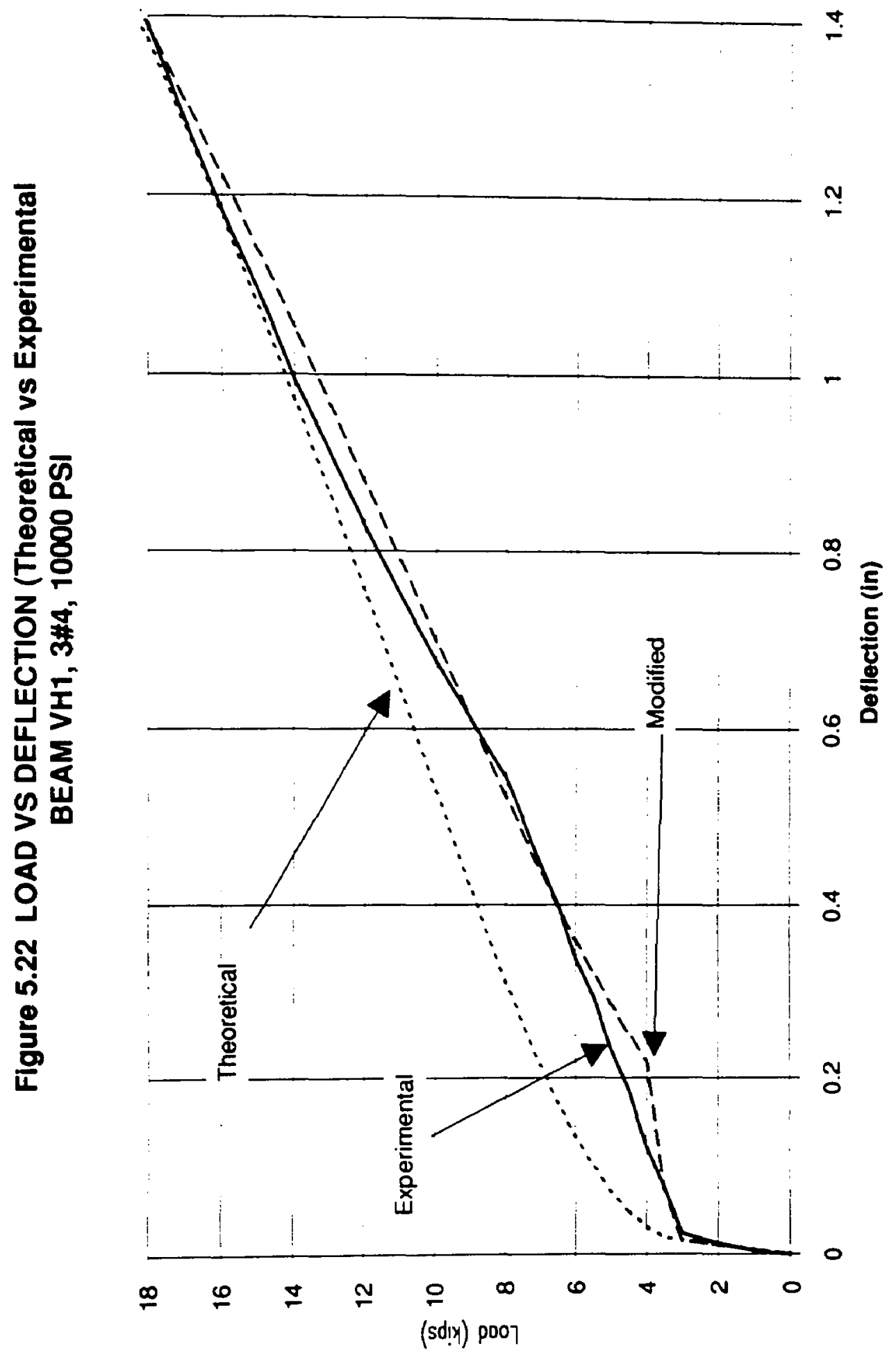




\section{Figure 5.23 Load vs Deflection (Theoretical vs Experimental)}

Beam \#H6 (2\#3)

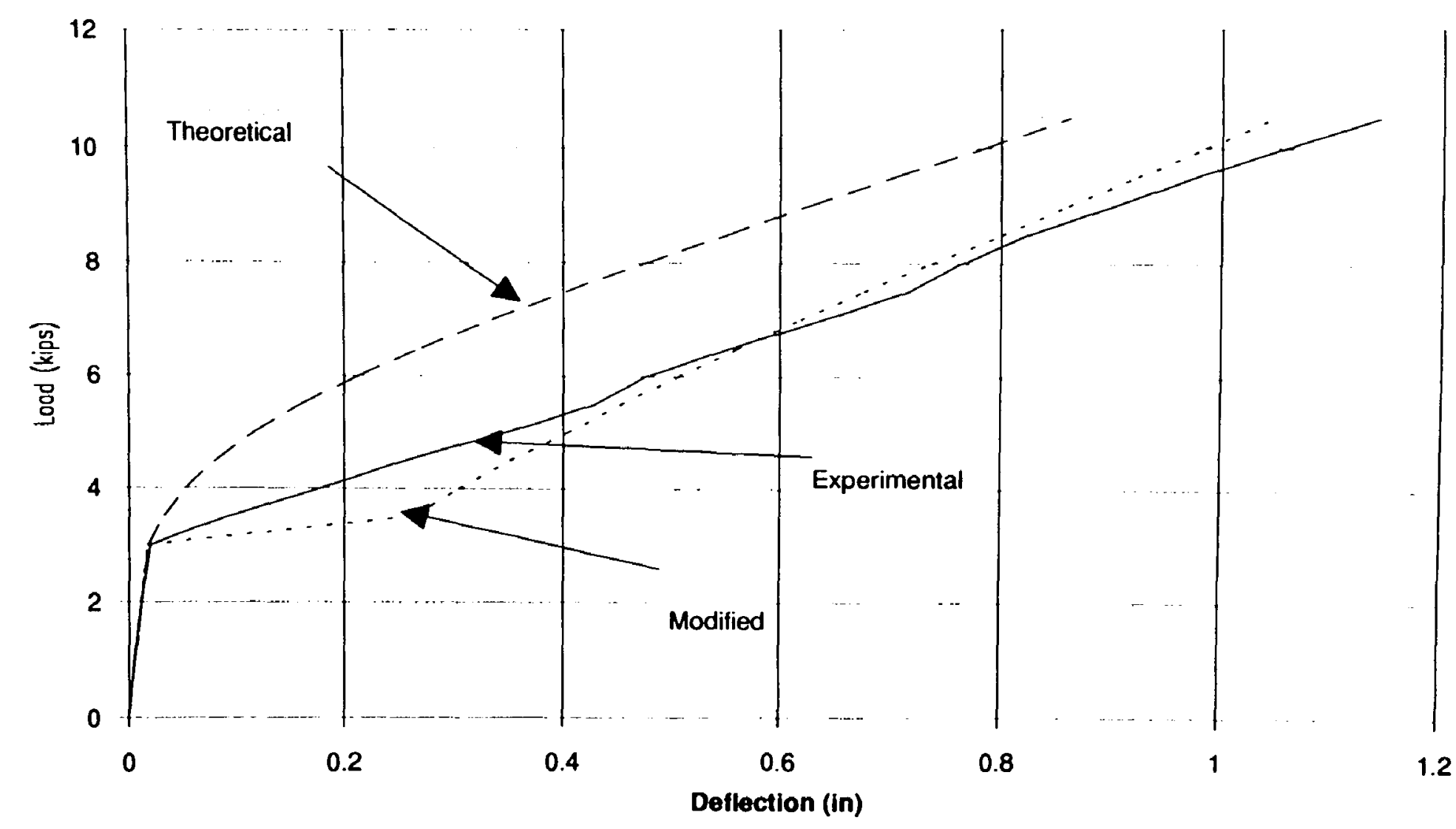




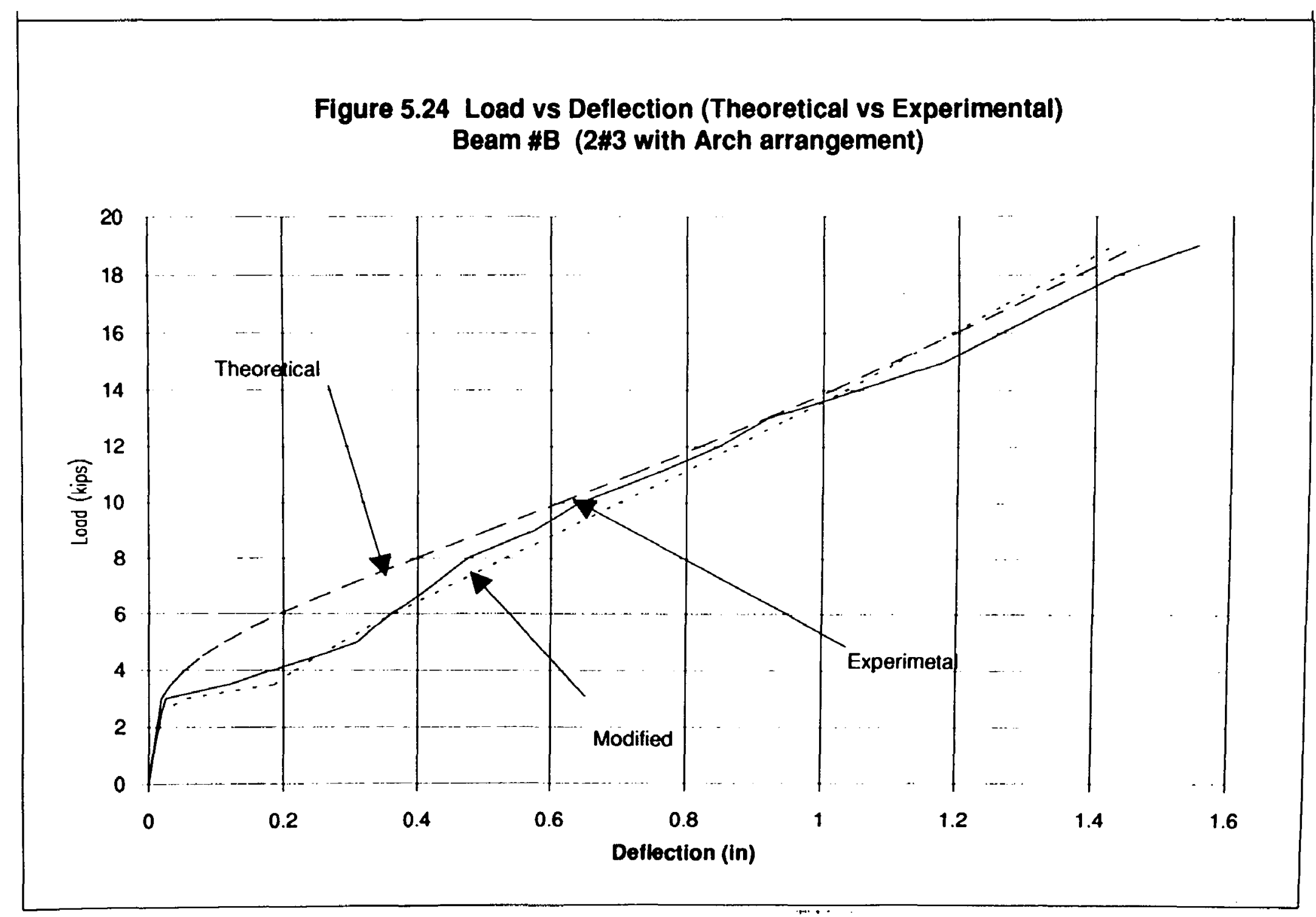




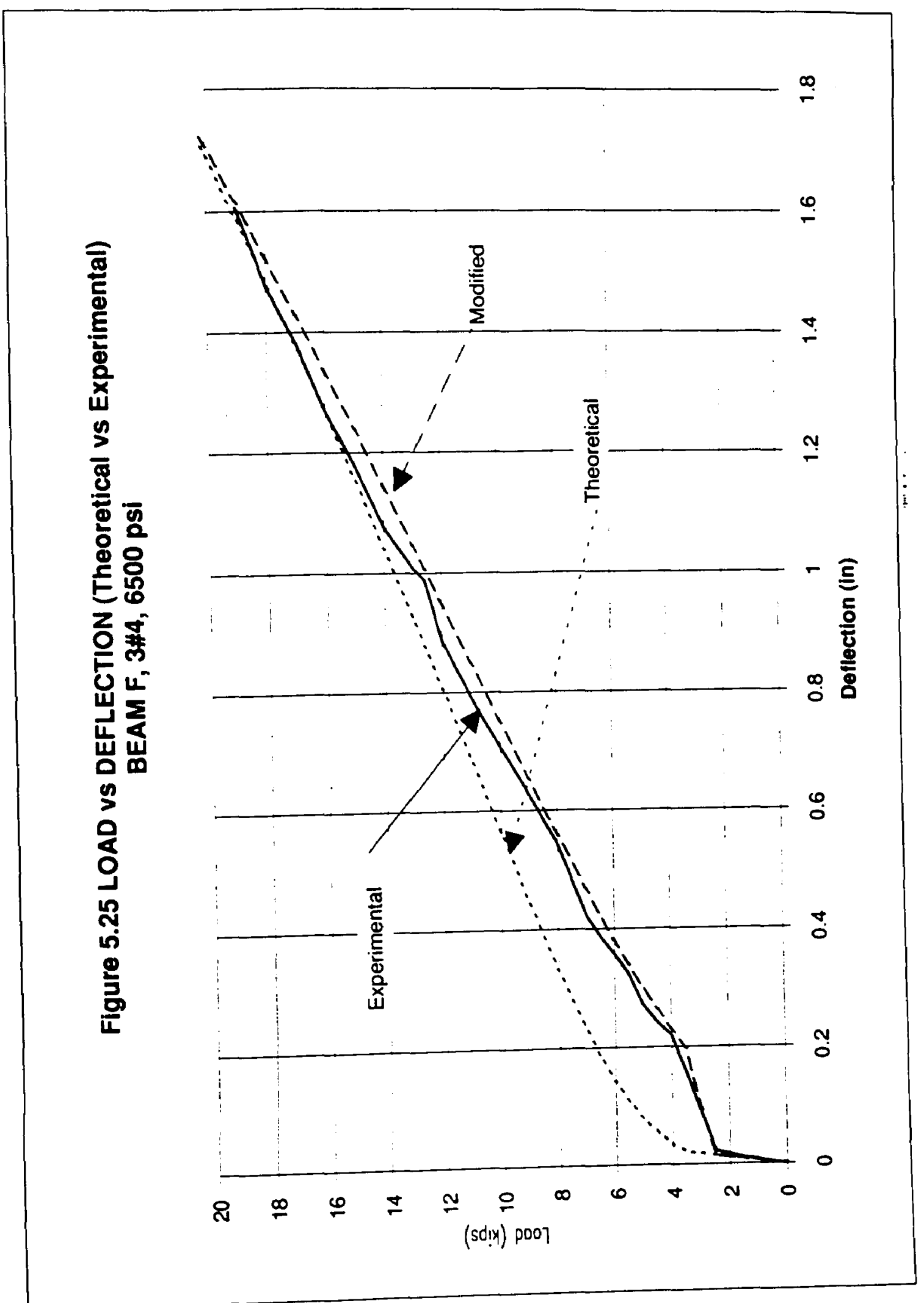




\subsection{Balanced Reinforcement Ratio}

Balanced reinforcement ratio, $P_{b}$ is a function of concrete strength, and modulus of elasticity, $\mathrm{E}_{\mathrm{f}}$, and the effective yield strength $f_{f y}$ of FRP rebars, irrespective of the section geometry. Using the strain distribution diagram for balanced strain conditions

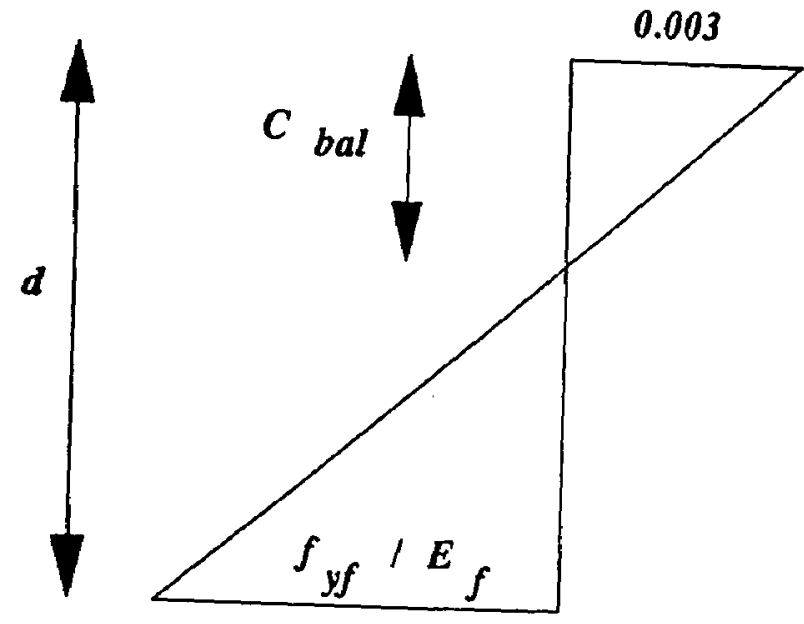

STRAIN

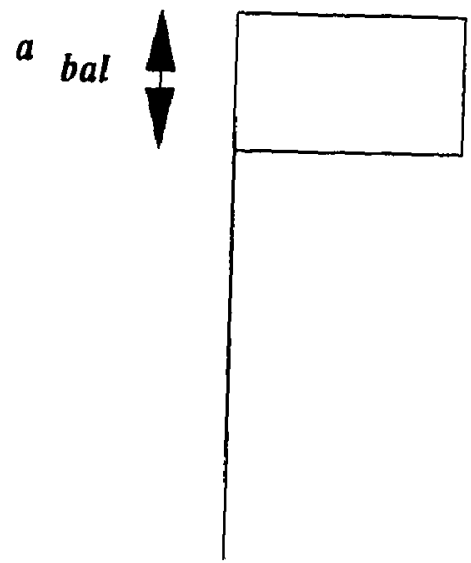

STRESS

Figure 5.26 Balanced strain conditions

$$
\frac{c_{b a l}}{d}=\frac{0.003}{0.003+\frac{f_{y f}}{E_{f}}}
$$

Taking $E_{f}$ as $6.5 \times 10^{6} \mathrm{psi}$, modulus of elasticity of FRP rebar under bending

$$
\frac{c_{\text {bal }}}{d}=\frac{19500}{19500+f_{y f}}
$$

for the balanced strain condition, the depth of the rectangular stress block is

$$
a_{b a l}=\beta_{l} c_{b a l}
$$

for equilibrium of the horizontal forces 


$$
A_{\text {faal }} f_{y}=0.85 f_{C}^{\prime} b a_{b a l}
$$

or

$$
\rho_{b a l}=\frac{A_{f b a l}}{b d}=\frac{0.85 f_{c}^{\prime}}{f_{y f}} \frac{a_{b a l}}{d}
$$

the balanced reinforcement ratio becomes

$$
\rho_{b a l}=\beta_{1} \frac{0.85 f_{c}^{\prime}}{f_{y f}} \frac{19500}{19500+f_{y f}}
$$

where $f_{y f}$ and $f_{c}^{\prime}$ are expressed in psi.

Thus if $f_{y f}$ and $f_{c}^{\prime}$ are known, $\rho_{b}$ can be obtained regardless of the geometry of the concrete section considered.

Design development are discussed in Chapter 6 incorporating equation 5.34.

\subsection{Bond Strength and Development Length}

Bond strength is a function of:

1) Adhesion between the concrete and FRP rebars which is controlled partly by the concrete strength and quality of the rebars.

2)Gripping forces resulting from the drying shrinkage of the surrounding concrete and the rebars.

3) Frictional resistance to sliding and interlock.

4) Mechanical anchorage of the rebar through development length, splicing, hooks, and transverse rebars. 
5) Diameter, shape (with or without wrapping, surface coating) and spacing of the rebars.

6) Moment stress gradient in a given zone.

Different types of tests are available to determine the bond quality to determine the bond quality of FRP rebars, such as the pull-out test, the cantilever bond test and the beam tests. This research included all three types of tests that were performed using FRP rebars. The straight pull-out test (cylinder pull-out) was used to give a comparison of the bond efficiency of various types of rebar surfaces and the corresponding embedment lengths. It is, however, not truly representative of the bond stress developed in a structural beam because, in a pull-out test, concrete is subjected to compression while the rebar is in tension. However, both the rebar and the surrounding concrete in a beam under bending are subjected to tension. In the cantilever bond test outlined in Chapter Four, both concrete and the rebar are subjected to tension as it is expected in case of a concrete beam under bending. In addition, a cantilever bond test setup goes further to simulate the situation adjacent to a diagonal crack as elaborated in the experimental setup in Chapter 4.

The strength results from pull-out specimens are used to compare surface condition effects on strength and embedment length. The results of cantilever specimens are evaluated in the following subsections to design for appropriate embedment length of FRP rebars that can minimize bond slip so that FRP rebars can attain full strength within a structural element without bond failure. 


\subsubsection{Anchorage and Adhesion Bond}

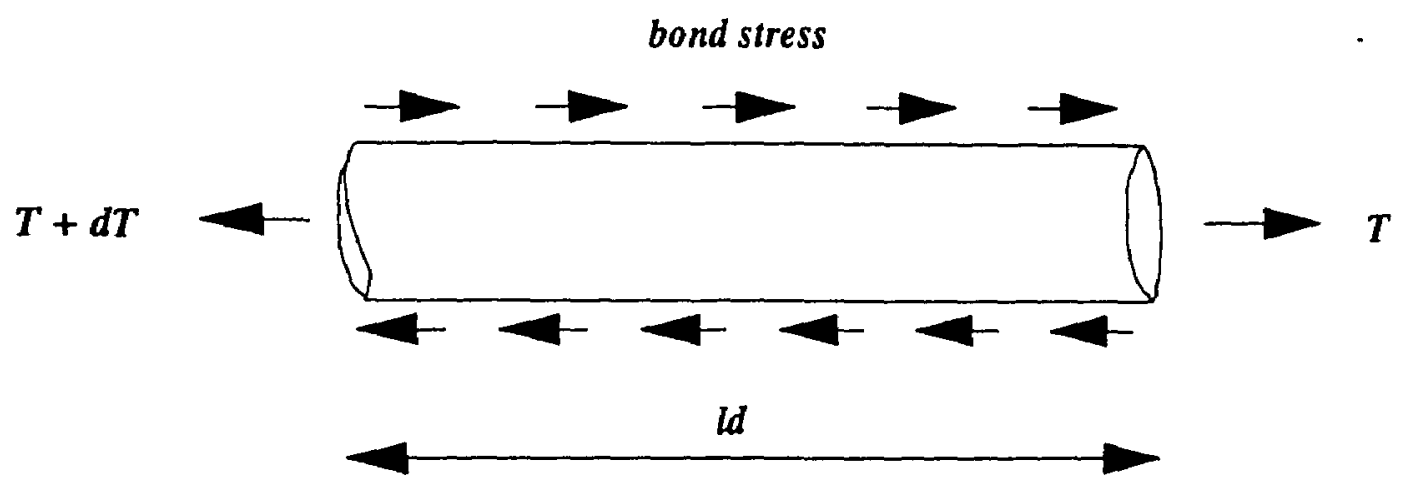

Figure 5.27 Bond forces between concrete and rebar

Assume $l_{d}$ to be the length of a rebar embedded in concrete and subjected to net pulling force dT. If $d_{b}$ is the rebar diameter, $\mu$ is the average bond stress and $f_{f}$ is the stress in FRP rebar due to bending in a beam which leads to a pull-out force, the anchorage pulling force $d T\left(=\mu \pi d_{b} l_{d}\right)$ is equal to the tensile force $\mathrm{dT}$ of the rebar cross section,

$$
d T=\frac{\pi d_{b}^{2}}{4} f_{f}
$$

hence, from equilibrium conditions,

$$
\mu \pi d_{b} l_{d}=\frac{\pi d_{b}^{2}}{4} f_{f}
$$

where,

$$
\begin{aligned}
& \mu=\text { Bond strength (psi) } \\
& d_{b}=\text { Rebar diameter (in) } \\
& l_{d}=\text { Embedment length (in) }
\end{aligned}
$$




$$
f_{f}=\text { Rebar stress }(\mathrm{psi})
$$

from which the bond strength, $\mu$, derived as:

$$
\mu=\frac{f_{f} d_{b}}{4 l_{d}}
$$

and the development length, $l_{d}$

$$
l_{d}=\frac{f_{f}}{4 \mu} d_{b}
$$

\subsubsection{Basic Development Length}

It has been verified by earlier tests on steel rebars that bond strength $\mu$, is a function of the compressive strength of concrete such that

$$
\mu=K \sqrt{f_{c}^{\prime}}
$$

where $K=$ constant

If the bond strength equals or exceeds the yield strength of a rebar with cross sectional area of $A_{b}=\frac{\pi d_{b}^{2}}{4}$, then,

$$
\pi d_{b} l_{d} \mu>A_{b} f_{y f}
$$

from Equation 5.39, the basic development length can be written as:

$$
l_{d b}=k_{b} \frac{A_{b} f_{y f}}{\sqrt{f_{c}^{\prime}}}
$$

where $k_{b}$ is a function of geometric property of a reinforcing bar and the relationship between bond strength and compressive strength of concrete. 


\subsubsection{ACl Approach}

The development length of rebars in tension is computed as function of rebar size, yield strength and concrete compressive strength. The basic development length is modified according to the requirements of the ACI 318-89 code subsections 12.2.3.1, 12.2.3.2 or 12.2.3.3 to reflect the influence of cover, spacing, transverse reinforcement, casting position, type of aggregate and epoxy coating.

The basic development length $l_{d b}$, as specified by the ACI 318-89 code for rebars size of $\# 11$ and smaller is:

$$
l_{d b}=0.04 \frac{A_{b} f_{y}}{\sqrt{f_{c}^{\prime}}}
$$

Where, $l_{d b}$ must not be less than 12 in. and $\sqrt{f_{c}^{\prime}}$ must be less than or equal to 100 which corresponds to concrete compressive strength of $10,000 \mathrm{psi}$.

\subsubsection{Basic development length for FRP rebars}

For FRP rebars deformed with helical wrap of 45 degree and sand coated, the following experimental bond stress $\left(\mu=P / \pi d_{b} l_{d}\right)$, values in Table 5.5 are based on the average of the experimental results of the cantilever test setup and straight pullout results of Chapter 4 outlined in Tables 4.4 and 4.5. In addition a reduction factor $\phi=0.75$, is used: 
Table 5.5 Average experimental bond stress

(concrete compressive strength, $\mathrm{f}_{\mathrm{c}}{ }^{\prime}=10,000 \mathrm{psi}$ )

\begin{tabular}{|c|c|c|c|}
\hline $\begin{array}{c}\text { FRP rebar } \\
\text { size }\end{array}$ & $\begin{array}{c}\text { Average } \\
\text { experimental } \\
\text { bond strength, } \mu \text { e } \\
\text { (psi) }\end{array}$ & $\begin{array}{c}\text { Reduction } \\
\text { factor } \\
\phi\end{array}$ & $\begin{array}{c}\text { Reduced } \\
\text { bond strength } \\
\mu=\phi \mu e \\
\text { (psi) }\end{array}$ \\
\hline \#3 Sand Coated & 2000 & 0.75 & 1500 \\
\hline \#4 Sand Coated & 1375 & 0.75 & 1035 \\
\hline
\end{tabular}

Using the reduced bond strength values in Table 5.5, theoretical development lengths is obtained using the following bond strength and development length relationship given in equation 5.37 which results in a minimum development length of $l_{d b}=6.5 \mathrm{in}$. for \#3 rebar and $10.38 \mathrm{in}$. for \#4 rebar. Using the ACI basic development length Equation (equation 5.41, $l_{d b}=K \frac{A_{b} f_{y f}}{\sqrt{f_{c^{\prime}}}}$, and applying the theoretical embedment length calculated above using equation 5.37, with $f_{y f}$ taken as the effective yield strength of FRP rebar, $f_{c}{ }_{c}^{\prime}$ taken as $10,000 \mathrm{psi}$, and $A_{b}$ as rebar cross sectional area (in ${ }^{2}$.

$$
\begin{aligned}
& K=(6.5 \times 100) /(0.11 \times 104,000)=0.057 \text { for \#3 rebar } \\
& K=(10.38 \times 100) /(0.196 \times 85,600)=0.062 \text { for } \# 4 \text { rebar }
\end{aligned}
$$

From the above calculation of the constant $\mathrm{K}$, the $\mathrm{ACl}$ basic development equation will be modified, to account for the use of FRP rebars: 


$$
l_{d b}=0.06 \frac{A_{b} f_{y f}}{\sqrt{f_{c}^{\prime}}}
$$

In the above calculations of the basic development length equation, a reduced bond strength value is assumed. If the maximum experimental bond stress value is used without a reduction factor $\phi$, the constant $K$ will become 0.0426 for $\# 3$ rebar and 0.0465 for \#4 rebar.

Taking into account that the ACI $318-89$ code provisions for the calculation of development length, $l_{d}$, include different safety factors that will increase the development length to a safe limit, it is therefore recommended that the $\mathrm{ACI}$ equation be used for FRP rebars with no alterations. Until more definitive stress levels are established by testing many more specimens, the values in Table 5.5 will be used for design purposes. 


\section{CHAPTER 6}

\section{DESIGN AIDS FOR CONCRETE BEAMS REINFORCED WITH FIBER REINFORCED PLASTIC REBARS}

Concrete beams can be designed either using the ultimate strength design theory or the working stress (elastic) design theory. Adequate information on FRP rebar material properties should be available to the designer in order to be able to design concrete sections to sustain the required loads. Based on the experimental results obtained by Wu (1990) on the properties of FRP rebars and based on our experimental and theoretical corelation of Chapter 4 and 5 , it is recommended to test a minimum of six rebar samples of the same size (as needed in a beam design) to obtain the ultimate tensile strength of a rebar. Considering the fact that FRP rebars do not exhibit a yield plateau as the steel rebars, for reasons of safety, it is necessary to assume a reduced value for an effective yield strength of the rebar.

The effective yield strength of FRP rebars should be calculated based on the following reduction factor, $r$

$$
f_{y e}=r f_{u l t}
$$

where,

$f_{y e}=$ Effective yield strength of FRP rebars

$f_{u l t}=$ Ultimate strength of FRP rebars obtained from the average of a minimum of six samples of the same size or values given in Table 6.1. 


$$
r=\text { Reduction factor }=0.8
$$

The reduction factor was arrived at after extensive testing of samples from both International Grating, Inc., and Vega Technologies, Inc. If testing of rebar samples is not possible, the following results (Table 6.1) can be used to obtain the effective yield strength of FRP rebars. These values are used throughout this chapter.

Table 6.1 Effective yield strength of FRP rebars

\begin{tabular}{|c|c|c|}
\hline REBAR & $\begin{array}{c}f_{u l t^{*}} \\
(p s i)\end{array}$ & $\begin{array}{c}f_{y e} \\
(p s i)\end{array}$ \\
\hline$\# 3$ & 130,000 & 104,000 \\
\hline$\# 4$ & 107,000 & 85,600 \\
\hline$\# 5$ & 95,000 & 76,000 \\
\hline$\# 6$ & 90,000 & 72,000 \\
\hline$\# 7$ & 85,000 & 68,000 \\
\hline & & \\
\hline & & 64,000 \\
\hline
\end{tabular}

* Based on tesı data on Kodiak Rebars 


\subsection{Design Charts and Tables}

Based on the yield strength of FRP rebars in Table 6.1, which are manufactured by International Grating, Inc., (KODIAK), the Design Charts and Design Tables in the Appendix were developed using the following equations.

$$
\begin{aligned}
& 0.85 \\
& \beta_{l}=0.85-0.05\left(\frac{f c^{\prime}-4000}{1000}\right) \\
& \text { for } f_{c}{ }^{\prime}<4000 p s i \\
& 0.65 \\
& \text { for } 4000<f_{C}^{\prime}<8000 p s i \\
& \text { for } f_{c}{ }^{\prime}>8000 \text { psi }
\end{aligned}
$$

Balanced Reinforcement Ratio ( Ultimate Strength Design Theory)

$$
\rho_{b a l}=\beta_{l} \frac{0.85 f_{\mathcal{C}}^{\prime}}{f_{y e}} \frac{19500}{19500+f_{y e}}
$$

Minimum Reinforcement Ratio

$$
\rho_{\min }=\frac{2.7 \sqrt{f_{c}^{\prime}}}{f_{y e}}
$$

Ultimate Strength Design Theory

$$
\begin{aligned}
\text { If } \rho<\rho_{b a l} \text { then } M / b d^{2}=\rho f_{y e}\left(l-0.585 \rho \frac{f y e}{f c^{\prime}}\right) \\
\text { If } \rho>\rho_{b a l} \text { then } M / b d^{2}=0.85 f_{c}^{\prime} Y(l-0.5 Y) \\
\text { where } \quad Y=\left(\frac{-1+\sqrt{1+4 X \beta_{1}}}{2 X}\right) \\
\text { and } \quad X=\frac{0.85 f_{c}^{\prime}}{0.003 E_{f} \rho}
\end{aligned}
$$


Crack width analysis

$$
W_{\text {max }}=0.14 f_{f} \frac{2 f_{t}^{\prime}}{\mu_{m}} \frac{A}{\pi D} \times 10^{-3} \text { (in) }
$$

Deflection and Modified Moment of Inertia

Two Concentrated Point Loads at Third Points, $(P, P)$

$$
\Delta_{\max }=\frac{23 P L^{3}}{648 E_{c} I_{m}}(\text { in })
$$

in which,

$$
I_{m}=\frac{23 I_{c r} I_{e}}{8 I_{c r}+15 I_{e}}
$$

One Concentrated Point Load, $P$

$$
\Delta_{\max }=\frac{P L^{3}}{48 E_{c} I_{m}}(\text { in })
$$

in which,

$$
I_{m}=\frac{54 I_{c r} I_{e}}{23 I_{c r}+45 I_{e}}
$$

Uniform Distributed Load, W

$$
\Delta_{\max }=\frac{5 W L^{4}}{384 E_{c} I_{m}} \text { (in) }
$$

in which,

$$
I_{m}=\frac{240 I_{c r} I_{e}}{45 I_{c r}+202 I_{e}}
$$




\section{Basic Development Length}

$$
l_{d b}=0.04 \frac{A_{b} f_{y e}}{\sqrt{f_{c}^{\prime}}}
$$

Working Stress (elastic) Design Theory

Assuming Allowable Stresses

$f_{c}=0.45 f_{c}^{\prime}$

$f_{f}=0.5 f_{y e}$

$k=\sqrt{\rho^{2} n^{2}+2 \rho n}-\rho n$

$k_{b a l}=\frac{n f_{c}}{n f_{c}+f_{f}}$

$\rho_{b a l}=\frac{k^{2}}{2 n(l-k)}$

If $k<k_{b a l}$ then $M / b d^{2}=\rho f_{f}(l-k / 3) \quad(F R P$ Controls Design)

If $k>k_{b a l}$ then $M / b d^{2}=0.5 f_{C} k(1-k / 3)$ (Concrete Controls Design) (6.2l)

\subsection{Design Procedures}

The following design procedures for flexure (using both the ultimate strength design theory and the working stress (elastic) design theory), crack width analysis, deflection behavior and development length are outlined for use with either the Design Equations from section 6.1, or the Design Tables and Charts that are included in the Appendix. 


\subsubsection{Design for Flexure (Ultimate strength design method)}

For a given span length, loading and end conditions, the following steps are needed to design a concrete cross section reinforced with FRP rebars.

Step 1: Choose concrete compressive strength, $\mathrm{f}_{\mathrm{c}}{ }^{\prime}$.

Step 2: Calculate factored moment required for given loading conditions.

Step 3: Assume approximate values for width, height and depth of reinforcement $(b, h$, and d)

Step 4: As a first trial, divide the required factored moment, $M_{n}$, by the assumed depth of the reinforcement, d. Use Design Chart \#1 to obtain the possible reinforcement size and quantity of rebars required by entering the value of $M_{n} / d$ on the $y$-axis of the chart.

Step 5: Obtain the effective yield strength of the rebar size specified in step \#4 from Table 6.1.

Step 6: Calculate balanced reinforcement ratio $\left(\rho_{\text {bal }}\right)$ from Equation 6.3, or obtain value from Design Chart $\# 2$ by entering the $y$-axis with the effective yield strength of FRP rebar used in the design and using the curve that corresponds to the concrete compressive strength.

Step 7: Calculate reinforcement ratio $\left(\rho=A_{f} / b d\right)$.Use the required chart from Design Charts \#3 relevant to the concrete compressive strength. Enter the reinforcement ratio on the $x$-axis. Using the curve that comesponds to the rebar size used obtain a value for $\mathrm{M} / \mathrm{bd}^{2}$. Equations 6.5 and 6.6 can be used to obtain the $M / b d^{2}$ value without using the Design Charts. 
Step 8: Obtain moment provided by multiplying value obtained in step 7 with $b d^{2}$. If moment provided is less than factored moment required, repeat Step 3.

\subsubsection{Design for Flexure (Working stress design theory)}

For a given span length, loading and end conditions, the following steps are to design a concrete cross section reinforced with FRP rebars.

Step 1: Choose concrete compressive strength, $\mathrm{f}_{\mathrm{c}}{ }^{\prime}$.

Step 2: Calculate moment required for given loading conditions.

Step 3: Assume approximate values for width, height and depth of reinforcement $(b, h$, and $d)$

Step 4: As a first trial, divide the required moment, $M$, by the assumed depth of the reinforcement, d. Use Design Char \#4 to obtain the possible reinforcement size and quantity of rebars required by entering the value of $M / d$ on the $y$-axis of the chart.

Step 5: Obtain the effective yield strength of the rebar size specified in step \#4 from Table 6.1. Calculate allowable stresses in concrete and FRP rebar as outlined in Equations 6.15 and 6.16 .

Step 6: Calculate $\mathrm{k}_{\mathrm{bal}}$ as shown in Equations 6.18. Calculate balanced reinforcement ratio $\left(\rho_{\text {bal }}\right.$ ) from Equations 6.19 , or obtain value from Design Chart \#5 by entering the $y$-axis with the allowable stress of FRP rebar used in the design and using the curve that corresponds to the concrete compressive strength used. 
Step 7: Calculate reinforcement ratio $\left(\rho=A_{f} /\right.$ bd $)$.Use the required chan from Design Chart \#6 relevant to the concrete compressive strength. Enter the reinforcement ratio on the $x$-axis. Using the curve that corresponds to the rebar size, obtain a value for $\mathrm{M} / \mathrm{bd}^{2}$. Equations 6.20 and 6.21 can be used to obtain the $\mathrm{M} / \mathrm{bd}^{2}$ value without using the Design Charts.

Step 8: Obtain moment multiplying the value obtained in step 7 with $b d^{2}$. If resisting moment is less than moment required, repeat Step 3.

\subsubsection{Crack Width Analysis}

In order to estimate the maximum crack width that is to form in a concrete beam reinforced with FRP rebars, Equation 6.7 or Design Chart $\# 7$ may be used.

For a concrete cross section, the maximum crack width is estimated using the following steps:

Step 1: Calculate area of concrete in tension that have the same centroid as the reinforcement dividing by the number of the rebars.

Step 2: Obtain the maximum bond stress value for the rebar used.

Step 3: For Ultimate strength design take the value of $f_{f}=f_{y e}$ while for the working stress design theory take $f_{f}$ as the allowable stress value (ksi).

Step 4: Use equation 6.7 to calculate $\mathrm{W}_{\max }$ or obtain crack spacing factor (I') from Design Chart \#7. If Charts are used, calculate $W_{\max }$ by the following relationship:

$$
W_{\max }=0.14 f_{f}\left(I^{\prime}\right)(A / D) \times 10^{-3}
$$

where, $A=$ area of concrete in tension and $D=$ diameter of FRP rebar used. 


\subsection{Deflection and Modified Moment of Inertia Design Equations}

Given span length, loading conditions, and end conditions, the modified moment of inertia equation and the maximum deflection are calculated from Equations 6.8 through 6.13 .

\subsubsection{Development Length}

To account for spacing, amount of cover and transverse reinforcement, the basic development length calculated from Equation 6.4 shall be multiplied by a development length factor from The ACI 318-89 code sections 12.2.3.1, 12.2.3.2 or 12.2.3.3 but shall not be less than 12 in.

\subsection{Design Example}

Design a simply supported concrete beam reinforced with FRP rebars to resist a moment of $M_{n}=3,500,000$ in.lb. using the Ultimate Strength Design Theory.

Solution:

1) Choose $f_{c}{ }^{\prime}=7000 \mathrm{psi}$

2) $M_{n}=3,500,000$ in.lb.

3) Take $b=d / 2$ to satisfy deflection requirements

$$
b=12, d=24 \text { and } h=27 \text { (in) }
$$

4) $M_{n} / d=145,833$

from Design Chart \#1, possible reinforcements are $3 \# 8,5 \# 6,7 \# 5$ or $9 \# 4$

5) Try \#6 rebars with $f_{y e}=72 \mathrm{ksi}$ from Table 6.1 
6) $\rho_{\text {bal }}=0.0123$ obtained from Design Chart \#2

$$
\rho_{\max }=0.00923
$$

7) When $5 \# 6$ rebars are used, $A_{f}=2.2$ in $^{2}$.

$$
\rho=0.00764>\rho_{\min }=0.00314
$$

8) Use Equations $6.5, \mathrm{M}=2.2 \times 72000 \times 24(1-0.585 \times 0.00764 \times 7000 / 72000)$

$$
=3,800,000 \text { in.lb. }>M_{n} \text { required }
$$

or obtain $\mathrm{M} / \mathrm{bd} \mathrm{d}^{2}$ from Design Chart \#3 for concrete compressive strength of $7000 \mathrm{psi}$,

$$
\mathrm{M} / \mathrm{bd}^{2}=550
$$

with $b=12$ in, and $d=24$ in, therefore, $M_{n}$ provided $=3.8 \times 10^{6}$ in.lb.

\section{DESIGN FOR FLEXURE O.K.}

Rework design Example to carry a service load bending moment of 1,900,000 in.lb.

(Using Working Stress Design Theory Equations and Design Charts)

Using Design Equations 6.15 - 6.21 and Design Chars \#4, \#5 and \#6.

1) Use Concrete compressive strength, $\mathrm{f}_{\mathrm{c}}{ }^{\prime}=7000 \mathrm{psi}, \mathrm{f}_{\mathrm{c}}=3150 \mathrm{psi}$

2) Use \#6 rebar, $f_{y e}=72000 \mathrm{psi}, f_{\mathrm{f}}=36,000 \mathrm{psi}$

3) $n=$ modular ratio $=1.5$ 
4) $\mathrm{k}_{\mathrm{bal}}=0.116$

5) $M=0.5 f_{c} b k d(d-k d / 3)$

assume $b=d / 2$

$1.9 \times 10^{6}=0.5 \times 3150 \times 0.5 \times 0.116 \times(1-0.0386) d^{3}$

$$
\begin{aligned}
& d^{3}=21634.2 \\
& d=27.86 \text { in and } b=13.93
\end{aligned}
$$

use $b=14$ in. and $d=28$ in.

$\mathrm{A}_{\mathrm{f}}$ required $=\left(1.9 \times 10^{6}\right) /\left(36000 \times 28 \times(1-0.0386)=1.96 \mathrm{in}^{2}\right.$

$\mathrm{A}_{\mathrm{f}}$ provided $=2.2 \mathrm{in}^{2}$

$\rho=0.0056$

$\mathrm{k}=0.121>\mathrm{k}_{\mathrm{bal}}=0.116$

Moment provided $=0.5 \times 3150 \times 14 \times 0.121 \times 28(28-1.13)=2,000,000$ in.lb. $>$ req'd

$$
f_{f}=34434 \text { psi (stress in FRP) }
$$

DESIGN FOR FLEXURE O.K.

\section{Crack Width Check}

1) For Ultimate Design

If Bond Strength is not available, use

$$
\mathrm{W}_{\max }=0.30 \times 72 \times 1.2 \times \sqrt[3]{3 \times 14.4} \times 10^{-3}=0.09 \mathrm{in}
$$


If Bond Strength is available for \#6 rebar ( $\mu=1000 \mathrm{psi}$ )

$$
\begin{aligned}
W_{\max } & =0.14 \times 72 \times(2 \times 627 \times 14.4) /(1000 \times 3.14 \times 0.75) \times 10^{-3} \\
& =0.077 \mathrm{in} .
\end{aligned}
$$

2) For Working Stress Design

If Bond Strength is not available,

$$
\mathrm{W}_{\max }=0.30 \times 36 \times 1.2 \times \sqrt[3]{3 \times 16.8} \times 10^{-3}=0.048 \mathrm{in}
$$

If Bond Strength is available for $\# 6$ rebar $(\mu=1000 \mathrm{psi})$

$$
\begin{aligned}
\mathrm{W}_{\max } & =0.14 \times 36 \times(2 \times 627 \times 16.8) /(1000 \times 3.14 \times 0.75) \times 10^{-3} \\
& =0.045 \mathrm{in} .
\end{aligned}
$$

Development Length Check

$$
\begin{aligned}
& l_{d b}=0.04 \times 0.60 \times 72000 / 83.67=20.65 \mathrm{in} . \\
& l_{d}=2.0 \times 20.65=41.31 \text { in. is the minimum development length. }
\end{aligned}
$$

\section{Deflection Check}

Depth to width ratio satisfy $\mathrm{ACI}$ requirements.

$$
I_{c r}=1655 \mathrm{in}^{4}, I_{e}=1977 \mathrm{in}^{4}, I_{m}=1754 \mathrm{in}^{4}
$$


Design summary and comparison with steel reinforced beam:

$$
\begin{aligned}
& b=12 \text { in } \\
& d=24 \text { in } \\
& h-27 \text { in } \\
& f_{c}^{\prime}=7000 \mathrm{psi} \\
& E_{c}=4.45 \times 10^{6} p s i
\end{aligned}
$$

\section{ERP Design}

Use 5\#6 FRP rebars, $A_{f}=2.2$ in $^{2}$

$$
\begin{aligned}
& \mathrm{f}_{\mathrm{ye}}=72,000 \mathrm{psi} \\
& \mathrm{E}_{\mathrm{f}}=6.5 \times 10^{6} \mathrm{psi} \\
& \text { Moment Provided, } \mathrm{M}_{\mathrm{n}}=3,800,000 \mathrm{in.l \textrm {l }}
\end{aligned}
$$

Use $10 \# 4$ FRP rebars, $A_{f}=2.0$ in $^{2}$

$$
\mathrm{f}_{\mathrm{ye}}=85,600 \mathrm{psi}
$$

Moment provided, $\mathrm{Mn}=3,870,00 \mathrm{in} . \mathrm{lb}$

Analysis of equivalent STEEL reinforced beam yileds the following:

$$
\text { For } 5 \text { \#6 Steel rods }\left(f_{y}=36,000 p s i\right), M_{n}=1,840,000 \text { in.lb }
$$

For $10 \# 4$ Steel rods $\left(f_{y}=36,000 p s i\right), M_{n}=1,600,000$ in.lb 


\section{CHAPTER 7}

\section{SUMMARY, CONCLUSIONS, AND RECOMMENDATIONS}

This Chapter contains a summary, conclusions and recommendations based on the experimental results outlined in Chapter 4, the theoretical correlations with experiment results of Chapter 5 and the recommended engineering design equations discussed in Chapters 5 and 6. It also lists some recommendations for future research.

\subsection{Summary}

Use of FRP rebars as reinforcing element of concrete members in constructed facilities has been limited due to several factors: poor quality of rebars, smoothness of surface and associated poor bond strength, lack of design guidelines, and high material cost, among others. However, salient characteristics of FRP rebars, mainly its noncorrosive and nonmagnetic nature, motivated practice engineers to use FRP rebars in reinforced concrete structures. The dramatic deterioration of the U.S. constructed facilities due to corrosion motivated further research in the area of FRP rebars. As a consequence, substantial improvements in the product have been achieved. Particularly important are the utilization of helical wrap and sand coating on the rebar surface to improve the bond between concrete and FRP rebar. Yet, current FRP rebar manufacturing and testing techniques are not standardized and concrete reinforced with FRP rebars design methods are far from reaching the advancements reached in concrete design with steel rods.

Based on the mechanical properties of FRP rebars obtained by Wu (1990), forty seven concrete beams were designed and tested subjected to bending and bond forces. 
Variables included concrete strengths (4 ksi - $10 \mathrm{ksi}$ ), type of FRP rebar (smooth, ribbed, sand coated), and rebar size. Pre- and post-cracking behavior of the concrete beams reinforced with FRP rebars load-deflection and stress variations, elastic and ultimate load carrying capacities, crack widths and patterns, bond stress and embedment length, and modes of failure were investigated. In order to take advantage of the high tensile strength of FRP rebars i.e. 80 to $130 \mathrm{ksi}$, use of high strength concrete in lieu of regular strength concrete (10 vs $4 \mathrm{ksi}$ ) was essential. The use of sand coated FRP rebars in addition to high strength concretes improved the overall behavior of the beams in terms of the ultimate moment capacity, crack width and propagation, bond strength and modes of failure. In addition, a $90 \%$ increase in ultimate moment capacity is achieved over beams reinforced with steel rebars for same area and concrete strength. The bond strength of FRP rebars is dependent on the quality of the surface condition of the rebarș. An average bond strength of 2200 psi was achieved when deformed sand coated \#3 rebar was used with concrete strength of 10,000 psi. FRP rebar strain distribution along the embedment length was established using strain gages along the embedment length which is found to be parabolic with maximum value near the loaded end as shown in Figure 4.17.

Theoretical correlations with experimental results was conducted using current ACI 318-89 code provisions. The current design methodology for steel reinforced concrete beams cannot be applied directly to FRP reinforced concrete beams. New design equations parallel to the ACI 318 code provisions were established based on the experimental results outlined in Chapter 4. Ultimate strength design method and working stress design method were developed. In addition, crack width, modified moment of inertia, and required development length expressions were established.

Using the design equations developed in Chapter 5, Design tables and charts were developed for different concrete strengths and different FRP rebar sizes. 


\subsection{Conclusions}

The following conclusions are based on the experimental results outlined in Chapter 4 and the theoretical correlations with experimental results of Chapter 5 and 6.

1. In order to take advantage of the high ultimate tensile strength of FRP rebars; i.e. 80 to $130 \mathrm{ksi}$, use of high strength concrete in lieu of regular strength concrete (10 ksi vs $4 \mathrm{ksi}$ ) is essential. The ultimate moment capacity of high strength concrete beams $\left(\mathrm{fc}^{\prime}=\mathbf{7 . 5} \mathrm{ksi}\right)$ was increased by $90 \%$ when FRP rebars of ultimate tensile strength of $130 \mathrm{ksi}$ were used in lieu of mild steel rods (60 ksi) as outlined in Table 4.2. In addition, ductility of FRP reinforced concrete beams is far superior ( 3 times more) to the steel reinforced beams.

2. The ultimate moment capacity of concrete beams reinforced with sand coated rebars is about $70 \%$ higher than beams reinforced with steel rebars for same area and concrete strength (Beam D\#VH2, Table 4.4). The use of sand coated FRP rebars in addition to high strength (6 - $10 \mathrm{ksi})$ concrete is found to increase the cracking moment of the beams and reduce the crack widths as shown in Figure 4.4, in addition to eliminating the sudden propagation of the cracks toward the compression zone. This behavior is related to a better bond between the sand coated rebar and concrete. The crack pattern is very similar to a pattern expected of a beam reinforced with steel rods.

3. A $50 \%$ increase in ultimate moment was obtained without bond failure when deformed FRP stirrups were used in lieu of smooth FRP stirrups. Increase the perimeter of the rebars, i.e. $5 \# 3$ versus $3 \# 4$, has lead to increase in the ultimate moment capacity by $50 \%$. Bond failure between smooth FRP rebar and concrete is observed (Beam \#C1).

4. Both the ultimate strength design method and the working stress (elastic) design method for flexure design of concrete beams reinforced with FRP rebars are acceptable. Design equations are developed to establish balanced reinforcement for both the ultimate 
design theory and working stress theory, so that engineers can design concrete beams reinforced with FRP rebars as required by the $\mathrm{ACI} 318-89$ provisions.

5. In order to estimate the maximum crack width of FRP reinforced concrete beams, knowledge of the rebar bond strength with concrete is essential before utilizing the proposed crack width equation 5.13. Otherwise, as a conservative design practice, the crack width may be estimated to be four times that of steel reinforced concrete beams (equation 5.9).

6. Due to the nature of crack formation and propagation in FRP reinforced concrete beams, and the low modulus of elasticity of FRP rebars, a modified effective moment of inertia equation is proposed herein to estimate deflection. The modified effective moment of inertia incorporates both the cracked moment of inertia as well as the current $\mathrm{ACI}$ code equation (equation 5.24).

7. The basic development length of FRP rebars should be computed using equation 5.42 utilizing the current ACI 318-89 code modifications for development lengths without any changes.

8. A reusable gripping mechanism for testing FRP rebars was developed (Figure 3.6). Tensile strengths of FRP rebars obtained by Wu (1990) coincide with the tensile strength of FRP rebars from the bond tests when rebar failure occurred outside the concrete block in tension and also the ultimate tensile strength of the rebars in concrete beams under bending at failure. Considering the fact that FRP rebars do not exhibit a yield plateau as the steel rebars, it is necessary to assume a reduced value of $85 \%$ of the ultimate tensile strength for an effective yield strength as a resistance factor for the FRP material. 


\subsection{Recommendations}

To improve the applicability of FRP rebars as reinforcing elements in concrete structures, the following work is recommended to be undertaken in the future.

\subsection{FRP rebars}

1. Development of standardized manufacturing techniques including surface conditions.

2. Development of standardized testing procedure.

3. Improvement of the strength and stiffness characteristic and their reliability.

4. Development of long term degradation / ageing behavior.

5. Understanding fatigue behavior.

\subsubsection{Concrete reinforced with FRP rebars}

1. Confirmation of proposed development length equation (5.44) through additional bond tests.

2. Understanding fatigue behavior.

3. Establishment of long term degradation / ageing behavior of concrete specimen reinforced with FRP rebars under harsh environments.

4. Development of accelerated standard technique to predict bond strength between concrete and FRP rebars by correlating 28 day tests with short term tests ( 3 day test).

5. Establishment of new specifications for crack control limits due to the absence of corrosion in FRP reinforced concrete beams. 
6. Establishment of creep and shrinkage properties.

7. Investigation of the behavior of concrete decks, columns, beam-column joints and other structural elements reinforced with FRP rebars. 


\section{REFERENCE}

A New Aramid Rod for the Reinforcement of Prestressed Concrete Structures, Teijin Limmited, Advanced Composites in Civil Engineering Structures, edited by S. L. Iyer, ASCE, NY, 1991.

AASHTO Standards Specifications for Highway Bridges, 13th edition, Washington, D.C., 1983.

ACI Building Code Requirements for Reinforced Concrete (ACI 318-89), American Concrete Institute, Detroit, MI, 1989.

Babei K., and C. S. Gloyd, "Fiber Reinforced Plastic Rods for Prestressed Concrete Structures," Transportation Research Board (TRB), 68th Annual Meeting, Washington, D.C., January 1989.

Brown V., and C. L. Bartholomew, "FRP Rebar in Reinforced Concrete Member," 8th ASCE Structures Congress, Baltimore, MD, April 1990.

Bunea, S. P., "Precast Concrete Reinforced with GFRP in Lieu of Conventional Steel," Fairleigh Dickinson University, Teaneck, N.J., 1989.

Faza S., and H. GangaRao, "Bending Response of Concrete Beams Reinforced with FRP Rebars for Varying Surface Conditions," Transportation Research Board (TRB), Washington, D.C., January 1991.

Faza S., and H. GangaRao, "Bending and Bond Behavior of Concrete Beams Reinforced with Plastic Rebars," Third Bridge Conference," Transportation Research Board (TRB), Denver, March 1991. 
Faza S., and H. GangaRao, "Bending Response of Beams Reinforced with FRP Rebars for Varying Concrete Strengths," ASCE Specialty Conference on Advanced Composites in Civil Engineering Structures, Las Vegas, January 1991.

Fiberglass Reinforced Plastic Rebar Data Sheet Marshall-Vega Technologies Inc., Marshall, AK, 1988.

Fiberglass Reinforced Plastic Rebar Data Sheet. KODIAK International Grating Inc., Houston, TX, 1989.

Franke L., and R. Wolff, "Glass Fiber Tendons for Prestressed Concrete Bridges", 13th IABSE Congress, Helsinki, 1988.

GangaRao H., and S. Faza, "Behavior of FRP Rebar Under Bending," Rescue of America's Infrastructure Conference, Mayaguez, Puerto Rico, July 1989.

Goldsworthy W., and G. Lubin ed., Handbook of Composites, Van Nostrand Reinhold, New York, pp. 479-490, 1982.

Greene A., "Glass Fiber Reinforced Composites in Building Construction," Transportation Research Board (TRB) Record \#1118, Washington, D.C., 1987.

Halvorsen G., "Code Requirements for Crack Control", Lewis H. Tuthill International Symposium on Concrete and Concrete Construction, ACI Fall Convention, Seattle, 1987.

Kemp E. and W. J. Wilhelm, ACI Journal, 76 (1), 47071 (1979).

Kimura H., H. Takagi and N. Shiratori, SAMPE International Symposium, 22. $1184,1990$. 
Kimura H., H. Takagi and Y. Tomioka, 1st Japan SAMPE International Symposium. 1593, 1989.

Larralde J., L. Renbaum and A. Morsi, "Fiberglass Reinforced Plastic Rebars in Lieu of Steel Rebars," ASCE 7th Annual Structures Congress, San Francisco, CA, 1989.

Larralde J., A. Hamid and A. Morsi, "Behavior of Concrete Beams Reinforced with FRP Rebars," Advanced Composites in Civil Engineering Structures, edited by S.L. Iyer, ASCE, NY, 1991.

Miesseler H., and F. Levacher, "Monitoring Stressing Behavior with Integrated Optical Fiber Sensors," 13th IABSE Congress, Helsinki, 1988.

Nawy E.G., and G. E. Newerth, ASCE Journal of the Structures Division. 1977.

Onig G., A. Otes, G. Giegerich and H. Miesseler, "Monitoring of the Structural Integrity of the ULENBERGSTRASSE Road Bridge in Dusseldorf (FRG)," 12th IABSE Congress, 1987.

Park P., and T. Paulay, Reinforced Concrete Structures, John Wiley and Sons, New York, 1975.

Pleimann, L., Tension and Bond Pull-out Tests of Deformed Fiberglass Rods. Marshall-Vega Technologies Inc., Marshall, AK, June 1987.

- Pleimann L., "Strength, MOE, and Bond of Deformed FRP Rods," Advanced Composites in Civil Engineering Structures, edited by S.L. Iyer, ASCE, NY, 1991. 
Porter M., et.al., "Testing of Glass Fiber Composite Rods for Reinforced Concrete Beams," Advanced Composites in Civil Engineering Structures, edited by S.L. Iyer, ASCE, NY, 1991.

Preis L., and T. Bell, "Fiberglass Tendons for Post-Tensioning Concrete Bridges," Transportation Research Board (TRB) Record \#1118, Washington, D.C., 1989.

Rehm G., "Synthetic resin Reinforced Bundled Glass Fiber Rods as Reinforcement in Concrete Construction", 60 Geburtstag Gewidmet/mit Beitragen Von A.W. Beeby, Berlin Ernst, Verlag Fur Architektur U. Techn. Wiss., 1984.

Roll R., "Use of GFRP Rebar in Concrete Structures," Advanced Composites in Civil Engineering Structures, edited by S.L. Iyer, ASCE, NY, 1991.

Rubinski I., and A. Rubinski, Magazine of Concrete Research. (6), $71-78$ (1954).

Saadatmanesh H., and M. Ehsani, "Fiber Composite Bars for Reinforced Concrete Construction, Univ. of Arizona, 1989.

Structural Plastics Design Manual, American Society of Civil Engineers (ASCE), N.Y., N.Y., 1984.

Wines J., and G. C. Hoff, "Laboratory Investigation of Plastic-Glass Fiber Reinforcement for Reinforced and Prestress Concrete," Reports 1 and 2, U.S. Army Corps of Engineers, Paper 6-779, 1966.

Wu, W. P., "Thermomechanical Properties of Fiber Reinforced Plastic Bars," Ph.D. Dissertation, West Virginia University, 1991. 
Wu W.P., H. GangaRao. and J. Prucz, "Mechanical Properties of Fiber Reinforced Plastic Bars," ASCE Journal of Materials in Civil Engineering, submitted for publication.

Zoch, H. Kimura, T. Iwasaki, and M. Heym, "Carbon Fiber Composite Cables A New Class of Prestressing Members," Transportation Reserach Board Meeting, Washington, DC, Jan., 1991. 
APPENDIX 
DESIGN TABLE \#1

FRP REBAR SELECTION TABLE

\begin{tabular}{|c|c|c|c|c|c|c|}
\hline REBAR SIZE & $\# 3$ & $\# 4$ & $\# 5$ & $\# 6$ & $\# 7$ & $\# 8$ \\
\hline DIAMETER & 0.375 & 0.5 & 0.625 & 0.75 & 0.825 & 1 \\
\hline \hline AREA (in^2) & 0.11 & 0.196 & 0.3 & 0.44 & 0.6 & 0.78 \\
\hline fU = ULTIMATE & 130 & 107 & 95 & 90 & 85 & 80 \\
\hline (YY $8=$ EFFECTIVE YIELD & 104 & 85.6 & 76 & 72 & 68 & 64 \\
\hline
\end{tabular}

\begin{tabular}{|c|c|c|c|c|c|c|}
\hline \hline NUMBER OF REBARS & Mn/bd & Mn/bd & Mn'bd & Mn/bd & Mn/bd & Mn/bd \\
\hline \hline 1 & 11.44 & 16.78 & 22.80 & 31.68 & 40.80 & 49.92 \\
\hline 2 & 22.88 & 33.55 & 45.60 & 63.36 & 81.60 & 99.84 \\
\hline 3 & 34.32 & 50.33 & 68.40 & 95.04 & 122.40 & 149.76 \\
\hline 4 & 45.76 & 67.10 & 91.20 & 126.72 & 163.20 & $199.688^{-}$ \\
\hline 5 & 57.20 & 83.88 & 114.00 & 158.40 & 204.00 & 249.60 \\
\hline 6 & 68.64 & 100.66 & 136.80 & 190.08 & 244.80 & 299.52 \\
\hline 7 & 80.08 & 117.43 & 159.60 & 221.76 & 285.60 & 349.44 \\
\hline 8 & 91.52 & 134.21 & 182.40 & 253.44 & 326.40 & 399.36 \\
\hline 9 & 102.96 & 150.98 & 205.20 & 285.12 & 367.20 & 449.28 \\
\hline 10 & 114.40 & 167.76 & 228.00 & 316.80 & 408.00 & 499.20 \\
\hline
\end{tabular}




\section{Design Chart \#1}

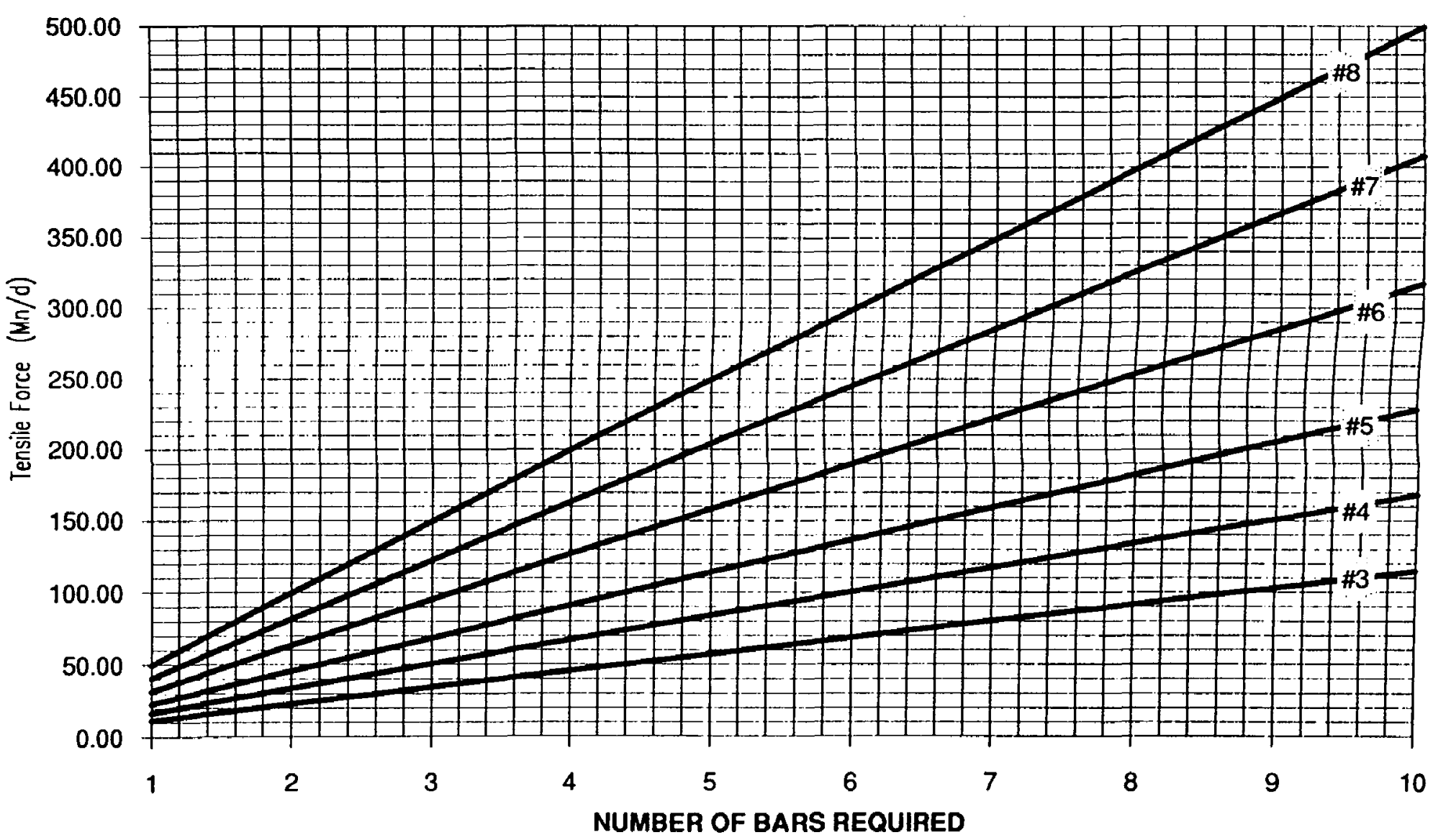


DESIGN TABLE \#2

\section{BALANCED REINFORCEMENT RATIO FOR DIFFERENT CONCRETE STRENGTHS ASSUMING $\mathrm{E}_{\mathrm{f}}=6,500,000$ psi}

\section{(ULTIMATE STRESS METHOD)}

\begin{tabular}{|c|c|c|c|c|c|c|c|}
\hline Fy & 4000 & 5000 & 6000 & 7000 & 8000 & 9000 & 10000 \\
\hline
\end{tabular}

\begin{tabular}{|c|c|c|c|c|c|c|c|}
\hline 50 & 0.016217 & 0.019079 & 0.021464 & 0.023372 & 0.024803 & 0.027903 & 0.031004 \\
\hline 52 & 0.015157 & \begin{tabular}{|l|}
0.017832 \\
\end{tabular} & 0.020061 & 0.021844 & 0.023182 & 0.02608 & 0.028977 \\
\hline 54 & 014199 & 0.016704 & 0.018793 & 0.020463 & 0.021716 & 0.02443 & 0.027145 \\
\hline 56 & 013329 & \begin{tabular}{|l|}
0.015681 \\
\end{tabular} & 0.017641 & \begin{tabular}{|l|}
0.019209 \\
\end{tabular} & 0.020386 & 0.022934 & 0.025482 \\
\hline 58 & 0.012537 & 0.01475 & 0.016593 & 0.018068 & 0.019175 & 0.021571 & 0.023968 \\
\hline 60 & 0.011814 & 0.013899 & 0.015637 & 0.017027 & 0.018069 & 0.020328 & 0.022586 \\
\hline 62 & 0.011153 & 0.013121 & 4761 & 0.016073 & 0.017057 & 0.019189 & 1321 \\
\hline 64 & 0.010545 & 0.012406 & 0.013957 & 0.015198 & 0.016128 & 0.018144 & 0.02016 \\
\hline 66 & 0.009987 & 0.011749 & 0.013218 & 0.014393 & 0.015274 & 0.017183 & 0.019092 \\
\hline 68 & 1471 & 0.011143 & 2536 & & 0.014486 & 6296 & 107 \\
\hline 70 & 0.00 & 0.01 & 1905 & 0.012964 & 0.013757 & 0.015477 & 197 \\
\hline 72 & 0.008554 & 0.010064 & 0.011322 & & & & 354 \\
\hline 74 & 0.008145 & 0.009582 & 0.01078 & 0.011738 & 0.012457 & 014 & 571 \\
\hline 76 & 7765 & 0.00 & 277 & 0.01119 & 0.011875 & 336 & 844 \\
\hline 78 & 0.00 & 0.008718 & 308 & & & & 167 \\
\hline 80 & 0.00708 & 0.008329 & 0.00937 & 0.010203 & 0.010828 & 181 & 3535 \\
\hline 82 & 0.00 & 0.0 & 0.008962 & 0.009758 & 0.010356 & 0.01165 & 945 \\
\hline 84 & & & & & & & 392 \\
\hline 86 & 0.006211 & 0.007307 & 0.008221 & & & 0.0 & 875 \\
\hline 88 & 0.005957 & 0.007008 & 0.007885 & 0.008585 & 0.009111 & & 389 \\
\hline 90 & 18 & 0.00 & 568 & 0.0 & 46 & & 932 \\
\hline 92 & 0.00 & & 271 & & 102 & & 503 \\
\hline 94 & 0.005282 & 0.006214 & 0.006991 & 0.007612 & 079 & 888 & 298 \\
\hline 96 & 0.00 & 0.005979 & 06727 & 0.00 & & 745 & \\
\hline 98 & 0.00 & 0.005758 & 0.006477 & 053 & 0.007485 & 421 & 356 \\
\hline 100 & 0.004716 & 0.005548 & 0.006242 & 0.006796 & 0.007213 & 0.008114 & 0016 \\
\hline 102 & 0.00 & & 19 & 0.0 & 955 & & 693 \\
\hline 104 & 0.004388 & 0.005162 & 0.005807 & 323 & 711 & 0.007549 & 388 \\
\hline 106 & 0.004236 & 0.004984 & 0.005607 & 0.006105 & 0.006479 & 0.007289 & 0.008099 \\
\hline 108 & 0.004093 & 0.004815 & 0.005417 & 5898 & 0.0 & 7042 & 824 \\
\hline 110 & 0.003956 & 4654 & 5236 & 0.005701 & 0.006051 & 6807 & 7563 \\
\hline 112 & 0.003826 & 0.004502 & 0.005064 & 0.005514 & 0.005852 & 0.006584 & 0.007315 \\
\hline 114 & 0.003703 & 0.004356 & 0.004901 & 0.005337 & 0.005663 & 0.006371 & 0.007079 \\
\hline 116 & 0.003585 & 0.004218 & 0.004745 & 0.005167 & 0.005484 & 0.006169 & 0.006854 \\
\hline 118 & 0.003473 & 0.004086 & 0.004597 & 0.005006 & 0.005312 & 0.005976 & 0.00664 \\
\hline 120 & 0.003366 & 0.003961 & 0.004456 & 0.004852 & 0.005149 & 0.005792 & 0.006436 \\
\hline
\end{tabular}


DESIGN TABLE \#2 CONT.

\begin{tabular}{|l|l|l|l|l|l|l|l||}
\hline 122 & 0.003264 & 0.003841 & 0.004321 & 0.004705 & 0.004993 & 0.005617 & 0.006241 \\
\hline \hline 124 & 0.003167 & 0.003726 & 0.004192 & 0.004564 & 0.004844 & 0.005449 & 0.006055 \\
\hline \hline 126 & 0.003074 & 0.003616 & 0.004068 & 0.00443 & 0.004701 & 0.005289 & 0.005877 \\
\hline 128 & 0.002985 & 0.003512 & 0.003951 & 0.004302 & 0.004565 & 0.005136 & 0.005706 \\
\hline \hline 130 & 0.0029 & 0.003411 & 0.003838 & 0.004179 & 0.004435 & 0.004989 & 0.005543 \\
\hline 132 & 0.002818 & 0.003315 & 0.00373 & 0.004061 & 0.00431 & 0.004849 & 0.005387 \\
\hline 134 & 0.00274 & 0.003223 & 0.003626 & 0.003949 & 0.00419 & 0.004714 & 0.005238 \\
\hline 136 & 0.002665 & 0.003135 & 0.003527 & 0.00384 & 0.004076 & 0.004585 & 0.005094 \\
\hline 138 & 0.002593 & 0.00305 & 0.003432 & 0.003737 & 0.003965 & 0.004461 & 0.004957 \\
\hline 140 & 0.002524 & 0.002969 & 0.00334 & 0.003637 & 0.00386 & 0.004342 & 0.004825 \\
\hline
\end{tabular}


CHART \#2 Ultimate Strength Design

Balanced Reinforcement Ratio, $(E f=6500000)$

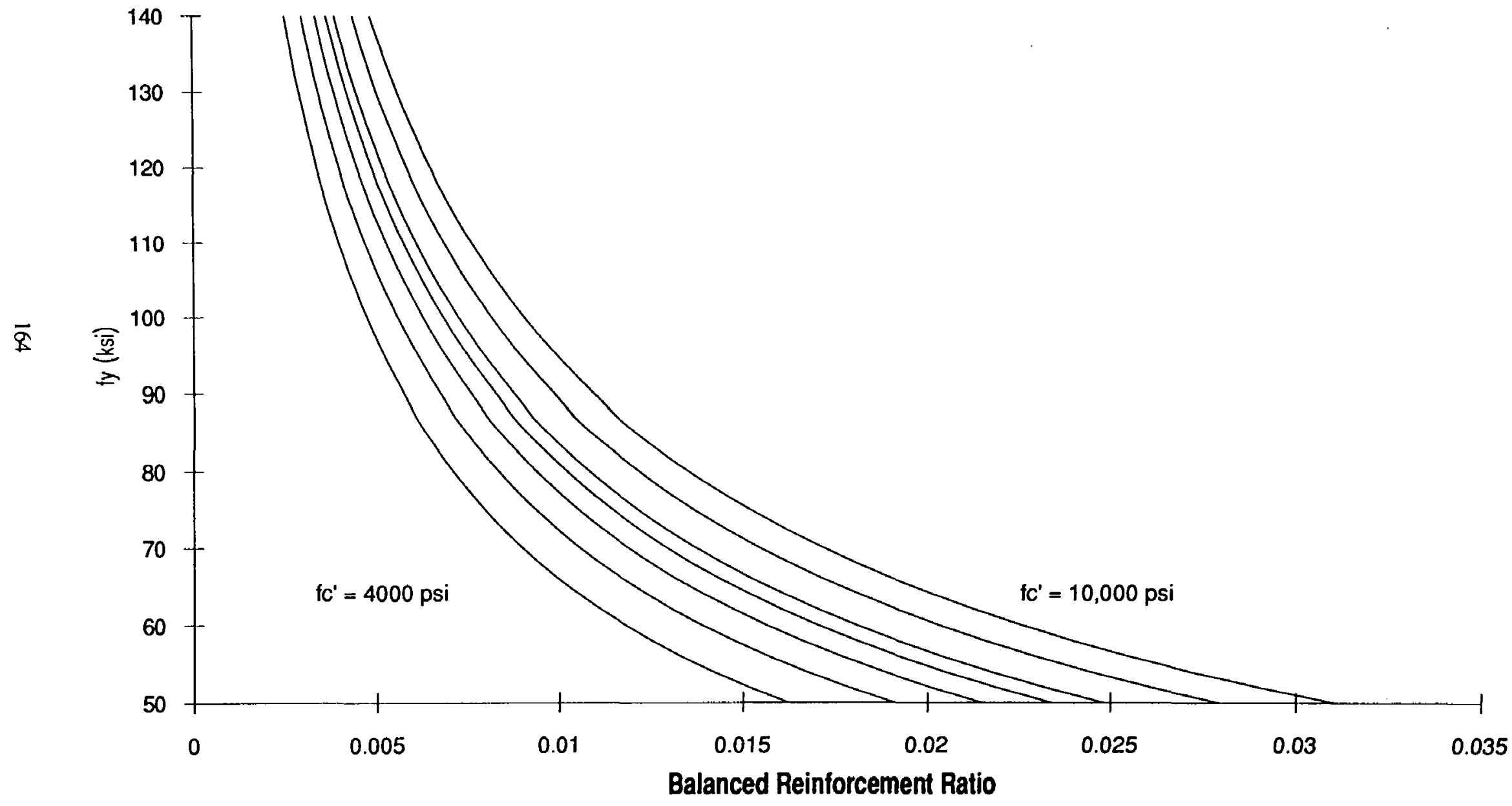


Design Table \#3

Ultimate Moment Capacity for Concrete Beams

Reintorced with FRP rebars $(6,000$ psi)

\begin{tabular}{|c|c|c|c|c|c|c|}
\hline ROW & $\begin{array}{c}\text { Mu/bo^2 } \\
\# 3 \\
\text { tye }=105 \mathrm{ksi}\end{array}$ & $\begin{array}{c}\text { Mu/bd^2 } \\
\# 4 \\
\text { tye }=85 \mathrm{ksi} \\
\end{array}$ & 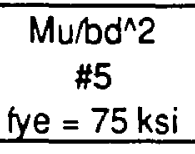 & $\begin{array}{c}\text { Mu/od^2 } \\
\quad \# 6 \\
\text { tye }=70 \mathrm{ksi} \\
\end{array}$ & $\begin{array}{c}\text { Mu/bd^2 } \\
\# 8 \\
\text { tye }=65 \mathrm{ksi}\end{array}$ & $\begin{array}{l}\text { Mu/bd^2 } \\
\text { Concrete } \\
\mathrm{tc}^{\prime}=6 \mathrm{ksi} \\
\end{array}$ \\
\hline 0.0005 & 52 & 42 & 37 & 35 & 32 & 184 \\
\hline 0.001 & 104 & 84 & 74 & 70 & 65 & 256 \\
\hline 0.0015 & 155 & 126 & 111 & 104 & 97 & 310 \\
\hline 0.002 & 206 & 167 & 148 & 138 & 128 & 354 \\
\hline 0.0025 & 256 & 208 & 184 & 172 & 160 & 391 \\
\hline 0.003 & 305 & 249 & 220 & 206 & 191 & 425 \\
\hline 0.0035 & 354 & 289 & 256 & 239 & 222 & 455 \\
\hline 0.004 & 403 & 329 & 291 & 272 & 253 & 483 \\
\hline 0.0045 & 451 & 368 & 326 & 305 & 284 & 508 \\
\hline 0.005 & 498 & 407 & 361 & 338 & 315 & 532 \\
\hline 0.0055 & 545 & 446 & 396 & 371 & 345 & 555 \\
\hline 0.006 & 591 & 485 & 430 & 403 & 375 & 576 \\
\hline 0.0065 & 637 & 523 & 464 & 435 & 405 & 596 \\
\hline 0.007 & 682 & 560 & 498 & 467 & 435 & 615 \\
\hline 0.0075 & 727 & 598 & 532 & 498 & 464 & 633 \\
\hline 0.008 & 771 & 635 & 565 & 529 & 494 & 650 \\
\hline 0.0085 & 815 & 672 & 598 & 560 & 523 & 667 \\
\hline 0.009 & 858 & 708 & 631 & 591 & 552 & 683 \\
\hline 0.0095 & 900 & 744 & 663 & 622 & 580 & 698 \\
\hline 0.01 & 943 & 780 & 695 & 652 & 609 & 713 \\
\hline 0.0105 & 984 & 815 & 727 & 682 & 637 & 727 \\
\hline 0.011 & 1025 & 850 & 759 & 712 & 665 & 741 \\
\hline 0.0115 & 1065 & 884 & 790 & 742 & 693 & 754 \\
\hline 0.012 & 1105 & 919 & 821 & 771 & 721 & 767 \\
\hline 0.0125 & 1145 & 952 & 852 & 800 & 748 & 780 \\
\hline 0.013 & 1183 & 986 & 882 & 829 & 775 & 792 \\
\hline 0.0135 & 1222 & 1019 & 913 & 858 & 802 & 804 \\
\hline 0.014 & 1259 & 1052 & 943 & 886 & 829 & 816 \\
\hline 0.0145 & 1296 & 1084 & 972 & 915 & 856 & 827 \\
\hline 0.015 & 1333 & 1117 & 1002 & 943 & 882 & 838 \\
\hline 0.0155 & 1369 & 1148 & 1031 & 970 & 909 & 849 \\
\hline 0.016 & 1405 & 1180 & 1060 & 998 & 935 & 859 \\
\hline
\end{tabular}




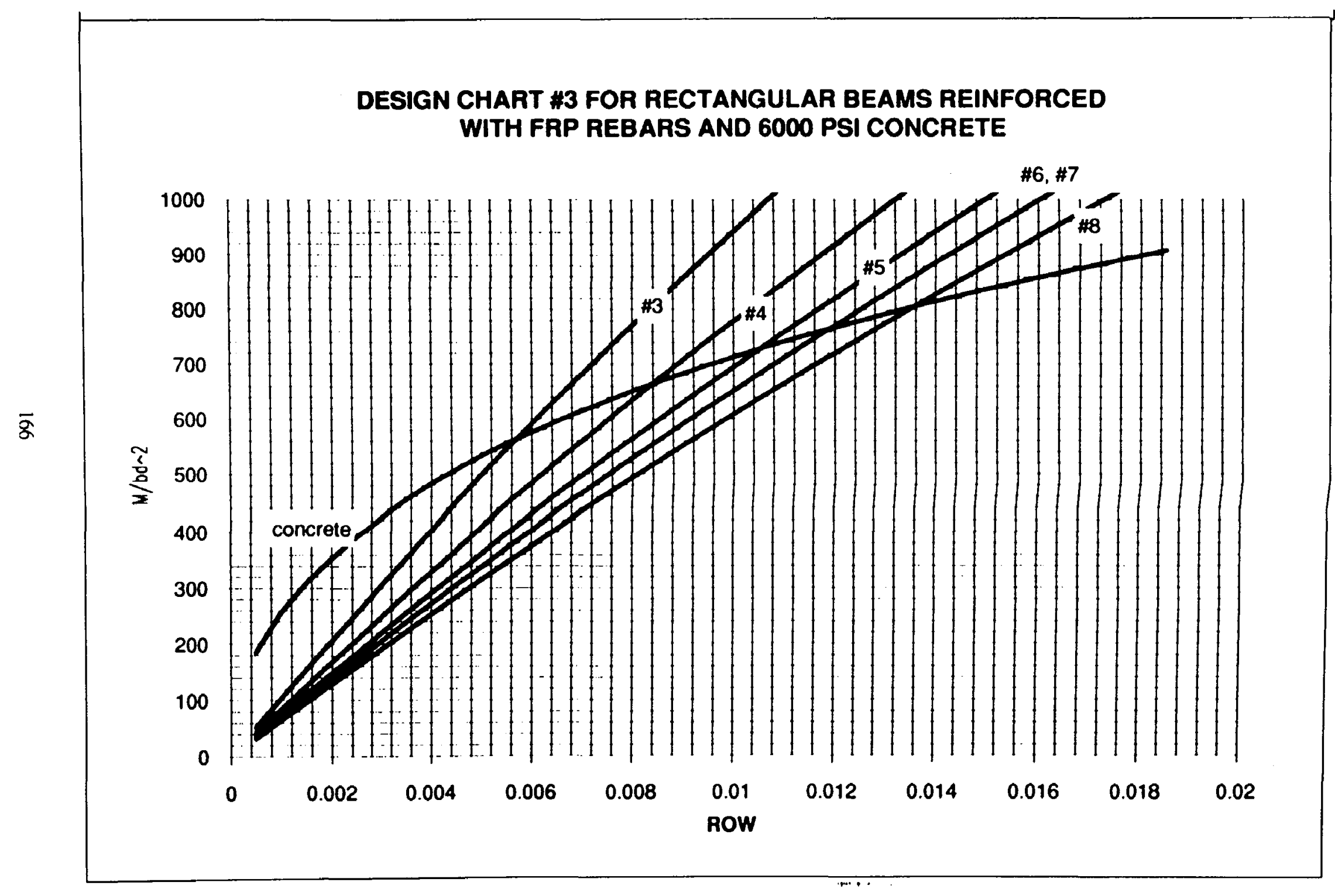


Design Table \#3

Ultimate Moment Capacity for Concrete Beams

Reinforced with FRP rebars $(7,000 \mathrm{psi})$

\begin{tabular}{|ccccccc|}
\hline ROW & Mu/bd^2 & Mu/bd^2 & Mu/bd^2 & Mu/bd^2 & Mu/bd^2 & Mu/bd^2 \\
& $\# 3$ & $\# 4$ & $\# 5$ & $\# 6$ & $\# 8$ & Concrete \\
& tye $=105 \mathrm{ksi}$ & fye $=85 \mathrm{ksi}$ & tye $=75 \mathrm{ksi}$ & tye $=70 \mathrm{ksi}$ & tye $=65 \mathrm{ksi}$ & fc' $=7 \mathrm{ksi}$ \\
\hline
\end{tabular}

\begin{tabular}{|c|c|c|c|c|c|c|}
\hline 0.0005 & 52 & 42 & 37 & 35 & 32 & 193 \\
\hline 0.001 & 104 & 84 & 75 & 70 & 65 & 269 \\
\hline 0.0015 & 155 & 126 & 111 & 104 & 97 & 325 \\
\hline 0.002 & 206 & 168 & 148 & 138 & 129 & 372 \\
\hline 0.0025 & 257 & 209 & 185 & 172 & 160 & 412 \\
\hline 0.003 & 307 & 250 & 221 & 206 & 192 & 447 \\
\hline 0.0035 & 356 & 290 & 257 & 240 & 223 & 479 \\
\hline 0.004 & 405 & 330 & 292 & 273 & 254 & 508 \\
\hline 0.0045 & 454 & 370 & 328 & 307 & 285 & 535 \\
\hline 0.005 & 502 & 410 & 363 & 340 & 316 & 561 \\
\hline 0.0055 & 550 & 449 & 398 & 373 & 347 & 584 \\
\hline 0.006 & 597 & 488 & 433 & 405 & 377 & 607 \\
\hline 0.0065 & 644 & 527 & 468 & 438 & 408 & 628 \\
\hline 0.007 & 690 & 565 & 502 & 470 & 438 & 648 \\
\hline 0.0075 & 736 & 604 & 536 & 502 & 468 & 668 \\
\hline 0.008 & 781 & 641 & 570 & 534 & 497 & 686 \\
\hline 0.0085 & 826 & 679 & 604 & 565 & 527 & 704 \\
\hline 0.009 & 870 & 716 & 637 & 597 & 556 & 721 \\
\hline 0.0095 & 914 & 753 & 670 & 628 & 586 & 738 \\
\hline 0.01 & 958 & 790 & 703 & 659 & 615 & 753 \\
\hline 0.0105 & 1001 & 826 & 736 & 690 & 644 & 769 \\
\hline 0.011 & 1044 & 862 & 768 & 720 & 672 & 784 \\
\hline 0.0115 & 1086 & 898 & 800 & 751 & 701 & 798 \\
\hline 0.012 & 1127 & 933 & 832 & 781 & 729 & 812 \\
\hline 0.0125 & 1169 & 968 & 864 & 811 & 757 & 826 \\
\hline 0.013 & 1209 & 1003 & 896 & 841 & 785 & 839 \\
\hline 0.0135 & 1250 & 1037 & 927 & 870 & 813 & 852 \\
\hline 0.014 & 1289 & 1072 & 958 & 900 & 841 & 864 \\
\hline 0.0145 & 1329 & 1106 & 989 & 929 & 868 & 876 \\
\hline 0.015 & 1368 & 1139 & 1019 & 958 & 896 & 888 \\
\hline 0.0155 & 1406 & 1172 & 1050 & 987 & 923 & 900 \\
\hline 0.016 & 1444 & 1205 & 1080 & 1015 & 950 & 911 \\
\hline & & & & & & \\
\hline
\end{tabular}




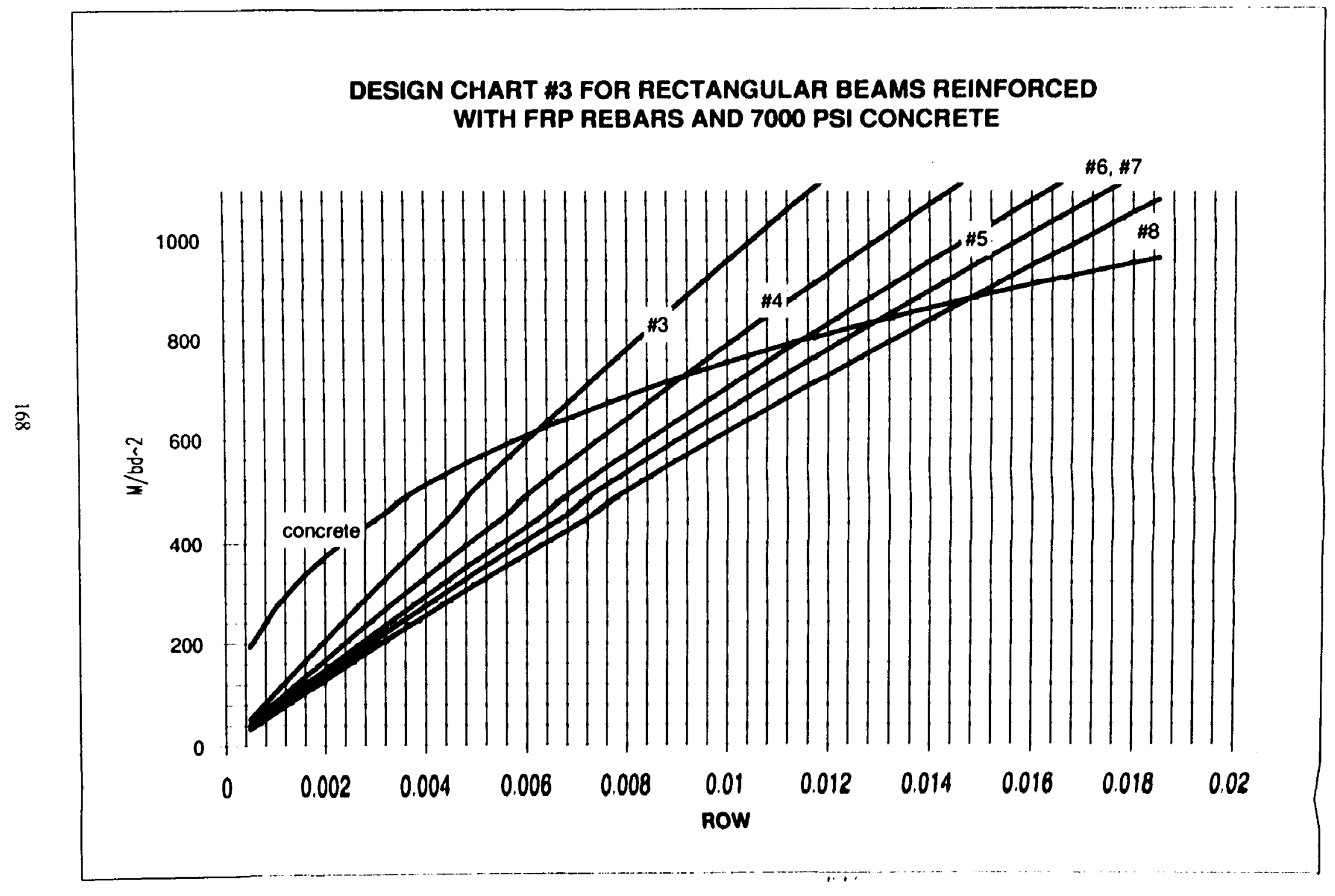


Design Table \#3

Ultimate Moment Capacity for Concrete Beams

Reinforced with FRP rebars (8,000 psi)

\begin{tabular}{|c|c|c|c|c|c|c|}
\hline ROW & 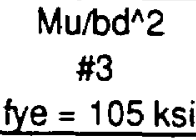 & $\begin{array}{c}\text { Mu/bd^2 } \\
\# 4 \\
\text { tye }=85 \mathrm{ksi}\end{array}$ & $\begin{array}{c}\text { Mu/bd^2 } \\
\# 5 \\
\text { tye }=75 \mathrm{ksi}\end{array}$ & $\begin{array}{c}\text { Mu/bd^2 } \\
\# 6 \\
\text { tye }=70 \mathrm{ksi} \\
\end{array}$ & $\begin{array}{c}\text { Mu/bd^2 } \\
\quad \# 8 \\
\text { tye }=65 \mathrm{ksi}\end{array}$ & $\begin{array}{l}\text { Mu/bd^2 } \\
\text { Concrete } \\
f^{\prime} c^{\prime}=8 \mathrm{ksi}\end{array}$ \\
\hline
\end{tabular}

\begin{tabular}{|c|c|c|c|c|c|c|}
\hline 0.0005 & 52 & 42 & 37 & 35 & 32 & 199 \\
\hline 0.001 & 104 & 84 & 75 & 70 & 65 & 278 \\
\hline 0.0015 & 156 & 126 & 112 & 104 & 97 & 336 \\
\hline 0.002 & 207 & 168 & 148 & 139 & 129 & 384 \\
\hline 0.0025 & 257 & 209 & 185 & 173 & 161 & 426 \\
\hline 0.003 & 308 & 250 & 221 & 207 & 192 & 463 \\
\hline 0.0035 & 358 & 291 & 257 & 241 & 224 & 496 \\
\hline 0.004 & 407 & 332 & 293 & 274 & 255 & 527 \\
\hline 0.0045 & 456 & 372 & 329 & 308 & 286 & 555 \\
\hline 0.005 & 505 & 412 & 365 & 341 & 317 & 582 \\
\hline 0.0055 & 553 & 452 & 400 & 374 & 348 & 607 \\
\hline 0.006 & 601 & 491 & 435 & 407 & 379 & 630 \\
\hline 0.0065 & 648 & 530 & 470 & 440 & 409 & 653 \\
\hline 0.007 & 695 & 569 & 505 & 472 & 440 & 674 \\
\hline 0.0075 & 742 & 608 & 539 & 505 & 470 & 694 \\
\hline 0.008 & 788 & 646 & 574 & 537 & 500 & 714 \\
\hline 0.0085 & 834 & 684 & 608 & 569 & 530 & 732 \\
\hline 0.009 & 880 & 722 & 642 & 601 & 560 & 750 \\
\hline 0.0095 & 925 & 760 & 675 & 633 & 590 & 767 \\
\hline 0.01 & 969 & 797 & 709 & 664 & 619 & 784 \\
\hline 0.0105 & 1014 & 834 & 742 & 695 & 648 & 800 \\
\hline 0.011 & 1057 & 871 & 775 & 727 & 678 & 816 \\
\hline 0.0115 & 1101 & 908 & 808 & 758 & 707 & 831 \\
\hline 0.012 & 1144 & 944 & 841 & 788 & 736 & 846 \\
\hline 0.0125 & 1187 & 980 & 873 & 819 & 764 & 860 \\
\hline 0.013 & 1229 & 1016 & 905 & 849 & 793 & 874 \\
\hline 0.0135 & 1271 & 1051 & 938 & 880 & 821 & 887 \\
\hline 0.014 & 1312 & 1086 & 969 & 910 & 849 & 901 \\
\hline 0.0145 & 1353 & 1121 & 1001 & 940 & 878 & 914 \\
\hline 0.015 & 1394 & 1156 & 1032 & 969 & 905 & 926 \\
\hline 0.0155 & 1434 & 1191 & 1064 & 999 & 933 & 938 \\
\hline 0.016 & 1474 & 1225 & 1095 & 1028 & 961 & 950 \\
\hline
\end{tabular}




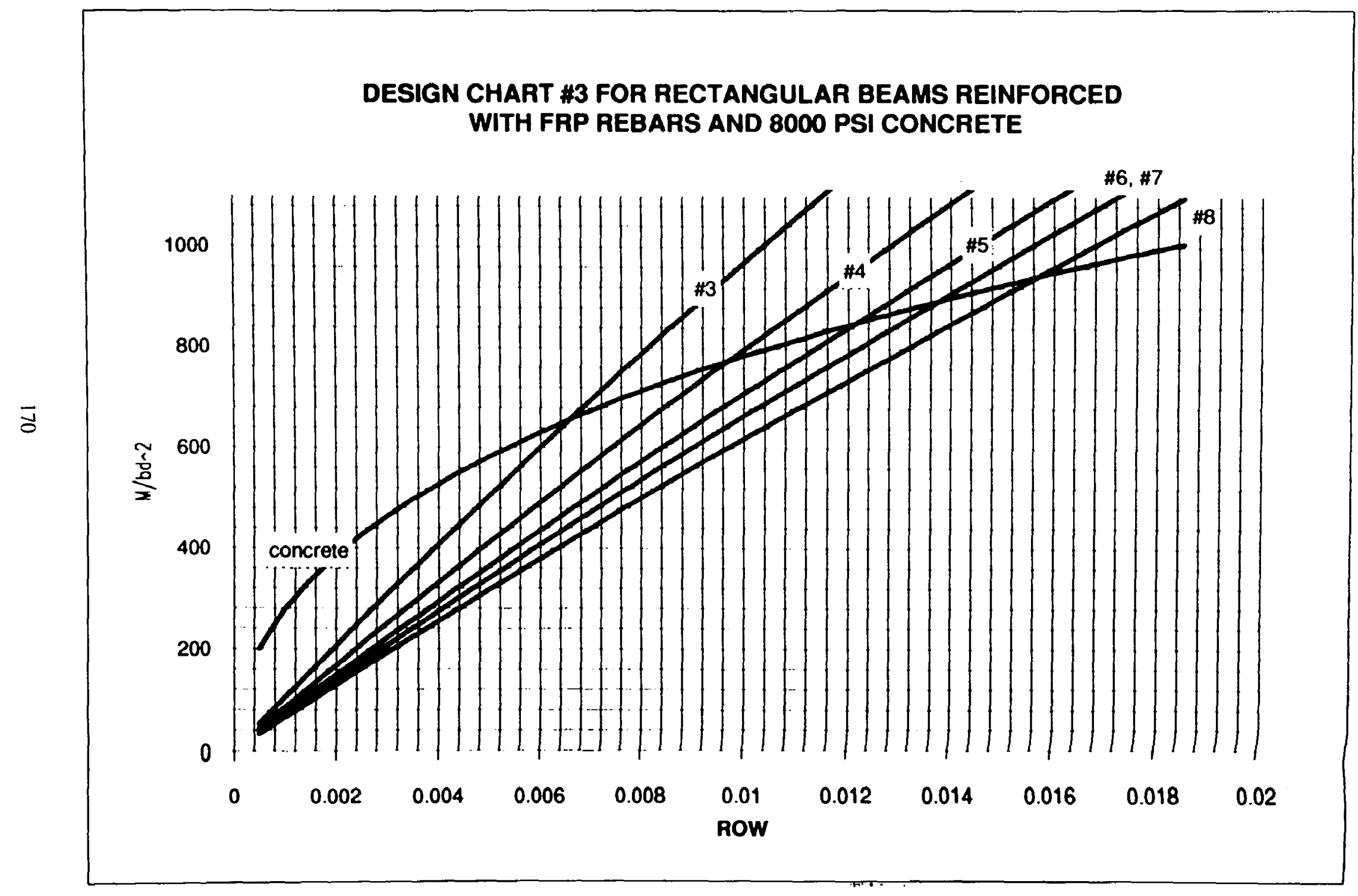




\section{Design Table \#3}

Uthimate Moment Capacity for Concrete Beams

Reinforced with FRP rebars (9,000 psi)

\begin{tabular}{|ccccccc|}
\hline ROW & Mu/bd^2 & Mu/bd^2 & Mu/bd^2 & Mu/bd^2 & Mu/bd^2 & Mu/bd^2 \\
& $\# 3$ & $\# 4$ & $\# 5$ & $\# 6$ & $\# 8$ & Concrete \\
& tye $=105 \mathrm{ksi}$ & fye $=85 \mathrm{ksi}$ & tye $=75 \mathrm{ksi}$ & tye $=70 \mathrm{ksi}$ & tye $=65 \mathrm{ksi}$ & fc' $=9 \mathrm{ksi}$ \\
\hline
\end{tabular}

\begin{tabular}{|c|c|c|c|c|c|c|}
\hline 0.0005 & 52 & 42 & 37 & 35 & 32 & 212 \\
\hline 0.001 & 104 & 85 & 75 & 70 & 65 & 295 \\
\hline 0.0015 & 156 & 126 & 112 & 104 & 97 & 358 \\
\hline 0.002 & 207 & 168 & 149 & 139 & 129 & 409 \\
\hline 0.0025 & 258 & 210 & 185 & 173 & 161 & 454 \\
\hline 0.003 & 309 & 251 & 222 & 207 & 193 & 493 \\
\hline 0.0035 & 359 & 292 & 258 & 241 & 224 & 529 \\
\hline 0.004 & 409 & 332 & 294 & 275 & 256 & 562 \\
\hline 0.0045 & 458 & 373 & 330 & 309 & 287 & 593 \\
\hline 0.005 & 507 & 413 & 366 & 342 & 318 & 621 \\
\hline 0.0055 & 556 & 453 & 401 & 375 & 349 & 648 \\
\hline 0.006 & 604 & 493 & 437 & 409 & 380 & 673 \\
\hline 0.0065 & 652 & 533 & 472 & 442 & 411 & 697 \\
\hline 0.007 & 700 & 572 & 507 & 474 & 442 & 720 \\
\hline 0.0075 & 747 & 611 & 542 & 507 & 472 & 742 \\
\hline 0.008 & 794 & 650 & 577 & 540 & 502 & 763 \\
\hline 0.0085 & 841 & 689 & 611 & 572 & 533 & 783 \\
\hline 0.009 & 887 & 727 & 645 & 604 & 563 & 803 \\
\hline 0.0095 & 933 & 765 & 680 & 636 & 593 & 821 \\
\hline 0.01 & 978 & 803 & 713 & 668 & 623 & 840 \\
\hline 0.0105 & 1023 & 841 & 747 & 700 & 652 & 857 \\
\hline 0.011 & 1068 & 878 & 781 & 731 & 682 & 874 \\
\hline 0.0115 & 1113 & 915 & 814 & 763 & 711 & 890 \\
\hline 0.012 & 1157 & 952 & 847 & 794 & 740 & 906 \\
\hline 0.0125 & 1201 & 989 & 880 & 825 & 770 & 922 \\
\hline 0.013 & 1244 & 1026 & 913 & 856 & 799 & 937 \\
\hline 0.0135 & 1287 & 1062 & 946 & 887 & 827 & 952 \\
\hline 0.014 & 1330 & 1098 & 978 & 918 & 856 & 966 \\
\hline 0.0145 & 1372 & 1134 & 1011 & 948 & 885 & 980 \\
\hline 0.015 & 1414 & 1169 & 1043 & 978 & 913 & 993 \\
\hline 0.0155 & 1455 & 1205 & 1075 & 1008 & 942 & 1007 \\
\hline 0.016 & 1497 & 1240 & 1106 & 1038 & 970 & 1020 \\
\hline & & & & & & \\
\hline
\end{tabular}




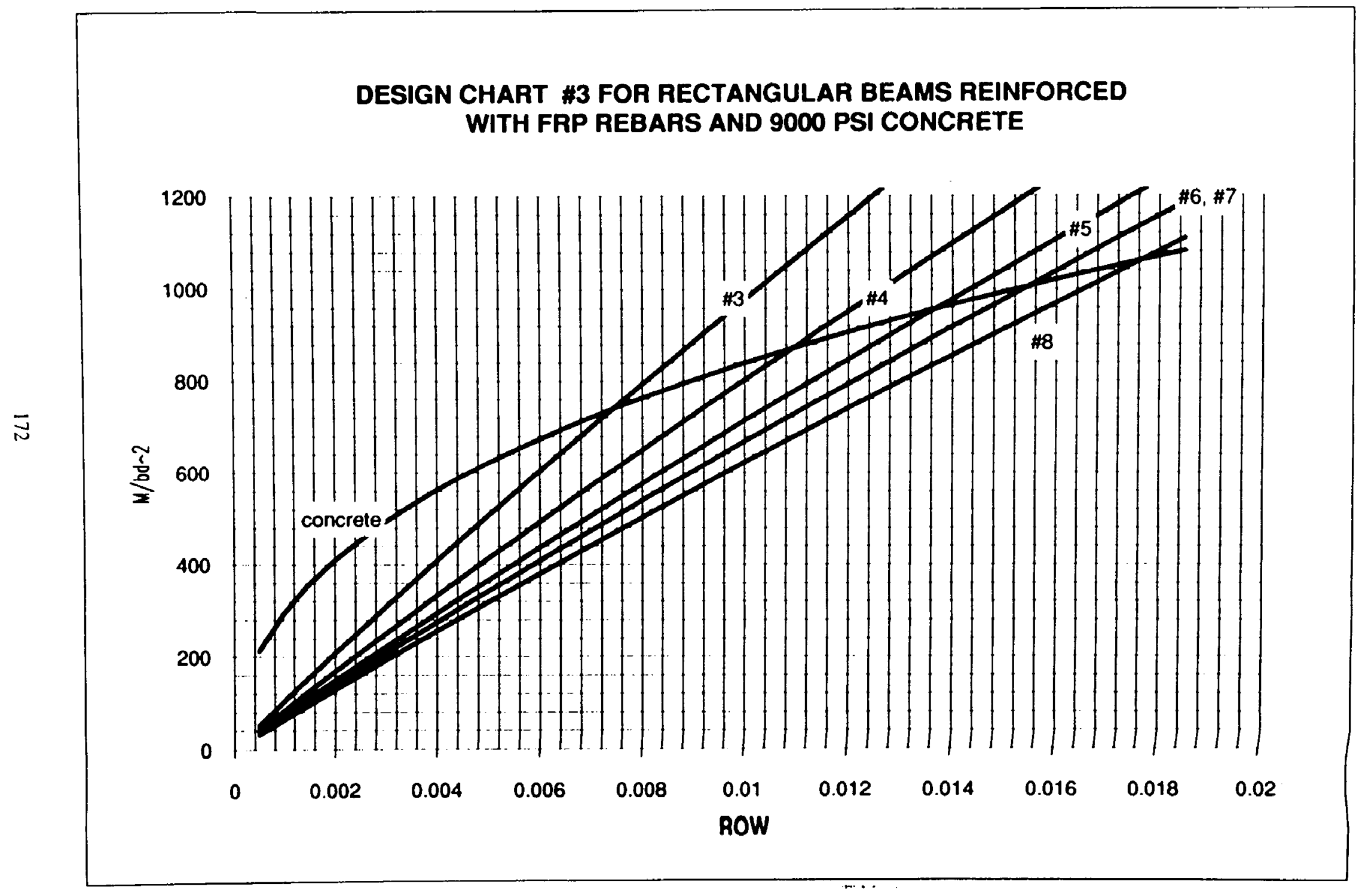


Design Table \#3

Ultimate Moment Capacity for Concrete Beams

Reinforced with FRP rebars $(10,000 \mathrm{psi})$

\begin{tabular}{|c|c|c|c|c|c|c|}
\hline ROW & $\begin{array}{c}\text { Mu/bd^2 } \\
\text { \#3 } \\
\text { fye }=105 \mathrm{ksi}\end{array}$ & $\begin{array}{c}\text { Mu/bd^2 } \\
\# 4 \\
\text { fye }=85 \mathrm{ksi}\end{array}$ & $\begin{array}{c}\mathrm{Mu} / \mathrm{bd}^{\wedge} 2 \\
\quad \# 5 \\
\text { tye }=75 \mathrm{ksi}\end{array}$ & $\begin{array}{c}\text { Mu/bd^2 } \\
\quad \# 6 \\
\text { tye }=70 \mathrm{ksi}\end{array}$ & $\begin{array}{c}\text { Mu/bd^2 } \\
\# 8 \\
\text { tye }=65 \mathrm{ksi}\end{array}$ & $\begin{array}{l}\text { Mu/bd^2 } \\
\text { Concrete } \\
f^{\prime}=10 \mathrm{ksi}\end{array}$ \\
\hline
\end{tabular}

\begin{tabular}{|c|c|c|c|c|c|c|}
\hline 0.0005 & 52 & 42 & 37 & 35 & 32 & 224 \\
\hline 0.001 & 104 & 85 & 75 & 70 & 65 & 313 \\
\hline 0.0015 & 156 & 127 & 112 & 104 & 97 & 379 \\
\hline 0.002 & 207 & 168 & 149 & 139 & 129 & 433 \\
\hline 0.0025 & 258 & 210 & 185 & 173 & 161 & 481 \\
\hline 0.003 & 309 & 251 & 222 & 207 & 193 & 523 \\
\hline 0.0035 & 360 & 292 & 258 & 241 & 224 & 561 \\
\hline 0.004 & 410 & 333 & 295 & 275 & 256 & 596 \\
\hline 0.0045 & 459 & 374 & 331 & 309 & 287 & 629 \\
\hline 0.005 & 509 & 414 & 367 & 343 & 319 & 659 \\
\hline 0.0055 & 558 & 455 & 403 & 376 & 350 & 688 \\
\hline 0.006 & 607 & 495 & 438 & 410 & 381 & 715 \\
\hline 0.0065 & 655 & 535 & 474 & 443 & 412 & 740 \\
\hline 0.007 & 703 & 574 & 509 & 476 & 443 & 765 \\
\hline 0.0075 & 751 & 614 & 544 & 509 & 474 & 788 \\
\hline 0.008 & 799 & 653 & 579 & 542 & 504 & 811 \\
\hline 0.0085 & 846 & 692 & 614 & 574 & 535 & 832 \\
\hline 0.009 & 893 & 731 & 648 & 607 & 565 & 853 \\
\hline 0.0095 & 939 & 769 & 683 & 639 & 595 & 873 \\
\hline 0.01 & 986 & 808 & 717 & 671 & 625 & 893 \\
\hline 0.0105 & 1031 & 846 & 751 & 703 & 655 & 911 \\
\hline 0.011 & 1077 & 884 & 785 & 735 & 685 & 929 \\
\hline 0.0115 & 1122 & 922 & 819 & 767 & 715 & 947 \\
\hline 0.012 & 1167 & 959 & 853 & 799 & 744 & 964 \\
\hline 0.0125 & 1212 & 996 & 886 & 830 & 774 & 981 \\
\hline 0.013 & 1256 & 1034 & 919 & 862 & 803 & 997 \\
\hline 0.0135 & 1300 & 1070 & 953 & 893 & 832 & 1013 \\
\hline 0.014 & 1344 & 1107 & 986 & 924 & 862 & 1028 \\
\hline 0.0145 & 1387 & 1144 & 1018 & 955 & 891 & 1043 \\
\hline 0.015 & 1430 & 1180 & 1051 & 986 & 919 & 1058 \\
\hline 0.0155 & 1473 & 1216 & 1083 & 1016 & 948 & 1072 \\
\hline 0.016 & 1515 & 1252 & 1116 & 1047 & 977 & 1086 \\
\hline 0.0165 & 1557 & 1287 & 1148 & 1077 & 1005 & 1100 \\
\hline 0.017 & 1599 & 1323 & 1180 & 1107 & 1034 & 1113 \\
\hline 0.0175 & 1640 & 1358 & 1212 & 1137 & 1062 & 1126 \\
\hline 0.018 & 1681 & 1393 & 1243 & 1167 & 1090 & 1139 \\
\hline 0.0185 & 1722 & 1428 & 1275 & 1197 & 1118 & 1152 \\
\hline
\end{tabular}




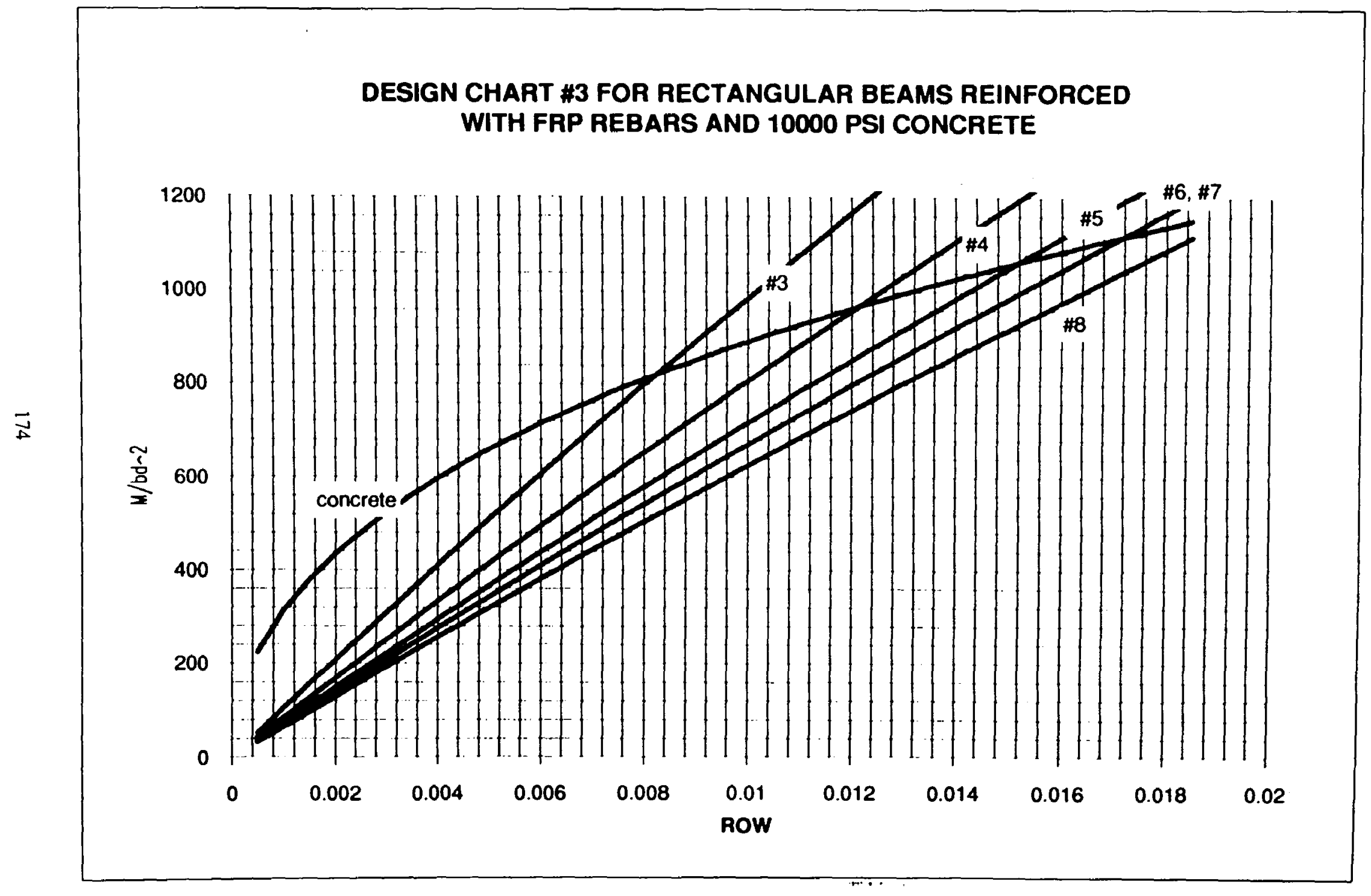


DESIGN TABLE \#4

FRP RREBAR SELECTION TABLE

\begin{tabular}{|c|c|c|c|c|c|c|}
\hline REBAR SIZE & $\# 3$ & $\# 4$ & $\# 5$ & $\# 6$ & $\# 7$ & $\# 8$ \\
\hline \hline DIAMETER & 0.375 & 0.5 & 0.625 & 0.75 & 0.825 & 1 \\
\hline AREA (in^2) & 0.11 & 0.196 & 0.3 & 0.44 & 0.6 & 0.78 \\
\hline \hline fu = ULTIMATE & 130 & 107 & 95 & 90 & 85 & 80 \\
\hline \hline fye = EFFECTIVE YIELD & 104 & 85.6 & 76 & 72 & 68 & 64 \\
\hline \hline $\mathrm{f}=$ WORKING STRESS & 52 & 42.8 & 38 & 36 & 34 & 32 \\
\hline
\end{tabular}

\begin{tabular}{|c|c|c|c|c|c|c|}
\hline NUMBER OF REBARS & Mnbd & Mn/bd & Mnbd & Mnbd & Mnbd & Mnbd \\
\hline 1 & 6 & 8 & 11 & 16 & 20 & 25 \\
\hline 2 & 11 & 17 & 23 & 32 & 41 & 50 \\
\hline 3 & 17 & 25 & 34 & 48 & 61 & 75 \\
\hline 4 & 23 & 34 & 46 & 63 & 82 & 100 \\
\hline 5 & 29 & 42 & 57 & 79 & 102 & 125 \\
\hline 6 & 34 & 50 & 68 & 95 & 122 & 150 \\
\hline 7 & 40 & 59 & 80 & 111 & 143 & 175 \\
\hline 8 & 46 & 67 & 91 & 127 & 163 & 200 \\
\hline 9 & 51 & 75 & 103 & 143 & 184 & 225 \\
\hline 10 & 57 & 84 & 114 & 158 & 204 & 250 \\
\hline
\end{tabular}




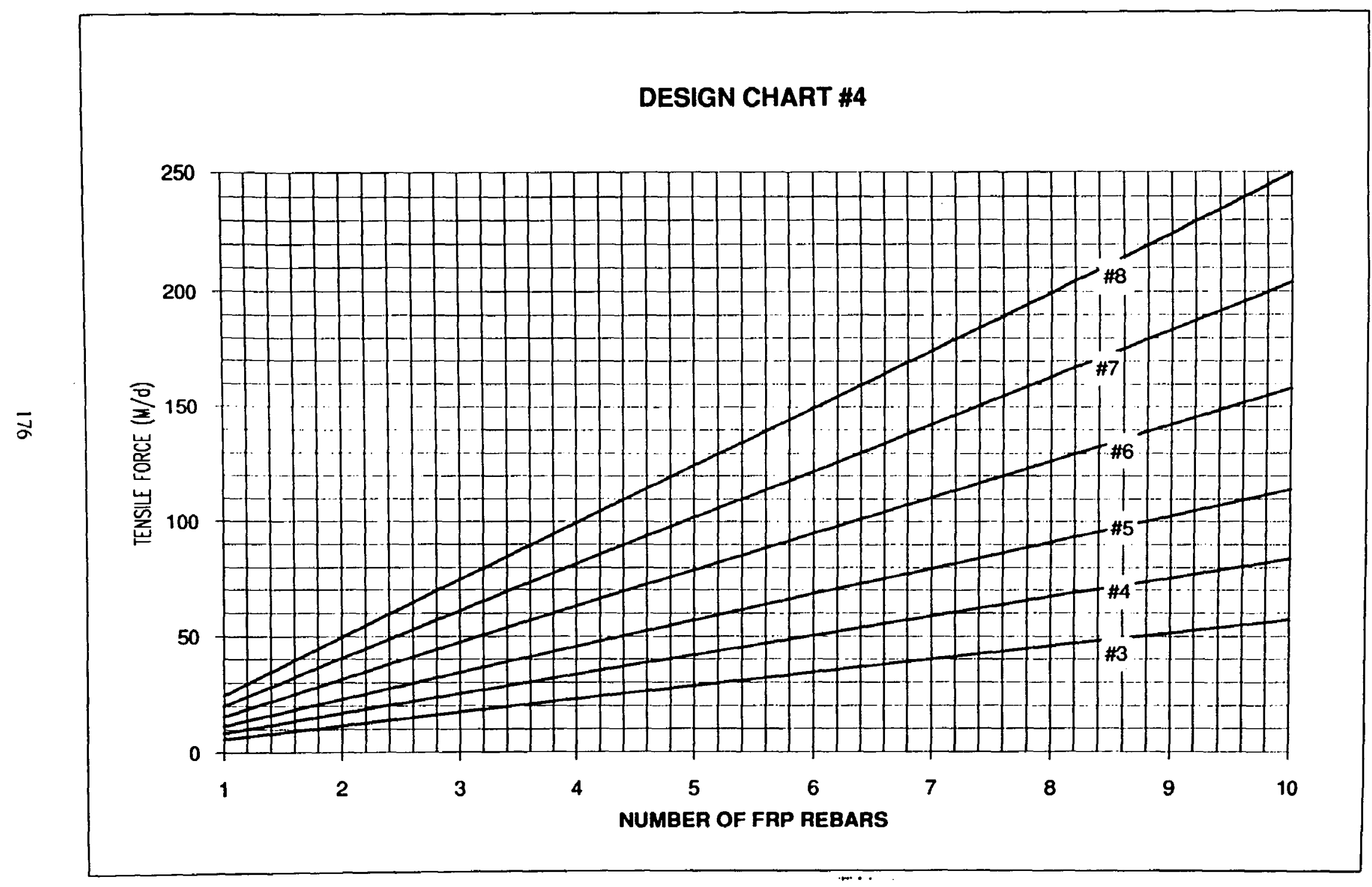


DESIGN TABLE \#5

BALANCED REINFORCEMENT RATIO FOR WORKING STRESS DESIGN ASSUMING Ef $=6,500,00 \mathrm{psi}$

\begin{tabular}{|c|c|c|c|c|c|c|c|c|c|c|c|c|c|c|}
\hline & & & $\infty$ & & 6000 & & 7000 & & 8000 & & 9000 & & 10000 & \\
\hline ty & & Ww & k & & & w & k & $\mathbf{w}$ & k & w & k & ow & k & row \\
\hline & & & & & & & & & & & & & & \\
\hline & & 223918 & & 257] & 3568 & 5482 & 829 & 539 & 3382742 & 894 & & 5911 & & \\
\hline 11000 & .2314142 & 2189339 & 0.2580101 & 0263874 & 2807167 & 344516 & 2004769 & 0.0430228 & 0.317279 & 0.0519184 & 3320379 & .0611307 & 0.347181 & ] \\
\hline 12000 & 2163009 & 0162226 & 2417062 & 02266 & 2634874 & .0296423 & 2825112 & 0.0370796 & 0.2987377 & 0448107 & 0.3130295 & .0528286 & 0.3277311 & 06144 \\
\hline 13000 & 0407] & 0.0140567 & 273403 & 196737 & 82507 & 257799 & 665726 & 0.0322963 & 2822438 & & 0797 & 1243 & 448 & 15371. \\
\hline 14000 & 0.1913124 & 0.0122987 & 0.2145863 & 0172435 & 0.2346799 & 0.0226299 & 2523364 & 0.0283879 & 0.2674759 & 0.0343898 & 0,2808712 & .0406297 & 0.2947103 & 047364 \\
\hline 15000 & .180865 & 0108519 & 2031873 & 015239 & 2225159 & 200264 & 2395437 & 0.0251521 & 0.2541766 & 305012 & 2671487 & 2684 & 0.2805755 & .042086 \\
\hline 16000 & 4996 & 096469 & 929382 & 566 & 5508 & 0178496 & 279855 & 0.0224423 & 2421372 & 72404 & 0.2547047 & .032239 & & \\
\hline 17000 & 0.1630563 & 0.0086324 & 836735 & 1549 & 0.2016156 & 0.0160106 & 0.2174914 & 0.0201499 & 0.2311867 & 0.0244786 & 0.2433683 & 0.0289921 & 0.256 & .033884 \\
\hline 18000 & 0.1554054 & 0077703 & 0.1752577 & 0.0109536 & 0.1925717 & 0.0144429 & 0.2079208 & 0.0181931 & 1838 & 0.02 & 0.2329981 & 0.0262147 & .245283 & .030 \\
\hline 19000 & 0.1484403 & 2070314 & 675794 & .0099225 & 1843043 & 30953 & 99157 & 0165091 & 106 & 852 & 0.2234756 & 0.02382 & 0.23 & 0.027877 \\
\hline 20000 & 0.1420728 & 0.0063933 & 0.1605456 & 0.0090307 & 0.1767176 & 0.011928 & 1911021 & 0.0150493 & 568 & 3211 & 0.2147008 & 0.0217404 & 0.2263056 & 0.025459 \\
\hline 21000 & 0.136229 & 0.0058384 & 0.1540785 & 0.0082542 & 0.1697308 & 0.0109113 & 0.1836735 & 0.0137755 & 0.1957721 & 0.0167805 & 0.2065891 & 0.0199229 & 0.2178771 & 0.023344 \\
\hline 22000 & 0.130847 & 0.0053528 & 1481123 & 0.0075739 & 632754 & 192 & 8007 & 0.0126573 & 1885512 & 4269 & 9068 & 325 & 0.21 & 0.021482 \\
\hline 23000 & 0.1258741 & 0.0049255 & 1425909 & 0.0069746 & 0.1572931 & 0.0092324 & 1704238 & 0.0116703 & 0.1818441 & 0.0142313 & 20753 & 0.0169125 & 0.202773 & 0.0198365 \\
\hline 24000 & 0.1212654 & 0.0045475 & 1374663 & 0.0064437 & 0.1517336 & 0.008535 & 0.1644909 & 0.0107947 & 0.1755977 & & 572 & 6578 & 0.15 & 83731 \\
\hline 25000 & 0.1169822 & 0.0042114 & 0.1326973 & 0.0059714 & 1465538 & 0.0079139 & 1589571 & 0.0100143 & 0.1697662 & 0.0122232 & \begin{tabular}{|l|}
0.179467 \\
\end{tabular} & 0.0145382 & 0.1896272 & 0.017066 \\
\hline 26000 & 0.1129913 & 0.0039112 & 1282481 & 0055492 & 17159 & 0.0073583 & 1537836 & 0.0093157 & 0.1643096 & 3753 & 0.17 & 0.0135348 & 0.18 & 0.015894 \\
\hline 27000 & 0.1092637 & 0.0036421 & 0.1240876 & 0.0051703 & 0.1371872 & 0.0068594 & 0.1489362 & 0.0086879 & 0.1591928 & 6129 & 8412 & 0.0126321 & 0822 . & 0.0148402 \\
\hline 28000 & 0.1057741 & 0.0033999 & 0.1201885 & 0.004829 & 0.132939 & 0.0064096 & 0.144385 & 0.0081217 & 0.1543851 & 0.0099248 & 0.1633799 & 0.011817 & 0.1728213 & 0.0138874 \\
\hline 29000 & 0.1025006 & 0.0031811 & 0.116527 & 0045204 & 0.128946 & 50027 & & 6091 & & & & & & \\
\hline 30000 & & 0.0029827 & 0.113082 & 0042406 & 0.1251859 & 0.0056334 & & 0.0071436 & 0.1455913 & 0.0087355 & 0.1541671 & 0.0104072 & 0.1631799 & 0.0122385 \\
\hline 31000 & 0.096526 & 0.0028024 & 0.1098349 & 0.0039859 & 0.1216389 & 0.0052972 & 0.1322603 & 0.0067197 & 0.1415596 & 0.0082196 & 0.1499397 & 0.0097953 & 0.1587517 & 0.0115223 \\
\hline 32000 & 0.0937925 & 0.0026379 & 0.106769 & 0.0037536 & 0.1182873 & 0.0049902 & 0.128659 & 0.0063324 & 0.1377452 & 0.0077482 & 0.1459379 & 0.009236 & 0.1545575 & 0.016 \\
\hline 33000 & & 0.0024875 & 0.1038697 & 0.003541 & 0.1151154 & 0.0047093 & 0.1252485 & & 0.134131 & & $0.1421441]$ & & & \\
\hline
\end{tabular}


DESIGN TABLE \#5 CONT.

BALANCED REINFORCEMENT RATIO FOR WORKING STRESS DESIGN

ASSUMING Ef $=6,500,00 \mathrm{psi}$

\begin{tabular}{|c|c|c|c|c|c|c|c|c|c|c|c|c|c|c|}
\hline & & & & & & & 0.1220142 & 66521 & 7016 & & & & & \\
\hline 5000 & & & & & & & & & & & & & & \\
\hline 36000 & & & & & & & & & & & & & & \\
\hline 37000 & & & & & & & & & & & & & & \\
\hline 38000 & 1704[ & ] & 1525 & & 1015062 & & & & & & & & & \\
\hline 3900 & & & & & & & & & & & & & & \\
\hline 40000 & & 205 & & & & & & & & & & & & \\
\hline 41000 & 7427 & 0.0016407 & 0.0853318 & 3414 & 7829 & 209 & 3352 & 9696 & 8605 & 4867 & 6724 & & & \\
\hline 42000 & & & & & & & & & & & & & & \\
\hline 43000 & & 968 & & & 745 & & & & & & & & & \\
\hline 44000 & 034 & 0.0014319 & 9791 & 2449 & 8949 & 275 & 728 & 7712 & & 582 & & & & 0. \\
\hline 45000 & 3544 & 3711 & 0.0 & 9585 & 0915 & 6127 & & 3258 & & & & & & \\
\hline 46000 & & & & & & & & & & & & & & \\
\hline 47000 & 2292 & 2606 & 2582 & 3014 & 6956 & 404 & 3485 & 611 & & & & & & \\
\hline 48000 & 463 & 2102 & 0.07 & 7298 & 0951 & 0.0 & 5159 & 9405 & & & & 1148 & & \\
\hline 49000 & & 1629 & 4089 & 6624 & 5547 & 0.0 & 479 & 8269 & & & & & & \\
\hline 50000 & 248 & & & & 1071 & 349 & & & & & & & & \\
\hline 51000 & & 7761 & 7674 & 1539 & 6409 & 0.0020552 & 7914 & 0.0026186 & 1035 & 2154 & 336 & 3452 & & 0.0 \\
\hline 52000 & & 0.0010364 & 5177 & 4824 & 2617 & 0.00 & 966 & 229 & & 984 & & & & 0.0 \\
\hline 53000 & .0588152 & 0.0009987 & 0.0673119 & 4288 & 49306 & 0.00 & 8536 & 24324 & & 9876 & & & & \\
\hline 54000 & & 0009631 & 0661479 & 3781 & 6452 & 3411 & 1598 & 3467 & & & & & & \\
\hline 55000 & 0.0567979 & 0.0009294 & .0650234 & & 4032 & 0.00 & 1126 & 2655 & & & & & & \\
\hline 56000 & 403 & 8974 & 0.0639365 & 0.0012844 & 0.0712023 & 0.0017165 & 7778098 & 0.0021884 & 0.0836497 & 0.0026887 & 0.0889569 & 3217 & 5837. & .00 \\
\hline 57000 & & & & 0.0012412 & 0406 & & 5492 & 152 & & & 5328 & & & \\
\hline 58000 & 0540188 & 88382 & & & & & & & & & & & & \\
\hline & 0.05 & 0.0008108 & 0.0608834 & 0.0011609 & 0.0678274 & 0.001552 & 0.0741467 & 0.0019793 & 0.0797355 & 0.0024326 & 0.0848173 & 0.0029114 & 0.0902082 & 0.003440 \\
\hline & & & 0.0599295 & 0011237 & .0667724 & & 012 & 0.00 & 35109 & 0.002 & 0.0835217 & 191 & & 131 \\
\hline
\end{tabular}


DESIGN TABLE \#5 CONT.

BALANCED REINFORCEMENT RATIO FOR WORKING STRESS DESIGN

ASSUMING Ef $=6,500,00$ psi

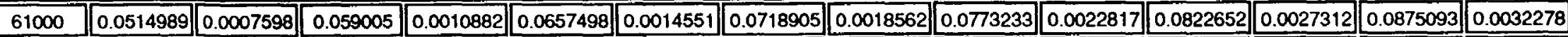

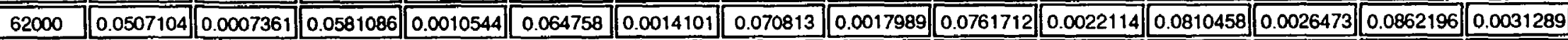

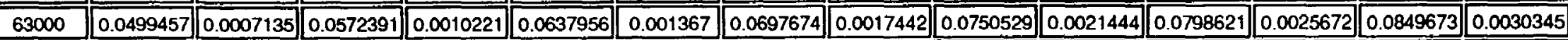

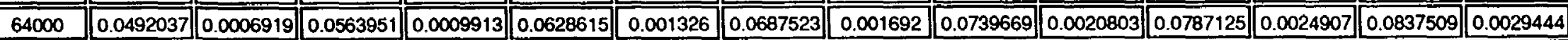

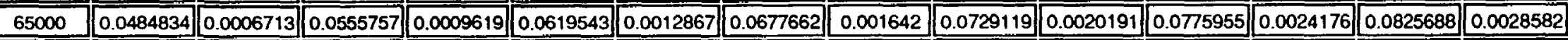

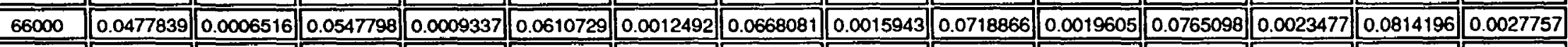

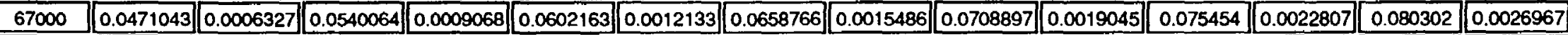

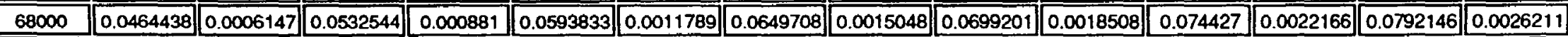

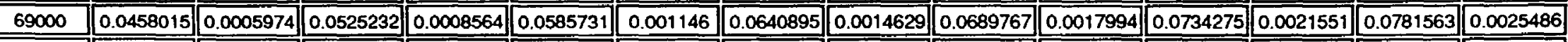

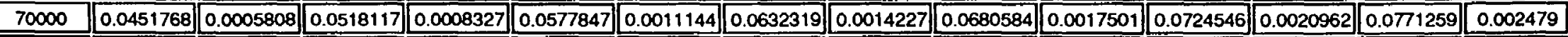

\begin{tabular}{|l|l|l|l|l|l|l|l|l|l|l|l|l|l|l|l|l|}
\hline 71000 & 0.0445688 & 0.000565 & 0.0511193 & 0.00081 & 0.0570173 & 0.0010841 & 0.0623968 & 0.0013842 & 0.0671642 & 0.0017028 & 0.071507 & 0.0020396 & 0.0761223 & 0.0024123 \\
\hline
\end{tabular}

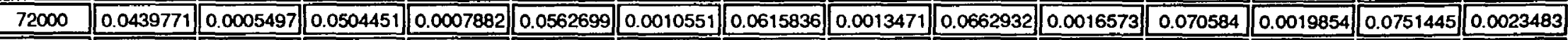

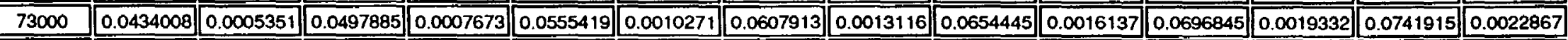

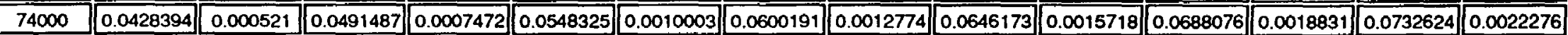

\begin{tabular}{|l|l|l|l|l|l|l|l|l|l|l|l|l|l|l|l|l|l|}
\hline 75000 & 0.0422924 & 0.0005075 & 0.0485252 & 0.0007279 & 0.054141 & 0.0009745 & 0.0592662 & 0.0012446 & 0.0638107 & 0.0015315 & 0.0679525 & 0.0018349 & 0.0723562 & 0.0021707 \\
\hline \hline
\end{tabular}

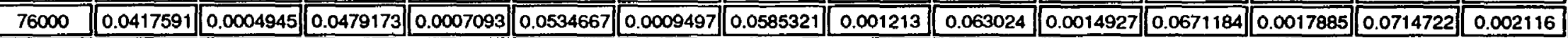

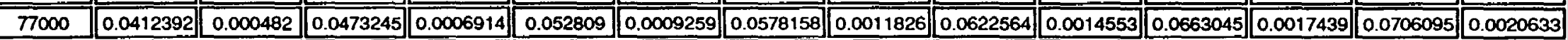

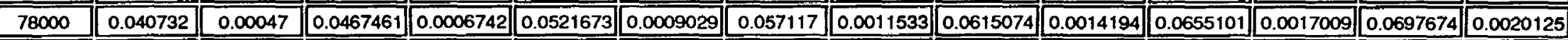

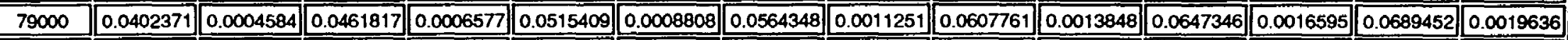

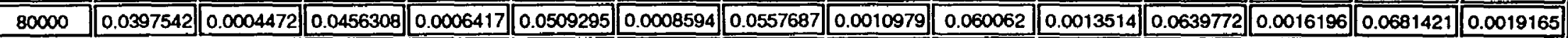

\begin{tabular}{|c|c|c|c|c|c|c|c|c|c|c|c|c|c|c|c|c|c|c|c|c|c|c|}
\hline 81000 & 0.0392827 & 0.0004365 & 0.0450928 & 0.0006263 & 0.0503324 & 0.0008389 & 0.0551181 & 0.0010717 & 0.0593645 & 0.0013192 & 0.0632373 & 0.0015811 & 0.0673575 & 0.001871 \\
\hline
\end{tabular}

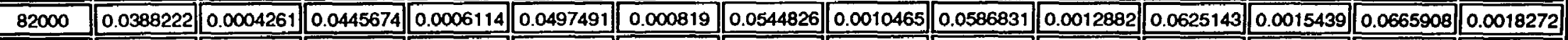

\begin{tabular}{|l|l|l|l|l|l|l|l|l|l|l|l|l|l|l|l|l|l|l|}
\hline 83000 & 0.0383724 & 0.0004161 & 0.0440541 & 0.0005971 & 0.0491792 & 0.0007999 & 0.0538615 & 0.0010221 & 0.0580171 & 0.0012582 & 0.0618077 & 0.0015081 & 0.0658413 & 0.0017849 \\
\hline
\end{tabular}

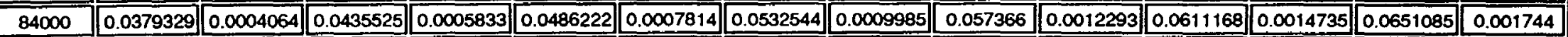

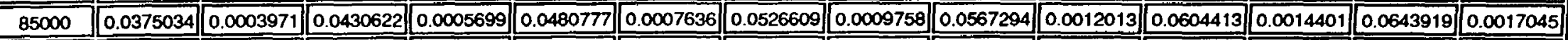

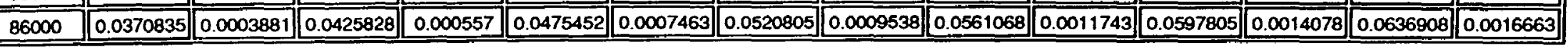




\section{CHART \#5 BALANCED REINFORCED RATIO}

WORKING STRESS DESIGN

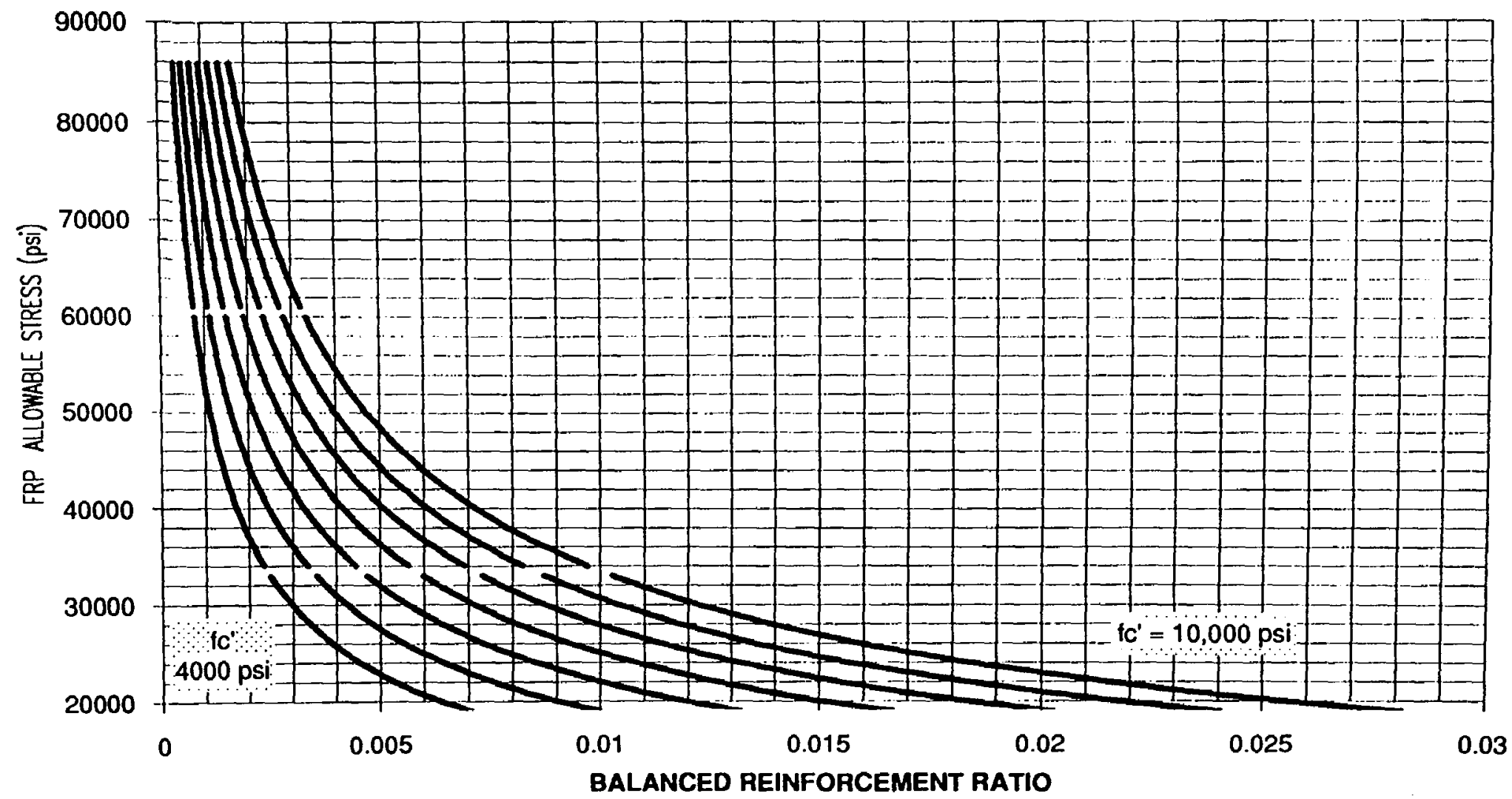


DESIGN TABLE 6

WORKING STRESS DESIGN FOR RECTANGULAR BEANS REINFORCED WITH FRP REBARS AND 6000 pSI CONCRETE

\begin{tabular}{|lr|}
\hline Concrete Strength (psi) & 6000 \\
Ec (psi) & $4.10 E+06$ \\
El (psi) & $6.50 E+06$ \\
ic (psi) & 2700 \\
Ht & $0.5^{\circ}$ tye \\
$n$ & 1.59 \\
\hline
\end{tabular}

\begin{tabular}{|c|c|c|c|c|c|c|}
\hline ROW & $\begin{array}{c}M u b d^{\wedge} 2 \\
\# 3 \\
f=52 \mathrm{ksi}\end{array}$ & $\begin{array}{c}\text { Mubd^2 } \\
44 \\
f f=43 \mathrm{ksi}\end{array}$ & $\begin{array}{c}\text { Mutod² } \\
* 5 \\
f=38 \mathrm{ksi}\end{array}$ & $\begin{array}{c}\text { Mubd² } \\
16 \\
\mathrm{f}=36 \mathrm{ksi}\end{array}$ & $\begin{array}{c}\text { Mubon2 } \\
77.08 \\
f=30 \mathrm{ksi}\end{array}$ & $\begin{array}{c}\text { Mubot2 } \\
\text { Concrete } \\
t=2700 \text { ps }\end{array}$ \\
\hline 0.0005 & 26 & 21 & 19 & 18 & 15 & 52 \\
\hline 0.001 & 51 & 42 & $\overline{37}$ & $\overline{35}$ & $\overline{29}$ & $\overline{73}$ \\
\hline 0.0015 & 76 & 63 & 56 & 53 & 44 & 88 \\
\hline 0.002 & 101 & 84 & 74 & 70 & 58 & 101 \\
\hline 0.0025 & 126 & 104 & 92 & 87 & 73 & 112 \\
\hline 0.003 & 151 & 125 & 110 & 105 & 87 & 122 \\
\hline 0.0035 & 176 & 145 & 129 & 122 & 101 & 131 \\
\hline 0.004 & 201 & 166 & 147 & 139 & 116 & 139 \\
\hline 0.0045 & 225 & 186 & 165 & 156 & 130 & 146 \\
\hline 0.005 & 250 & 207 & 183 & 173 & 144 & 154 \\
\hline 0.0055 & 274 & 227 & 200 & 190 & 158 & 160 \\
\hline 0.006 & 299 & 247 & 218 & 207 & 172 & 167 \\
\hline 0.0065 & 323 & 267 & 236 & 224 & 186 & 173 \\
\hline 0.007 & 347 & 287 & 254 & 240 & 200 & 178 \\
\hline 0.0075 & 371 & 307 & 271 & 257 & 214 & 184 \\
\hline 0.008 & 396 & 327 & 289 & 274 & 228 & 189 \\
\hline 0.0085 & 420 & 347 & 307 & 291 & 242 & 194 \\
\hline 0.009 & 444 & 367 & 324 & 307 & 256 & 199 \\
\hline 0.0095 & 468 & 387 & 342 & 324 & 270 & 204 \\
\hline 0.01 & 492 & 407 & 359 & 340 & 284 & 208 \\
\hline 0.0105 & 516 & 426 & 377 & 357 & 297 & 213 \\
\hline 0.011 & 540 & 446 & 394 & 374 & 311 & 217 \\
\hline 0.0115 & 563 & 466 & 4112 & 390 & 325 & 221 \\
\hline 0.012 & 587 & 486 & 429 & 406 & 339 & 225 \\
\hline .00125 & 611 & 505 & 446 & 423 & 352 & 229 \\
\hline 0.013 & 635 & 525 & 464 & 439 & 366 & 233 \\
\hline 0.0135 & 658 & 544 & 481 & 456 & 380 & 237 \\
\hline 0.014 & 682 & 564 & 498 & 472 & 393 & 240 \\
\hline 0.0145 & 706 & 583 & 516 & 488 & 407 & 244 \\
\hline
\end{tabular}




\section{DESIGN TABLE \#6 CONT. \\ WORKING STRESS DESIGN FOR RECTANGULAR BEAMS REINFORCED WITH FRP REBARS AND 6000 psi CONCRETE}

\begin{tabular}{|lr|}
\hline Concrete Strength (psi) & 6000 \\
Ec (psi) & $4.10 E+06$ \\
Ef (psi) & $6.50 E+06$ \\
$\mathrm{fc}(\mathrm{psi})$ & 2700 \\
$\mathrm{ff}$ & $0.5^{\circ}$ fye \\
$n$ & 1.59 \\
\hline
\end{tabular}

\begin{tabular}{|c|c|c|c|c|c|c|}
\hline ROW & $\begin{array}{c}\text { Mu/bod } 2 \\
\# 3 \\
f f=52 \mathrm{ksi} \\
\end{array}$ & $\begin{array}{c}\text { Mu/bo^2 } \\
\# 4 \\
f f=43 \mathrm{ksi}\end{array}$ & $\begin{array}{c}\text { Mu/bd^2 } \\
\# 5 \\
f f=38 \mathrm{ksi}\end{array}$ & $\begin{array}{c}\text { Mu/bod^2 } \\
\# 6 \\
f f=36 \mathrm{ksi}\end{array}$ & $\begin{array}{c}\text { Mu/bd^2 } \\
\# 7, \# 8 \\
f=30 \mathrm{ksi}\end{array}$ & $\begin{array}{c}\text { Mu/bd^2 } \\
\text { Concrete } \\
\text { fc }=2700 \text { psi }\end{array}$ \\
\hline
\end{tabular}

\begin{tabular}{|c|c|c|c|c|c|c|}
\hline 0.015 & 729 & 603 & 533 & 505 & 421 & 247 \\
\hline 0.0155 & 753 & 622 & 550 & 521 & 434 & 251 \\
\hline 0.016 & 776 & 642 & 567 & 537 & 448 & 254 \\
\hline 0.0165 & 800 & 661 & 584 & 554 & 461 & 257 \\
\hline 0.017 & 823 & 681 & 601 & $\overline{570}$ & $\overline{475}$ & 260 \\
\hline 0.0175 & 846 & 700 & 619 & 586 & 488 & 263 \\
\hline 0.018 & 870 & 719 & 636 & 602 & 502 & 266 \\
\hline 0.0185 & 893 & 739 & 653 & 618 & 515 & 269 \\
\hline 0.019 & 916 & 758 & 670 & 634 & 529 & 272 \\
\hline 0.0195 & 940 & 777 & 687 & 651 & 542 & 275 \\
\hline 0.02 & 963 & 796 & 704 & 667 & 556 & 278 \\
\hline 0.0205 & 986 & 815 & 721 & 683 & 569 & 281 \\
\hline 0.021 & 1009 & 835 & 738 & 699 & 582 & 283 \\
\hline 0.0215 & 1032 & 854 & 754 & 715 & 596 & 286 \\
\hline 0.022 & 1056 & 873 & 771 & 731 & 609 & 289 \\
\hline 0.0225 & 1079 & 892 & 788 & 747 & 622 & 291 \\
\hline 0.023 & 1102 & 911 & 805 & 763 & 636 & 294 \\
\hline 0.0235 & 1125 & 930 & 822 & 779 & 649 & 296 \\
\hline 0.024 & 1148 & 949 & 839 & 795 & 662 & 299 \\
\hline 0.0245 & 1171 & 968 & 856 & 811 & 675 & 301 \\
\hline 0.025 & 1194 & 987 & 872 & 827 & 689 & 304 \\
\hline 0.0255 & 1217 & 1006 & 889 & 842 & 702 & 306 \\
\hline 0.026 & 1240 & 1025 & 906 & 858 & 715 & 308 \\
\hline 0.0265 & 1263 & 1044 & 923 & 874 & 728 & 311 \\
\hline 0.027 & 1285 & 1063 & 939 & 890 & 742 & 313 \\
\hline 0.0275 & 1308 & 1082 & 956 & 906 & 755 & 315 \\
\hline 0.028 & 1331 & 1101 & 973 & 922 & 768 & 317 \\
\hline 0.0285 & 1354 & 1120 & 989 & 937 & 781 & 320 \\
\hline 0.029 & 1377 & 1138 & 1006 & 953 & 794 & 322 \\
\hline 0.0295 & 1400 & 1157 & 1023 & 969 & 807 & 324 \\
\hline
\end{tabular}




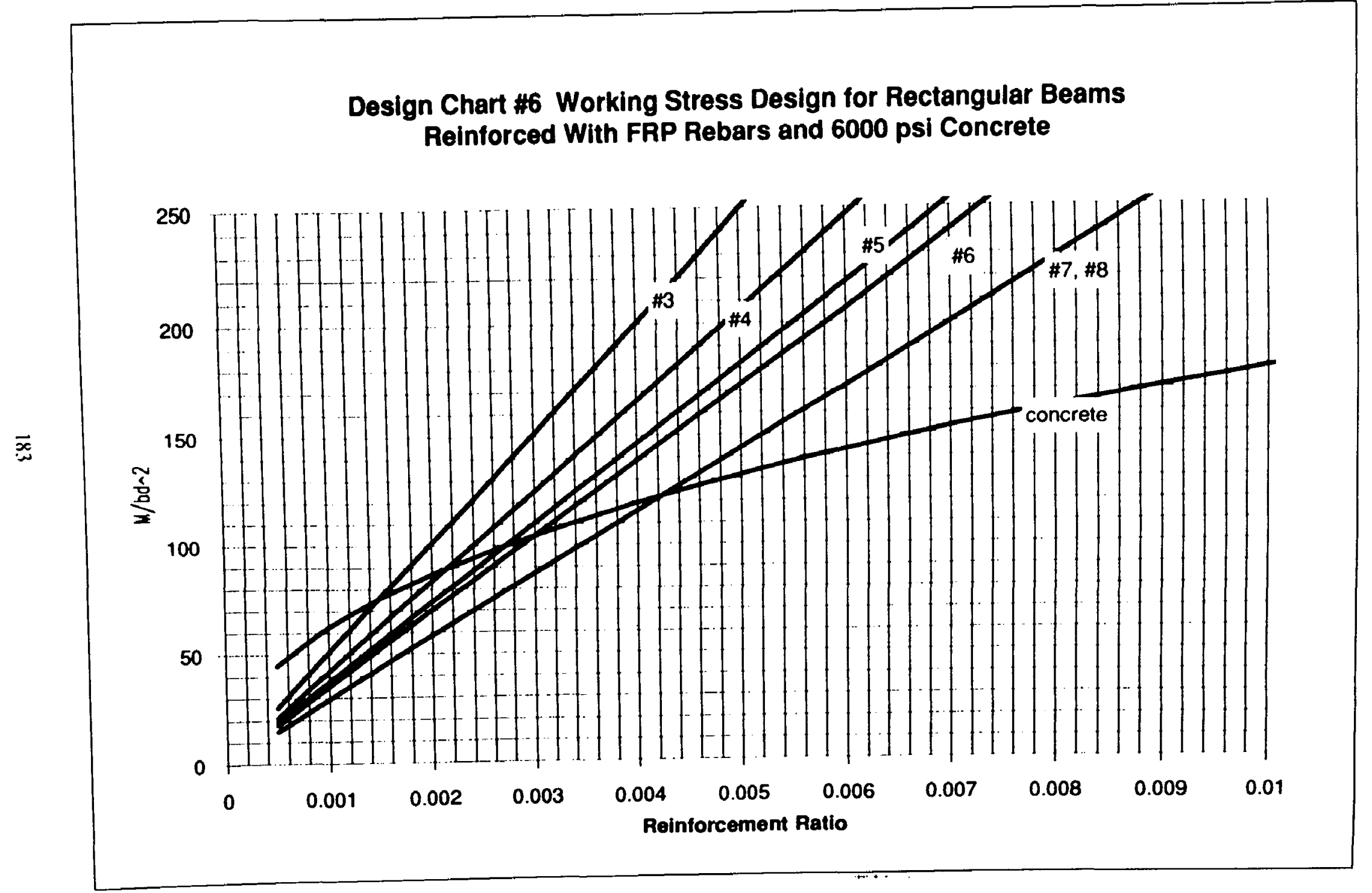


DESIGN TABLE \#6

WORKING STRESS DESIGN FOR RECTANGULAR BEAMS REINFORCED WITH FRP REBARS AND 7000 PSi CONCRETE

\begin{tabular}{|lr|}
\hline Concrete Strength (psi) & 7000 \\
Ec (psi) & $4.34 E+06$ \\
Ef (psi) & $6.50 E+06$ \\
ic (psi) & 3150 \\
H & $0.5^{*}$ fye \\
$n$ & 1.5 \\
\hline
\end{tabular}

\begin{tabular}{|c|c|c|c|c|c|c|}
\hline ROW & $\begin{array}{c}M u / b d^{\wedge} 2 \\
\# 3 \\
H=52 \mathrm{ksi}\end{array}$ & $\begin{array}{c}\text { Mu/bd^2 } \\
\begin{array}{l}\# 4 \\
H=43 \mathrm{ksi}\end{array}\end{array}$ & $\begin{array}{c}\text { Mu/bd^2 } \\
\# 5 \\
H=38 \mathrm{ksi}\end{array}$ & 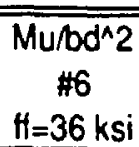 & 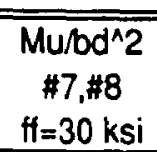 & $\begin{array}{c}\text { Mu/Dd^2 } \\
\text { Concrele } \\
\text { fc }=2700 \text { psi }\end{array}$ \\
\hline
\end{tabular}

\begin{tabular}{|c|c|c|c|c|c|c|}
\hline 0.0005 & 26 & 21 & 19 & 18 & 15 & 59 \\
\hline 0.001 & 51 & 42 & 37 & 35 & 29 & 82 \\
\hline 0.0015 & 76 & 63 & 56 & 53 & 44 & 100 \\
\hline 0.002 & 101 & 84 & 74 & 70 & 59 & 114 \\
\hline 0.0025 & 126 & 105 & 92 & 88 & 73 & 127 \\
\hline 0.003 & 151 & 125 & 111 & 105 & 87 & 138 \\
\hline 0.0035 & 176 & 146 & 129 & 122 & 102 & 148 \\
\hline 0.004 & 201 & 166 & 147 & 139 & 116 & 158 \\
\hline 0.0045 & 225 & 186 & 165 & 156 & 130 & 166 \\
\hline 0.005 & 250 & 207 & 183 & 173 & 144 & 174 \\
\hline 0.0055 & 275 & 227 & 201 & 190 & 158 & 182 \\
\hline 0.006 & 299 & 247 & 218 & 207 & 172 & 189 \\
\hline 0.0065 & 323 & 267 & 236 & 224 & 187 & 196 \\
\hline 0.007 & 348 & 287 & 254 & 241 & 201 & 203 \\
\hline 0.0075 & 372 & 308 & 272 & 257 & 215 & 209 \\
\hline 0.008 & 396 & 328 & 289 & 274 & 229 & 215 \\
\hline 0.0085 & 420 & 348 & 307 & 291 & 242 & 221 \\
\hline 0.009 & 444 & 367 & 325 & 308 & 256 & 226 \\
\hline 0.0095 & 468 & 387 & 342 & 324 & 270 & 232 \\
\hline 0.01 & 492 & 407 & 360 & 341 & 284 & 237 \\
\hline 0.0105 & 516 & 427 & 377 & 358 & 298 & 242 \\
\hline 0.011 & 540 & 447 & 395 & 374 & 312 & 247 \\
\hline 0.0115 & 564 & 467 & 412 & 391 & 326 & 252 \\
\hline 0.012 & 588 & 486 & 430 & 407 & 339 & 256 \\
\hline 0.0125 & 612 & 506 & 447 & 424 & 353 & 261 \\
\hline 0.013 & 636 & 526 & 465 & 440 & 367 & 265 \\
\hline 0.0135 & 659 & 545 & 482 & 457 & 380 & 269 \\
\hline 0.014 & 683 & 565 & 499 & 473 & 394 & 273 \\
\hline 0.0145 & 707 & 584 & 516 & 489 & 408 & 277 \\
\hline 0.015 & 730 & 604 & 534 & 506 & 421 & 281 \\
\hline 0.0155 & 754 & 623 & 551 & 522 & 435 & 285 \\
\hline 0.016 & 778 & 643 & 568 & 538 & 449 & 289 \\
\hline 0.0165 & 801 & 662 & 585 & 555 & 462 & 293 \\
\hline
\end{tabular}




\section{DESIGN TABLE \#6 CONT. \\ WORKING STRESS DESIGN FOR RECTANGULAR BEAMS REINFORCED WITH FRP REBARS AND 7000 pSi CONCRETE}

\begin{tabular}{|lr|}
\hline Concrete Strength (psi) & 7000 \\
Ec (psi) & $4.34 E+06$ \\
Ef (psi) & $6.50 E+06$ \\
fc (psi) & 3150 \\
ff & $0.5^{\circ}$ tye \\
$n$ & 1.5 \\
\hline
\end{tabular}

\begin{tabular}{|ccccccc|}
\hline ROW & Mu/bd^2 & $M u / b d^{\wedge} 2$ & $M u / b d^{\wedge} 2$ & $M u / b d^{\wedge} 2$ & $M u / b d^{\wedge} 2$ & $M u / b d^{\wedge} 2$ \\
& $\# 3$ & $\# 4$ & $\# 5$ & $\# 6$ & $\# 7, \# 8$ & Concrete \\
& $H=52 \mathrm{ksi}$ & $H=43 \mathrm{ksi}$ & $\mathrm{H}=38 \mathrm{ksi}$ & $H=36 \mathrm{ksi}$ & $H=30 \mathrm{ksi}$ & $\mathrm{lC}=2700 \mathrm{psi}$ \\
\hline
\end{tabular}

\begin{tabular}{|c|c|c|c|c|c|c|}
\hline 0.017 & 825 & 682 & 603 & 571 & 476 & 296 \\
\hline 0.0175 & 848 & 701 & 620 & 587 & 489 & 300 \\
\hline 0.018 & 871 & 721 & 637 & 603 & 503 & 303 \\
\hline 0.0185 & 895 & 740 & 654 & 619 & 516 & 307 \\
\hline 0.019 & 918 & 759 & 671 & 636 & 530 & 310 \\
\hline 0.0195 & 942 & 779 & 688 & 652 & 543 & 314 \\
\hline 0.02 & 965 & 798 & 705 & 668 & 557 & 317 \\
\hline 0.0205 & 988 & 817 & 722 & 684 & 570 & 320 \\
\hline 0.021 & 1011 & 836 & 739 & 700 & 583 & 323 \\
\hline 0.0215 & 1035 & 856 & 756 & 716 & 597 & 326 \\
\hline 0.022 & 1058 & 875 & 773 & 732 & 610 & 329 \\
\hline 0.0225 & 1081 & 894 & 790 & 748 & 624 & 332 \\
\hline 0.023 & 1104 & 913 & 807 & 764 & 637 & 335 \\
\hline 0.0235 & 1127 & 932 & 824 & 780 & 650 & 338 \\
\hline 0.024 & 1150 & 951 & 841 & 796 & 664 & 341 \\
\hline 0.0245 & 1173 & 970 & 858 & 812 & 677 & 344 \\
\hline 0.025 & 1196 & 989 & 874 & 828 & 690 & 346 \\
\hline 0.0255 & 1219 & 1008 & 891 & 844 & 704 & 349 \\
\hline 0.026 & 1242 & 1027 & 908 & 860 & 717 & 352 \\
\hline 0.0265 & 1265 & 1046 & 925 & 876 & 730 & 354 \\
\hline 0.027 & 1288 & 1065 & 942 & 892 & 743 & 357 \\
\hline 0.0275 & 1311 & 1084 & 958 & 908 & 757 & 360 \\
\hline 0.028 & 1334 & 1103 & 975 & 924 & 770 & 362 \\
\hline 0.0285 & 1357 & 1122 & 992 & 940 & 783 & 365 \\
\hline 0.029 & 1380 & 1141 & 1008 & 955 & 796 & 367 \\
\hline
\end{tabular}




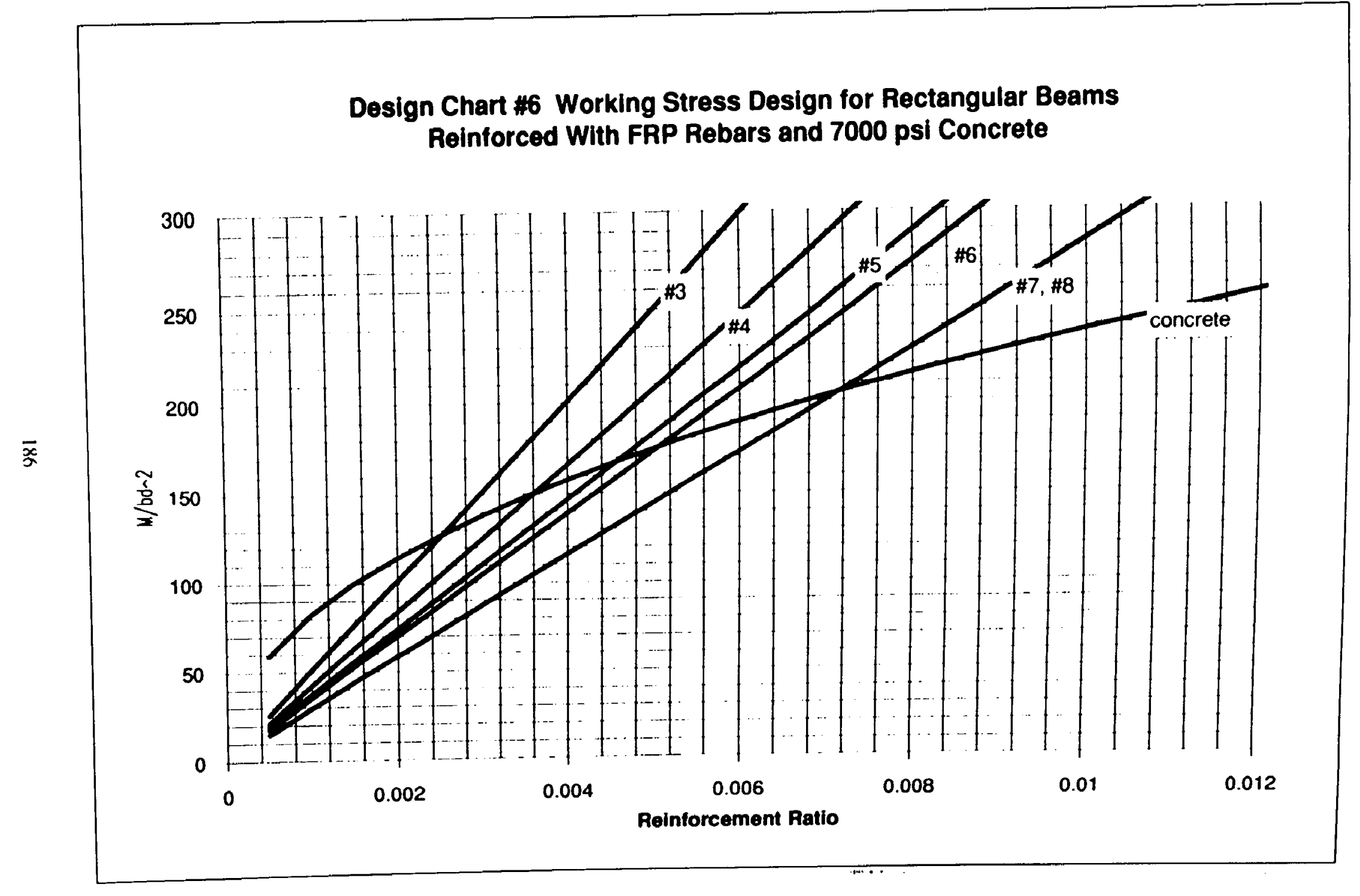




\section{DESIGN TABLE \#6}

WORKING STRESS DESIGN FOR RECTANGULAR BEAMS REINFORCED WITH FRP REBARS AND 8000 psi CONCRETE

\begin{tabular}{|lr|}
\hline Concrete Strength (psi) & 8000 \\
Ec (psi) & $4.57 E+06$ \\
Ef (psi) & $6.50 E+06$ \\
tc (psi) & 3600 \\
th & $0.5^{*}$ fye \\
n & 1.5 \\
\hline
\end{tabular}

\begin{tabular}{|c|c|c|c|c|c|c|}
\hline ROW & $\begin{array}{c}\text { Mu/bod^2 } \\
\# 3 \\
H=52 \mathrm{ksi}\end{array}$ & $\begin{array}{c}\text { Mu/bd^2 } \\
\# 4 \\
H=43 \mathrm{ksi}\end{array}$ & $\begin{array}{c}M u / b d^{\wedge} 2 \\
\# 5 \\
f f=38 \mathrm{ksi}\end{array}$ & $\begin{array}{c}\text { Mu/bd^2 } \\
\# 6 \\
H=36 \mathrm{ksi}\end{array}$ & $\begin{array}{c}\text { Mu/ddA2 } \\
\# 7, \# 8 \\
t f=30 \mathrm{ksi}\end{array}$ & $\begin{array}{c}\text { Mu/bd^2 } \\
\text { Concrete } \\
\mathrm{fc}=3600 \mathrm{psi}\end{array}$ \\
\hline
\end{tabular}

\begin{tabular}{|c|c|c|c|c|c|c|}
\hline 0.0005 & 26 & 21 & 19 & 18 & 15 & 66 \\
\hline 0.001 & 51 & 42 & 37 & 35 & 29 & 92 \\
\hline 0.0015 & 76 & 63 & 56 & 53 & 44 & 111 \\
\hline 0.002 & 101 & 84 & 74 & 70 & 59 & 127 \\
\hline 0.0025 & 126 & 105 & 92 & 88 & 73 & 141 \\
\hline 0.003 & 151 & 125 & 111 & 105 & 87 & 154 \\
\hline 0.0035 & 176 & 146 & 129 & 122 & 102 & 165 \\
\hline 0.004 & 201 & 166 & 147 & 139 & 116 & 176 \\
\hline 0.0045 & 226 & 187 & 165 & 156 & 130 & 185 \\
\hline 0.005 & 250 & 207 & 183 & 173 & 144 & 195 \\
\hline 0.0055 & 275 & 227 & 201 & 190 & 159 & 203 \\
\hline 0.006 & 299 & 247 & 219 & 207 & 173 & 211 \\
\hline 0.0065 & 324 & 268 & 237 & 224 & 187 & 219 \\
\hline 0.007 & 348 & 288 & 254 & 241 & 201 & 226 \\
\hline 0.0075 & 372 & 308 & 272 & 258 & 215 & 233 \\
\hline 0.008 & 397 & 328 & 290 & 275 & 229 & 240 \\
\hline 0.0085 & 421 & 348 & 308 & 291 & 243 & 246 \\
\hline 0.0095 & 469 & 388 & 343 & 325 & 271 & 259 \\
\hline 0.01 & 493 & 408 & 360 & 341 & 285 & 264 \\
\hline 0.0105 & 517 & 428 & 378 & 358 & 298 & 270 \\
\hline 0.011 & 541 & 447 & 395 & 375 & 312 & 276 \\
\hline 0.0115 & 565 & 467 & 413 & 391 & 326 & 281 \\
\hline 0.012 & 589 & 487 & 430 & 408 & 340 & 286 \\
\hline 0.0125 & 613 & 507 & 448 & 424 & 354 & 291 \\
\hline 0.013 & 637 & 526 & 465 & 441 & 367 & 296 \\
\hline 0.0135 & 660 & 546 & 483 & 457 & 381 & 301 \\
\hline 0.014 & 684 & 566 & 500 & 474 & 395 & 305 \\
\hline 0.0145 & 708 & 585 & 517 & 490 & 408 & 310 \\
\hline 0.015 & 732 & 605 & 535 & 506 & 422 & 314 \\
\hline 0.0155 & 755 & 625 & 552 & 523 & 436 & 319 \\
\hline 0.016 & 779 & 644 & 569 & 539 & 449 & 323 \\
\hline
\end{tabular}


DESIGN TABLE \#6 CONT.

WORKING STRESS DESIGN FOR RECTANGULAR BEAMS

REINFORCED WITH FRP REBARS AND 8000 psi CONCRETE

\begin{tabular}{|lr|}
\hline Concrete Strength (psi) & 8000 \\
Ec (psi) & $4.57 \mathrm{E}+06$ \\
Ef (psi) & $6.50 E+06$ \\
fc (psi) & 3600 \\
ft & $0.5^{\circ}$ tye \\
$n$ & 1.5 \\
\hline
\end{tabular}

\begin{tabular}{|c|c|c|c|c|c|c|}
\hline 0.0165 & 802 & 664 & 586 & 556 & 463 & 327 \\
\hline 0.017 & 826 & 683 & 604 & 572 & 477 & 331 \\
\hline 0.0175 & 849 & 702 & 621 & 588 & 490 & 335 \\
\hline 0.018 & 873 & 722 & 638 & 604 & 504 & 339 \\
\hline 0.0185 & 896 & 741 & 655 & 621 & 517 & 343 \\
\hline 0.019 & 920 & 761 & 672 & 637 & 531 & 347 \\
\hline 0.0195 & 943 & 780 & 689 & 653 & 544 & 350 \\
\hline 0.02 & 967 & 799 & 706 & 669 & 558 & 354 \\
\hline 0.0205 & 990 & 819 & 723 & 685 & 571 & 358 \\
\hline 0.021 & 1013 & 838 & 740 & 702 & 585 & 361 \\
\hline 0.0215 & 1037 & 857 & 758 & 718 & 598 & 365 \\
\hline 0.022 & 1060 & 876 & 775 & 734 & 611 & 368 \\
\hline 0.0225 & 1083 & 896 & 791 & 750 & 625 & 371 \\
\hline 0.023 & 1106 & 915 & 808 & 766 & 638 & 375 \\
\hline 0.0235 & 1129 & 934 & 825 & 782 & 652 & 378 \\
\hline 0.024 & 1153 & 953 & 842 & 798 & 665 & 381 \\
\hline 0.0245 & 1176 & 972 & 859 & 814 & 678 & 384 \\
\hline 0.025 & 1199 & 991 & 876 & 830 & 692 & 387 \\
\hline 0.0255 & 1222 & 1010 & 893 & 846 & 705 & 390 \\
\hline 0.026 & 1245 & 1030 & 910 & 862 & 718 & 393 \\
\hline 0.0265 & 1268 & 1049 & 927 & 878 & 732 & 396 \\
\hline 0.027 & 1291 & 1068 & 944 & 894 & 745 & 399 \\
\hline 0.0275 & 1314 & 1087 & 960 & 910 & 758 & 402 \\
\hline 0.028 & 1337 & 1106 & 977 & 926 & 771 & 405 \\
\hline 0.0285 & 1360 & 1125 & 994 & 942 & 785 & 408 \\
\hline 0.029 & 1383 & 1144 & 1011 & 957 & 798 & 411 \\
\hline 0.0295 & 1406 & 1163 & 1027 & 973 & 811 & 413 \\
\hline 0.03 & 1429 & 1181 & 1044 & 989 & 824 & 416 \\
\hline 0.0305 & 1452 & 1200 & 1061 & 1005 & 837 & 419 \\
\hline 0.031 & 1474 & 1219 & 1077 & 1021 & 851 & 421 \\
\hline 0.0315 & 1497 & 1238 & 1094 & 1037 & 864 & 424 \\
\hline 0.032 & 1520 & 1257 & 1111 & 1052 & 877 & 427 \\
\hline
\end{tabular}



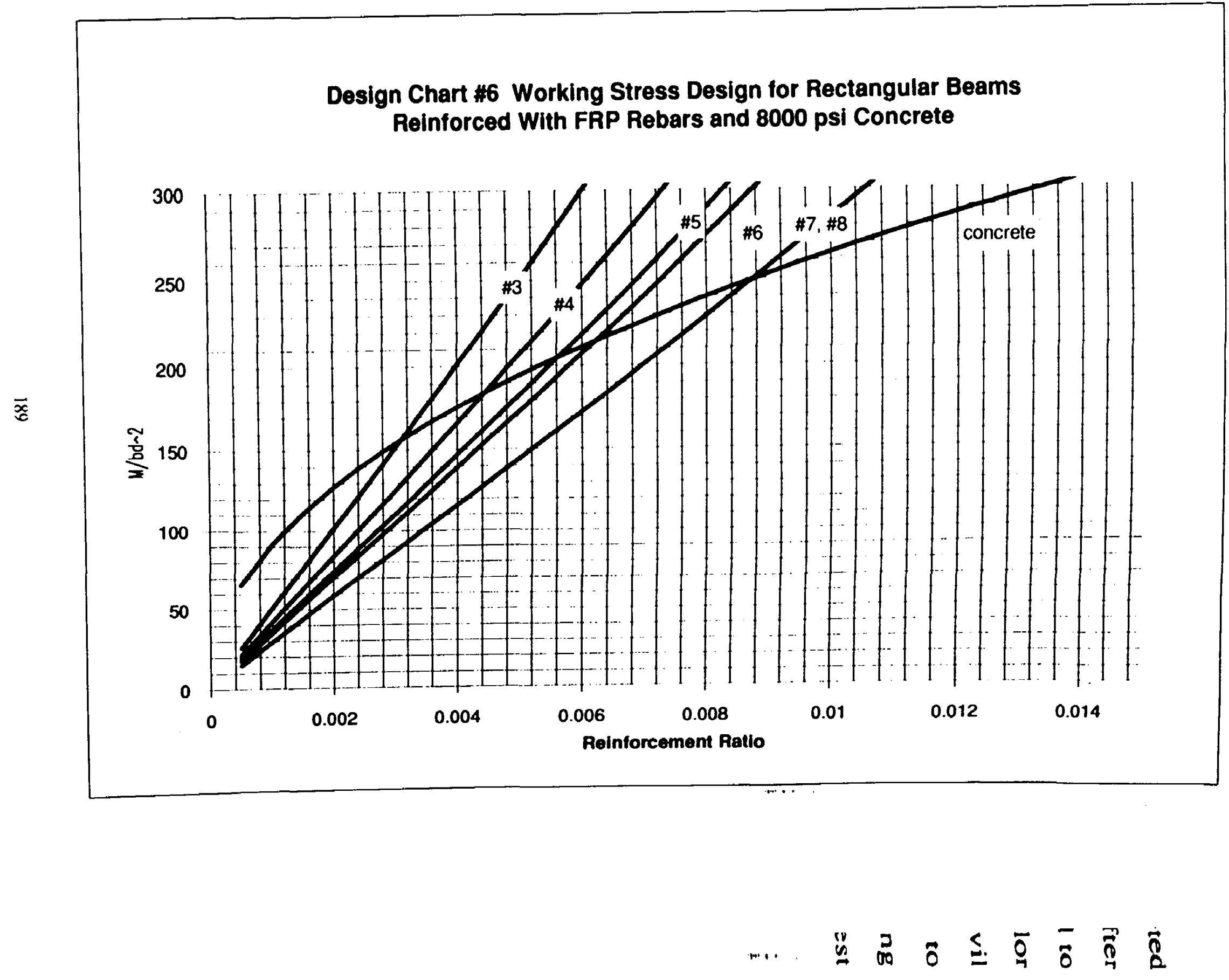
DESIGN TABLE \#6

WORKING STRESS DESIGN FOR RECTANGULAR BEAMS

REINFORCED WITH FRP REBARS AND 9000 psi CONCRETE

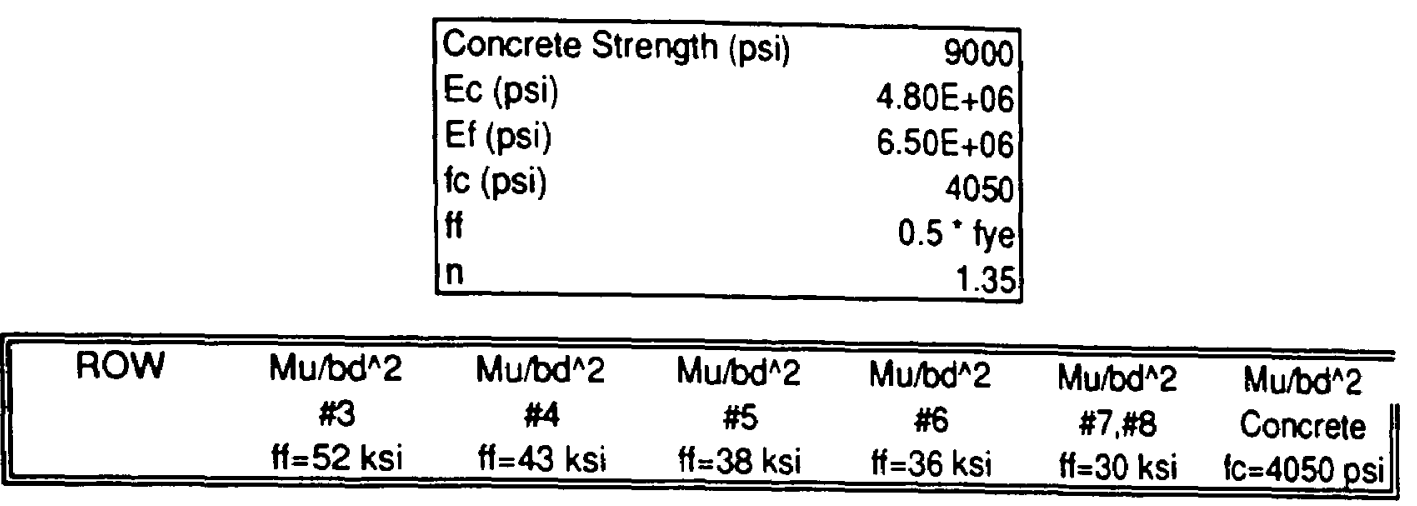

Eted

Ifter

d to

elor

ivil

1 to

ling

\begin{tabular}{|c|c|c|c|c|c|c|}
\hline 0.0005 & 26 & 21 & 19 & 18 & 15 & 72 \\
\hline 0.001 & 51 & 42 & 37 & 35 & 29 & 101 \\
\hline 0.0015 & 76 & 63 & 56 & 53 & 44 & 122 \\
\hline 0.002 & 102 & 84 & 74 & 70 & 59 & 140 \\
\hline 0.0025 & 127 & 105 & 93 & 88 & 73 & 155 \\
\hline 0.003 & 152 & 125 & 111 & 105 & 87 & 169 \\
\hline 0.0035 & 176 & 146 & & & & 'est \\
\hline
\end{tabular}

\begin{tabular}{|c|c|c|c|c|c|c|}
\hline 0.0035 & 176 & 146 & 129 & 122 & 102 & 182 \\
\hline 0.004 & 201 & 166 & 147 & 139 & 116 & 193 \\
\hline 0.0045 & 226 & 187 & 165 & 156 & 130 & 204 \\
\hline 0.005 & 250 & 207 & 183 & 173 & 145 & 214 \\
\hline 0.0055 & 275 & 227 & 201 & 190 & 159 & 223 \\
\hline 0.006 & 300 & 248 & 219 & 207 & 173 & 232 \\
\hline 0.0065 & 324 & 268 & 237 & 224 & 187 & 241 \\
\hline 0.007 & 348 & 288 & 255 & 241 & 201 & 249 \\
\hline 0.0075 & 373 & 308 & 272 & 258 & 215 & 257 \\
\hline 0.008 & 397 & 328 & 290 & 275 & 229 & 264 \\
\hline 0.0085 & 421 & 348 & 308 & 292 & 243 & 271 \\
\hline 0.009 & 446 & 368 & 326 & 308 & 257 & 278 \\
\hline 0.0095 & 470 & 388 & 343 & 325 & 271 & 285 \\
\hline 0.01 & 494 & 408 & 361 & 342 & 285 & 291 \\
\hline 0.0105 & 518 & 428 & 378 & 358 & 299 & 297 \\
\hline 0.011 & 542 & 448 & 396 & 375 & 313 & 303 \\
\hline 0.0115 & 566 & 468 & 413 & 392 & 326 & 309 \\
\hline 0.012 & 590 & 488 & 431 & 408 & 340 & 315 \\
\hline 0.0125 & 614 & 507 & 448 & 425 & 354 & 320 \\
\hline 0.013 & 638 & 527 & 466 & 441 & 368 & 326 \\
\hline 0.0135 & 661 & 547 & 483 & 458 & 382 & 331 \\
\hline 0.014 & 685 & 567 & 501 & 474 & 395 & 336 \\
\hline 0.0145 & 709 & 586 & 518 & 491 & 409 & 341 \\
\hline 0.015 & 733 & 606 & 535 & 507 & 423 & 346 \\
\hline 0.0155 & 756 & 625 & 553 & 524 & 436 & 351 \\
\hline
\end{tabular}


DESIGN TABLE \#6 CONT.

WORKING STRESS DESIGN FOR RECTANGULAR BEAMS REINFORCED WITH FRP REBARS AND 9000 pSi CONCRETE

\begin{tabular}{|lr|}
\hline Concrete Strength (psi) & 9000 \\
Ec (psi) & $4.80 \mathrm{E}+06$ \\
Ef (psi) & $6.50 \mathrm{E}+06$ \\
fc (psi) & 4050 \\
Ht & $0.5 *$ tye \\
$\mathrm{n}$ & 1.35 \\
\hline
\end{tabular}

ipleted

After

rred to

\begin{tabular}{|c|c|c|c|c|c|c|}
\hline ROW & $\begin{array}{c}\text { Mu/bd^2 } \\
\begin{array}{c}* 3 \\
H=52 \mathrm{ksi}\end{array}\end{array}$ & $\begin{array}{c}\text { Mu/bd^2 } \\
\# 4 \\
H=43 \mathrm{ksi}\end{array}$ & $\begin{array}{c}M u / b d^{\wedge} 2 \\
\# 5 \\
H=38 \mathrm{ksi}\end{array}$ & $\begin{array}{c}\begin{array}{c}\text { Mu/bod } 2 \\
\# 6 \\
H=36 \mathrm{ksi}\end{array} \\
\end{array}$ & 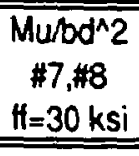 & $\begin{array}{c}\text { Mu/bod } 2 \\
\text { Concrete } \\
\text { fc }=4050 \text { psi }\end{array}$ \\
\hline
\end{tabular}

chelor

Civil

lan to

\begin{tabular}{|c|c|c|c|c|c|c|}
\hline 0.016 & 780 & 645 & 570 & 540 & 450 & 356 \\
\hline 0.0165 & 804 & 665 & 587 & 556 & 464 & 360 \\
\hline 0.017 & 827 & 684 & 605 & 573 & 477 & 365 \\
\hline 0.0175 & 851 & 704 & 622 & 589 & 491 & 369 \\
\hline 0.018 & 874 & 723 & 639 & 605 & 504 & 374 \\
\hline 0.0185 & 898 & 742 & 656 & 622 & 518 & 378 \\
\hline 0.019 & 921 & 762 & 673 & 638 & 532 & 382 \\
\hline 0.0195 & 945 & 781 & 690 & 654 & 545 & 386 \\
\hline 0.02 & 968 & 801 & 708 & 670 & 559 & 390 \\
\hline
\end{tabular}




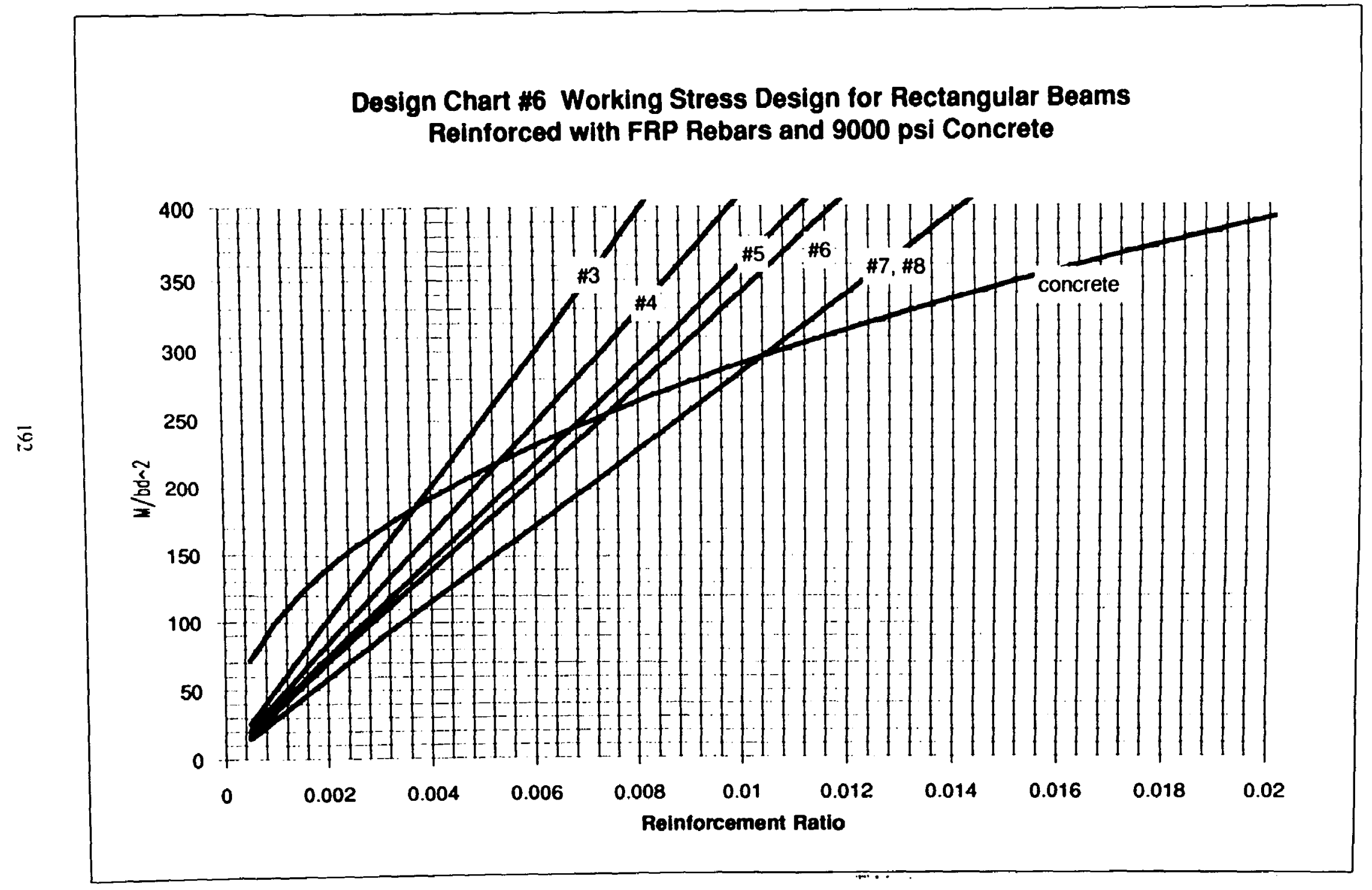




\section{DESIGN TABLE \#6 \\ WORKING STRESS DESIGN FOR RECTANGULAR BEAMS REINFORCED WITH FRP REBARS AND 10,000 psi CONCRETE}

\begin{tabular}{|lr|}
\hline Concrete Strength (psi) & 10000 \\
Ec (psi) & $5.00 E+06$ \\
El (psi) & $6.50 E+06$ \\
ic (psi) & 4500 \\
ht & $0.5 *$ tye \\
n & 1.35 \\
\hline
\end{tabular}

\begin{tabular}{|c|c|c|c|c|c|c|}
\hline ROW & 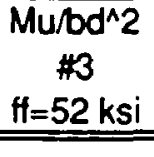 & $\begin{array}{c}\text { Mu/bod^2 } \\
\$ 4 \\
\mathrm{ff}=43 \mathrm{ksi} \\
\end{array}$ & 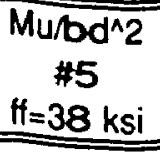 & $\begin{array}{c}\begin{array}{c}\text { Mu/bo/2 } \\
\# 6 \\
\mathrm{H}=36 \mathrm{ksi}\end{array} \\
\end{array}$ & $\begin{array}{c}\text { Mu/bd^2 } \\
\# 7, \# 8 \\
t=30 \mathrm{ksi} \\
\end{array}$ & $\begin{array}{r}\text { Mu/bod2 } \\
\text { Concrete } \\
1 \mathrm{c}=5000 \text { psi }\end{array}$ \\
\hline 0.0005 & 26 & 21 & 19 & 18 & 15 & 79 \\
\hline 0.001 & 51 & 42 & 37 & 35 & 30 & 110 \\
\hline 0.0015 & 76 & 63 & 56 & 53 & 44 & 133 \\
\hline 0.002 & 102 & 84 & 74 & 70 & 59 & 153 \\
\hline 0.0025 & 127 & 105 & 93 & 88 & 73 & 170 \\
\hline 0.003 & 152 & 125 & 111 & 105 & 87 & 185 \\
\hline 0.0035 & 176 & 146 & 129 & 122 & 102 & 198 \\
\hline 0.004 & 201 & 166 & 147 & 139 & 116 & 211 \\
\hline 0.0045 & 226 & 187 & 165 & 156 & 130 & 223 \\
\hline 0.005 & 251 & 207 & 183 & 174 & 145 & 234 \\
\hline 0.0055 & 275 & 228 & 201 & 191 & 159 & 244 \\
\hline 0.006 & 300 & 248 & 219 & 208 & 173 & 254 \\
\hline 0.0065 & 324 & 268 & 237 & 224 & 187 & 263 \\
\hline 0.007 & 349 & 288 & 255 & 241 & 201 & 272 \\
\hline 0.0075 & 373 & 309 & 273 & 258 & 215 & 280 \\
\hline 0.008 & 397 & 329 & 290 & 275 & 229 & 288 \\
\hline 0.0085 & 422 & 349 & 308 & 292 & 243 & 296 \\
\hline 0.009 & 446 & 369 & 326 & 309 & 257 & 304 \\
\hline 0.0095 & 470 & 389 & 344 & 325 & 271 & 311 \\
\hline 0.01 & 494 & 409 & 361 & 342 & 285 & 318 \\
\hline 0.0105 & 518 & 429 & 379 & 359 & 299 & 325 \\
\hline 0.011 & 542 & 448 & 396 & 375 & 313 & 332 \\
\hline 0.0115 & 566 & 468 & 414 & 392 & 327 & 338 \\
\hline 0.012 & 590 & 488 & 431 & 409 & 341 & 344 \\
\hline 0.0125 & 614 & 508 & 449 & 425 & 354 & 350 \\
\hline 0.013 & 638 & 528 & 466 & 442 & 368 & 356 \\
\hline 0.0135 & 662 & 547 & 484 & 458 & 382 & 362 \\
\hline 0.014 & 686 & 567 & 501 & 475 & 396 & 368 \\
\hline 0.0145 & 710 & 587 & 519 & 491 & 409 & 373 \\
\hline 0.015 & 733 & 607 & 536 & 508 & 423 & 379 \\
\hline 0.0155 & 757 & 626 & 553 & 524 & 437 & 384 \\
\hline 0.016 & 781 & 646 & 571 & 541 & 451 & 389 \\
\hline 0.0165 & 805 & 665 & 588 & 557 & 464 & 394 \\
\hline
\end{tabular}




\section{DESIGN TABLE \#6 CONT \\ WORKING STRESS DESIGN FOR RECTANGULAR BEAMS REINFORCED WITH FRP REBARS AND 10,000 psi CONCRETE}

\begin{tabular}{|lr|}
\hline Concrete Strength (psi) & 10000 \\
Ec (psi) & $5.00 E+06$ \\
Ef (psi) & $6.50 E+06$ \\
ic (psi) & 4500 \\
ff & $0.5^{\circ}$ fye \\
$n$ & 1.35 \\
\hline
\end{tabular}

\begin{tabular}{|c|c|c|c|c|c|c|}
\hline ROW & 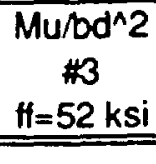 & 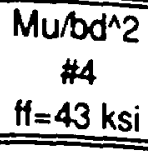 & $\begin{array}{c}\begin{array}{c}M / 2 d^{\wedge} 2 \\
\# 5 \\
H=38 \mathrm{ksi}\end{array} \\
\end{array}$ & $\begin{array}{c}\begin{array}{c}M u / b d^{\wedge} 2 \\
\# 6 \\
H=36 \\
H s i\end{array} \\
\end{array}$ & $\begin{array}{c}M u / b d^{\wedge} 2 \\
\# 7, \# 8 \\
H=30 \mathrm{ksi}\end{array}$ & $\begin{array}{c}\text { Mu/bod } 2 \\
\text { Concrete } \\
\text { ic=5000 psi }\end{array}$ \\
\hline
\end{tabular}

\begin{tabular}{|c|c|c|c|c|c|c|}
\hline 0.017 & 828 & 685 & 605 & 573 & 478 & 399 \\
\hline 0.0175 & 852 & 704 & 622 & 590 & 491 & 404 \\
\hline 0.018 & 875 & 724 & 640 & 606 & 505 & 409 \\
\hline 0.0185 & 899 & 743 & 657 & 622 & 519 & 413 \\
\hline 0.019 & 922 & 763 & 674 & 639 & 532 & 418 \\
\hline 0.0195 & 946 & 782 & 691 & 655 & 546 & 422 \\
\hline 0.02 & 969 & 802 & 708 & 671 & 559 & 427 \\
\hline 0.0205 & 993 & 821 & 726 & 687 & 573 & 431 \\
\hline 0.021 & 1016 & 840 & 743 & 704 & 586 & 435 \\
\hline 0.0215 & 1040 & 860 & 760 & 720 & 600 & 440 \\
\hline 0.022 & 1063 & 879 & 777 & 736 & 613 & 444 \\
\hline 0.0225 & 1086 & 898 & 794 & 752 & 627 & 448 \\
\hline 0.023 & 1110 & 918 & 811 & 768 & 640 & 452 \\
\hline 0.0235 & 1133 & 937 & 828 & 784 & 654 & 456 \\
\hline 0.024 & 1156 & 956 & 845 & 800 & 667 & 460 \\
\hline 0.0245 & 1179 & 975 & 862 & 817 & 680 & 464 \\
\hline 0.025 & 1203 & 995 & 879 & 833 & 694 & 467 \\
\hline 0.0255 & 1226 & 1014 & 896 & 849 & 707 & 471 \\
\hline 0.026 & 1249 & 1033 & 913 & 865 & 721 & 475 \\
\hline 0.0265 & 1272 & 1052 & 930 & 881 & 734 & 478 \\
\hline 0.027 & 1295 & 1071 & 947 & 897 & 747 & 482 \\
\hline 0.0275 & 1318 & 1090 & 963 & 913 & 761 & 485 \\
\hline 0.028 & 1342 & 1109 & 980 & 929 & 774 & 489 \\
\hline 0.0285 & 1365 & 1128 & 997 & 945 & 787 & 492 \\
\hline 0.029 & 1388 & 1147 & 1014 & 961 & 801 & 496 \\
\hline 0.0295 & 1411 & 1166 & 1031 & 977 & 814 & 499 \\
\hline 0.03 & 1434 & 1186 & 1048 & 993 & 827 & 502 \\
\hline 0.0305 & 1457 & 1205 & 1064 & 1008 & 840 & 506 \\
\hline 0.031 & 1480 & 1223 & 1081 & 1024 & 854 & 509 \\
\hline 0.0315 & 1503 & 1242 & 1098 & 1040 & 867 & 512 \\
\hline 0.032 & 1525 & 1261 & 1115 & 1056 & 880 & 515 \\
\hline & & & & & & \\
\hline
\end{tabular}




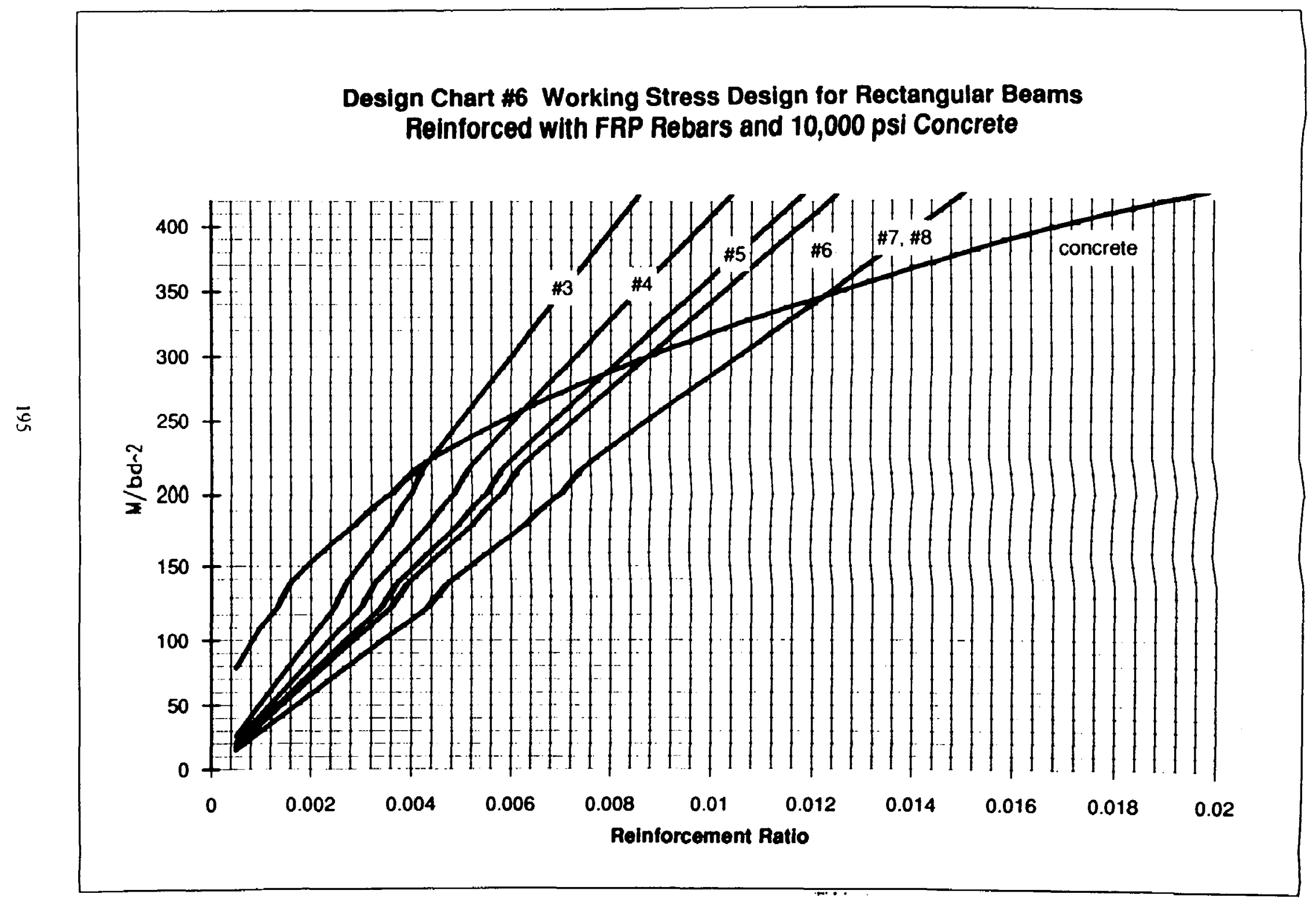




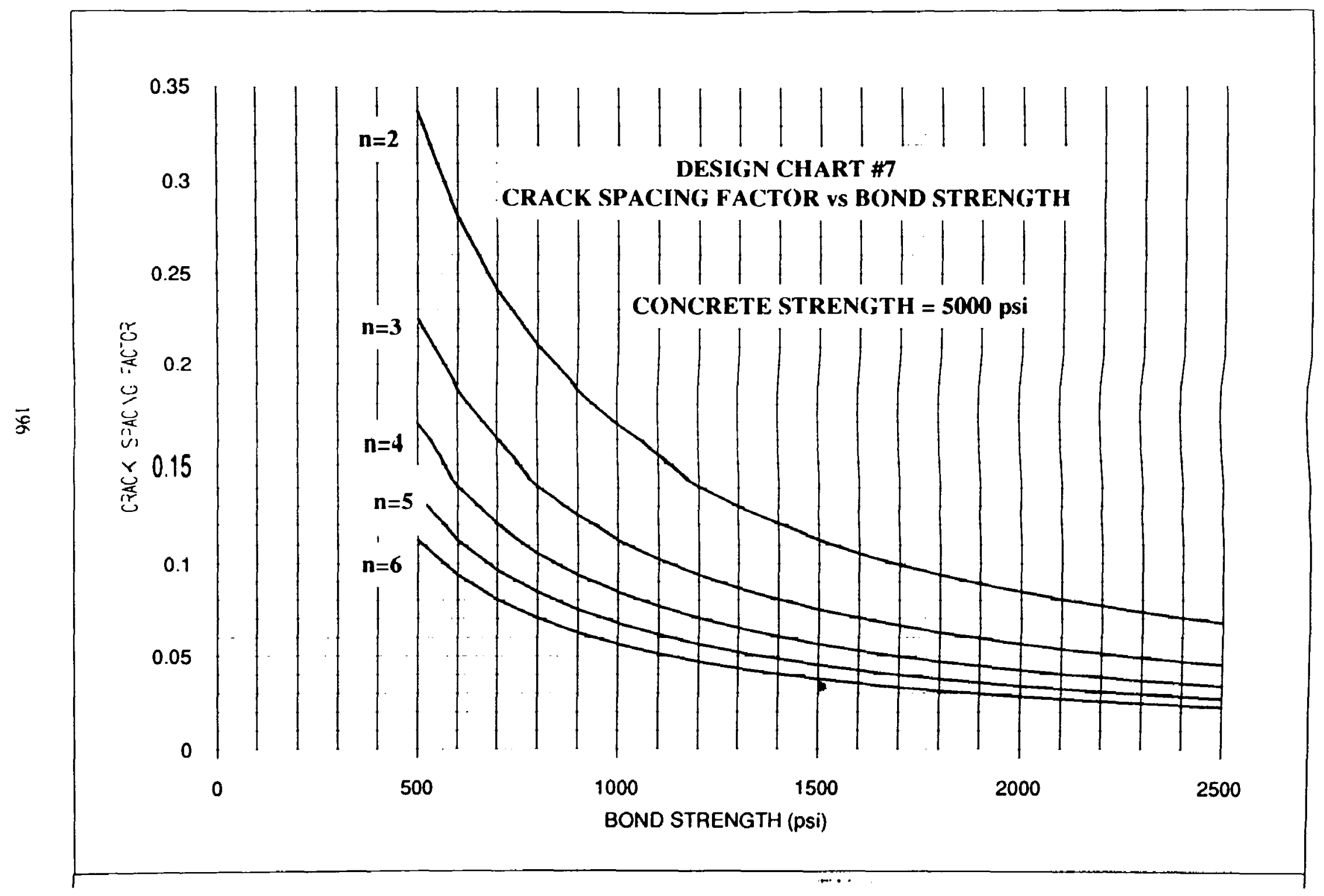




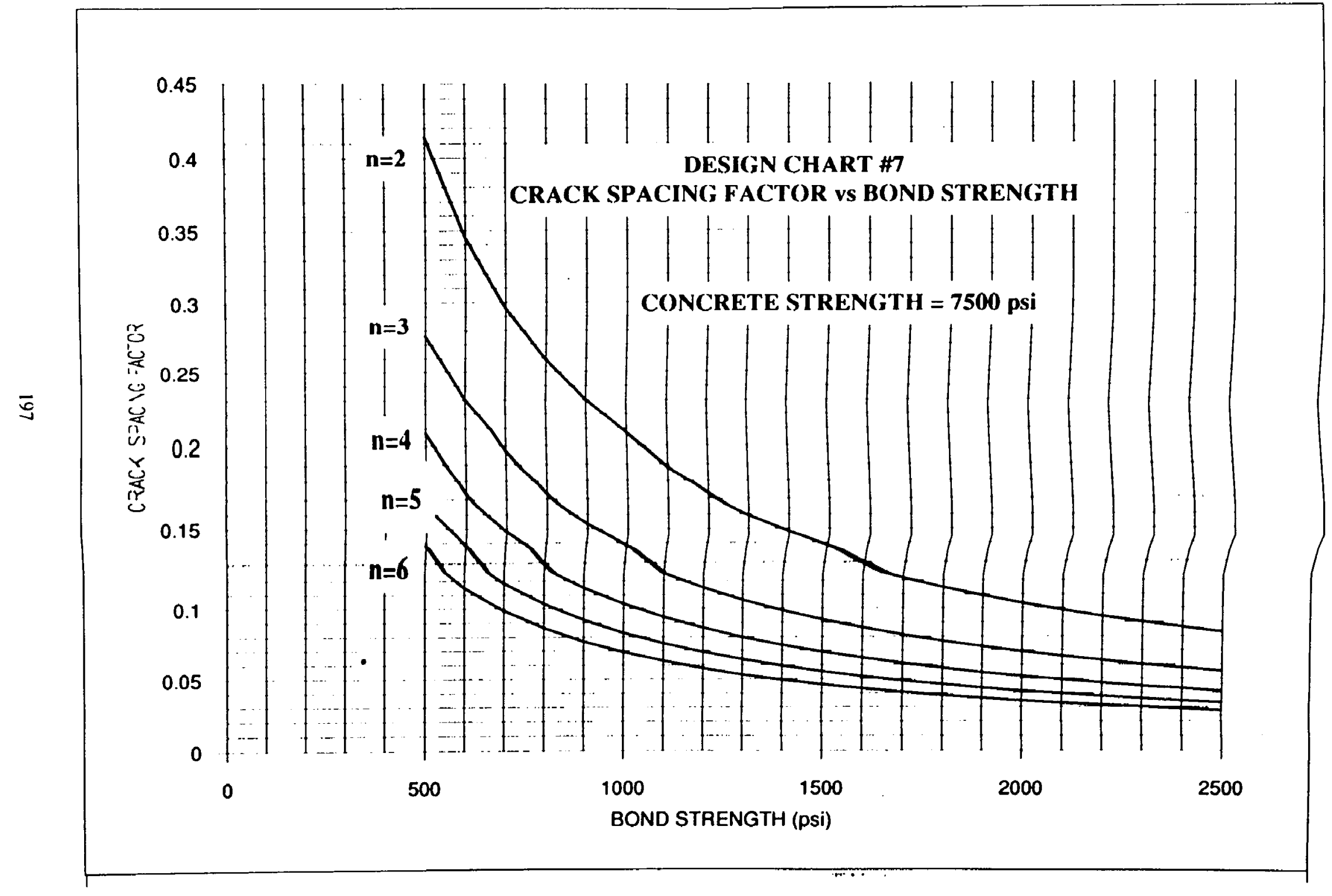




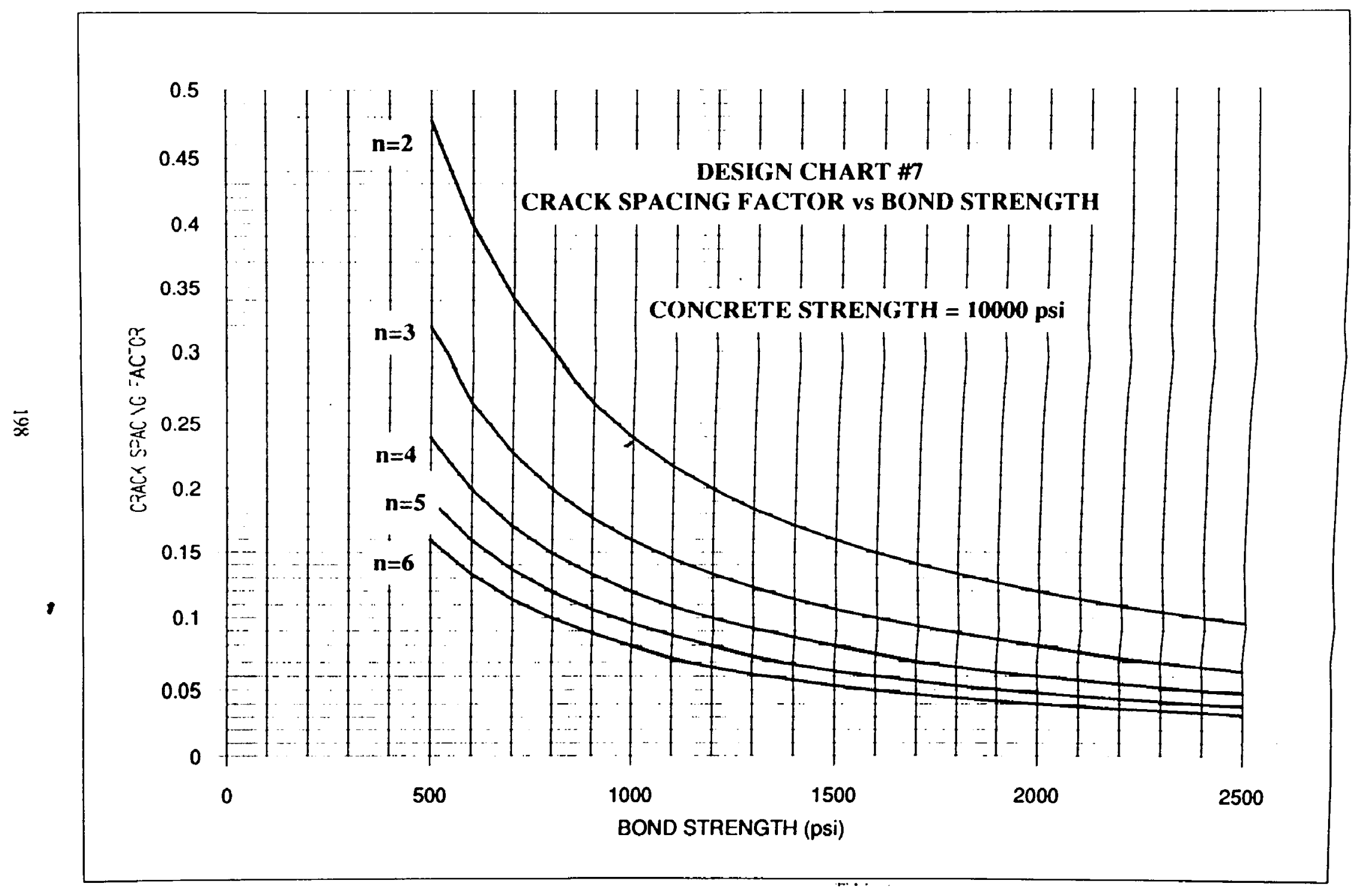




\section{VITA}

Salem Samir Faza was born in Amman, Jordan, on September 19, 1960. He completed his elementary and ordinary level education at La Salle College in Jordan. After receiving his Advanced Level Certificate at Oakham School in England, he transferred to West Virginia University in Morgantown, West Virginia, where he received a Bachelor of Science in Civil Engineering Degree in May, 1983, and a Master of Science in Civil Engineering Degree in December, 1984. Upon graduation, he returned to Jordan to fulfill his military obligations. While working at the Royal Scientific Society, Building Technology Center, in Amman, Jordan, he was accepted into the Ph.D. program at West Virginia University. He is presently a candidate for the Ph.D. 


\section{APPROVAL OF EXAMINING COMMITTEE}
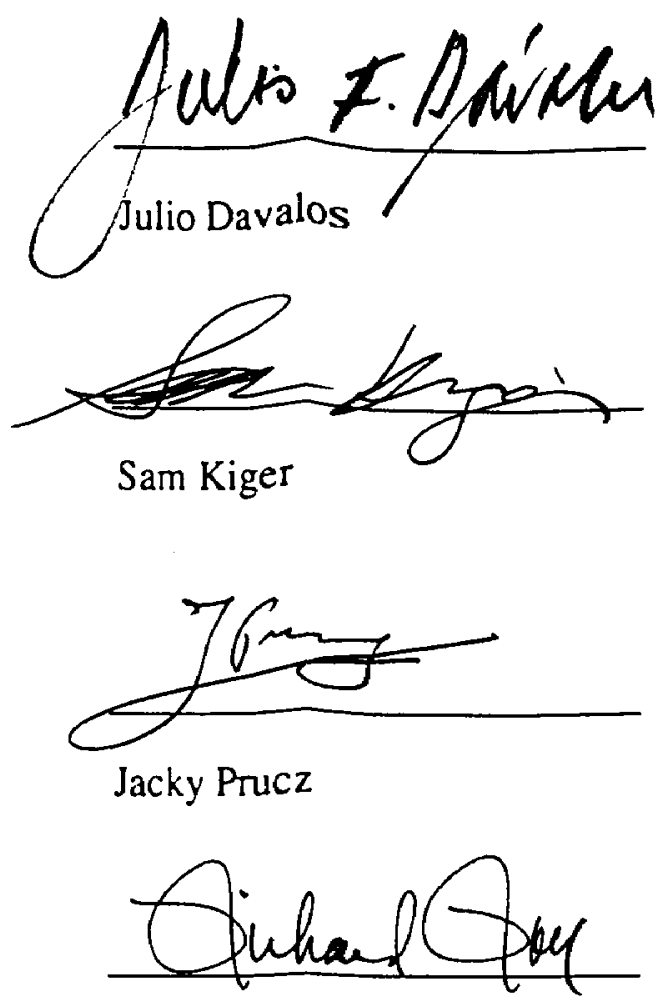

Richard Roll

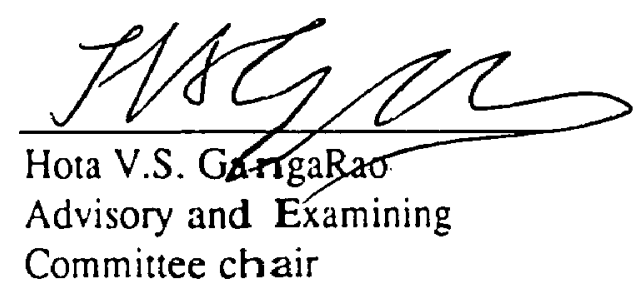

